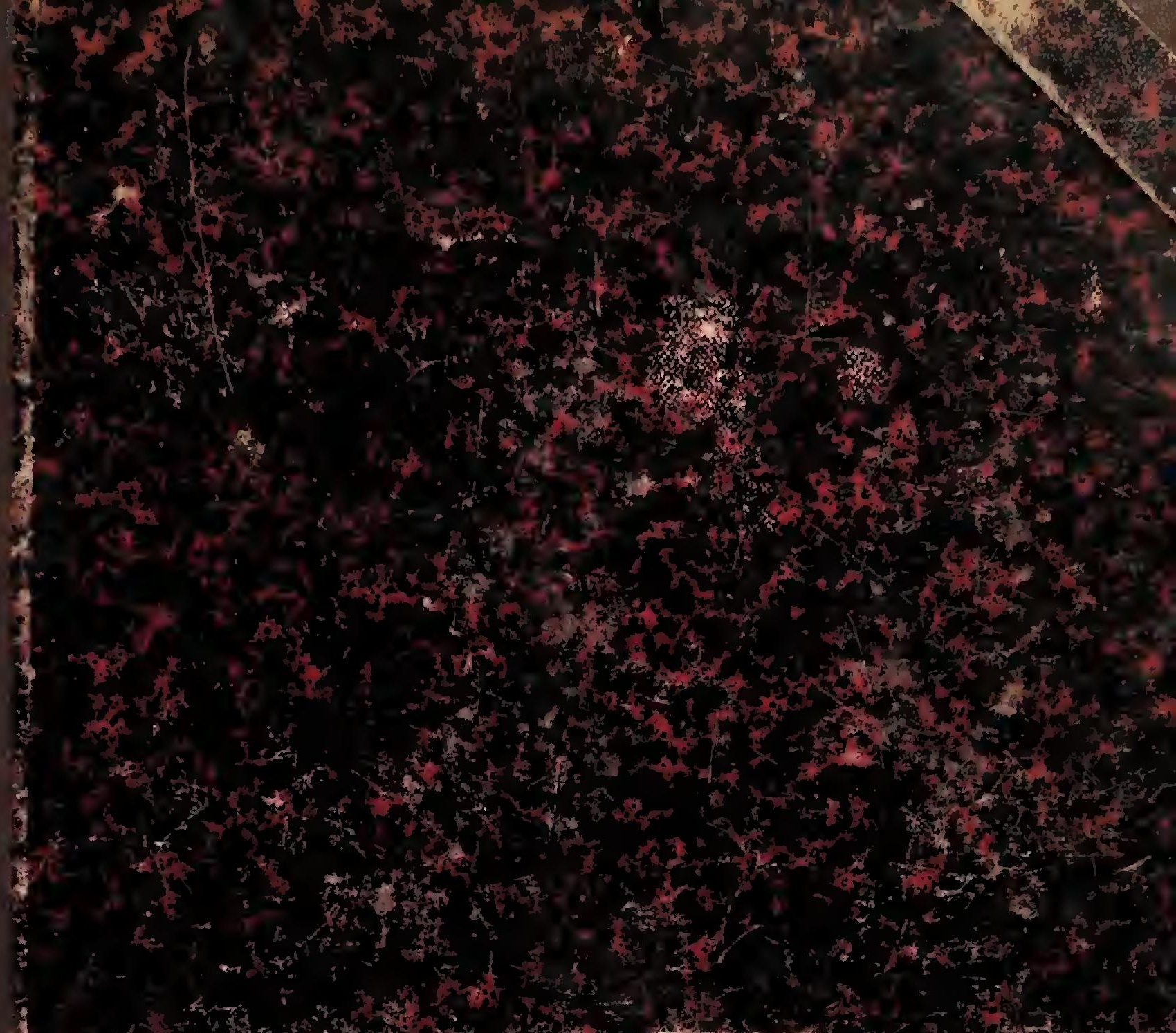

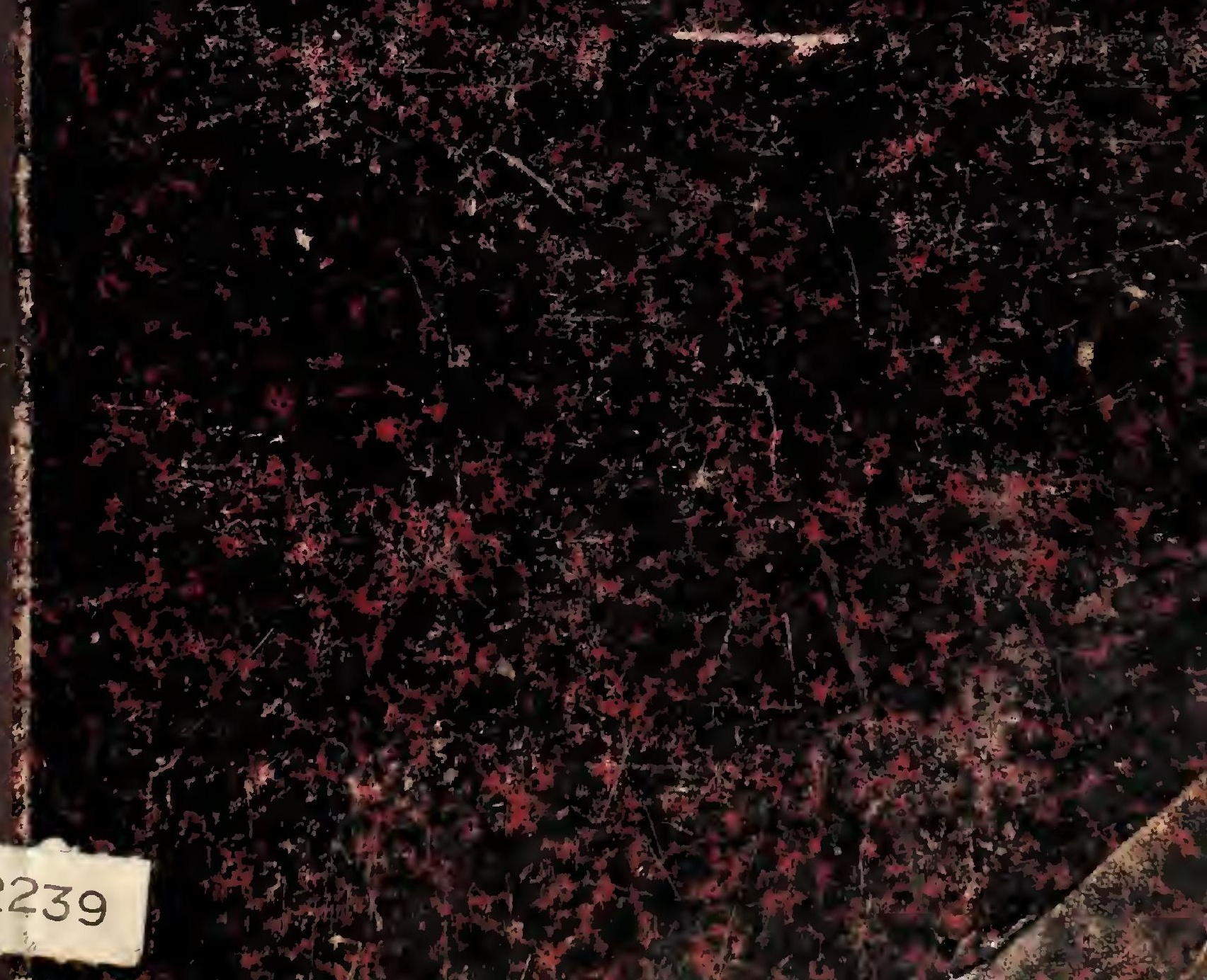


M.xiv.

$E \times L$ L BR IS

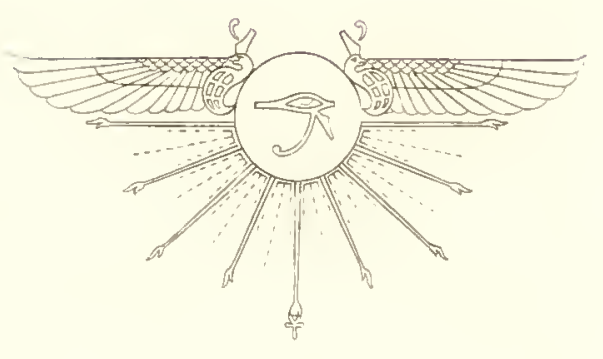

Wellcome Bureau of Scientific Research

LONDON 
Med

K5496 


\section{Digitized by the Internet Archive in 2017 with funding from Wellcome Library}

https://archive.org/details/b29336065_0001 


\section{AUSL ÄNDISCHE}

\section{K ULTURPF L A N Z E N}

IN FARBTGEN WANDTAFELN

MIT ERLÄL'LRXIEM TEXT

ERSTE I B TEILU Y G 
. 


\section{AUSL A NI) ISCHE}

\section{KULTURPFLANZEN}

IN FARBIGEN WANDTAFELN

MIT ERLÄUTERNDEM TEXT

IS C II

HERMANN ZIPPEL

NEI B EAREEI'E'

$\operatorname{VOx}$

PROF. Ir. OTTO WILHELII THOMÉ

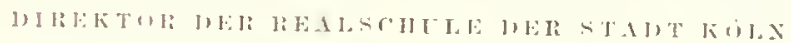

Z E I C H X Y G E

$\operatorname{VON}$

KART BOLLIANN ZU GERA

\section{$\mathrm{TEX} \mathrm{T}$}

Fiste Abteilnug

Iit einem Atlas, enthaltend 22 Tafeln mit 23 grofsen Pfanzenbildern und 144 Abbildungen charakteristischer Pflanzenteile

Vierte, neubeabeitete Inflase

BRAUNSCHWEIG

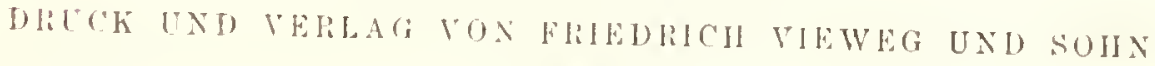

1 ) ! 
Alle Rechte, namentlich dasjenige der Übersetzung in fremde Sprachen, vorbehalten.

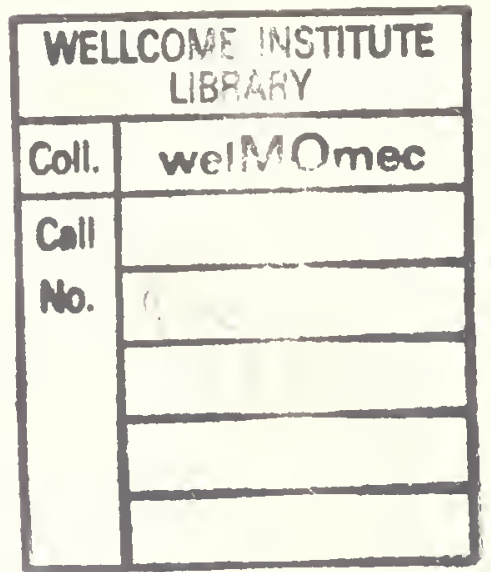




\section{IUS DER VORRRDE \\ \% $11:$}

\section{ERSTEN ICFLAGE.}

Die bekannten .Allgemeinen Bestimmungen" des Preulsischen Kultusministerimms verlangen mit Recht, dafs im hotanischen Unterrichte a 17 er sichulen auch rie wichtigsten Kulturpflanzen des Auslandes die gebührende Berücksichtigmng finden.

Soll aber dieser interessante und Nutzen bringende Unterricht erfolgreich sein, so mufs er unterstiitzt werlen durch naturgetreue Abbildungen, die grofs genug sint, rlafs sie jerler Schüler der Klasse von seinem Platze aus zu sehen vermag. Ein derartiges Werk wurde bis jetzt schmerzlich vermifst. Diesem Bedürfnisse abzuhelfen, ist ller $/$ weck der vorliegenclen 'Tafeln.

Ein bewährter Zeichner, Herr Lithograph Karl Bollmann in Gera. fertigte unter meiner Leitung die Abbildungen gröstenteils und, soweit nur immer die Originale in den botanischen Gärten orler in Herbariensammlungen vorhanden waren, nach der Natur, und man ist uns dabei allseitig mit liebenswürrliger Bereitwilligkeit entgegengekonmen. Insbesondere fühlen wir uns gerlrungen, Herm Hofrat Professor Dr. Schenk, Direktor res botanischen Gartens zı Leipzig, für seine vielfache gütige Unterstütznng hiernit ergebenst zu lanken. War es trotz unserer Bemühungen nicht möglich, irgend eine Bliite oder F'ucht, oder vielleicht sogar eine ganze Pflanze in Natura zu beschaffen, 


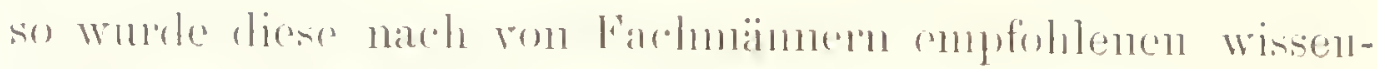
schattlichen Werkin mezeirlnet.

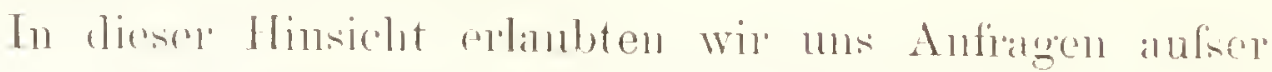

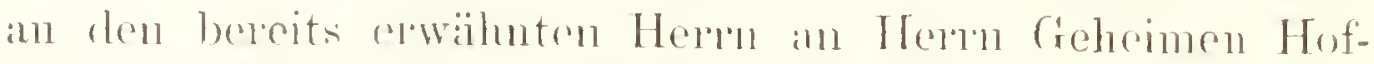

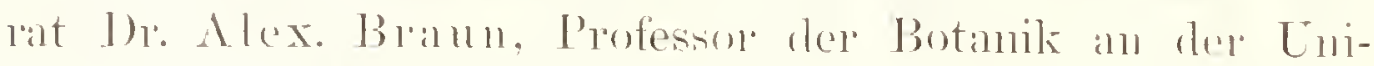
versitait zal Borlin nud Direktor des botanischen Gartens dasclbst. Hermen 1)r. T. Frank. I'rivatdocent der Botanik an dre Universität zu Loipzige und Knstos des Lniversitäts-

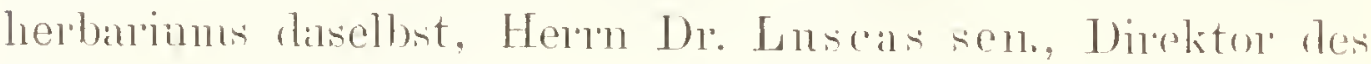
punologischen Tnstituts zn Reutlingen. Hernon Dr. Kanl Mïller-Halle, Mitherausgober der .. Xatur" und zu wierlerholten Malen an Herr'n Dr. Wiesner. Professon dor Anatomie und Plysiologie der Pflanzen an der IVienes. Universität. zu richten. Diesen Her'ren für ilne gütign Anskunftserteilungen anch hier nnseren tiefgefiihltestron Dank ansausprechen, halten wir für eine angenehne Pflicht.

Unser Werk diüfte nicht nur für alle Arten höherer. nud niederer allgemeiner Bildungsanstalten. sonslern anch für Droguisten und Kolonialwalenlä̈ndler von ITert und Interesse sein.

Wals den Text anlangt. so gliubte sich dor Terfissere im Hinblick auf den Raum so kurz fasson zu miissen. als es bei der Reichhaltigkeit und Wichtigkeit des stoftes num.

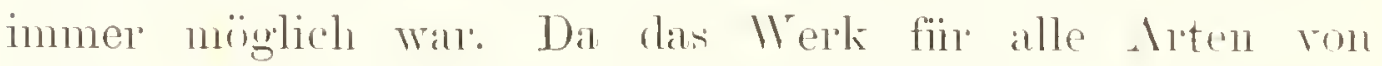
Schulen bostimmt ist. so Will es gehoten. in einfachster Darstellung das notwendige Material nach einer leicht en'kennbaren Disposition zu geben.

Der 'l'ext wirl, un den Lelı'en ein billiges Mittal zur Vorbereitnug für den Unterricht zu hieten. anch ohne Wamkltafeln abgegeluen.

(iel’a, inl ef nuli 1876.

Hermann Zippel. 


\section{VORWORT ZITR VIERTEN AUHLAGE.}

Vom der Verlagshandlung nit der Bearbeitung einer nenen Auflage des bekannten und bewährten 'Tafelwerkes Zippel-Bollmann, ..Auskïndische Kulturpflanzen", betrant, fand ich bei den tafeln meine Anfgabe darin, mifsverstandene und unrichtige Figuren durch nene zn ersetzen, weniger bedentsame 'T'eilzeichnnngen anszumerzen und dafür besonder's kemnzeichnende anfzunehmen, namentlich aher die für den Menschen wichtigen Pflanzenteile mehr, als bis dahin geschehen, in den Vordergrund zu rïcken, so Same und Haar der Baumwolle, Kaffee- und Kakaobohne, Mandel, Pimentfrucht, Pfeffer-. Reis-. Hirsekorn, und anderes mehr.

Im 'Texte wurde zunächst eine kurze l̈bersicht über die Reihen der Bedecktsimigen Pfianzen gregeben, sodimn das Ganze so nungearbeitet, dilfs es alles enthält, was zum Verständnis und zur Frklïrmng der Tafeln, sowie zur I'bersicht ïber die Bedentung der Pflanzen als Knlturpflanzen nötig ist. Dar die früheren Anflagen sich in gleichen Bahnen bewegen, konnte der ïbersichtliche Aufban der Darstellung, sowie manches von dieser sellst. beibehalten werdeu. Anfyrgeben wurde hingegen der frïher unternommene Versuch, dits rorliegende Werk als t'eil eines Gesantwerkes anfzufasion, .in welchem das ganze System durch Pflanzen, die fïr diss praktische Leben Wert haben, anfigebaut writ:. Die hier behandelten P'flanzen verdienen 
an sich - mol dem gegeniiber ist ilue Stellumg im System recht gleichgiiltig - unsore vollste Proaclitumg, mud jetzt un so melol, als Deutsoliland in die Reihe der. Kolonialnächte getreten ist, mon nunmehr andelı uns die Kultur \%allheicher auslänlischer NutzpHanzen obliegt. Es ist zwar erst wenig, und doch dante es mit ringent patriotischen Stolz crfüllen, dalis die dritte, den Kaffee helandelnde T'atel vollständig nach Material nmgearbeitot werden komnte, das deutschen Plantagen in Kinnerun entstammt.

Das Register soll gleichzeitig einen ïherblick über die Warenkiude geben.

Köln, Neujahr 1899.

Dir. Prof. Dr. Thomé. 


\section{XIALTSIERZEICIINS.}

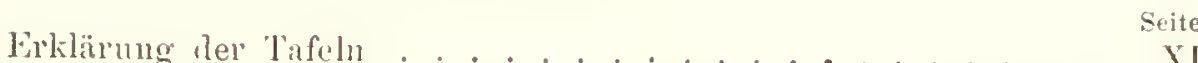

Finleiture

Tafel 1. Krantige Baumwolle (6)

Tire

2. Virginischer Tahak (Nicotiana Tabucum Limee) . . . . . . . 18

3. Laffeebaum (Coffece urabira Linuć) . . . . . . . . . . . . 33

4. 'Theestranch (Thea chinemsis Linn') . . . . . . . . . . . 56

5. Lakaobaun (Theobroma Cacao Limné) . . . . . . . . . . . 7 1

6. Zuckerohr (succharum officinam Linné). . . . . . . . . 80

7. Gemeiner Mandelbaum (Prunus amy!ydulus Stokes). . . . . . 89

8. Citrone (Citrus Limonum Risso) . . . . . . . . . . . . 95

9. Vanille (Vanilla plunifolia Andrews) . . . . . . . . . . . . . 103

10. Ceylonischer Zimtbaum (Cimamomum ceylomicum lireyn) . . . . 111

11. Schwarzer Pfeffer (l'iper nigrum Linní) . . . . . . . . . . 119

" 12. Nelkenpfeffer (Pincnta officinalis berg). . . . . . . . . . . 124

" 13. Gewürnelkenbaum (Jrmbosa Caryophyllus Niedenzu) . . . . . . 127

" 14. Echter Ingwer (Kingibe officinale Roscoe) . . . . . . . . . . . 131

"15. Muskatnufsbaum (Myristice fragrans Ilouttuyn) . . . . . . . . 135

. 16. Edler Lorber (Lam nobilis Linné) . . . . . . . . . . . . . . . 140

"17. Fieberrindenbaum (Cinchonu Calisaya, var. Josephiana Weddell). 143

. 18 I. Hirse (Punicum miliarm Linne). . . . . . . . . . . . 148

"18II. Reis (Ory.a satira Linné) . . . . . . . . . . . . . . . . . . . 151

"19. Naniok- oder Kassawastrauch (Wouthot utilissima Poinl) . . . . 156

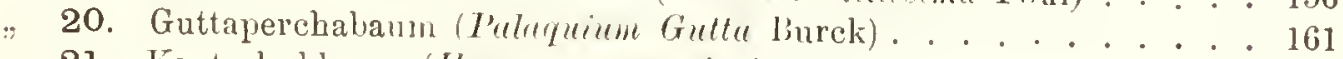

"21. Kautschukbaum (Ilece gn! gurnsis Aublet) . . . . . . . . . . . . . 166

. 22. Mahagonitaum (Suirtenil Mahregni Linné). . . . . . . . 174 Register. . . . . . . . . . . . . . . . . . . 178 


\section{ERKIIRUNG DER TAFEIST.}

Tafel 1. Krautige Baumwolle (ross!num herlucenm Limné, var. hivintum).

l'flanzenteil in natiirlicher Grörse.

1. Blite nach Entfernmg der Blumenkrone, " Itüllkelch. li Kelch; Vergrölsermug 2.

2. Staubblatt; Vergr. 75.

3. Fruchtlinoten im Läingsschnitt; Vergr. 30.

4. Nahezn reife Frucht der Uplandptlanze; nat. Grïfse.

5. Same mit Wolle, im Iängsschnitt; Samenlappen stark gefaltet; Vergr. 20.

6. Same ohne Wolle; Vergr. 30.

7. Teile eines Bammwollhares, mit den Zellen der S'amenschale. zwischen denen das Haar entspringt; Vergr. 500. (Nach Stra fsburger.)

Tafel 2. Virginischer Tabak (Nicotianu Tubucum Linné).

Pflanzenteil in natiirlicher Grölse.

1. Bliite; Vergr. $21 / 2$.

2. Geöffnete, ausgebreitete Blumenkrone mit den Stanbblättern; Vergr. : :

3. Stempel und unterer 'Teil der I'liite; letzterer nebst Fruchtkuoten im Längsschnitt; Vergr. : $: 1 / 2$.

4. Im Kelche sitzende, aufgesprungene Kapsel; Vergr. う.

5. Sime; Vergr. 48.

6. Same im Längsschnitt; l: Keimling, $e$ Sameneiweifs; Vergr. 48.

Tafel 3. Kaffeebaum (Coffen arubicu Linné).

Pflanzenteil, etwas vergrölsert.

1. Aufgeschnittene Bhmenkrone mit den Stiubblïtter'n; Vergr. 5.

2. Kelch und Stempel; Vergr. 5.

3. Kelch nnd Fruchtknoten im Iüngsschnitt; Vergr: 15.

4. Frucht; Vergr. 5.

5. Frucht, in ihrer oberen Hälfte vom Fruchtfleische befreit, so dal's die beiden l'ergamentschichten freigelegt sind; Veror. s. 


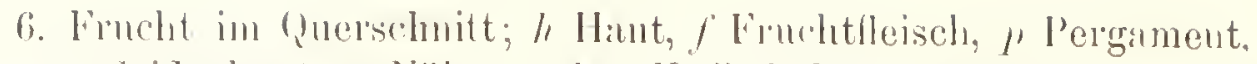
$\therefore$ Scidenlatut, Nählugewebc (Kaffrebohne); Verorr. 8.

7. Vergannentliaflee, das ist der Same in der l'erommentschicht; V'rers. 6.

s. Ilalbe Perganentschicht eines Fuchtfaches; Velogr: fi.

?. Silne, das ist die bohne in der Seidenhatut; Ver:"r. fo.

10. Kaffeebohme, das ist der Same ohne dio Seidenhant; Veron. 6.

Tafel 4. Theestrauch (Thro mimensis limué).

\%weig in doppelter natiulicher Grölse.

1. I Jingsschnitt der Blïte; Vergr. 12.

2. u. :3. Staubblatt in Vorler- und Riickansicht; Vergy. 50.

4. Muerschnitt durch den Fruchtinoten; Vergr. 50.

5. Anfspringende Frucht; Vergr. 5.

6. Same, mit Eindriicken vou verkiummerten Samenanlagen; Velogl: S.

Tafel 5. Kakaobaum (Thoulmoma C'ucuo Limué).

Pflan\%enteil in natuilicher Gröse.

1. Längsschnitt der Bliite; Vergr. 25.

2. Einzelnes Blumenblatt, von innen gesehen; Verenr. 25.

3. Staubhlattröhre, ans welcher die Narbe hervorlagt; Tergr. 36.

4. Staubhlatt mit aufgesprungenen Fächer'n; Vergr. 131).

5. Geöftinete, eingetrocknete Frucht; natürliche Grölise.

6. 'Trockener Same; Vergr'. 4.

7. 'Trockener Same im Querschnitt; Vergr'. 4.

8. Keimling mit gefurchter Oberfläche; Veron'. 4.

Tafel 6. Zuckerrohr (Succharmm officinarmm Linnir).

Pflanze, ein Aclitel der natiulichen Grölse.

1. Stiick eines Astes der Iiliitenrispe; " sitzendes. I gestieltes ̈̈hrchen; Verers. 30.

2. Ausgebreitetes Ährchen; " Spelze, welche foir sich ein unfiruchtbares libiitchen darstell, l, und $c$ spelzen der fruchtbaren /witterbliite; Vergr. 30.

3. Der untere Teil eines Halmes mit drei ganzen Giliedern und 'Teilen der Nachbarglierler; zwei der ersteren tragen Achselknospen; unter den Knospen der weifse, Wachstiilen ausscheidende (iirrtel, dariiber der warzige Ring. ans wolchem die Wurzeln entspringen; natüliche riölse.

4., 5. 11. 6. Stengelstiicke verschierlener sipielarten; natiurliche Giöilse.

Tafel 7. Gemeiner Mandelbaum ('Pmm: (m)!ydulus Stokes). Blütenzweig in natiirlicher Grölse.

1. Kweig mit Bliittern; natüliche Grölse.

2. Piliite von ohen gesehen; Verogr. 4.

3. Bliite nach lintferumng der Blumenkrone im laingsschnitt; Vergr. 1 is. 
4. Fiucht; Velorr. 3.

5. Anfgesprungene Frucht; Vergr. 3.

6. Frucht nach lintfernumg der vorderen liilfte der äufseren Fruchtschicht; Vergr. :3.

Tafel 8. Limone oder Citrone (Cihnu Limomnm Risso).

lilitenzweig, natiuliche Grölse.

1. Bliite im laingsschnitt; d Diskus; Vergr. 10.

2. Etwas gröfsere Binte olme die Blumenkrone; Vergr. 10.

3. Stiick eincs Staubfadenbiindels mit cinen Staubbeutel; Vergr. 50.

4. Stempel nit halhiertem Fruchtknoten; / Diskus; Vergr. 25.

5. Frucht, die "Citrone" des Handels; natiirliche Grölse.

6. Frucht im Querschnitt; natürliche Grölse.

7. Same; Vergr. 3.

Tafel 9. Vanille (I milla mamifolia Andrews).

Zweigg in natiurlicher Gröl'se.

1. Griffelsäule $y s$, Honiglippe 1, oberer Teil des Fruchtkuotens $f$; auf der Spitze des letzteren die Reste der abreschnittenen Bliitenhiillblätter; Vergr. :

2. Geöffnete Honiglippe; s Saftmal; Vergr. 3.

3. ()berer 'Teil der Griffelsïule; sb Staubblatt, I' Narbenplättchen; Vergr. 5.

4. Frnchtknoten im Querschnitt; Vergr. 30.

5. Reife, an ihrem unteren Ende aufgeplatzte Frucht; natiirliche Grölse.

6. Same; Vergr. 300.

7. Same im Längsschnitt; Vergr. 300.

Teilzeichnungen nach schmidt u. Berg.

Tafel 10. Ceylonischer Zimtbaum (Cimnomomm ceylonicum Breyn).

Zweig in doppelter Grölse.

1. Bliite; Vergr. 25.

2. Bliite im Längsschnitt; s Staubblätter: s1 der äufsersten Reihe, s\& der zweiten, sis der dritten, st der vierten Reihe; $s$ samenanlage; V'ergr. 50.

3. Aufgesprungenes Stuubblatt einer der beiden äufsersten Reihen; Vergr. 80.

4. Staubblatt der dritten Reihe mit zwei grundstïndigen Staminodien; Vergr. 80.

5. Jeere im lielche; Vergr. 4.

Tafel 11. Schwarzer Pfeffer (I'iper minmm Limín).

Pflanzenteil, in doppelter natiirlicher Grölse.

1. Stiick der Bliitenähre; Vergrr. 20.

2. Bliite; Vergr. 30.

3. Stiubblatt; Vergr. 120. 
4. Endstiick der ïlne mit hallneifen Friichten; Verer. 20.

万. Stiiels ler Fruchtiihre; Versr. 12.

(i. Iaingsschnitt durch die Frncht; li lieimling; "iulseres, i imneres Niilurgewche; Vergr. 15.

Tafel 12. Nelkenpfeffer (I'imml" "yficimalis lierg).

Kweig in doppelter natiolicher cioilse.

1. liliitenknospe; Veror. :

2. Bütenknospe der Länge nach durohschnitten; Vergr. 31.

: B. Bite ron oben gesehen; Vergr. 30 .

4. Stambblatt in Vorder- mol Riickansicht; Vergr. 180.

$\therefore$ 'Teil eines Fruclitstandes; Vergr. 5 .

b. Frucht im lïngssehnitt; oben rechts ein vcrkimmerter Sime; Vergl. 1ः.

7. Simme; Vergr. 10.

Tafel 13. Gew ürznelkenbaum (.Jumhsice Ciryorhyllus Niedenzu). \%weig in dreifacher natiulicher Gröse.

1. Iänegsschnitt dmrch die Plïtenknospe; li Kelch; b Blunen-

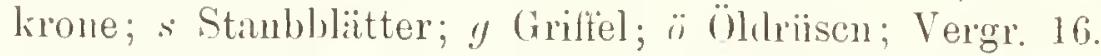

2. Deckelartig alogeworfene Bhmenkrone; Vergr. 15.

3 Oberes Ende des Griffels mit der Narbe; Vergr. う0.

4. Staubblatt; Vergr. 120.

5. Getrocknete Bliitenknospe: Gewiirznelkc; Vergr. 10.

6. Fruclit; Vergr. 5.

Tafel 14. Echter Ing wer (Zimgilu' "fficinale Ruscoe).

Pflanze in natiolicher Grölse.

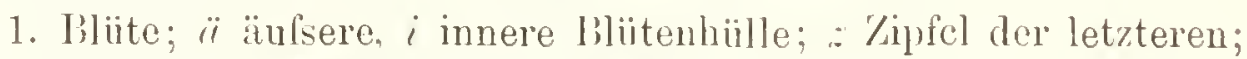
7 Lippe; "II Mittelband; "Narbe; Vergr. 5.

2. Liingsschnitt einer Blüte, nach Entfernung der änlseren IBütenhülle; st Staminorimm; Vergr. 5.

:3. Querschnitt durch das Sitaublslatt; M Mittelband; I' Bliitenstaub; !) Griffel; Vergr. 41).

4. Querschnitt durch den Frnchtknoten; Vergr. 35.

Tafel 15. Muskatnufsbaum (Myristice finmons: Honttnyn).

Kwcig in doppelter Groilse.

1. Mämnliche Bliite im Iängsschnitt; V'rorgr. 1ㄹ.

2. Querschintt durch die in vorliegenden Falle aus lis miteinander verwachscnen Stauhlılittern bestehcude staubblattsiiule;

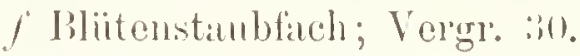

:) Weibliclıe Biite in Lïngsschnitt; Vergr. 1.).

4. Fuchtknoten in Lïngsschnitt; Velogr. 1).

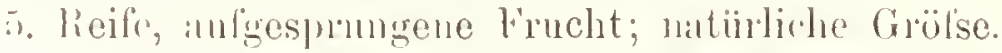

fi. Samo; m Simnemmantel: die Mnskathliite des Ilandels; lelogl:. :-

7. Sitnenkern: die Muskatmuls des Hinululs; Verogr."

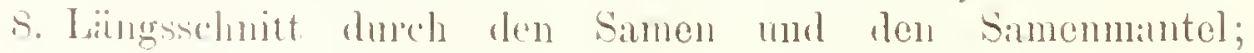


m Samenunantel; s Samenschale; it das durch llineinwachsen der imnersten Schicht der Simenschale zerkliiltete Nïhrgewebe: li licimling: Verere: :3.

Tafel 16. Edler Lorber (lanms mbilis Linné).

Zweig, ctwas veroriolsert.

1. 'T'eil des IBliitenstindes, rechts und links dic Stiele abgeschnittener Blïtenbüischel; Vergr. 7 .

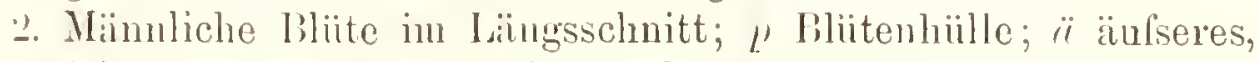
$i$ imneres Staubblatt; s Stempel; Vergr. 50.

$\therefore$ Staubblatt des äufseren lireises; Staulfaden beiderseits mit je einer Drüse; die beiden Fïcher sind mit niach oben gerichteten Klappen aufgesprungen; Vergr. 75.

4. Weibliche Bliite im Längsschnitt; Vergr. 10.

5. Frucht in natiirlicher Grölse.

6. Frucht: Vergr. 10.

7. Frucht im (Wuerschnitt; Vergr. 12.

Tafel 1\%. Fieberindenbaum (Cinchome caliscen, var. Josephinum Wedilell).

Zweig, etwas vergrölsert.

1. Hiite; Veror. 15 .

‥ Geöffnete Blumenkrone mit den Staubblättern; Vergr. 15.

:3elch und Stempel; Vergr. 25.

4. Querschnitt des Fruchtknotens; Vergr. 60.

$\therefore$ Vom Grunde scheidewandspaltig aufspringende Kapsel; Vergr. 6.

15. Same im Längsschnitt; $k$ Keim; Vergr. 25.

Tafel 18I. Hirse (Ímincmm milieceme Linnú).

Halm, natürliche Grösse.

1. ت̈lrchen; Vergr. 20.

$\therefore$. Blïte ohne die Spelzen; s Saftschmppen; Vergr. 25.

$\therefore$ Frucht; $n$ Nabelfteck; Vergr. 20.

Tafel 18II. Reis (Orysur suliva Linné).

Halm, natiirliche Grïlse.

4. und $\bar{~}$. Ihrohen einer begrannten und einer unbegrannten Abart; Vergr. 12.

6. Blüte ohne dic S.pelzen; s Saftschuppen; Vergr. 20.

7. Frucht; "Nabelfleck; Vergr. 15.

Tafel 19. Maniok-oder Kassawastrauch (Muritut utilissima Pohl).

Zweigr, natïrliche Grölse.

1. Männliche Bliite; Verorr. 10.

2. Männliche Bliite im Längsschnitt; Vergr. 10.

:3. Weibliche Bliite im Lïngsschnitt; Vergr. 10.

4. Weibliche liliite, nach Entfernung der lihitenhiille; "l Diskus; rergr. 1.5. 
5. Frucht; Velogl: j.

(i. Sime: Verigr. 10.

7. Wur\%el, ein Viertel natiillicher (irrofse.

Tafel 20. Guttaperchabaum ('ulndrim" ('ullu liurck).

/weig in natürlicher Grölse.

1. Ehen geöffnete Bliite; Verer. 1.5.

‥ Blite; I'ergr. 15 .

:S. Staubblatt; Velor. T5.

4. Stempel und Iäingsschnitt durch den Fruchtlinoten; Verogr. 2.5.

5. (?uerschnitt durch den Fuchtlinoten; Verogr. 40.

6. F'ucht; Vergr. 10.

Tafel 21. Kautschukbaum (Ilerme y"!!nmmis Aublet). 7weig in naturlicher Gröse.

1. Teil des Bliitenstandes; Vergr. ז.

2. Weibliche Bliite; Velor. 25.

3. Männliche Bliite nach Entfernung des Kicheses; Veror. 25.

4. Weibliche Blite nach Entfernung des Kelches; Vergr. 2...

5. Querschnitt durch den Fruchtknoten; Vergr. $41 \%$

Tafel 22. Mahagonibaum (Sucietenin Muthermoni Linné).

1. Bliitenknospe; Veror. 2.5.

2. Geöffnete Bliite; s Staubblattröhre, Verorr. 20.

$\therefore$ Bliitenlängsschnitt; $k$ Kelch; 6 Blumenkrone; s Stanbblattlöhre; d Dislius; Veror. $: 30$.

4. Fruchtknoten; d Diskus; Veror. 45.

5. Tom Grunde aus scheidewandspaltig sich öffnende Kinpsel; natiirliche Grölse.

6. Mittels̈̈ule der Kapsel mit einem Samen; lergr. 2.

7. Same; Vergr. 4. 
Die in vorliegendem Werke behandelten Pflanzen kïnnen nicht alle im strengsten Simne des Wortes als . Ausländisclue Kulturpflanzen" bezeichnet werden; so dürfte sich z. B. der Mahagonibaum bis jetzt kaum einer ausgedehnteren Kultur erfreuen, und der Tabak wird in Dentschland in beträchtlichem Mafse angebaut - aber wertvolle Nutzpflanzen sind sie alle in hohem Grade, und wir sind gar nicht im stande anzugeben, wie sich unsere Lebensfülırung und unsere Technik gestellt haben wïrden, wenn wir die wiehtigeren unter ilnen entbehren müisten.

Um ein Bild ron der Stellung der behandelten Pflanzen in der l'flanzenwelt zu ermöglichen, möge zunächst, im Anschlusse an "Engler-Prantl, Natuirliche Pflanzenfamilien", eine kurze, bis auf die Pflanzenreihen zurückführende Übersicht folgen.

Alle gehören zur Abteilung der Blïten pflanzen (Thanerogamae). Diese pflanzen sich durch Samen fort und heilsen daher auch Samenpflanzen (Spermaphytu). Der Samen entsteht ans einer Samenanlage, welche in Knospenkern und Kinospenhiille zerfällt. In der Achse des Kernes bildet sich der Embryo- oder Keimsack mit den Eizellen. Letztere werden durch eine Zelle befruchtet, die von einem Bliitenstaubkorn gebildet und durch den Pollenschlauch dem Ei zugeführt wird, ein Vorgang, der den Blïtenpflanzen auch den Namen Pollenschlauchpflanzen (Siphonoguma) eingebracht hat. Aus der befruchteten Eizelle entsteht ein Keim oder Embryo, der sich schon im Samen in eine Achse nit St:mmscheitel und Keimwurzel, sowie in Keimblätter oder Kotyledonen gliedert.

Die Bliitenpflanzen zerfallen in zwei Unterabteilungen, Nacktsamige (Crymospermac) und Bodecktsamige (Angiospermae). Bei den Nacktsamigen sind die Samen nackt, d. h. nicht in einen Fruchtknoten eingeschlossen; sie sitzen vielmehr an den offenen, einer Nirbe entbehrenden Fruchtblättern. Ihre Pollenlï̈ner bestehen schon ror dem Verstiiuben aus mehreren nebeneinander liegenden Zellen; in dem Embryosacke bilden sich schon vor der Befiuchtnng Nïhrgewebe (Sameneiweifs), sowie die Archegonien, welche die Eizellen erzeugen. Demgegeniiber sind die Samenanlagen der Bedecktsamigen in einen Fruchtinoten eingeschlossen. Die reifen Bliitristaubkïner bilden bei ihnen einen cinzigen Zellraum, welcher eine kleine Befruchtmingszelle umschliefst. In dem Embryosacke werden sechs Zellen, am oberen Ende dis Ei und zwei Gehiilfimen, am unteren Ende drei Cegenfuifs- 
lerinnen webildet. Die Lefruchtungszelle wird dem Ei mittels des l'ollenschlanches, eines ans dem l'ollenkorne hervorgetriebenen Auswuchses, zugetiiht. Nachlem nuter' Treihnahme der Gehülfmmen die Befruchtnng vollzogen ist, wïchst das Ei zum Keime heran.

Die Unterahteilung der Gy m nospermen zerfiillt in vier K'lassen:

A. Befruchtung durch hewegliche Ref'uchtungskörper, Spermatozoiden.

1. Holzgewïchse mit einfach, seltener doppelt gefiederten Blättern. Die Staubbliitter trigen an ihrer Unterseite zahlreiche I'ollensïckchen. 1. Klasse: Cykaden, Cyrudules.

2. Holrgewïchse mit Hachen, breit-keilförmigen, ein- oder mehrmal der Länge nach eingeschnittenen Blättern. 2. Klasse: Ginkgop flanzen, Cinligoules.

B. Befruchtung durch unbewegliche lierne.

1. Blïten ohne Bliitenhülle. 3. Klasse: Nadelhölzer, Coniferw.

2. Bliite mit Bliitenhïlle. 4. Klasse: Gneteen, Guctules.

Die Unterabteilung der Angiospermen zerfillt in zwei Klassen:

1. Keim mit einem Samenlappen; Stamm mit auf dem Querschnitte zerstreut stehenden, geschlossenen Gefïfshiindeln. Bliten meist dreizählig; Blïtter meist streifennervig. 1. Klisse: Einkeimblätterige, Mlonocotyledonere.

2. Keim fast immer mit zwei Keimblättern; Gefuifsbündel offen und am Stamme zu einem mehr oder weniger rollstindigen Pinge vereinigt. Blïten meist fünf-, seltener vierzählig. Bliitter nicht parallelnervig. 2. Klasse: \%weikeimbliit terige. Dicotigedoneue.

\section{Monokotyledonen.}

Die Klasse der Einkeimblätterigen zerfillt in zehn Reihen:

1. Blïtenhiille gar nicht orler doch nur wenigg ansgehildet.

1. Same ohne Nährgewebe; Wasser- oder Sumpfptianzen. 2. Reihe: Sumpflilien, Hetwiue.

2. Same mit Nährgewebe.

a) Bliiten nackt, oder mit siner diinnhäutigen, hochblittartigen liille, in zusammengesetzten kugeligen oder. lolligen likitenstïnden. Sumpfkrïnter oder Bïime mit linealischen bliittern. 1. Reihe: I'andang geflanzen, I'omdenules.

b) Blïten nackt, oller mit harfömmiger Bhiitenhiille, ron späiter trockenhäutigen, hochblitterigen spelzen bedeckt: Grasplanzen. 3. Feihe: Spelzenbliitige, Cilumifleren.

c) Bliiten mit einfacher lliille. Fist ansschlief'slich unverzweigte St:inme, mit strahlig-oder lierlernervigen Blïtern. Bhiitrn in einfiachen orler zusammengesetzten kolligen Ïhren. 4. Reihe: l'almen, Lrimeipus.

(1) Lihiten aingeschlechtig. Die mïnnlichen und die woils- 
lichen IBliten bedecken in regehmilfsigr abwechsehnder Verteilung dic ganze Oherfläclse eines sattigen, unverzweigten, ron mehreren kihnförmigen Blattscheiden eingeschlossenen Kolbens. Finchtknoten in die Kolbenachse eingesenkt und mitereinander vereinigt. 5. Reihe: Vereintbliitige, Symonthere.

e) Bliiten in einficher, von einem scheidenartigen Hochblatte umschlossener, kolbiger Ïhre. 6. Reihe: Scheidenbliitige, Sputhiflorce.

B. Blïtenhülle doppelt.

1. Bliitenhiille strahlig, meist unterständig.

a) Samenanlage geradläntig; Nährgewebe mehlig. 7. Reihe: Mehlsamige, Furinosue.

b) Samenanlage umgewendet; Niihrgewebe fleischig oder knorpelig. S. Reihe: Lilienbliitige, Liliiflorac.

2. Bliitenhïlle seitlich-symmetrisch, oberständig.

a) Nit Nährgewebe; Stanbhlätter bis auf eines in blumenblattartige Staminodion umgebildet. 9. Reihe: Gewiirzschilfe, Scitamineac.

b) Ohne Nährgewebe; Staubbeutel und Stempel, oder Blütenhiille und Fruchtknoten verwachsen. 10. Reihe: Kleinsamige, Microspermuc.

\section{Dikotyledonen.}

Die Klasse der //weikeimblätterigen zerfällt in zwei Unterklassen:

1. Bliiten nitckt (Apctulue), oder mit einfacher Blütenhülle (Mronopetalue), oder mit Kelch und Blumenkrone; diese aber aus mehreren getrennten Blättern bestehend (Choripetaluc). 1. Unterklasse: Freiblïtterige Dikotylen, Ardichlomydene.

2. Bliiten mit Kelch und verwachsen-blätteriger Blmmenkirone. 2. Unterklasse: Verwachsenblïtterige Dikotylen, Momochlemydeae oder simmuetrdue.

Freiblätterig'e Dikotylen, Arhichlomydeat.

Die in diese Unterklasse gehörenden Familien zerfallen in 24 Reihen, die zunäichst in fünf Reihengruppen vereint werden können.

1. Bliiten ohme oder mit einfacher Bliitenhiille, sclten mit doppelter Llïtenhiille (letzteres bei den Mittensamigen).

I. Bliiten klein und unansehnlich, ohne oder nit einficher Bliitenhiiile, meist in käitzhenartigen Bliitenständen. 1. Reihengruple: Blütenhülllose, Aptulue. Ilierher sichen lieihen:

a) Samenanlage mit vielen (20 und mehı) Emlnyosiicken.

1. Reihe: Quirlblätterige, Troticillutue.

b) Samenanlage in der Regrel mit nur einem Embryosack.

1. Samen mit doppeltem, innerem und ïnfseren, Nihn-

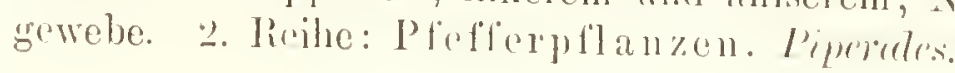


2. Samen olme Nïlrgewebe.

a) Fruchtinoten oberständig. Frucht ans zwei Frnchthlïtern gehildet, mit zahlreichen kleinen Samen; letztere unit grundståndigem Haruschopfe.

3. Reihe: Weidenuflanzen, Srlicrlcs.

ß) Fruchtknoten unterstïndig.

a) Bliiten olme Blïtenhiulle. Steinfrucht. 4. Reihe: Gagelptlanzen, Myricules.

b) Blüten mit Blïtenhiille.

* Blätter umparig gefiedert, mit Nebenh)iittern. Fruchtknoten einfächerig, mit einer grundständigen, aufrechten Samenanlage. 5. Reihe: ITalıulsp flanzen, Ju!flundules.

Blattur einfach, ohne Nebenblätter. Fuchtknoten mehrfächerigr. 6. Reihe: Buchenpflanzen, Fagales.

3. Samen mit inneren Nihrgewebe. 7. Reihe: Nesselp flanzen, livierles.

II. Bliiten ansehnlich, mit einer Blitenhiille, nicht in Kiitzchen. 2. Reihengruppe: Einhüllige, Monochtommaleae. Hierher drei Reilien :

a) Samenanlage ohne Hülle. Schmarutzerpflanzen. S. Reihe: Santelpflanzen, Sumlutules.

b) Samenanlage mit Iliille.

1. Bliitenhiille blumenkronartig, mnterstïndig. \%. Reilıe: P'rotaceenpflanzen. Trotroles.

2. Bliitenhiille oberstindig. Viele sind blattgrinulose Schmarotzer. 10. Reihe: Osterluzeipflanzen, Aristolochinde's.

III. Bliite mit einfacher Hïlle, oder mit Kelch und Bhmenkrone. Fruchtknoten oherständig mit einer grundständigen Samenanlage oder mit einem aclisenstindigen Samentrïger. 3. Reilıngruppe: Mittensamige, (motripmme. Hiencr \%wei lieihen:

1. Fuchtinoton oherstindig, einfächerign, nit ciner aufrechten Samenanlage. 11. Tieihe: Kü̈terichpflanzen, Polygomertes.

2. Samenamlige krummlïulig, grundstindig, oder auf achsenstämligem Samonträigrer. 12. lieihe: Mittcusamigre, Cenlowiprimere.

13. Hiiton mit Kelch nun Blumenkrone.

I. lihitenteile in zahlreichen, armglientrigen Kreisen, oder spiralig angeordnet. 4. liciliengrupe: Spiralblütige, Aphonoryrlicrn. Hienher vier lieilun: 
a) Fruchthlïter 1 bis rahlreich, meist getrennt bleibend. 13. Reihe: Vielfrii chtige, Romales.

b) Fruchthläter 2 bis viele, zu rimem fruchtknoten vereinigrt.

I. Iruchtluoten obristindig.

a) Fruchtinoten meist scheidewandlos. 14. Reilıe: Mohnpflanzen, lihoculules.

p) Fuchtknoten ein- bis mehrfaicherigr. Blätter insektenfingend. 15. Reihe: In selitenfänge $\mathbf{l}^{\circ}$, suraruceniales.

2. Fruclitknoten unterständig. 16. Reihe. Opuntien, Opuntiales.

II. Blütenteile in ausgeprägten Kreisen georduet, lıäufig mit doppelter oder noch höherer Staubblattzahl. Ђ. Reihengruppe: Kreisblütige, Eucyctiene. Hierher neun Reihen:

a) Fruehtinoten aus einem Fruchtblatte gebildet, einfäclıerig, oder wenu aus mehreren F'ruchtblätteru gebildet, mit melıreren getrennten Griftelı. 17. Reihe: Rosen planzen, Rosules.

b) Melrere Fruchtblätter sind zu einem mehrfächerigen, oberständigen Fruchtknoten rerwachsen.

1. Staubblätter nicht verzweigt.

a) Ein Diskus fehlt. Staubblätter des äufseren Kreises ror den Kronblättern angeheftet. Samennaht der Innenseite der Bliite zugewendet. Samenanlage hängend. 18. Reihe: Storch schnabelgewächse, Geraniales.

p) Bliite mit Diskus.

a) Die Staubblätter stehen meist in zwei Kreisen; Samenanlage hängend. 19. Reihe: Rofskastaniengewäclsse, Srmindales.

b) Die Staubblätter bilden nur cinen Kreis; Samenanlage aufrecht. 20. Rieihe: Faulbaumartige, Rhammules.

2. Staubblätter ver\%weigt. Keleh mitklappiger, Blumenkrone mit gedrehter Kinospenlage. 21. Reihe: Malvenptilanzen, Mulvules.

c) Fruchtknoten meist einficherig, nit starkem, wandstïndigem Samenträger.

1. Iruchtknoten meist oberständig; Nihrowebe vielfach öl- oder proteinhaltig. 22. Reile: Waudfrüchtige, P'arictules.

2. Fuchtknoten unterständig, in die becherliormige Achse eingesenkt.

() Blïtter gegenstiindig; Fuchtknoten eingriflelig; ohme Jiskus. 23. lieiho: Myrtenblumige, Migrliflorar. 
(3) Bliitter wechselstiindig; Finchtlonoten zweigriffelig; zwischen Stiubblïttern und Fruchtknoten findet sich ein I)iskus. 24. Reile: Doldonbliitige, limbelliflonere.

\section{Verwachsenblätterige Dikotylen, Metrmhmyder.}

In diese Unterklasse schören zwei Reihengruppen mit acht Iieihen:

A. Die Zahl der den Stempel zusammensetzenden fruchtbliitter ist der Zailıl der Krelchbliitter gleich. 1. Reihengruppe: Gleichzählige, Isoctrpecte.

a) I) Fre Fuchthliitter stehen vor den Zipfehn der lihmenkrone; Stanbbläter frei. 1. Reihe: Heidekriinter, Eriruls:

b) Dic Fruchthliitter stehen vor den Kelchblaittern. Stanbblïtter der Krone angewachsen.

1. Fruchtknoten eimfächerig, mit freiem, mittelständigen Samentrïiger. 2. Reihe: I'rimelbliitige, I'rimulules.

2. Fruchtknoten mehrfächerig. Immergriine, tropische Holzgewächse. 3. Reihe: Ebenholzpflanzen, Elomeles.

13. Die Zalıl der den Stempel zusammensetzenden Fruchthlïtter ist der Zahl der Kelchblätter nicht gleich und hetrïgt gewöhnlich zwei.

2. Reilengruppe: Ungleichzählige, Anisocmprere

a) Kelch und Blumenkrone unterständig.

1. Blïten fü̈nfoliederig, indes nur mit zwei oder drei Fruchtbliittern.

(.) Bliiten regelmülsigr, mit gedrehter Ḱnospendeckung. Zwei Fruchtblïtter. Blätter einfach, gegenstïndig, nebenblattlos. 4. Reihe: Drelıblïtige, Contontue.

p) Bliiten regehmïlisig oder seitlich-symmetrisch, in let\%teren Falle meist vier Stanbblätter. Kinospenlagre nicht gedreht. Fruchtknoten meist zweiziilhliw. 5. Reihe: Rölrenblïtige, Tubiflorer.

2. Blüten regelmälsig, viergliederig, meist aber nur zwei Fruchthlätter. Frucht cine cin- his vierfïcherige Kapsel. 6. Reihe: Wegerichpflanzen, Pluntugimules.

b) Kelch und Ishmenkrone oberstïndie.

1. Bliiten fünf- bis viergliederig, nit ehensoviel oder weniger Staub- und Fruchthliittern. Staubblïtter frei. T. Reihe: Krapploliitige, Rubiales.

2. Bliiten fünforliederig, mit ehensoviel Staublittern und meist weniger Fruchtbliittern. Stanbblïter znsammenneirend orler teilweise miteinander vereint. 8. licihe: Glorkenhliitige, Commumulutue.

Anf die Unterscheidung der jeder Kilasse. Reihe n. s. W. :mgehörenten Fanilien kamn hier nicht eingegangen werden. 


\section{Tafel 1.}

Baumwolle (Grssypium lerboceum).

Dic Baumwolle gchört in die Unterklasse der Freiblätterigen Dikotylen, zur Reihe der Malvenpflanzen (Mutrules) und zur Familie der Malvengewächse (Mutruccer).

Dic Familie der Malvengewächse enthält Kräuter, Sträucher oder Bïume mit meist stark beharten, grü̈en Teilen, deren Biätter auf Nebcnblätter gestiitzt sind. Der Kelch ist oft an Grunde mit einer ein- oder mehrbliittcrigen Hülle, einem äufseren Hïllkelche rersehen. er ist unterstïndig und in der Kuospenlage klappig. Die Bhnmenblïtter haben eine gedrehte Knospenlage und sind in gleicher Anzahl wie die Kelchziptel rorhanden. Die Staubfäden sind am Grunde mit den Blumenblättern und nnter sich einbrïiderig rerwachsen, so dafs sic eine den Fruchtknoten bedcckende R̈̈hrc bilden. Die einfä̈herigen, nicrenfürmigen Staubbentel üftnen sich mit ciner halbkreisförmigen Spalte; sie entlassen grofse, bestachelte Pliitenstanblïrner. Der oberstaindige Fruchtknoten bestcht aus fïnf oder zahlreichen Fruchtblättern. Griffel sind cben, oder doppelt so viel als Fruchtbliitter vorhanden und meist hoch hinauf miteinander verwachsen. Die Frucht ist meist cine Kapsel, oder sic zerfiillt in Teilfriehte. Die Keime sind in der liegel gekrïmmt, haben zusammengefaltete, blattartige Samenlappen und sind vou Nälngewcbe umgeben. Viele Arten sind reich an Schleim. Etwa 40 Gattungen mit 675 Arten.

Die Gattung Baumwolle (Cossyprim I.). Kränter und fist baumartige Sträncher mit abwechselnd gestellten, drei- bis fünflappigen, selten ganzen Blïttern, anf deren Untcrscite, nalıe dem Lilattstiele. meist eine odcr melncre Driisen sitzen. I)ic grolsen und schüncn Blüten stehen cinzelı anf Sticlen in den Blattwinkeln und sind an Grunde von drei grolsen herzförmigen Hiillblïttern nmgehen; iln keleh ist gestutzt oder kurz fïnfspaltig, ilne Blumenkrone fünfblitterig. Dic fïnffächerige Fruchtkapsel springt bei der Reile fichspaltig in elsenso viele Klappen anf, wobei dic langen Samenlatare clastisch hervoryuellen. 
I)ie sehr zahhoichen Kulturformen lassen sich wahrscheinlich in zwoi oder drei Arten zusammenfassen; dazn kommen dann noch drei Arten von den Sindwichinseln, cine ron Afrikı, eine von Indien, eine vun Austrilion,

I) kultivierten Arten unterscheiden sich folgendermal'sen:

A. Wolle leicht ron den Samen zu trennen; Samen nach Entfermung der Wolle nackt; der Nenen Wolt angehörig: Westindische Baumwolle (Gossmpium barludense L.).

B. Wolle nicht leicht von den Simen zu tremmen; zwischen den langen Simmenharen findet sich auf den Samen ein kurzer, dichter Fil\%; der Alten Welt angehörigs.

a) Blattripfel an dem Grunde verschnälert. Blumenlirone purpurrot: Baumartige Baumwolle (Gossynum anboremm L.).

b) Blattzipfel eiförmig, breit: Blumenkrone gelb: Krautigre Baumwolle (cosstpium herbuccum L.).

1. Die Krautige Baumwolle (Gossypium herbuccum L.) ist je nach ihrer kíultur bald nur ein-, bald zweijährig und daher auch in Gröfse verschieden, $1 / 2$ bis $2 \mathrm{~m}$ hoch. Ihre Pfahlwurzel geht 30 bis $45 \mathrm{~cm}$ tief in die Erde. Der Stengel ist walzenrund, erst krautig, dinn holzig, finger-bis armdick, wenig und seln fein behart, fast glatt.

Blätter gestielt, 8 bis $14 \mathrm{~cm}$ lang und ebenso breit, unterseits eindrüsig, handher'zfömig, mit fünf (selten drei) stachelspitzigen, breiten Lappen, oben dunkel-, unten mattgriin, fein behaart.

Blüten winkelstïndig, einzeln orler zu zweien, gelb, ron einer grofsen, dreiblätterigen, gesïgten, feimharigen $\mathrm{H} u ̈ l l e$ mmschlossen. Kelch krugförmig, fïnt fach gelappt, hlalsgriin, hunkel punktiert, filzig. Blumenblätter fünf, am Grunle zusammengewachsen und dunkelrot gefïrbt, sonst fast schwefelgelb, entfilten sich selteng gan\%, behalten meist dis Ḱnospenlagre bei. Staubblätter zahlreich, einbrïlerig verwachsen. Freie Enden der Staubfäden kurz, mit eintächerigen, rundlich-nicrenlörmigen, zweiklapprigen staubbeuteln, aus dereu Mitte die keulenförmige, ron fünt Furchen durchzogene Narbe herrortritt.

Die Frucht ist eine Kapsel ron der Gröfse einer Walnuls, die sich aher in der Wärme schr ausdehnt, drei, selten vier Fïcher enthält, die in ehensoviel kilupen aufspringen und schr vicle brane, mit ciner weilsen, feinen, dichten, kn'zstipeligen Wolle rerseheno und rom mittelstiindigen Sanenträger ansgehende Samen einschlielst. Ein cinzelner Banmwolliaden erscheint nuter den Mikioskop als ein langes, schmales Tiindchen. Den bau nach bildet jede Baumwollfaser eine gestreckte \%clle, die urspringlich ein lohles liöhrchen war, das sich durch Buntrockncm zu cinem Bande verllacht und stellenweise schrauhenatig godreht hat. Thueife l'asern sind 
noch nit unverzehrten Inlalt erfiillt mul bilden in reiner Ware als sogenamnte tote Wolle einen wesentlichen Fehler, da sie keine Fïrhung annehmen.

Hauptblütezeit: Ende Mai, Anfing Juni.

Das Vaterland der Krantigen laumwolle ist Mittel- und Siidasien, sie ist die am weitesten verbreitete Art, kam durch die Araber nach İgypten, dem siidlichen Europa und wahrscheinlich elst 1774 mach Amerika. Sie wird seit ïher $2 \frac{1}{2}$ tausent Jahren in Ostindien und Arabien angebaut; heute namentliclı in den Centralprovinzen Indiens (Frzengungsgebiete: Iinghunghit, Oomrawutten, Verawal, Comptah), ferner in Bombay (Dlarwar, Broach, Dholeralı), im Industhal (Scinde), in Bengalen (Bengal), Burmah (Rangun), Malras (Tinnerclly) und in Natal in Afrika, in Vordcrasien, Griechenland, Igypten (Zagazig, Mansurah, Beharah u. s. w.).

Man unterscheidet zwei Abarten:

a) Die Feinhaarige Baumwolle (Cossymim religiosum L.). Sie ist wenig behaart oder fast kahl; die Blätter haben fünf dreiseitige Lappen; die Blïten sind rein gelb. Filz und Wolle der Samen sind gleichfarbig. Die gelbwollige Form ist als Nanking baumwolle bekannt.

b) Dic Rauhhaarige Baumwolle (Gossyminm hirsutum L.). Ihre Blätter haben verlängerte Lappen. Blumenkrone gelb, am Grunde mit roten Flecken. Filz der Samen grau oder grïn, Wolle reils.

2. Die Baumartige Baumwolle (Gossypium wroreum L.) hat man in Oberguinea, Abessinien, Sennaar und Oberïgypten wildwachsend gesehen; sie ist auch nach Asien verbreitet worden. Sie ist ein Strituch von 3,2 bis $5 \mathrm{~m}$ Höhe mit handförmig-fïnflappigen Bliittern, braun-purpurnen oder gelben Bliiten und weilser, kurzstapeliger Wolle. Sie wird hauptsiichlich in Ägypten, Arabien und Indien angebaut.

3. Die Westindische Baum wolle (Gossumium bubatense L.) ist auch strauchartig und stimmt in ilıren Merkmalen viel mit denen der Krautigen Baumwolle iiberein, aber ihre Blätter sind unterseits atuf dem Mitteherr mit drei Driisen vcrsehen, und ihre Samen sind schwarz oder grïnlich. Die Blume ist am ersten 'Tage gelb mit rotem frumde, am zweiten aber ganz rot. Boden und Klima iiben auf die Grölse, Farbe und Behaalung der Samen Einfluls aus. Die Grölse der Samen schwankt zwischen derjenigen kleiner und grofser Erbsen. Heimat: Mittelamerika. Die Spielarten dicser Art werden in die Gruppen Sea Island und Upland gesondert. Die Samenwolle beider Spielarten wirl von den Spimem am meisten begehrt. a) Die seaIsland-Banmwolle gedeiht an bestcn auf den kleinen, der Kïiste von Georgia vorgelagerten Inseh. Min nennt sie auch die „Iangstapelige", ihre Wolle iibertrifft alle iibrigen Sorten durch Stärke, 
länge und schönheit des Stapels. Je weiter lamleinwärts diese I hamnwolle gebaut wirl. desto kiirzer wirel dor Stapel. so ist $\%$ li. die Sorte Georgian l pland, anch lioweds genant, eme im linnenlande geziichtefr Wolle dieser Spiclart. Die Scis-Island-liammolle wird aufser-

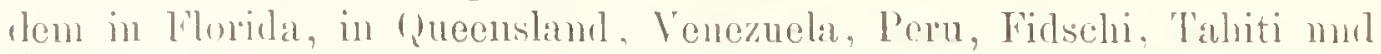
Ïgrpten angehaut. h) I)ie Cpland-Banmwolle wird anch schlechtweg lie kurstapelige genamnt. Sie wirl in Georgia und siid-('arolina. Alahama mod amgrenzenden Gegenden, Texas, Mississippi und Ionisiana, P'ernamlunco, Nord- und Ostliiste ron Brasilien, San Paolo. Sin Salvadur, İgypten. auf den westindischen Inseln, in Veneznela und Peru angebaut.

Wo es angängig ist, sollte die spielart sea Island der Westindischen oder Amerikanischen lianmolle kultiviert werlcn, la sie $\mathrm{mm}$ cin Viertel his cin I)rittel mehr und langstapeligere Baumwolle bringt, als die Krantige oder Indische Baumwolle. Nächst dieser diirfte die Upland für den Anbau ins Luge zu fassen sein. In der Wertschätzung rerhalten sie sich zu einander wie 13 (Sea Island) zu 6 (Upland). Ton ihnen sincl wieder zahlreiche Unterspielarten bekiannt.

Banmwolle wird first in allen Lündern der heisen \%one und mit Vorteil besonder's in den Gegenden angehant, in denen ocemisches Klima und eine mittlere Würme von 25 bis $23^{\circ} \mathrm{C}$. rorherrscht. Sie gedeiht aher anch noch in den wärmeren Ländern der gemälsigten Zone bis zum 36: Grade nördl. Preite, wenn in denselben eine möglichst gleichmälsige Wiirme von 18 his $26^{\circ}$ C. vorhanden ist. Auf der nördlichen Halblingel sind der 40. und 41. (irad der Breite (Yeapel. V'alencia) die Grenze der Baumwollkultur (nur fïr die Krantige Baumwolle). die Hallinsel Krim (his zum 45. Grarle) reicht dariiber hintus. Inf der siillichen Halbkugel ist der :30. Grad die Grenze. In der heilsen Zone wird die lammolle an den Pergen hinanf bis auf $1300 \mathrm{~m}$ Hïle angehaut. Ine Krantige laumwolle ist etwas klimahärter als ric Westindische. Der zur Kultur verwendete Boden liann gering, soll aber tiefgrindig, dhrchlïssig und sandig sein und muls reichlich mit Bammollsamemmehl gredlïngt werden. Das Feld soll eine vor Windlen gesicherte, sonnige I are haben. Das Kinlturfeld muls durch Kanäle leicht zu he- und entwässern scin; stehendes Wasser ist der Pllanze ebenso schïidlich wie grolse Trockenheit. Es eiguen sich daher \%um Lannwollbau an besten the südlichen Staten ter nordamerikanischen Inion. Aussat findet in Norlamerilia im Mïi\% und April statt. Dis grit gepfliigte field teilt man in 201 breite Streifen und lest die Samen für einjälnigen Mnbau in etwa t5 $\mathrm{cm}$ grolsen '/wischentüumen, doch allemal mehrere zusimmen, um später, indem man die schwachen l’flanzen entfernt, nur lï̈̈ftige Stöcke zu hahen, dis man hier und da wieder auf $5 \mathrm{~cm}$ rerkiimt, damit die Staude

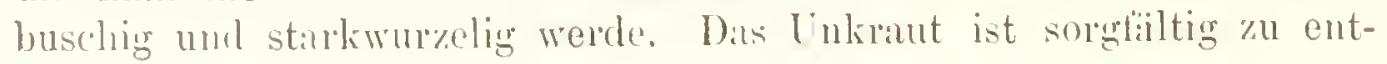


fernen. Zwei Monate nach der Anssal beginnt die Pflanze Rilitron zu troiben. Die Knospen brechen norgens früh aul und sind gegen Mittay voll entwickelt. Dic libiten der Upland-lianmwolle sind rein wcils, die der Sea-Islandphlanze gell). Licilc zeigen aber am Nachmittag gelbe Streifen, sind am näichsten Morgen Heischlarbig, verwelken damn nud fallen des Mittags ab. Innerhall, $2 \frac{1}{2}$ his 3 Momaten entwickehn sich dic Kapsehn bis zmr Reife Die Pflanze crfordert. solange die Kapsel geschlossen ist, viel legen, damit dicse sich voller und runder ausbilde und die Faser möglichst lang werho: hat sich aber die Krapscl geöflnet, so wirkt der Regen sehr nachtcilig, wcil er die Wolle bräunt nund wertlos macht. Dic f'cuchte Laft hillt auch bri Somnenschein dic mit cinem gummiartigen Stoffe verschlossenen Niilite der Kapsehn lüsen, und die geschmeidigen Kílappen rollen dann vollstïndig \%urick. Die Ernte ist sehr mühcroll und dauert mehrere Wochen, da die Kapseln nicht zu gleicher Zeit aufplatzen. Die Kapseln müssen von der Grölse eines Perlhuhneies und darüber sein. Zum Einsammehı der Früchte ${ }^{1}$ ) empfüingt jeder Arbeiter einen Sack mit einem 'Tragband, das er auf die Schulter' liängt. Der Sack reicht lis zur Erde, damit ihn der Arbeiter nicht zu tragen, sondern nur zu lieben braucht, wenn er zur nïichsten Staude will. Wenn ein Sack roll ist, wird er anf den nächsten Weg gestellt, wo ihn der die Runde machende Wagen, der auch leere Sïcke vertcilt. aufnimmt. Besclmutrte, beschïdigte oder fehlerhafte Wolle wird in eine Tasche besonders gebracht. Im Wirtschaftsgebäude mufs die Baumwolle auf einem hölzernen Trockenboden getrocknet werden. Sie wird dann durch eine Iaschinc gereinigt, durch eine Fntkörnungsmaschine (Gin) von den Samen geschierlen und durch eine Pressc zusammengeprefst. Sie liann zur Dichtigkeit von Uhmenholz geprefst werden. Die Ballen werden ituf den Längsseiten mit Eiscndraht verschnürt und sind dann zum Tersand fertig.

Schädlinge. Gefïhrliche Feinde der Baumwollstaude sind: 1. die Raupe der Baumwollmotte (Alctic x!llime), 2. die Kapsehraupe (IIf tiothis comigere) und ein Rostpilz.

Die Baumwollfaser ist infolge ilres Baues, ihrer gcwundenen Form und ihrer verdicktcn, gerundeten Rainder bcfiihigt, zahlreichen Zwecken zu dienen. Die Fasern werden beim Spimcn fest zusammengefügt, cine Faser faltet sich übcr dic gerundeten Ränder der anderen und gewinnt so, diesclhen ergreifend, einen Halt. Dadurch ist dic Herstcllung cines langen Fardens von betrïichtlicher Stiirke möglich. Je fein- nnd langstapchiger dic Baumwolle ist, nm so diinner ist der Faden spimbar. Cnreif geerntete oder mil'sgebildetc Fasern sind weniger gewunden und becintröichtigen, zn (Xarn versponnen, dessen zusammenlaltende Liraft. Die Fasern der ägyptischen nud nord-

1) Nach Semler, Tropische Agrikultur. 
amerikanischen liaumwollsolten sind am vollkommensten entwickelt und am regelmälisigsten grewunden. linter dem Vikroskop zaihlt man 40 bis 120 solcher Windungen anf den Contimeter. Die Rammwollfasel hesitzt einen wachsartign Überzug, del durch die Blerche entfernt wird. Sind dieser Überzug und der Kellstoff ant chemischem Wege entfernt, so elscheint die Baumwollfaser unter starker Vergrölserumgr aus konzentrischen lingen bestehend, die an die Jahresringe der Baumstämme erinneru. Je mehr Ringbildung in der liaser vorlanden ist, desto wertloser ist sie. In Bezug auf Festigkeit nimmt die ägyptische Faser don ersten liang ein. Unreife und iiberreife Fasern nehmen, weil ilme iulsere Wand aufserordentlich diun ist, Farbstoffe nicht gut aut, nur die vollreifen thun dies in rollkoimmenem Malse.

Warenkunde. Gleichfömigkeit in der Beschaffenheit, Glanz, Weichheit, Biegsamkeit, Irehung mol Elasticität sind Merkmale einer guten baumwollfaser. Nach ihrer Länge (4,05 bis 1,0:3 cm; je länger, je lieber) teilt man die Fasern in lang-, mittel- und kurzstapelige. Nach ihrer Feinheit verwendet man sie zu feinen oder geringeren Geweben. Gelbliche Fïrbung und Glanz ("Seidigkeit") der Wolle (amerikinnische und ägyptische Sorten) gelten als Keichen der Festiglieit der Faser. Die Wolle mufs rein und knotenlos sein. Dic Feinheit der Batumwolle hängt lesonders von der Feinheit der Faser ab, je kleiner ilu Querschnitt ist, desto feiner ist sie. Feinste Sorte: SeaIsland-Baumwolle, auch lange Georgia genannt. Sie ist die lingstapeligste und feinste, hat stets einen Stich ins Gelbliche und wird nur zu den feinsten Garnen versponnen. Die brasilianischen (die besten von P'ernaml)uco und Ceara, Balia und Mlinas novas) Bammwollen sind weifs, selır glänzend und „seidig“". Die Baumwolle von Louisiana ist langstapelig, weils (bläulichweils), glinzend. Ihr ännlich, aber gewöhnlich unreiner und kurzfiseriger ist die A la ba ma oller Mobile-Baumwolle. Eine weilse, kurzstapelige Sorte ist lie kurze Georgia (Upland). Die bessere baumwolle vou Guayana gleicht der von Permanbuco, die geringen Sorten sind unrein. Die columbische ist sehr glïnzend, aber ungleichfarbig (gelblich und weil'slich). Die peruanischen Sorten sind graulichweils und grering. bie westindischen Wollen können mit den nordamerikanischen verglichen werlen. Die meisten ostindischen Sorten sind kräftig grelblich gefiirbt und grob. Jie besten Sorten sind ,Dharwar", ans amorikanischen, und "Hinghunghât. aus indischen Samen gezorgen. Von den ibrigen Sorten ist die ägyptische, Mako-orler dumalwolle, hervor\%uluben. Sie ist "zwar nicht rein, etwas ungleichfarbig (nntwerler weils mul atwas röthlichrgelh, oder gelblich), aber seln tein, weich monl langstipelig. Die australische Bammwolle hat eine wolse /unkunft. lieste Sorte die ron Honolulu. Sie ist wrifsritlich. \% \%oit scheint es, als wenn das russische Centralasien, das 
schon jetat cin Drittel des lienlarfes in Rufslund deckt, Ostindien als Batumwollatusfuhriand ablöson sollte.

Verarbeitung und Gebrauch der Baumwolle. Schon lange vor Christus verstanden morgenlïndische Völker, besonders die Inder, die bammolle zu Garnen und Geweben zu verarbeiten. Solange indes die Baumwolle lediglich durch die IIand verarbeitet werden mufste, waren die daraus gefertigten Kileider sohr teuer und konnten nicht zu allgemeinem Gebranch kommen. Erst ils man in England Spinmmaschinen md mechanische Webstïhle erfunden hatte (Ende des rorigen, Anfang dieses Jahrhunderts), wurde durch das billigere Fabrikat stïkerer und allgemeinerer Verlorauch dessellen hervorgerufen und die Herrschaft der emropäischen (englischen) Paumwollindustrie begrïndet. Ehe die Verarbeitung der Baumwolle zu Garn heginnt, wird sie zunächst mit gröfseren llengen derselben Sorte gemischt, um Garne von möglichst gleicher Güte zu erzielen, bei $30^{\circ} \mathrm{C}$. getrocknet, in einer Maschine, dem Wolf, gelockert. gründlich gereinigt, damn, nachdem sie von der Schlag-oder Wattenmaschine in breite. zusimmenhïngende, flache Stiicke (Watte) gebracht worden ist, von der Kratzmaschine in zarte, lockere Bänder verwandelt, worauf sie durch die Streckwalzen gestreckt und geglättet, und endlich in der Vorspinmmaschine verfeinert und erst zu dicken, lockeren, lann durch Wiederholung zu feineren Fïden gedreht wird. Diese noch groben Fïden werden nun auf der Spinnmaschine zu Garn gesponnen. Ein Pfund feinstes Garn soll einen 1670 liilometer langen Farlen bilden (von Leipzig bis Konstantinopel). Auf mechanischen Webstiihlen werden nun Gewebe verschiedenster Art, teils rein aus Banmwolle, teils rermischt mit anderen Stoffen gefertigt, die dann noch gefärbt oder gedruckt werden, - In rohem Zustande dient die Baumwolle zum Polstern. Wattieren, Verpacken 11. s. w. Das feinste Maschinengarn heifst Twist, das stärkste Gam Wassergarn (Wutertuist), das weniger gedrehte, weiche Mulegarn (Mulc-twist). Die glatten oder geköperten Zeuge kommen nach der Feinheit des Garnes unter folgenden Namen in Handel: Kattun (vom arabischen qoton oder Kutun = Baumwolle), Indienne (aus Ostindien stammend, mit gemalten Figuren), Calico (zuerst itus Calcuttı), Nanking (gelhliches oder rötliches Baumwollzeug aus Nanking), Perkal (Perkalin, geprefste Baumwollzenge für Tuchbinder), Musselin (von der tiirkischen Stadt Mossnl), Jaeonet (französische, glatte Musseline), Gingan (rom javanischen ginggum, d. i. rergelıend, verbleichend), T'üll (von der französischen stadt 'Tnlle, netzartiges /2wirnzeug), Barchent (ein auf einer Seite rauhes lianmwollzeug, dessen Kette linnen), P'iyní (haumwollzeug, gesteppter Arbeit :̈hnlich), Manchester, Velvet (Biumwollsamt) u, s. w. In der lleilkunde wird die baumwolle und die aus ihr gefertigte 11 atte als einhiullender, wiirmender Stoff bei Gicht u. s. w., als Vurbandmittel bei Verbrenuungen mod Wunden und nach den lirfahrmong des deutsch- 
französischon livicges als bestro Ersatz füir die leinene Charpie verwondet. Anl'serilem gehraucht man in der Chirurgie das aus der Schielshanmwolln hereitete Kollodium oder den Kílebither, da er :ı der Lult durch Verdunsten des Ïthers schnell ein Hïutchen bildet. Kollodium wird auch in der Photographie, sowie in der Gäirtnerei (an Stelle von lianmwachs) angewendet. Ferner wird aus lianmwolle durch Eintauchen in ein Gemisch von Silpetersäure und Schwefelsäure die Schiefsbaumwolle (Tyroxylin, Nitrocellulose) dargestellt. Sie ist leicht entziindlich und explosibel nnd dient für artilleristische und hiittenmännische Zwecke zum Sprengen, Aus Schiefsbaumwolle nud Kimpfer stellt man durch starkes /usammenpressen das Celluloid, eine harte, feste, hornähnliche Hasse dar, welche zur Anfertigung ron Kïmmen, Griffen, Billardkugeln, spielsachen u. s. w. an Stelle von Horn nnd Elfenbein angewendet wird. - Früher warf man die Samen der lianmwollpflanze weg. Seitdem man aber gefunden hat, dafs sie ein brauchbares öl enthalten, ist der Anbau der Pflanze noch nutzbringender geworden. Ja, man wïrde heute die Pflanze lediglich als ÖlpHanzc kultivieren, wenn sie nicht die Faser lieferte. Der Same der Baumwolle giebt 20 bis 25 I'roz. Öl, Cottollöl, das gereinigt eine klare. strohgelhe Farbe, einen schwachen, erdigen Geruch und einen angenehmen, nufsähnlichen Geschmack hat. Es besteht aus Palmitin und Oleï; sein specifisches Gewicht ist 0,9306. Es wird zur Seifenfabrikation, zur Ilerstellung von Schmierölen nud zur Verfülschung von Speiseölen verwendet. Aus den Prefsriickständen werden Ölkuchen gewomnen. I) der Same 13.95 Proz. Fett und 43,40 Proz. liweifsstoffe enthält, giebt er nach Entferuung der Schale ein sehr gutes Futter für die Haustiere. - Die Samen enthalten aufserdem einen Farbstoff, das Gossypin, der Wolle nnd Seide kräftig, aber nicht dauend braun fürbt. Ein ïnnlicher Farbstoff ist in der Wurzelrinde der Pflanze nachgewiesen worden.

Angaben über Elnten, Handel und Verbrauch ${ }^{1}$ ). Fs wurden 1890 in der Weltindustrie nachweisbar etwa 30 Millionen Neter-Centner Baumwolle produziert. Daron entfillen auf die Vereinigten Stanten von Nordameriki 19600000 m-Ctr.. anl Britisch-Ostindien $4000000 \mathrm{~m}$ - ('tr., auf Ïgypten $1800000 \mathrm{~m}$-Ctr., auf Yexiko

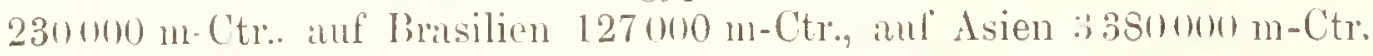

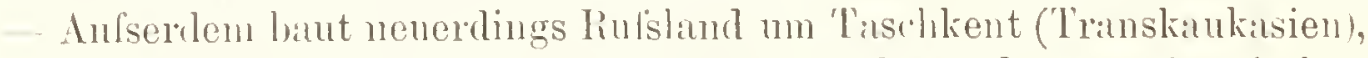
an den Cfern des Amu-Darja (Bochalril) und an der transkaspischen lisenbalm liatumwolle ron romiiglicher Giite.

I) Siidstaaten Nortamerikas liihren in Inurchschnitt der Jilne zwei I) ritteile ilner Entemengen ans, und zwar rorzugsweise nach Grolishitamien, dam aber anch nach Dentschland, Frankreich, liuls-

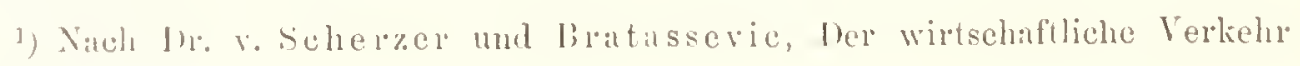
der regenwart. 
linnd 1. s. W. Wie sich in Europa die Verabluitung und der Verbranch der banmwolle stellt, ist aus folgender 'l'abelle zu ersehen:

\begin{tabular}{|c|c|c|c|c|c|}
\hline \multirow[b]{2}{*}{ L i i nder } & \multicolumn{2}{|c|}{$\begin{array}{c}\text { Bammwollverbranch } \\
1886 \text { bis } 1890\end{array}$} & & \multirow{2}{*}{$\begin{array}{c}\text { Zahl } \\
\text { der } \\
\text { Spindeln }\end{array}$} & \multirow{2}{*}{$\begin{array}{c}\text { Kahl } \\
\text { der mecha- } \\
\text { nischen } \\
\text { Welıstühle }\end{array}$} \\
\hline & $\begin{array}{c}\text { im } \\
\text { Durchischuitt } \\
\text { m-Ctr. }\end{array}$ & $\begin{array}{l}\text { aut } \\
\text { den liopf } \\
\mathrm{kg}\end{array}$ & & & \\
\hline Grolsbritammicn u. Irland & 7002200 & 19,00 & 1890 & 44504819 & 615714 \\
\hline Schwciz . . . . . . & 238300 & 8,14 & 188 & 1798000 & 23721 \\
\hline Deutsches licich... & 2010500 & 4,19 & 1891 & 5000000 & 245000 \\
\hline Belgien . . . . & 223700 & 3,72 & 1883 & 800000 & - \\
\hline Frankreich. . . . . & 1152100 & 3,01 & 1890 & 4914547 & 72784 \\
\hline Niederlande ..... & 100300 & 2,25 & $18-3$ & 300000 & - \\
\hline spanien . . . . . & 496100 & $: 3,12$ & 1883 & 1885000 & 7559 \\
\hline Schwoden . . . . . & 117500 & 2,47 & 1884 & 300000 & - \\
\hline iisterreich-Ungarn . . . & 909000 & 2,24 & $18 ! 11$ & 2898610 & 49650 \\
\hline Italien . . . . . . . & 666000 & 2,24 & $1 \triangleleft 90$ & 1800000 & 30000 \\
\hline liufsland. . . . . . & 147520 & 1,55 & 1883 & 3600000 & 90000 \\
\hline Portugal . . . . . . & 59700 & 1,30 & - & - & - \\
\hline Norwegen . . . . . & 240110 & 1,22 & - & - & - \\
\hline
\end{tabular}

Die Einfuln ron roher Baumwolle im Deutschen Reiche stieg von $2440440 \mathrm{~m}$-Ctr. im Jahre 1859 auf $2506408 \mathrm{~m}$-Ctr. im Jahre 1890 und auf $3024690 \mathrm{~m}$-Ctr., im Werte ron 231 Mill. Mlk. im Jahre 1897; die Einfulır von Baumwollwaren fiel ron 219262 m-Ctr. im Jahre 1889 auf $18816+\mathrm{m}$-Ctr. im Jahre 1890 und $80610 \mathrm{~m}$-Ctr. im Jahre 1897. Unsere Ausfuhr von Baumwollwaren betrug 1897 782560 m-Ctr. im Werte von 177,2 Mill. Mk,

.. Kotton is King" (Baumwolle ist die Königin der Industrie), sagt der Englïnder, sagen auch wir mit Riecht. Wie viele Millionen Menschen leben vou der Kultur, dem Handel, der Verarbeitung der Baumwolle und dem Vertrieb der Fabrikate, und wie viele Millionen kleiden sich in baumwollene Stoffe! Hinsichtlich unserer Einfuhr stelıt Baumwolle obenan, beziiglich der Ausfuhr wird sie nur von Zucker und Wollwaren ühertroffen.

Geschichte der Baumwolle. Das ilteste Kulturland der Baumwolle ist zweifellos Indien. Sie wird in den Gesetzbiichern des Manu oft als Karpasi erwïhnt. Eine Baumwollenart (ciossypum reli-

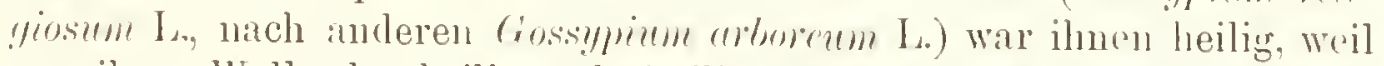
aus ihrer Wolle der heilige, Ireiteilige Faden der Brahmanen, dieses Simbild der göttlichen Ireiheit, gespomen wird. Sicher ist, daf's schon 500 Jahre vor der christlichen \%eitrechunng Baumwolle in betriichtlichn Mengen \%u Geweben veralrbeitet wurle. Ilerodot und Kitesias berichten zuerst und zwar nach persischen Quellen ibber die I:ammwolle in Indien. Herodot sagt: „Die wild wachsenden liämme tragen als lirucht eine 
Wolle, welche die der schale an Schönheit und Gïte ïbertrifft; die Wolle dieser binmo vorwenden die Inder auch zu ihren Ḱleidungsstïcken." Nach Herodot ist anch das indische Hiilfscorps des Xerxes in Baumwolle gokloidet gewesen. I) lírieger, mit welchen Alrxanders des Grolsen Soldaten an Indus zusammentrafen, trugen baumwollene Gewebe. Die liaumwolle trat den Macedonier'u so liäufig entgegen, dals: sie dieselle zum Ansstopfen von Kiopflissen nud Plerdesätteh benutzten. Theophrast berichtot ebenfalls vou der liaumwollphanze, welche die Inder wie die Weinstöcke in Reihen auf die Felder pHanzen und ron welcher sie ihre Kleider machen. Aufserden kamen Baumwollpflanzungen anf der im Eingange des Prrsischen Golfes gelegenen Insel Tylos (Bachraim) und in Arabien vor. Durch die Perserherrschaft wurde der Gebrauch der Baumwolle allgemeiner. Plinius erwähnt zuerst Baumwolle in Ober:̈gypten. Nach China kam sie 200 r. Chr., blieb aber bis zum 11. Jahrhundert Gartengewächs und wurde nm erst im freien Felde angepflanzt, doch nie in der Ausdehnung, dals man auf die Einfuhr ans Indien und Burmah hïtte verzichten liönnen. Gegen Ende des 18. Jahrhunderts brach eine grolse Hungersnot ans, und der Kaiser verordnete nun, dafs der grö̈ste Teil des Anbaulandes dem Getreideban zuriickgogeben werden sollte. Die Araher dehnten das Verbreitungsgebiet der laamwolle weiter aus; im 12. Jahrhundert betrieben sie den Anbau der Pflanze in Sicilien, an der Küiste ron Andalusien, in Ïgypten, in Palästina, bei Gaza und an der Tigrismündung bei Bassora. Der arabische Yame für die Ptlanze Qutn oder Kutn ging in die neucren Sprachen Suideuropas als Cotone, Coton, Algodon über, und unser "Kattun" erimnert ebenfalls an den arabischen Ursprung. Kolumbus. Cortez, l'izarro und Amalgro fanden den Gebrauch der Baumwolle in Amerika, die Portugiesen bei den Kaffern und Mnngo Park bei den Negern in Senegambien und Guinca. Abdurhaman III. (912 bis 961) liefs die laumwolle in Spanien anbauen und rerarbeiten. Von hier ans gelangte die Kultur der Bannwolle nach Italien und Griechenland, ohne eine wichtige liolle zu spielen. Von der Fomheit der indischen Banmwollgewebe erzïhlen zwei Araber, die im 9. Jahrhundert Indien hereisten, dal's dort fast röllig durchsichtige Kkloider verfertigt wïrden, so fein, dals ein wanzer liock durch einen Fingerring sezogen werden könne. Tavernier rrählt, dirls tiirkische Thurbane ans $16 \mathrm{~m}$ feinstem indischen Musselin zusammengewunden seien, doch nur vier L'nzen wöggen. I)ie feinsten dieser (iewebe, zu Gantipmm mud Ditta in Indien gefertigt, sieht man nicht, wem sie auf eine Wiese grebreitet vom T'in befenchtet

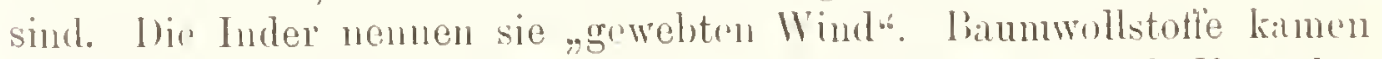
in Furopar erst scit dem Mittelalter in Anfualume. Joseph II. verbot das Tragen derselhen wegen ihres hohen l'reises. In Europa sollen die Ilollinder zuerst den kintun nach Art des indischen verfertigt hiben. l'nter Heinrich Vlll. wurde in Isancashire, moter Eduard l'I. 
in Manchester und Clieshire Baumwolle verarboitet. Dio englisch. Baumwollindustric entwickelte sich mehr nach binfiihrumg des liattundruckes und infolge des Verbotes indischer Kenge gregen Linde des 17. Jahrhunderts, sie iiberiligelte aber die aller Länder Europas, uachedem Watt die Dampfmaschine verbessert latte und die Spinmmaschine und der mechanische Webstuhl erfunden worden waren. Ums Jalı 1770 wurden in Nordamerika die crsten Anbanversuche nit der Banmwollenstiude gemacht, und schou nach Beendigung der napoleonischen Kriege bezog England 85 Proz. seines Rammwollberlarfes durch /ufulr aus Amerika. Im Jahre 1860 crzeugte Nordamerika $4 \$ 24000$ Ballen Baumwolle. Infolge des amerikanischen Bürgerkrieges (1S61 his 1864) wurde die Baumwollindustric in Nordamerika zuriekgeworfen und dardurch der sogenannte "Baumwollhunger" hervorgerufen. \%ur Stillung desselben wurde der Anbau der Baumwollpflanze in anderen geeigneten Ländern versucht, gegenwärtig ist aber die Erzeugung der Faser in Nordamerika wieder hoclogestiegen. Nach Beschluls des deutschen Kolonialrates soll der Anbau dieser wichtigen Pflanze in DeutschOstafrika im grofsen rersucht werden. 


\section{Tafel 2.}

\section{Tabak (Nicotiana tabacum L.).}

Der Virginische T'abak gehört zur Unterklasse der Ver'wachsenblätterig’en Dikotyledonen, zur Reihe der Röhrenblütigen (Tubiflorue) und zur Familie der Nachtschattengewächse (Solumucere).

Zur Familie der Nachtschattengewächse (Solumcenc) gehören einjïhrige und perennierende Kräuter, aufrechte ofler kletternde Sträucher und kleine Biiume mit häufig ungeteilten, oft buchtiggezïhnten, gelappten oder fiederschnittigen Blättern. In der Bliitenregion sind die Blätter oft gepaart. Die Blïten erscheinen endstïndig. an Haupt- und Seitenachsen, sie stehen einzeln oder in Trugdolden und entspringen oft scheinbar aufserhalb der Blattachseln an der Seite der Stengelglieder; sie sind meist strahlig, seltener seitlich symmetrisch. Der Kelch ist einbliitterig, fünfspaltig oder fïnfteilig, bleibent. Die Bhumenkrone ist meist fünf-, selten drei- oder vierlappig, ralförmig, trichterig oder tellerförmig, in der kinospe lïngsfaltig oder klappig, öfter's rechts gedreht. Die fünf Staubblïtter stehen in der Röhre der Blumenkrone abwechsehnd mit den Sambappen derselben; zuweilen ist eines derselben verkiummert. Der Fruchtknoten ist oberstindig, zweifïcherig, mitunter, durch nachtrïglich anftretende Scheidewiinde, dreibis lüifficherig, oder durch Verkiummerung einfïcherig. Die Frucht ist emo Kapsel oder Beere, die sich entweder scheidewandspaltiw, zweiklappig. oder nit Deckel öfnet. Simmen sind meist viele vorlanden, sie sitzen un scheidewandstänligen Samenleisten; sie enthalten grolses, theischincs Niihrgewelse, in welchem der gerade oder gekrimmte lieinling ringebettot ist.

7o Gittungen mit 1650 Arten in den T'ropen und den genililsigten \%onen; dinnter wiehtige Armei- und gef:iluliche Giftpflanzen.

Die Gattung Tabak (Niolimu L.) umfalst meist einjïhrige lin̈uter, selten Halhstrïncher, nit istigen Stengel, ganzrandigen, olt driisigen Bliittern. Mliiten in endstindigen Trauben oder Rispen. Der Kelch ist röhrig-glockenlörnigg, länflappig, die happen sind meist un- 
gleich. Die trichter- ouler sticltellerförmige Iilumenkrone lat einen fiuflappigen, abstchenden, etwas seitlich-symmetrischen Samm, dessen Falten in der linospe zusammenneigend gedrelıt sind. Die fïnf Staubblïtter sind mit der Bhmmenuöhre verwachsen, nur oben frei, eingeschlossen, zu vier ungefïh gleich langen gesellt sich ein kürzeres. Die Staubbeutel sind kugelig oder eiförmigr, zweilaicherig, ler Lä̈nge nach aufspringend. Der stempel ist sitzend, der Fruchtknoten zweibis rierficherig. Der Griffel trägt eine kopflörmige, zweilappige Narbe. Die trockene, zwcificherige Kapsel springt scheidewandspaltig, zweiklappig, seltener rierklappigr auf. Die Samen sind zahlreich, sehr klein, fast nierenfömig, netzaderig. Keimling in der Achse des ölig-fleischigen Eiweilses, leicht geliummt, fast stielrund; Simrnlappen kurz, fast keulenförmig. - Hicrher etwa 50 Arten, davon 40 in Amerika.

Virginischer Tabak (Nicotimm tubucum I.).

Die Wurzel ist einjährig, senkrecht, ästig, gelblichweifs, mit vielen Wurzelfasern besetzt.

Der stengel ist einfach oder wenig ästig, lirautartig, aufrecht, fast stielrund, driisig und kurz behaart, frisch etwas klebrig, 1 bis $2 \mathrm{~m}$ hoch, oben in cine weit ausgesperte Rispe ibergehend.

Die Blätter sitzen zerstreut, sind nach oben kleiner und schmäler und in die linien-lanzettförmigen Deckblättchen übcrgelıend; sie sind oberseits tiefgrün, unten blasser, kurz und drüsig behaart, etwas klebrig, gerippt, schwach wellenförmig, getrocknet braun und leicht zerbrechlich. Die Wurzelblätter sind liinglich-elliptisch, zugespitzt, in den Blattstiel verschmälert. 30 bis $70 \mathrm{~cm}$ lang, $16 \mathrm{~cm}$ breit, frül absterbend; die unteren Stengelblätter sind länglich-lanzettförmig, sitzend, lierablaufend, zuweilen etwas stengelumtiassend, zugespitzt, seltener mehr eiförmig und gesticlt; der Blattstiel fehlt meist, seltener ist er breiter oder schmäler geflügelt und mit ohrenförmigem Grunde stengelumfassend; Seitennerven unter spitzen Winkeln a us der Mitte verlatend.

Die Blütenrispe ist fast doldentraubig, endstïndig, klebrigbohaart, weit ausgebreitet, vielblïtig, mit aufrecht abstelnenden İsten; die Deckblätter sind linienlanzettförmigr; die Blïtenstielchen sind stielrund, meist kürzer als der Kelch.

Die Blüte ist 40 bis $50 \mathrm{~mm}$ lil gr, aul'sen drüsig-behaart und klebrig. Der $\mathrm{Kelch}$ ist fast glockenförmig, blafsgrïn, zweimal kiirzer als die Blume, bleibend, fiinfspaltig, Lappen ctwas mngleicl, linzettförmig, lang zugespitzt. Blumenkrone tricliterförmig, oben fleisch-oder rosenrot, nach unten grünlich, abfallend; liöhre litng;, walzenförmigr, gregen den Schlund aufgeblasen; Saum grefialtet, fünfspaltigr, ausgebreitet, zuletzt etwas zuriickgeschlagen; Lappen eilommig, lang zugespitzt, selten stumpf. Staubblätter fïnf, haum aus dem Schlunde hervorragend. Staubfïlen mit dem unteren Drittel ilrer Länge der Blumenröhre angewachsen, oben frei, ungrleich, einer 
merklich kiirzer, pfriemförmig, an ihrem freien Ende unten behart. Staubbeutel länglich, an beiden Enden ausgerandet, auf dem Riiicken angewachsen, zweiffïcherig; Fïcher der Tuinge nach an den Seiten anfepringend. Stempel oberstindig, kahl, so lang wie die Staubblïtter. Fruchtknoten aus eiförmigem Grunde lïnglich, etwas von der Seite zusammengedruickt, zweifïcherig; Samenleis te grofs, Samen anlagen sehr zahlreich, klein, krummlïufig; Griffel fadenförmig, abfallend, Narbe kopfförmig, durch eine Querfurche schwach zweilappig, griü, klebrig-behaart.

\section{Die Blütezeit dauert etwa 14 Tagre.}

Kapsel eilïnglich, oben schmäler, länger als der Kelch, scheidewandspaltig-zweiklappig, mit zweispaltigen Klappen. Samenleiste zuletzt frei, vielsamig.

Samen sehr zahlıeich, klein, brïunlich, eiförmig, etwas nierenförmig, auf der Oberfäche fein netzgrubig, mit geschlïngelten Maschen.

Keimling bogenförınig, walzenrund, kü̈rer als das ölig-fleischige Eiweifs; Wiirzelchen doppelt so lang als die Samenlappen.

Diese Pflanze ist riicksichtlich ihres Wuchses und der Grölse ihrer Blïtter selır verïnderlich.

Die Heimat les Virginischen Tabaks ist Suidamerika.

Verbreitung: Als Kulturptlanze in zahlreichen Formen in fast allen gemälsigten und wärmeren Ländern verbreitet. $\mathrm{Er}$ wird ron allen Tabakarten am meisten angebant, auch in Deutschland.

Von den etwa 50 bekannten Arten der Gattung Tabak sind nur wenige Arten für die Tabakgewinnung von Wichtigkeit: 1. Der oben beschriebene Virginische oder Gemeine Tabak. Ton ihm stammen die meisten Tabaksorten. Besondere Kulturformen sind: der Baumknaster ( $N$. finticose L.), der Gundi-Tabak (N. pumdurutu), der holländische Amersfoorter 'Tabak, der deutsche Landtabak u. a. Wahrscheinlich dïrte lierher auch der Maryland-Tabak ( . mucroph!nllu, surmy.) gehören, der breite, stumpfe, am Grunde geöhrte, sitzende oder gefliigelt-gestielte Blätter, sowie einen gedrungenen Bliitenstand liat und der rorzüglich in Centralanerika, Ungarn und der T'ïrkei angebaut wird und in desseu Formenkreis anch der Chinesische

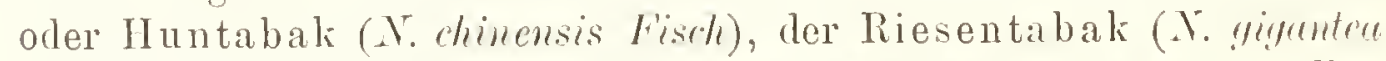
Led.), der Langbläterige Tabak (N. lancifoliu Ag.) u. a. zu stellen simd. 2. Der Bauerntabak ( $\lambda$. moticu L., auch Ungarischer, Veilchen-, 'Tiirkischer, Latakia. Englischer, A siatischer', Brasilianischer 'Tabak genanut). Er hat eine klunere, gelblichgriine Bhumenkrone, die aus einer walzenförmigen Röhre besteht und eincu rundlichen Sinm mit stumpfen, fast rundlichen Ziptehn hat. Die oberen liliitter sind sitzend, die unteren gesticlt, alle sind rund-eiförmig. Wiihrend ihres Wachstumes dick, sind sie nach dem Gïreu und Trocknen diimn und clastisch. Diese Art wird rorkïglich in Südeuropa, in West- 
asien und Afrika gebant; sie ist von allen Arten am klimaluartesten. 3. Die Persische 'l'abalipflanze ( N. persica I.) reichnet sich durch weilse, röhenformige liuten aus; die Biatter sind sitzend, lang und schmal, die unteron breiter als die obcren. Der Schirastabale ist ihre hekannteste Spiclart. Weniger Verwondung funden A. repmolu Mith.7. in Centralamerika und Mexiko, der durch scine langröhrige, weifs-rötliche Blumenkrone mit abstchendem Saum ansgezeichnot ist,

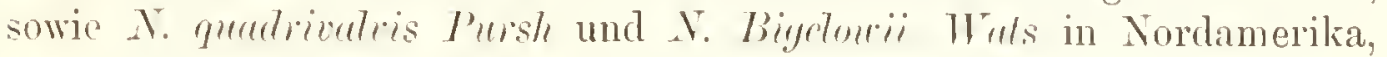
deren Fruchtknoten vielficherig ist.

Am besten gedeiht der 'l'abak nördlich und südlich vom İquator' zwischen dem 15. lis 35. Grade. Wo die Weintraube nicht mehr zur rollen Reife gelangt, gewähnt auch der 'Tabakbau keine Befriedigung. Die 'Tabalipflanze verlangt, bis sich die Blïtter voll entwickelt hiben, ein beträchtliches Mals vou Fenchtiglieit; folgen dariiber hinaus noch anhaltende Regengiisse, so beginnen die Bläter zu faulen, dic Entwickelung ihres Aromas wird rerhindert und sie werden grobrippig. Die Pfianze verlangt einen lockeren, tiefgriindigen, milden, warmen, etwas sandigen wnd nicht allzu sehr gediungten Boden (sonst grobrippige Bliitter). Auf frisch geroletem Lande gedeiht sie am besten und bekommt hellfarbige Blaitter. Der beste Boden ist ein sandiger, kalk- und humushaltiger, warm liegender Lehm, der mit Kompost, Stalldiinger, 'Thomasschlacke, Kaliumsulfat, Ammoniumsulfat oder' Guano gediungt wird. Zu viel Stickstoff erhöht den Nikotingehalt der Blïtter; giebt ilınen grobe Rippen und wirkt nachteilig auf Aroma und Milde des Geschmackes; auch Chlorverbindungen (Kainit) sowie Dung mit Latrin ist zu vermeiden. Das Eisen des Bodens teilt den Bliittern eine lebhafte Fïrbung mit. Nach Schlösings Untersuchungen brennt der Tabak, wenn er eine genügende Menge von Kalisalzen enthält, er kohlt nur, wenn dieser Bestandteil gering ist. Die folgende 'Tahelle giebt das Mittel von 10 Aschenanalysen nordamerikanischer Tabakssorten:

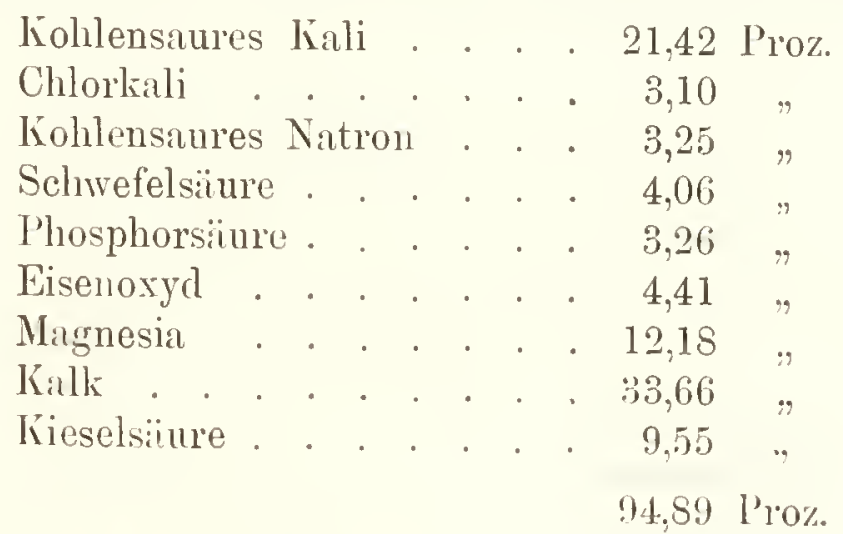

Gute 'Tabakbliitter hinterlassen nach der V'erbrennung durchschnittlich 25 bis 30 Pro\%. Asche, ein Beweis dafiin, dals diese Pllanze den lioden sehr aussaugt. Aus der Aschenanalyse ist leicht ersichtlich, welche Stoffe dem Kulturfelde durch Dïngung wieder zurufiilıreı 
sind. - Es ist festgestellt 1 ) worden, dal's die Geschmacksstärke des Tahaks von seinem Nikotingehalt abhïngt. Bei gleichen iibrigen Verhältnissen wird der Nikotingelıalt un so höher, je weiter die I'flanzen anseinanderstehen, je weniger bliitter ihuen gelassen werden, je höher die letzteren am Stengel sitzen und je spaiter die Ernte eingeheimst wird. Der Nikotingehalt der Blätter sinkt um 50 Proz., wem die P'flanzen so eng gesetzt werden, dafs mehr als 12000 auf den llektar gehen. Der Nikotingehalt schwankt in den Verhältnissen von 1 zu 1.27 und 1,72, je nachdem der Pflanze 14, 10 oder 6 Blätter gelassen werden. Ein Tabak, der bei seiner Vollreife 6 bis 7 Proz. Nikotin enthält, wird, wenn er 14 Tage vor diesem Zeitpunkte geerntet wird, nur 3 Proz. enthalten. - Dis Tabakfeld mul's so ausgewählt werden, dafs es weder ron Hiefsendem Gewiisser noch von heftigen Regengïssen iiberschwemmt werden kann. Werden die Tabakptianzen von Staubwolken beschmutzt, so können die klebrigen Ausschwitzungen nicht statifinden.

Die Kultur beginnt mit der Anlegung der Samenbeete. Die Beete sind vor den heilsen Somnenstrahlen zu schiitzen. Die Pflänzlinge mïssen in Abstïnden von etwa $75 \mathrm{~cm}$, nach jeder Richtung hin, gesetzt werden. Um ein schnelles Wachstum der I'flanze zu befördern, ist der Boden wenige Tage nach dem Einsetzen des Pflïnzlings ins Feld zu lockern. Je schneller die Pflanze wächst, desto feiner wird das Blatt. Ian bricht den jungen 23 bis $26 \mathrm{~cm}$ grolsen Pflanzen die Seitentriebe (..Diebe"), später die Blütenrispen ("Köple"), dam die sich in den Blattwinkeln wieder entwickelnden Triebe („Geizen") und nimmt endlich auch die Stengelblätter unten nach und nach weg (..abblatten"), alles, um die Hauptblätter krïftiger werden zn lassen. Das Ungeziefer muls fleifsig abgelesen und das T'nkraut ausgejätet werden. Frost, nafskalte Witterung, Windbruch und Hagel, der die Bliitter durchlöchert, können die Ernte zu nichte machen. Auch erscheint oft ein Rost in braunen Flecken auf den Blïttern und liilst sie absterben. Wenn die Blätter gelblich werden und sich senken, sind sie zur Ernte reif. Man schneidet entweder die ganze P'tlanze ab, oder man bricht die reifen liliitter aus. Aul Cuba und dem benachbarten Festiande schmeidet man das kirant am Boden ab mnd gewinnt ron den neuen Schölslingen eine zweite, aber an Qualitiit schwäichere Ernte. Nan trocknet die Blätter, nachdem man den feineren derselben die starke Mittelrippe (..ausgerippt") herausgenommen, langsan muter Bedachung, bringt sie durch Umwickehurg mit Bindfaden in möhrenförmige Bïndel (Karotten) und verkault sie an die Tabakfabrikanten. Die Kultur des Tabaks verlangt sehr viel Handirbeit. Anch grinstige Ernten geben nur ein Prozent feinste Blitter. Nach ihrer Verwendung nenut man die Sorten der Bliitter. Schneidegut (Cigalrentabak), Karottengut (Sclnupftabak) nnd Spinngut (Kau- mol holltabak).

1) Fon sichlösing, birektor der Schule der Statsmanufakturen rou Frankreich. 
Dic liohleule (Mumestm bressiene), die Yosilonenle (Plusin ynmmu).

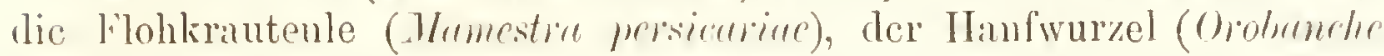
inmsin) mol einige, auf den Blïttcrn braune Flccken crzengcnde I'ilze sind benerkenswerte Feinde des 'Tabaks.

Verarbeitung der Blätter. Nur in der heilsen \%one und unter den guinstigsten liedingungen gercifte Bliitter können sofort gerollt und geraucht wcrden, doch sollen diese Cigarren sehr scharf und betäubend wirken und iibel riechen, da sie eiweilsartige Stoffe enthalten, die erst durch die "Fermentation", eine Art Gärung, zerstört wcrden. Bei dieser werden im allgemeinen einigc beim Verbrennen ïbelriechende Stoffc durch aromatische ersetzt; auch wird dadurch das in den Bliittern enthaltcne Nikotin (siehe unten) vermindert oder in Nikotianin übergefülnt. Bei der Gärung wirkcn wesentlich Spaltpilze mit; der geringere Wert der europäischen 'Tabake wird von manchem auf den Gang der Gärung zuriickgefïhlıt. Jedenfalls wird das Studium dcr Tabaligärung ähnliche Erfolge aufzuweisen haben, wie das der Weingäirung. Nach der Gärung werden die Bliitter ebenfalls getroclinet und sortiert. Geringcre Sorten werden sauciert, d. h. durch eine Beize angefeuchtet, um Geschmack, Geruch und Farbe zu verbessern, und damn rasch getrocknet. Man schneidet die Blätter nun auf Schneidemaschinen sehr klein und stampft sie dann (Schnupftahak; wird noch stärker gebeizt), oder windet sie ohne Saucierung zu dicken Seilen auf der Spinnmaschine zusammen (Rollentabak), oder man wickelt kleincrc Blïtter oder Blattteile in ein grölseres zu einem Röllchen (spanisch Cigárro, d. i. Glimmstcngel) zusammen. Die Bestandteile einer Cigarre (Einlage und Umblatt bilden den Wickel, darum kommt das Deckblatt) werden gewöhnlich von verschiedenen Sorten genommen. Die fetten, schweren Tabake (Kentuckyblätter) werden nach der Saucierung zu kleinen Stangen gcrollt und geprefst und geben deu Kautabak. Den fcrmentierten Tabak beizt man häufig mit Salpeter, oder man taucht ihn cinen Augenblick in einprozentige Lösung von Kaliumkarbonat, um seine Verbrennbarkcit zu erhöhen.

Bestandteile des Tabaks ${ }^{1}$ ). Die Blätter aller Arten der Gattung Tabak riechen in frischem Zustande mchr oder weniger widerlich und betäubend und schmecken scharf bitter'; die Ursache sind die in ihmen enthaltenen heftigen Gifte Nikotin und Nikotianin. Durch die fallrikmäfsigc Behandlung der Blütter geht vicl von dem natiirlichen Gift verloren.

I) Nikotin $\left(\mathrm{C}_{10} \mathrm{II}_{14} \mathrm{~N}_{2}\right)$ ist cin sehr giftiges Allaloid, das durch verschiedene Abscheidungen rein dargestellt einc ölige, farblose, aus Kiohlen-, Wasser- und Stickstoff bestehendc fliichtigc Fliissigkeit mit starkem Tabaksgcruch und -reschnnack biket, in Wasser zicmlich löslich ist und sich durchs Lagern des Tabaks bedentend vcruingert.

1) Nach Semler, l. c. 
Lis ist schwerer als Wasser (1,027 specifisches Gewicht), riecht in der lialte fist gar nicht und ist ron lange nachhaltigem. ätzend scharfem (ieschmack. Am Dorht brennt das Nikotin wie (j) mit lebhafter, rufsender Flamme. In winzig kleinen Gaben erzeugt es Schwindel und Kopfschmerzen, in hedeutenderen Zuckungen nnd den Tod. Beim Verbremen und Verkohlen (Rauchen) des Blattes wird das Nikotin zersetzt, und der Raucher erhïlt dabei nur einen kleinen Bruchteil der Wirkungen desselben, die sich als narkotische kennzeichnen; aufserdem entstehen neue Verbindungen, wie Ammoniak, Blausäure n. s. w. Boden und Kilima können in der Tabakpflanze die Bildung von Nikotin begiinstigen und zwar auf Kosten des romas. Eine Tabaksorte kann stark mit geringem Aroma oder sehr aromatisch mit schwachem Nikotingehalt sein. Scharf gediingter Virginiatabak enthält im trockenen Blatt 4,50 Proz. Nikotin, dagegen Seedleaves ron Wisconsin und Illinois nur 0,86 Proz. und Blätter ans dem Miamithal nur 0,63 Proz. Der berïhmte Havanatabak enthält durchschnittlich 2 Proz. Nikotin, die in Deutschland und Frankreich gereiften bis iiber 8 Proz. Nikotin. Ein zweiter Bestandteil des Tabaks ist ein kampfer-

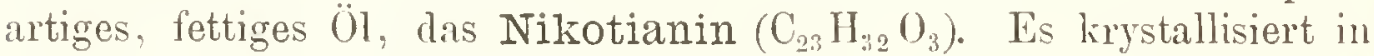
weifsen Blättchen, riecht milde, etwa wie ein Gemisch ron 'Tabak und Fliederblumen. schmeckt nicht scharf. nur hitter aromatisch, ist wenig in Wasser, mehr in $\ddot{A}$ ther oder Weingeist löslich, schmilzt in der Wärme und verfliichtigt sich unter Entwickelung seines Aromis. In der Nase erregt es Niesen. Fin Gramm innerlich genommen erregt schwindel, Übelkeit und Erbrechen. Dieses Gift ist nur in ganz geringen Mengen in den Tabakblättern enthalten, doch wird namentlich anch ihm die betiiubende Wirkung des Tabakdampfes zugeschrieben. Ein dritter Bestandteil des Tabaks, das Nikotian, ist als eine nicht krystallisierbare Salzbase unterschieden worden; es ist ron gelblich-weifser Farbe, olme Geruch und Geschmack, in Wasser, Weingeist und Äther unlöslich, es bildet mit Säuren unlösliche, geschmacklose Salze, die durch IIitze oder Ammoniak zersetzt werden.

Aufserdem enthält der Tabak noch Extraktivstoff, Gummi, Harz, Fiweifsstoffe, Wachs, Apfelsäure. Gallussïure, Gerbsïnre, fette und fliich tige Öle. Im südlichen Rufsland gewinnt man das fette (il aus dem Samen und verwendet es zu Beleuclitungszwecken. Für den Gehalt des wasserfreien Tabaks ergeben sich nach 96 Analysen im Nittel folgende Zahlen 1): Gesamt-Stickstoff 4,01 Proz., Nikotin 1,32 Proz., Ammoniak 0.57 P'roz, Salpetersiure 0,49 Proz., Salpeter 1.0S Proz., Fett 4,32 Pro\%, Ische 22,81 Proz., Gesamt-Kali 3,29 Proz., Natron 0.49 Proz.; in del Asche: Kaliumkarbonat 1,96 Proz. Calciumkarbonat 15,05 P'roz. Leim liauchen sondert sich ein Saft (Schmergel, Schmurgel) ab. der so giftig ist, dafs man mit in diese Flüsigkeit getanchten

1) Nach Könier, Nie menschlichen Nahrungs- und Genufsmittel II. 
Nadeln Insekten töten kaum. Je weifser die Asche, desto besser dic Tabaksorte.

Gebrauch und Wirkung des Tabaks. Dor Gelrauch des Tabaks als Rauch-, lian- und Schumpltabak ist bekannt und über die aanze Finde verbreitet. I)er Genufs des 'Tabaks wirkt höchst markotisch, reist und betiiubt die Nerven. Te frischer der 'labak, desto stairker sind die Wirkungen. Ein Neuling wird die narkotischen Wirkungen in Erbrechen, Durchfall, Kopfweh, Betïubung und Angst (Taloaksangst) zu verspüren laben; ¿iltere Raucher empfinden diese Wirkungen weniger. Nur das milisige lauchen vou melrr duft-als nikotinreichem labak ist der Gesundheit nicht schädlich, wirkt morgens zur $\Lambda$ bschleimung und Leibesöftnung, liann aber zur Verdauungszeit durch vieles Fortgeben ron Speichel nachteilig sein. Allbckannt ist, dals das Rauchen die Atmungsorgane reizt; - weniger verbreitet dagegen die Kienntnis. dals os Herzklopfen hervorrufe, dals es Nervenleiden jeder Art zu erzengen, die Entwickelung im Alter des Reifens zu verzögern und zu zerstören und eine Art Blindheit herbeizuführen vermöge. Das Schumpfen sollte nie eine Angewohnheit, sondern nur bei Augenentziundung, Stockschmupfen und Kopfschmerzen ein ermunterndes, die Gehirnthätigkeit anregendes, aber voribergehend gelorauchtes Reiznittel scin. um durch gesteigerte Absonderung des Nasenschleims abzuleiten. Regelmailsig fortgesetztes Schmupfen wirkt schädlich auf die Nasenschleimhaut und deren Nerven. Personen, die an Halskiankheiten und Verdauungsbeschwerden leiden, sollten weder rauchen noch schmupfen. Merke: Rauche $11 m r$, wenn du vollstindig erwachsen und ganz gesund bist! Ranche nie eine Cigarre olme Spitze bis zum Ende, weil sonst der Mund alle durch das Verbrennen hervorgerufenen Destillationsprodukte aufuehmen muls! Rauche mälsig leichten, trockenen Tabak aus wohl gereinigten Pfeifenköpfen mit Wassersäicken und mit grolsgrebohrten 'Tabakröhren, nicht aus alten Mecrschaumköpfen, nicht aus 'Thoupfeifen. Rauche lieber 'Tabak aus der Pfeife, als Cigarren!

Das Liauchen ist för unreife Knaben doppelt schädlich, da sich durch dasselbe eine Menge von Wïnschen, Begierden und diunkelhaften Regungen entziinden, die bis dahin geschlummert haben. Wie Dr. Debaisne der britischen, society of Public Medicine" mitteilt, luat derselbe 35 Knaben im Alter von 9 bis 14 Jahren behandelt, welche lïngere Keit gerancht hatten. Bei 27 ron ihmen zeigten sich als Folgen des Rauchens gestörter Bhutumlanf und Verdaumng, Her\%klopfen, Alstumpfung des Geistes und meist cin starker IIang nach alkoholischen Getränken. Das Blut zeigte in S Fïllen Verminderung der roten Blutkörperchen. 12 Kualıen litten anhaltend an Nasenbluter. 10 klagten ïber gestörten Schlaf und Alpriäcken. Jo jünger die Kinder, desto stïrker offenlarten sich diese nachteiligen Folgen; rie wohlgenährtesten litten an wenigsten. Nur die linaben, welche das Ranchen ganz ınterliefsen. wurden hergestellt. 
Das Kanen des Tabaks ist bei den Seeleuten und besonders in Yordimerika bei der mämnlichen Bevölkerung gebräuchlich. Es wirkt stiirker als das Ramehen. da der ganze Gehalt an Nikotin, das hier nicht dureh das Verbrennen zersetzt wird, in den Speiehel aufgenommen werden muls.

Warenkunde. Die Guite des Tabaks hïngt sehr ron seinen liulturorten, also ron Klima, Bodenbeschaffenheit, Lage der Felder, rom Simen und von der Witterung al). Der vom Ïquator nördlieh und südlich ïber den 35. Grad linaus gebaute 'labak enthält viel Nikotin. Amerika liefert den besten und meisten Tabak und hier wieder die Westseite der Insel Cuba in dem welthekamnten Haranatabak (Cigarren). Die Handelssorten werden meist nach ihren Erzengungsländern benannt; die wiclitigsten sind:

1. Siidamerikaniseher Tabak. a) Varinas (Kanaster) ans den l'rovinzen Varinas, Merida, Margarita u. s. w. der liepublik Venezuela, kommt teils in Bliitterbiischeln, teils in 7 bis 8 lig schweren, 4 bis 5 em dieken gesponnenen Rollen, in Körben aus gespaltenem Roln (crmustru) in Ilandel. Dieser seln milde, feine, weiehe, kastanienbraune 'Tabak ist der feinste lianchitabak. Beste Sorte „Muffkanaster". b) Orinokokanaster in Rollen. Er ist sehr dick, dunkelbraun. e) Orinokokanasterblïtter, heller von Furbe, mit kleineren Blättern. d) Cumanatabak mit leiehten, dünnen, hellhraunen Blättern. e) Brasiliseher Tabak in Rollen wie in Blättern kommt in drei Sorten ror. 1. Sorte: die Bliitter sind dünn, leicht, hellbraun bis rötlichgelb und haben einen Zimtgerueh; sie werden zu feinen Cigarren und feinem Ramehtabak verwendet. 2. Sorte: fette. schwarze Bliatter mit einem suifslieh-sänerliehen Gesehmaek; sie werden zu Selınupftabak verarbeitet. 3. Sorte: Bliitter braun und selıwarzbraun, einen ordinären Rauehtabak liefernd. f) Paraguaytabak, vielfach sehr stark. g) Columbia aus Neugranada und den angrenzenden Lä̈ndern: Carmen, GironPalmyra, Ambalema, meist zu Cigarren verarbeitet, stehen dem Varinas nahe. h) Mexikanischer Tabak ist erst in der neveren Zeit auf den Weltmarkt gekommen.

2. Westindiseher Tabak. a) Cuba und Havana, die rorzïglichsten aller Tabake, deren ausgesuchteste und teuerste Biiitter, Cabanos. als Vuelta Ibajo, l'artidos und Remedios exporticrt wer(len. I) on Havanatabik verarbeitet man meist im Lrzeugingsgebiet anf Cigitren, doels kommen auch Bilitter in Bïndeln und Seronen meh Enropa, die dam meist als Deckblitter verwendet werden; ferner gehen fette, schwere Bläter nach Spanien (Sevilla). wo sie zur Herstellnng eines Schmplitabaks, des spaniols, dienen. Der Cubatabali, in verschiedenen Gegenden der Insel gewachsen, ist dem Itavani ziemlich gleich, in der Qualität etwals geringer, or wird meist zu Ciganren verarbeitet. l)ie anm häuligsten rorkommenle Specialsorte ist Yara. 1) Jomingo, von der gleichnamigen Insel, Jortuga mul samine, 
mit grofsen, langen, gelben bis lichtbrammen Blättern; die diimnen werlen als Deckblatt, die dicken zu lianchtabak benutat. c) l'ortorico, nachst Varinas dex beste Rauchtabil, wird im Er\%engungslande riel auf Cigarren verarbeitet.

3. Nordamerikanische Tabake. a) Maryland, hat eine hellhrame bis blalsgelbe Farbe und einen angenehmen, siil'sen Geruch. Ohiotabak ist ron gleicher Qnalität. h) Virginia, lebhalt braun gefärbt, liefert fette, schwere Sortcn fiir feinen Schmupftabak und leichtere Blitter für mittleren Rauchtabak. c) K cntucky ist von sehr verschiedener lieschaffenheit und wird auch verschioden verwendet. Ihm reihen sich die 'J'abake aus 'Tennessee und Missouri an. Seedleaf, in Pennsylranien, Connecticut und Ohio aus Samen ron Cuba erzogen, dient zu Cigarren. Geschätzt ist der Floridatabali, da er ein gutes, schön geflecktes Deckblatt giebt.

4. Asiatischer 'Tabak ist von geringerer Bedeutung als der amerikanische. a) Manila, brennt sehr gut und besitzt einen milden, lieblichen Geruch und Geschmack, wird hauptsächlich zu Cigarren verarbeitet. b) Java, mit seinem gewürzhaften Geruch und Geschmack, liefert ein schönes Deckblatt. c) Sumatra liefert das dïnnste Deckblatt ron schöner, brauner Farbe und fast seidenartigem Aussehen. Die rorziiglichen Tabake Sumatras haben sich sogar den nordamerikanischen Markt erobert und machen denen der Insel Cuba Konkurrenz. d) Persien baut den Schiras und e) Syrien und Kleinasien den Latakia.

5. Afrikanischer Tabak. Der Tabak von Algier und Tunis ist geringwertig infolge des lufttrockenen Klimas; dagegen bringen verschicdene Landschaften Ostafrikas meist brauchbaren, einzelne sogar vorzïgliche Tabake hervor. In Deutsch-Ostafrika werden Anbauversuche im grofen muternommen.

6. Australischer Tabak. Der' in Kaiser-Wilhehmsland bei Stephansort ron der Neu-Guinea-Compagnie seit dem Jahre 1891 gebaute 'Tabak entspricht dem Sumatratabak.

7. Europïischer Tabak. a) Holländischer, beste Sorte "Amersfoorter." mit feinen, wohlriechenden Blïttern, die meist auf Schnupftabak verarbeitet werden, wiihrend die leichtesten davon als Cigarrendeckblïtter Verwendung finder. Der l'abak von Nijmegen, Nijkerk etc. ist wie auch der belgische von geringerer Qualitit. b) Ungarischer Tabak, aus Asien stammend, nïhert sich in den besten Sorten dem tiirkischen. Sein dïnnes, weiches, gclbes Blatt lat einen eigentiimlichen, durchdringenden Geruch und ist etwas erhitzend. Die besten Sorten sind der Debroer und der Debrecriner. c) 'Tiurkischer', bester' europäischer 'l'aluak, dessen vorzüglichste Sorten bis fast an die (Jualitit der Havanatabake heranreichen, mit zarten, handgrofsen, herzförmigen, bräiunlichen oder goldgelben liliittern. Die bosten Sorten sind die aus Macelonien: Druma, l'rarista, Inemirli, 
Yenidje, Sarishaban. Ginbeck etc.; sie sind in lange, diinne Fïden geschnitten, schïn golibraun, aromatisch, kräiftios, trocken und schmackhaft. Schwerer mol stärker sind die 'Tahake der asiatischen 'Tiirkei. 1) Von den deutschen Tabaken ist ler P'fälzer der wichtigste. Er wird im nördlichen Baden und in der Rheinpfalz gehant und hauntsiichlich als Cigarrentabak benutzt, der nicht nur an Bremer und llamburger Firmen alggegeben, sondern sogar nach Amerika exportiert wird. Der Altmärker und Uckermärker liefern geringere Sorten, die geringsten aber die in der Gegend ron Hanau, Wanfried. Eschwege, Nienburg, Göttingen und Nürnberg gebauten Tabake.

Die 'Tabakbliitter werden mitnnter untermischt und verfälscht mit den Bliittern rom Rhabarber, Runkelriiben, Grofsem Ampfer, Kohl, Kartoffel, Huflattich, Buche u. s. w. Kirschen-, Rosen- und Weichselkirschblätter sind im Gesetz rom 16. Tuli 1879, betreffend die Besteucrung des Tabaks, als erlaubte Zusïtze aufgezïlhlt. Orientalischer Tabak entlält mitunter hetäubende Stoffe, Opium oder Blätter ron Tollkirsche, Bilsenkraut und Stechapfel. Den Haranatabak rersetzt man zu seinem Vorteil (?) mit den aromatischen Blättern und Blüten ron Pipurin trincren. Am meisten wird der Schnupftabak mit fremden, schïdlichen Bestandteilen (Niefswurz, Vitriol, Alaun, Salmiak, Torf, Lohe, Sand u. a.) versehen. Damit er nicht schnell austrockne, packt man ihn in dünn geschlagenes Metall ein, welches Zinn sein soll, jedoch oft stark mit Blei versetzt ist, wodurch die fenchte Masse des Sclinupftabaks bleihaltig wird und sehr schädlich wirkt.

Angaben über Ernte, Handel und Verbrauch. Über die Tabaksgewinnung geben v. Scherzer und Bratassević') folgende Zahlen. Fs wurden im Durchschnitt der jüngst vergangenen Jahre gewonnen:

In den Vereinigten Staaten von Nordamerika $247636000 \mathrm{~kg}$ Tabak

.. Mexiko

.. Cuba .

.. Puertorico.

. Ilayti (San Domingo) .

" dem übrigen Westindien

. Centralamerika

., Colombia

.. Venczuela

.. Brasilien, Chile, Pern .

. Parragnaly mud Argentinien

, Jap:m

"Chima

Anf den Philippinen

In Britisch-Ostindien

\begin{tabular}{|c|c|}
\hline 7500000 & \\
\hline 10000000 & , \\
\hline 2500000 & \\
\hline 3500000 & . \\
\hline 33000 & י \\
\hline 500000 & .. \\
\hline 5500000 & .. \\
\hline 218000 & " \\
\hline 350000000 & .. \\
\hline 78000000 & \\
\hline 40800000 & .. \\
\hline 1000000 & \\
\hline () 861.000 & \\
\hline 700001000 & \\
\hline
\end{tabular}

1) Jer wirtechaftliche Verkehr der Gegenwart. 
In Niederländisch-Ostiudien (Sumatral, Java) 17000000 lig Tabak

. Persien

"der asiatischen 'lïrlei

2600000

Zusammen

14785000

Ferner in Europa:

In Österreich-U'ngarn

Im Deutschen Reiche (1896)

In Rufsland

.. der europ. Türkei, Thessalien, Bulgarien

.. Frankieich

. Griechenland

.. Italien

"den Niederlanden

. Rumänien

.. Serbien

. der Schweiz

¿ anderen Lïindern

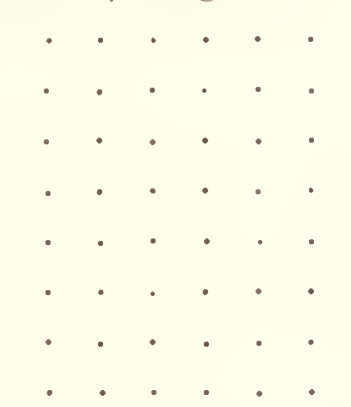

Zusammen $.5765: 56000 \mathrm{kgg}$ labliak

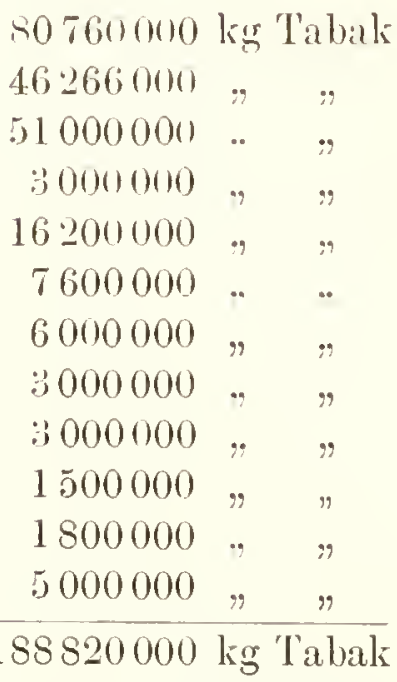

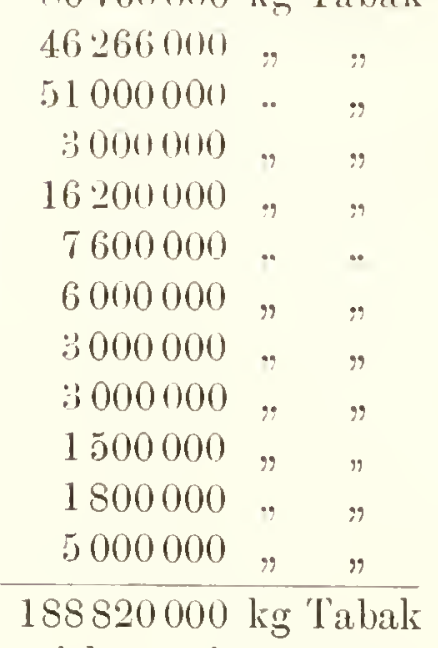

Die Tabakproduktion auf der Erde beläuft sich somit. olme Berechnung des eigenen Verbrauches in den meisten anlsereuropäischen Produktionsländern, auf ungefälı 765 Millionen Kilogramm.

Im Erntejahr 1896 waren in Preufsen 6595, in Deutschland 22096 Hektar mit Tabak bepflanzt; dieselben ergaben einen Ertrag von 12577 bez. 46266 Tonnen getrockneter Tabakblätter, und einen Ertrag ron 4732000 bez. 20717000 Mark. Obenan steht dabei Baden mit 8601 Hektar, dann folgen Bayern mit 3418, Brandenburg 2935. Elsafs-Lothringen 1802, Pommern 1575 Hektar.

Was den Verbrauch anlangt, so entfallen auf den Kopf der Bevölkerung:

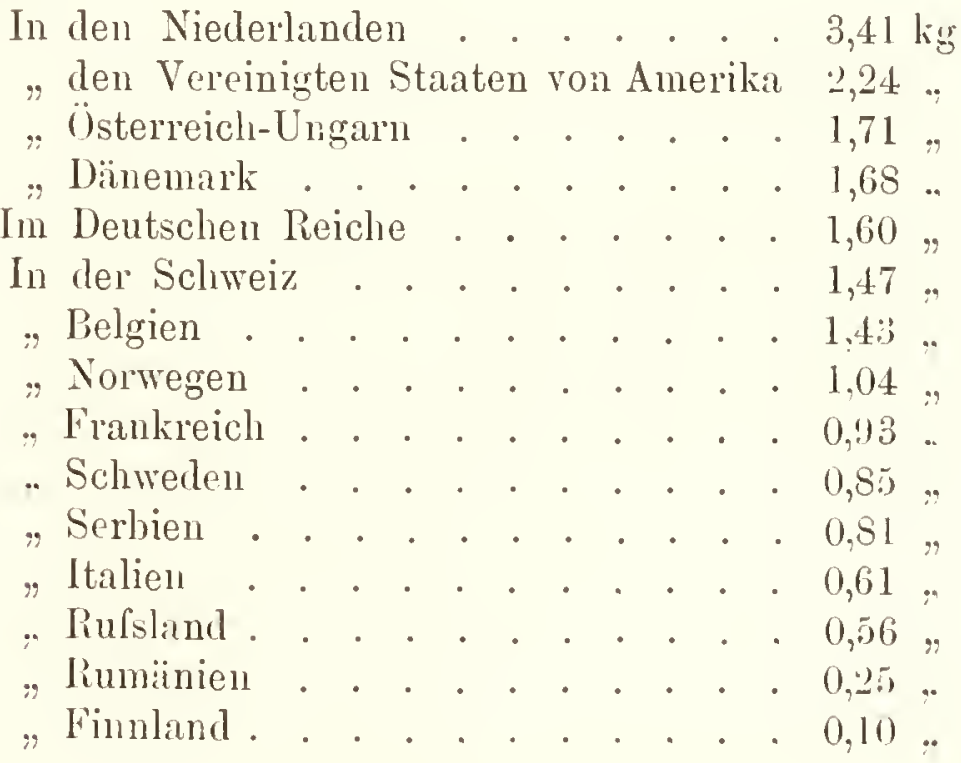


Ther Einfuhr und A usfuhr von Rohtabak und Tabakfabrikaten und ihre Werte bringt die oben genannte Quelle folgende Angaben:

I. Rohtabilk. E infuh $r^{\prime}$

Länder

Deutsches Rieich (1897)

Grolsbritannien und Irland (i)sterreich-Ungarn

Niederlande.

Frankireich

Italien

Belgien

Rufsland

Dïnemark .

Schweiz

Norwegen .

Schweden.

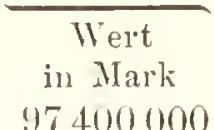

$\begin{array}{cc}\text { Nenge } & \text { Wert } \\ \text { in NI.Ctr. } & \text { in Nark } \\ 5599: 30 & 97400000\end{array}$

$3521: 4$

280984

226594

126218

82406

55488

34200

$3+000$

17236

$22 \$ 10$
50003028

2858.800

25544000

18127520

12986784

11680000

6936000

5800000

5200000

$2587+00$

2016000
$1: 38: 07$
A usfuhl

$\begin{array}{cc}\text { Menge } & \text { Wert } \\ \text { in M.-Ctr. } & \text { in Mark } \\ 7250 & 1300000\end{array}$

28.46

3756718

52.335

$366: 450$

55857

12104090

1742

90584

24112

$\because 0140000$

$69 !$

500110

1000

60000

Dem Werte nach nahmen unbearbeitete Tabakblätter in unserer Einfuhr im Jahre 1897 die siebente Stelle ein.

II. Tabakfabrikate.

\begin{tabular}{|c|c|c|c|c|}
\hline \multirow[b]{2}{*}{$\begin{array}{l}\text { Länder } \\
\text { di-Ungarn }\end{array}$} & \multicolumn{2}{|c|}{ Einfuhr } & \multicolumn{2}{|c|}{ A usfubr } \\
\hline & $\begin{array}{l}\text { Menge } \\
\text { in M.-Ctr. } \\
2-814\end{array}$ & $\begin{array}{c}\text { Wert } \\
\text { in Hark } \\
34000520\end{array}$ & $\begin{array}{c}\text { Nenge } \\
\text { in } . \mathrm{I} \text {.-Ctr. } \\
15549\end{array}$ & $\begin{array}{c}\text { Wert } \\
\text { in Mark } \\
8785185\end{array}$ \\
\hline & 17252 & 25636472 & 6117 & $: \because 976050$ \\
\hline Reich $(1897)$ & $52 \cdot 20$ & 10900000 & .51140 & 3500000 \\
\hline . . . . & 2400 & +608000 & $: 750$ & $\because 377.500$ \\
\hline . & 1548 & 2972160 & 1710 & 1084140 \\
\hline . & $1+79$ & 2 S:39680 & - & - \\
\hline . & $1: 300$ & $2+116000$ & 1750 & 1109500 \\
\hline . & 2100 & 424800 & 7410 & $259: 3500$ \\
\hline
\end{tabular}

An dem Werte dieser Ausfuhn beteiligten sich die Tabalk bauenden Länder fiir die Jahre $18 s 8$ und $18 s 9$ in folgendem Malso: Amerika im . ahre $18 s 8$ mit 107 Mill. Mark, in . Jahre 1s8! mit 94,9 Mill. Mark; lirasilien in Jahre $18 s 8$ mit 12,6 Mill. Mark, im Jahne 1s8!) nit 1.5, Mill. Mark; Mexiko in Juhre 1888 mit 4 Mill. Mark, im Jahre

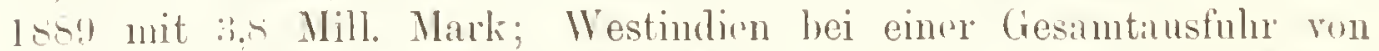
„2,1 Mill. Kílugramm und 99 Mill. Stiick Cigarren mit 3,1 Mill. Mark; I'aragnay (Ausfulur \& Mill. Kiloggramm) nit 2,; Mill. Mark; S:m Domingo (Menge 4,8 Mill. Kilogramm) mit :3,1 Mill. Mark; Ecuador mit 11.4 Mill. Mank; Ostindien bei einer Gesamtausfulur ron 24.2 Mill. 
Kilogranm mit 12,25 Mill. Mark; die Philippinen (Ansfuhr 4,:3 Mill. Kilogramm nul $9 ! 9,6$ Mill. Stiick Cigarren) mit 5,1 Mill. Mark; Persien (Ausfuln 2,6 Mill. Kilogramm) mit 1,1 Mill. Mark; China mit 4,1 Mill. Mark und Algrier mit 0.2 Millionen Mark. Vou den europäischen Lüindern steht wieder Österreich-Ungarn in erster Linie mit 16,6 Mill. Mark im Jahre 1SSs und 16.8 Mill. Mark im Jahre 1ss9 obenan.

Geschichte des Tabaks. Es scheint ziemlich fest zu stehen, dafs keine Tabakart nrspriinglich in Asien vorkommt; ungefiihr 40 Arten finden sich in Amerika, und zwar vorherrschend in den nicht tropischen, westlichen Teilen; ; Arten lionmen anl' den Sundainseln, 1 in Australien, einige auf den Inseln des Stillen Oceans vor. Zur Zeit der Entdeckung Amerikas war der Gebrauch des Rauchens, Schumpfens oder Kauens im gröfsten Teile des Erdtciles verbreitet. In Siidamerika rauchte man nicht, man hediente sich aber des Schnupf- und Kautabalis; nur in der La Plata-Region, in Urugnay und Paraguay wurde der Tabak in keinerlei Weise gebrancht. In Nordamerika war der Gebrauch des Rauchens ron der Landenge von Panama und den Intillen bis nach Kanada und Kalifornien cin allgemeiner, nnd er war mit Umständeu verkniipft, welche auf ein holes Alter hinweisen. So hat man Pfeifen in den Gräiber'n der Azteken Mexilios und in den Grabhiiigeln der Vereinigten Staaten gefunden. Dieselben sind sehr zahlreich und ron einer besonderen Arbeit; einige stellen Tiere dar', die Nordamerika fremd sind. Der virginische Tabak war die verbreitetste Irt und zuweilen die einzige, welche man in Südamerika und auf den Antillen gebrauchte. Der Bauerntabak (Nicotimu rustica) wurde bei den alten Vexikanern und den Eingeborenen im Norden Mexikos häutig angebaut. Er scheint in Mexiko, Texas oder Kalifornien seine Heimat zu habeu. Bis zum Jahre 160:3 kennt man in Asien keine Tabakpflanze und auclı den Gebrauch des Tabaks nicht. Nach der Türkei kam die PHanze im Anfange des 17. Jahrhunderts, später nach Persien. Durch die Portugiesen war die l'Hanze schon frïher nach Süd- und Ostasien gekommen. Sonit sind auch der Persische und der Chinesische Tabak amerikanischen Ursprungs. 1535 banten in Südamerika die Neger auf den Pflanzungen für ilure Herren und für sich T'abak. Bald kultivierten die Spanier auf Domingo, die Portngiesen in Brasilien und die Engländer in Virginien Tabak. Im Jahre 1559 erhicht der französische Gesandte in Lissahon, Jean Nicot, von einem Fremnde aus Amerika Tabaksamen, den er 1560 in scinem Garten pflanzte. Nach ilm that die I'flanze ron Linné ihren Gattungsnamen Virotimme erhalten, anch nannte man sie, da die Kinren bekannt geworden waren, Gesandtschaftskiaut. Nicot schickte nun 'T'abaksamen nebst Anweisung nach Frankreich zur Königin-Mntter, Kathlarina von Medicis, und zum

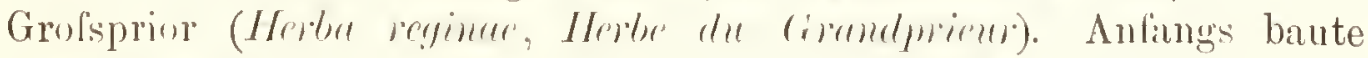
man den 'Tabak in Europa wegen sciner Heilkrïiftr an mul heilte mit einen durch Destillation aus den Bliittern sgewonnenen Silft ...alte, 
faulende, büsartige Geschwüre, den Brand, die Räude, Flechten, Krätze mul Nebel der Angen" (Clusius 1576). Das Rauchen verbreitete sich ron Spanien aus sehr schnell; nach I)entschland kan es im :30 jährigen hriegre durch fremde Truppen. Erst ranchten nur Matrosen und Schiffssoldaten, bald indes auch die höheren Stände. Unter Jakob I. ratuchte man in Theatern und Kirchen. Katharina ron Nledicis soll ihrem Sohne Karl IX. das Tabakschnupfen als IIeilmittel gegen Kiopfschmer\% geraten haben. Von Staat und linche wurde das Rauchen bestraft. In Rnfsland schnitt man unter Iwan den Rauchern die Nase ab, und der Sultan Amurath VI. liefs 1610 einen Tïrken in Konstantinopel mit turch die Nase gesteckter Pteife über die Strafsen peitschen. Papst Urban VIII. schleuderte gegen Raucher und Schnupfer den Bannstrahl - alles vergeblich. Endlich rauchten auch Fürsten (Tabakskollegium Friedrich Willelms I. vou Preulsen), und ein Papst (Benedikt XIII.) schnupfte. Ludwig XIV. verteilte goldene Tabatièren an answärtige Grofse als besondere Zeichen seiner Gnade. Als die Regenten einsahen, dafs sie den Gebrauch des Tabaks nicht unterdrücken konnten, legten sie sehr hohe Steuern auf das Kraut, oder monopolisierten den Handel damit (Portugal, Spanien, Frankreich und Österreich-Ungarn) und ötheten dadurch ihren Staatskassen hohe Einnahmequellen. Deutschland hatte in Eintejahr 189697 rom Tabak 63294700 Mark Einnalıme, das ist 1,19 Mark auf den Kopf der Perülkerung. - In Europa banten die Holländer zuerst 1615 Tabak, Sachsen 1631. 


\section{Tafel 3.}

\section{Kaffee b a um (Cotjea arabica L.).}

Der Káaffeebaum gehört zur Unterklasse der Verwachsenblätterig'en Dikotyledonen, zur Reihe der Krappblüigen, zur Familie der Krappgewächse (Rubiaceuc) und zur Unterfamilie der Kaffeegewäichse (Coffeoidcue).

Die Familie der Krapppflanzen (Tuldiucenc) umfafst Kräuter, Sträucher und Bänme mit rundem oder vierkantigem, mitunter knotig gegliedertem Stengel, mit kreuzgegenständigen, einfrachen, ganzrandigen Blättern und zwischen ihnen stehenden ganzen oder zerteilten Nebenblättern, die oft den eigentlichen Laubblättern sehr ähnlich sind, wodurch dann ein falscher Blattquirl gebildet wird. Die meist vollständigen und regelmälsigen Bliiten stehen in kreuzgegenstïndigen Rispen oder in Trugdolden, die nicht selten koptig zusammengezoren sind. Der Kelch ist meist offen und bildet um den oberen Rand des Fruchtknotens einen zwei- bis sechsspaltigen oder gez:ilnten oder abgestutzten, ganzen Silum, der dem Fruchtknoten angewachsen ist. Zuweilen sind ein oder mehrere Abschnitte blattartig vergrölsert. Die Blumenkrone ist oberständigr, einblätterig. nneist regelniilsig gespalten, glocken-, trichter-oder präsentiertellerförmig, selten kreuz- oder röhrenfürmig, sie hat eine klappige, dachiziegelige oder linksgedrehte Knospenlage. Keleh- und Blumenzipfel sind in der gleichen Zahl wie die Staubblïtter rorhanden. Die Staubblätter sind der Blumenkronröhre angewachsen, wechsehn mit den /ipfeln derselben al, und laben einwärts gewendete, zweifücherige, in längsspalten sich öfnende Staublueutel. Der unterstindige Fruchtknoten luat meist zwei Fächer nnd in jedem eine bis viele Samenanlagen; der Griffel ist ladenförmig mit kopfigem Ende oder zwei-bis viclästig. Die Frucht ist eine Steinfrucht, Beere, Kápsel oder eine Spaltfrucht. Lie Samen enthalten selır viel dichtes, lornartiges (Kalfeebohnen) oder lleischiges Eiweifs und einen geraden oder gekriimmten Keimling. 343 Gattungen mit etwa 4500 Nrten. 
Die Unterfamilie der Kaffeegewächse (Coffrovilcue) ist durch ihre einsamigen firuehtkmonfïicher sekennzeichnet.

bie Gattung Kaffeebaum (coffere I.) enthïlt immergrine, kleine Ibinme und Sträucher, deren Nehenblätter beiderseits einzeh stehen. Ihre Blumenkrone ist gedreht. Der Kinospenmund der Samen ist nuch unten gewendet, der Same selbst anfistrebend.

Yon etwa 25 Arten kommt der mrölsere Teil anf Afrika. Von den afrikanischen Arten sind die meisten an der Westkiiste, einige an der Ostkïste, im Inneren oder auf Mauritius einheimisch.

Der Echte Kaffeebaum (Colfor urubica L.) ist ron einem anmutigen Gesamtaussehen. Der schlanke Stamm entspringt einer grofsen, ribenförmigen Hauptwurzel, erreicht eine Höhe ron 5 bis if $\mathrm{m}$ und einen Durchmesser von $\mathrm{S}$ bis $1: 3 \mathrm{~cm}$. Seine grünlichgraue, nahezu glatte fiinde wird vertrocknet rissigr. Die ebenfalls schlanken Iste und Zweige wachsen wagrecht oder leicht abwärts geneigt, sind absatzweise knotig nnd einander in der Weise gegeniiberstehcul, dafs sich immer ein Paar mit dem folgenden kreuzt und die Krone des Baumes eine Pyramide lildet. Die immergrïnen Blätter sind diinn, lederartig, kreuzstiandig, kurz gestielt, länglich-eiförmig, zugespitzt glatt, oben saftig dunkelgriin, unten blal's, $3,5 \mathrm{~cm}$ breit, 8 bis $14 \mathrm{~cm}$ lang, geruchlos und von krautartigem Geschmack. Zwischen jedem Paar sitzen am Grunde auf den nackten Flächen der Zweige zwei kinze, spitze, am Grunde ein wenig miteinander verbundene Nebenblättchen.

Die Blüten sind fünfgliederig, weifs, knrz gestielt; sie verbliihen sehr schnell und stehen zu 4 his 16 in Biischehn in den Blattwinkehn. Der hinfïllige, auf dem Fruchtknoten sitzende Kelch ist schr klein, einblätterig, kronenartig - finfzïhnig.

Die einblätterigge Blumenkrone ist trichterförmig; ilıre Röhre cylindrisch, viel läng(' als der Kelch; die Niindung in fiint lanzettförmige, offene. : Die füinf Staubblätter ragen mit ihren linienförmigen Stauhbeuteln über die Krone heraus und wechseln mit deren Abschnitten ah. Der unterstindige Fruchtknoten hat einen einfachen Griffel mit zweispaltiger Narbe.

Die Frucht wird bald als zweisteinige Steinfrucht, hald als zweiliernige beere hoschrieben, ohne eigentlich einen dioser Namen zu verdienen; da sie in Ciröfse, linrm, Farbe und Bildung einigermal'sen einer Kirsche greicht, wird sie anch wohl haffeckirsche genannt. Sie ist anfïnglich grïn, dann gelb, rot, zuletzt dunkel purpurviolett refärbt, sciten ist sie woifs (Weilsfruchtige Abart, ralr. Inucrucupu); je nach der Sorte ist sie liugelig his oval, 1 his $2 \mathrm{~cm}$ lang und 5 his 10 nnm lreit. Sie laifst sich am beston einem Apfel rorgleichen. Wic licser zeigt sie auf ihrer spitze eine Bekrönung dureh den mudentlich sewordenen Kelch, anlserdem aber anch noch durch den 
selieihenförmigen, in der Nitte etwas vertieften Grund des Griftels. Wie jener besteht sie aus drei Schichten: anf eine diime, aher zienlich tiste sichale folgt ein saftiges Fruchtfleisch, auf dieses eine pergamentartige Schicht, welche die Fruchtfäicher umkleidet. Wilhrend aber der Apfel in der liegel fiinf Ficher lesitat, finden sich deren in der Katheekirsche nur zwei, mul jedes dieser Fäicher enthält nur einen, es vollstïndig ausfïllenden Samen. Iieim Trocknen bildet die Schale in Verein mit einem Teile des Fleisches, das dmukelrot und schleimig ist, widerlich süfs schmeckt und Mar'k genannt wird, eine Art Fruchthülle, die $\mathrm{Hülse,} \mathrm{in} \mathrm{welcher,} \mathrm{von} \mathrm{den} \mathrm{iibrigen} \mathrm{Fleiseh-}$ teilen ziemlich locker umgeben, zwei Steine oder Kerne liegen. Die Hülse zeigt oft beiderseits cine den Kanten der Steine entsprechende Lïngsfurche. Die Steine werden umkleidet von der imnersten, citronengelb gefirilsten Fruchtschicht, die ihrer Beschaffenheit nach das Pergament heifst, und um so meln dem in ihr liegenden samen anzugchören scheint, als sie :iufserlich dessen Gestalt nahe kommt. Der in der l'ergamentschicht liegende, dem Apfellierne entsprechende Same besitzt eine ganz dïnne, leicht ablösbare, grane, silberigglänzende Schale, die Silberhaut; den Kern bildet die Kaffeebohne. Die Bohne besteht zum allergrörsten Teil aus einem hornartigen, gelblich, braun, grïnlichgrau oder bläulichgrau gefürbten Nährgewobe (Sameneiweils), das an seinem Grunde einen ganzkleinen Keimling mit eifümigen Samenlappen umschliefst. Der Same ist mit seinen beiden Rüindern derart eingerollt, dafs der eine Rand (bei den Friichten eines aus Kamerun stammenden Zweiges war es bald der rechte, bald der linke) den anderen iiberdeckt. Von der dadurch entstchenden, die flache Innenseite der Bohne der Länge nach durchziehenden Furche geht ein gewundener Spalt, in den sich die Silberhaut lineinzieht, nach innen. Die bohnen sind $4,5 \mathrm{~mm}$ bis über $1 \mathrm{~cm}$ lang, 2,7 bis $8 \mathrm{~mm}$ breit und his $3,25 \mathrm{~mm}$ dick. Oft bildet sicl in der Frucht nur ein einziger Same aus; dieser ist dann auch auf der Innenseite rundlich, mithin walzenförmig. Solche Samen sind als Perlkaffee, Erbsen- oder Männliche Iohnen bekannt; sie werden mitunter gesucht, besitzen aber keinen besonderen Vorzug.

Infolge von Boden- und klimatischen Einfliissen liaben sich rom Echten Kaffeebaume Spielarten mit schwachen Unterscheidungsmerkmalen und wenig Beständigkeit abgezweigt.

Die Heimat des Echten Kaffeebumes ist im heifsen Afrika zu suchen. Wild wachsend wurde er in Mhessinien, im Sudan, an der Ḱiiste ron Mozambique, an den Ufern des Viktoria-Njanza und iı nehreren Gegenden im IIerzen $\Lambda$ frikas, an der Kïuste von Guinca und selbst in Angola gefunden.

Von den übrigren Arten der Gattung Kaffeebaum hat nur der Liberische Kaffeebaum (Coffece liberere llieronymus) fiir Anbauversuche Wert, da seine grolsen Bohnen durch feinen Ge- 
schmack ansgezeichnet siml. Er ist höher und hreitäistiger als der Echte Kaffechaum und rermag der Laubkrankheit infolge seines kräftigen Warhstums hesser z.n wilerstehen. F,r besityt viel grölsere Pliitter. sechs- his siebengliederige, grölsere Bliten und rotblaue, 2 bis $2 \frac{1}{2} \mathrm{~cm}$ lange becren. Er ist eine Tiellandspflanze, die in ihrer Ileimat nicht höh'r als $140 \mathrm{~m}$ ïher den Meeresspiegel steigt mul ein feuchtwarmes Kilima, sowie einen leichten, etwals samdigen Boden liebt. Der biam ist mit hestem Erfolge an dor ganzen Westliiste Afrikas und in den Kiistengegenden der Westindischen Inseln angepllanzt worden.

Das älteste Kulturland des Kaffechames ist das gliickliche Arabien, die Landschaft Jemen mit der Stadt Mocha oder Mokka. Mokka selbst bringt keinen Kaffee mehr hervor, aber wohl von hier aus hat die PHanze ihre Wanderung un die Erde angetreten.

Verbreitungsgebiet. Aufser in den bezeichneten Ländern wird der Echte Kaffeebalum gegenwärtig angebaut: in der Levante, auf Ceylon und weiten Lïndereien in Britisch-Indien, auf der Halhinsel Malakka. aul Sumatra, Java, Celebes und den L'hilippinen; in Florida, 'Texas, Kalifornien, Nexiko, ganz Centralamerika, auf den Antillen, im tropischen Siidamerika, in Ecuador, Peru, Bolivia, Paraguay und ganz besonder's stark in Brasilien (rom Amazonenstrom südwärts lis zur Provinz Sao Paolo und ron der Küuste bis zur Westgrenze der Republik); in Afrika aulser in den genannten Heimatlindern anf Madagaskar, Bourbon und Mauritius; in Australien auf den Salomo-, Fidschi-. Samoa- und Sandwichinseln; selbst in Europa hat man den Kaffeebaum anzubauen rersucht, freilich ohne Erfolg.

Der Kaffeebaum ist eine ganz ausgesprochene Bergptianze, der die schwïlen Ebenen der Tropen nicht zusagen. Er gedeiht am besten in Klimaten mit einer mittleren Wiirme ron $19^{\circ} \mathrm{C}$, deren Temperatur zwischen 15 his 25" C. schwankt. Ausuahmen von kurzer Dauer, selbst ein weiteres Zuriickgehen um etwa $5^{\circ}$ sind nicht seh:̈idlich. Kialte, zu grolse Hitze und Trockenheit sagen ilhm nicht zur; Regen (220 bis $330 \mathrm{ccm}$ im Jahre), die Ilauptblïtezeit ausrenommen, oder kiinstliche Bewïsserung ist notwendig. Unter den Tropen kommen die Ianpternten ummittelbar nach den Schluls der liegenzeit \%ur lieife. Sind die Nichlerschlïge zu spärlich, so fallen viele Firuchte vor der Ruife al), und die Ernte wird cine leichte. Kaffee kann nur dal mit Xntmon erzengt werden, wo die Eruten in engbegrenzten Zeitabschnitten reifon. Ilic besten Ergehnisse werlen in einem Boden er\%irlt, der einen starken, ron Wäildern herrihrenden IIumsrelaalt besitst. Auch griindlich verwitterte hava, rermischt mit Waldhumms, wird als Dusterbodeu bezeichnet. Bramer Schwemmboden und studiger Lehm eignen sich, wenn sic mit IInmus rermischt sind, ebenfills zum Auban des Katfechanmes. Wie Fmolutharkeit des Bodens ist durch stickstoffeiche Dünuemittel zu nnterstiitzen. Heftiger, znminl trocken'. Wind ist den Pflanzungen verderblich, daher sind 
sie an besten auf sanlt genrigten Haingen anzulegen, die entwerler durch rie Bodenform oder dureh Waldstroifen geschiityt sind. liei licurteilung dor geeigneten Höho der Kulturieldre sind liegenfall, Winine, liegohnifsigkeit der Winde, Futfernung vom Meere u. s. wolıl zu beriicksichtigen.

l) Kaffeebäume werden vielfach aus Wildlingen, besser aber aus Samen gezogen. Spaiter werden dic jungen Bäumchen in die Pflanzungen, Kaffeegärten, Kaffeeplantagen in schumgeraden lieihen ill Alstänlen von ctwa $3 \mathrm{~m}$ eingesetyt. Je weiter die Abstände sind, desto krifitiger entwickeln sich die Pllanzen. nud desto seltener und schwächcr tritt die Ialubkrankleit (siche unten "Schïllinge"6) auf. Wïhrend man in hohen, kïllen Tagen die Kaffeebäumelıen das volle Sonnenlieht genielsen lälst, giebt man ihnen auf wïnmeren Gelïinlen einen heilsanen Schutz. durch selattenspendende Bïıme, die man beim Ausroden des Waldes stehen läist. Legt man die PHanzung auf baumlosen Häingen an, so ptlanzt man gleielnzeitig mit den Kaffeebäumen Bananen an, weil diese schnell wachsen, Nutzen bringen und ohne Kosten vermehrt werden können. Der Kaffeegarten muls stets von Unkl'ant rein gehalten werden. Wïhrend man in Arabien den Biomen ihren natiurlichen IVuchs lälst und nur die unteren /weige abschneidet, hiilt man sie in den meisten ïbrigen Kulturlinderu, auf $11 /$, bis $2 \mathrm{~m}$, unter der Schere, wodurch sie nach unten buschiger werden, mehr Friehte geben und sich loicht und billig abernten lassen. In Tenczuela trägt 1 Hektå Iand ungefäh 2560 Bånme. Damit Licht und Luft ungehindert bis zum Stamme rordringen können, werden den $̈$ isten, auf eine Eutfer'nung von etwa $15 \mathrm{~cm}$ rom Stamme an, alle Zweige und dem Stamme selbst die ïberfliissigen Schöl'slinge genommen. Eine weitere Lichtung wird in der Weise durchgefiihrt, dafs nan aus den Zweigen abweehselnd je cinen der parigen Seitenzweige ausbricht. Nach der Ernte werlen die abgeernteten /weige entfornt, dimit sich die jungen \%weige, die künftigen Fruchtträger, kriftig entwickeln können. Die Ptlanzen beginnen etwa im dritten Jahre zu tragen und erreichen zwischen dem fünften und siebenten Jahre ihre Vollkraft, doch werden die Friichte mit \%nnelimendem Alter des Stranches immer vor\%iiglicher. Iäinger als 20 Jalnc bleibt cin Baum selten fruchtbar.

Die Kaffeebïmme blühen fast acht Monate lang, da sich an den neu wachsenden /weigen auch immer neue Bliten entwickeln. Xach den ersten Rugenschanern erscheinen die lihitenknospen in lorun kloner, dunkelgriner spitzen. Je grölser sie werden, desto lichter wird ilue Farhe, allmililich werden sie strohgell, unl schlicfilich nalıe\%u weil's. Einige Schaner noch, und der Kafleegarten liegt in unbeschreihlich schönen liitenschmuck la. Die späiter noch folgenden zwei oder drei Nachblüten stehen der ersten Bhiite an Wichtigkeit Mach. Schon nalu zwei 'lagen werden die bliiten brann und vorwelken. So unerwïnscht 
der Regen wiihrend der Bhiitezeit ist, so notwendig ist er nuch derselben, um dis Ansetzen der jungen Früchte unterstiitzen zu helfen. Blüte- und Erntezeit sind in den verschiedenen Erzeugungslïndern je nach deren Lage verschieden. So liegen beispielsweise die Erntezeit'n ron Costarica und Guatemala drei Monate auseinander. In siebenten Nonate pHegt die Fruchtreife einzutreten. Kaum eine andere Pflanzungr grleicht an Schönheit der cines iippigen Kafficeberges, wo aus dunklem Laube Millionen ron dunkelroten Kirschen hervorlugen. Nan erntet die Früchte, wenn sie purpurbis schwarzot werden. Die Araber lassen sie "todreif" werden und schiittehn dann die riolett gefürbten Friichte auf untergebreitete Matten ab. Da die Frïchte nicht gleichzeitig reifen, finden meist drei Ernten statt, ron denen die zweite die wichtigste ist. Der Ertrag ist ein sehr ungleicher; während man in Arabien von jedem Bitume etwa $3 \mathrm{~kg}$, von hoeh gewachsenen, gut gedüngten sogar das Doppelte erntet, in Frasilien und Cuba 2 bis $21 / 2 \mathrm{~kg}$ erhält, tragen die Pflanzungen in Java nur 1,2 his $1 / 4 \mathrm{~kg}$ ein.

Von allen Schädlingen des Kaffeebaumes hat der die Laubkrankheit herrorrufende Blattpilz, Hemileiu eustutrix lierk., seit scinem massenhaften Auftreten auf Ceylon, vom Jahre 1869 an, ungeheure Verheerungen angerichtet. Der Pilz ruft das Absterben der Bliitter hervor. Er zeigt sich auf deren Unterseite in orangeroten Flecken, welche Myceliumfäden und davon sich abschnürende, blalsorangefurbige Sporen enthaiten. Der Schaden, den der Pilz auf Ceylın allein bis zum Jahre 1880 dem Kaffeebau gebracht hat, wird auf 15 Mill. Pfund Sterling geschätzt.

Die Gewinnung der Samen, der Kaffeebohnen, aus den Früchten erfordert sorgfältige Arbeit. Nur da, wo es an Arbeitskräften mangelt, den Kaffee mit Aufmerksamkeit zu behandelı, und in kleineren Pflanzungen wird dic ganze Frucht getrocknet, anfbewahrt und später gestampft. Diesen liaffee nennt man in Venezucha Parapara. Sonst wendet man zwei verschicdene Verfahren an, die Handelsware zu hereiten. Bei dem alten, trockenen Verfahren werden die Frïchte drei bis vier 'Tagre in der Sonne getrocknet, bis die "Hiilsen", das ist die Oberhaut, und das Mark, ferner das Persament und die Scidenhaut bröckelig werden. Darauf befreit man die Samen auf Walzmïhlen (Huller) und durch Schwingen von ihren Hlüllen. Nath dem nassen Verfalluen (westindische P'riparation) werden die Samen in nassen /hustande enthïlst, d. h. mittels einel

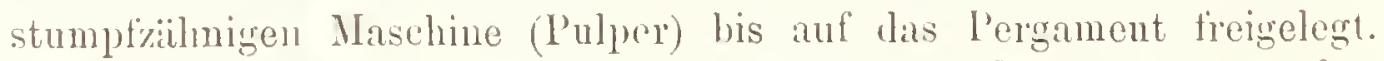
1)arauf wird dieser Pergamentkaffee einer Gïrung muterworfon. gotrocknet und mittels eines liollerganges und eines Voutilitors rom P'ergument und dureh den Polierapparat von der Seilenhaut befreit.

Jie Bohnen werden, geröstet, gemahlen, mit kochentem llasser iibergossen, zn einen allgemein bekannten Getränk bereitet. Ge- 
röstet müissen sie werden, um dio Bohnen leicht zermahllan zu machen und aromatisches, flüchtiges Ölı), Kaffeol, das ein selu starkes liaffeearoma besityt mul von dem der Wohlgeschmack des liaflees abhängt, zu entwickeln. Dieses :itherische (j) betrïgt höchstens 2 l'roz. dros Gewichtes der IBohnen; die Unterschiede in der Quantitït desselben bedingen die Verschiedenheit der Surten. 1 Pfund dieses Öles wïrle etwas iber 1000 Mark wert sein. Tor dem Rösten soll man die bolnen auslosen und etwa 10 bis 12 Minuten lang abspiilen, weil sie teils bei ihrer Gewimung, teils beim Transport stark mit fremrartigen Stoffen rerumeinigt werden, und weil man sich dadurch anch iiberzengen kinn, ol sie gefürbt willen. Das hüsten geschieht am besten über schwachem Fener in verschlossenen Gefiifsen. Man benutze dazu Apparate, bei denen sich eine IIohlkugel oder ein Hohlcylinder aus Drahtgeflecht oder siebartig gelochtem Blech in einer Blechkapsel dreht, um eine möglichst gुleichmälsige Übertragung der Wämme zu ermöglichen. In einem derartigen, für den Grofsbetrieh eingerichteten Apparate grebrannter Kaftee heifst im Haudel Dampfkaffee. Es wird als wesentlich bezeichnet, die sich zuerst entwickelnden Dämpfe entweichen zu lassen. Un die V'erflüchtignug des aromatischen Öles zu verhindern, empfiehlt Liebig, dem Kaffee während des Brennens einige Stiicke Zucker zuzusetzen, welcher ron der Hitze schmilzt und die Bohnen mit einer dïnnen Zuckerhiille überzieht. Es ist ratsam, kleinere Quantitäten und lieber recht oft zu rösten, da frisch gebramnter Kaffee das beste Getränk liefert und aulserdem das fette Öl in zu lange aufbewahrten gerösteten Bohnen leicht ranzig wird. Man muls das Rösten beendigen, wenn die Bohne plötzlich aufschwillt, kastanienbraun wird und zu glänzen beginnt. Der Inhalt der' Trommel mufs damn durch dïmnes Ausschütten auf eine kalte Platte rasch abgekühlt werden. Beim Rösten steigt del Gewichtsrerlust der Bohmen auf 15 bis 30 Proc., der Umfang derselben auf 30 bis 50 Proz. Schwärzliche Bohnen geben dem Kíftee einen verbrannten, trockenen Geschmack. Mokkakaffee soll am besten auf 14 his 15 Proz. Gewichtsverlust, rötlichgelb geröstet werden, Bourbon auf 16 his 18 Proz., hellbronze, Martinique auf 20 Proz., kastinienbraun. Brame Farbe riihrt von dem grebranuten Zucker her.

Ein wichtiger Bestandteil des Kaffees ist das Kaffeïn. Es ist je nach der Güte der Sorte von 1/2 bis 1 l'roz. darin enthalten, wird auch in 'lhee (Theïn), Naté, Guarana, Kíakao u. s. w. gefinden und zeichnet sich durch einen grol'sen Gehalt an Stichstoft aus. Ihm ist jedenfalls ein gutes Teil der Wirkung des Kaffees und der grenannten

1) Dieses flüchtige Öl ist nicht mit dem fetten öl (Fett) der Kalteebolnen zu verwechseln, welches in weit grölserer Menge darin enthalten ist und dem Kaffee, wenn es ranzig geworden ist, einen widerlichen Gerach und Geschmack verleiht. 
(ienufsmittel zuzuschueihen. Kleine Mengen, 0,2 bis 0,5 a, strigern die geistige und die Muskelthätigkeit. den Blutdruck mud die Ilarnalsondel'ung; etwils grölsele Jengen crregen besonders die Phantasic; noch stïrkere er\%engen Ciedąnkenverwirrmug, Olrensausen, I'ulsieręu der schliife, Reklemmmng, aussetzenden Puls und nachfolgende gedriickte Gemiitsstimmum mo Geistesabspanmng. Kaffë̈nsalze werden gegen Nerreuleiden, Kopfschmerz u. s. w. ingewendet.

Die in den Bohnen enthaltene Gerbsäure (3 bis 5 P'roz.) gieht dem Getränk cinen bitteren, etwas zusammenziehenden Geschmark mol bewirkt eine schwer verdanliche Verbindung desselben mit der dem Kaffee zugesetzten Milch oder Sahne. Schwachen Magen ist daher der Groul's schwarzen Kaffees vorteilhafter.

Üher die verschiedenen Bestandteile der rohen Kaffeebohnen und deren annïhernde Menge giebt uns cine Analyse ron A. Payen Autschlufs:

\section{Prozent}

IVasser

Eiweilsstofle 10 bis $1: 9,1$

Kíffeïn .

Kaffeegerbsaures Kaffeinkali . . . . 3.5 bis 5.11

Fett.

11) bis 13,0

'Traubenzucker, Dextrin, organische Sïnren

(Citronensämre) .

15,5

Itherisches Öl, aromatische Stoffe.

Holzfaser (Zellgewebe) . . . . . . . . . 34,0

Mineralstotie. . . . . . . . . . . . 6.697

Eine andere, mehr summarische Analyse, zngleich fiir geristeten Kaffee, lantet:

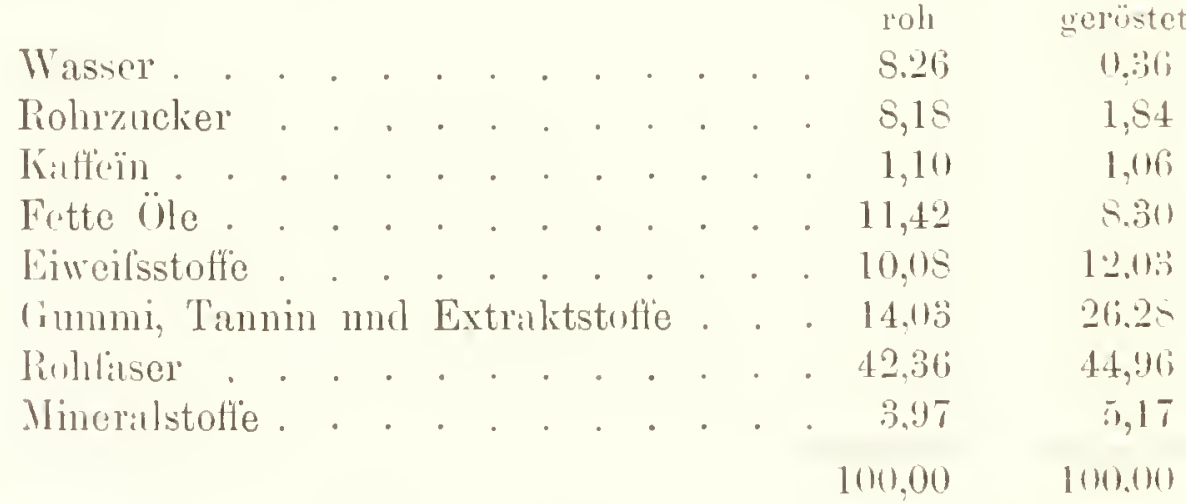

Iliernach sind die Verïnderungen zu ersehrn, die der Kattee heim liiisten enloidet; genaner erforscht sind lieselben indes noch nicht. Ins Kalfein hleiht zwal mverändert, verllichtigt sich indes zmm 'Teil, aher noben nenen brenzlichen Stoflen entsteht besonders das hereits elvialunte líllicol.

Vic gebrannte Bohne ist aufserordentlich empliudlich tiir 
alles sie Beriihrende und nimmt \%. Li. leicht den Geschmack des Ilolzes an, womit man den liaffee mmriilnt. Sie wirl am besten in metallenen oder gläscrnen Gefilsen anhewalnt. Dis Wasser, das man zur Bereitung des Getränkes rorwendet, kamu selı viel da\%n boitraron, den Kiflee einen stärkren Geschmack zu geben; hesonders wenn es recht wenig erdige Stolfe, dagegon Alkalien, wio Sitrium oder Kali, entläilt, wird es die Restandteile des Kraflees leiehter lösen mud vollkommener in sich aufnelmen. Deshalh sind Badeorte mit ihrem mineralisclen Wasser wegen ihres ror"ügliehen liaftees beriihnt. Dassellue lïst sich erreiehen, wemn man dem Getriinke ror dem Aufgiefsen etwas Selterswasser oder Sodipulver (kolilensaures Natron) zusetzt. Beim Kochen verliert der Kaftee den grösten Teil seines Aromas, weshalb nur der Antigufs ron ganz kvehendem Tasser zur Bereitung des Getrinkes zu verwenden und dasselbe lieils vorzusetzen ist. Jede Verdunstung ist zu vermeiden.

Die Morgenländer bringen das I'ulver jedesmal friseh gerösteten Laffees in kleine Tassen, giefsen siedendes Wasser darauf und geniefsen das Getränk olme Nileh und Zucker. Die Araber rösten die fleisehigen Hülsen oder das getroeknete Mark der Friehte, übergiefsen es mit kochendem Masser und trinken den Aufurn's unter dem Namen Sakka-oder Sultanskaffee. Die ärmeren Volksklassen in Orient bereiten aus den Schalen der Bolmen ein leichtes, helles Getriinli rom Geschmaek des Kaffees. den Kisr (Kishr). Wie aber der Kíffee in Heimatlande des Kaffeebaumes genossen wird, dariber wird im :Glolus" n. a. folgendes berielitet: "Alle diese Stämme, welehe das Heimatland des Kaffeehammes bewohnen, sind in hohem Grade anf den Gemuls seiner Frueht erpieht und betrachten sie als ein ganz unentbehrlielres Nahrungsmittel, aher sie bereiten weder Kaffee in unserer Weise durch einen Aufguls von koehendem Wasser aut die gebrannten Pohnen, noeh stellen sie in der arabischen Weise aus dem getroekneten Fruehttleisch den theeartigen Kisr dar. Ihre Bereitungsart ist vielmehr folgende: In einem 'Topfe wird zunächst. Sesamöl oder liutter bis zum Sivden erlitat; jede Familie hat dizu einen eigenen Topf, den man ausseliliefslich \%u diesem \%weeke verwendet, damit ja nichts ron dem köstlielıen Aroma verloren gehe. In das kochende Fett wirtt man die Kafleekirsehen. die man zuror zerbissen hat, damit es hesser eindringen kann; dann setzt man einen genan schliefsenden beekel anf" und lälist lie Kirschen eine Keitlang schmoren. Mittlerweile haben die Gäste Platz genommen, ihre spärliche liekleidumg als schmalen ling um die Lenden grewichelt, und der Inhalt des 'Topfes wirl in eine Ilolyschiissel gegossen und rirknliert. Jeder Anwesende nimmt cinen Iäffel roll des parfïmierten (j) und grielst ihn sioln in die rechte Iland; mit der linken beginnt er damn zunächst seine Olnen mud soine Nisc einznsalben, dann reibt er den Rest aul" seinen Kïrper ein, und einer lillt den and"ren die Stellen zu reiben, die er nicht sollust rreichen hann. 
Mittlerweile ist die Schïssel wieder zu der Frau zurïckgelangt. welche das Kohlenfoner mit einem l'almblatt nuterhalten lat; sie übergiefst nun die geschmorten hirschen mit frischer, geschmolzener Batter und mit Bienenhonig, oder noch licher mit dem Safte des Zuckerrohres, und $n n n$ ist das Gericht fertig. Jeder Gast fiilt sich die rechte Hand, die al. 'Tasse dienen mufs, mit diesem Leckerbissen, mit der linken holt 'r aus einer anderen Schiissel den gekochten Mais, der die gewöhnliche Nahrung liklet, und tunkt das Fett damit aus. Um diese Leckerei gielot der Somali alles andere hin; auch die frauen sind sehr hegierig darauf, doch kommt meist wenig genug davon an sie."

Dis Malaien ant Sumatra micl Java genielsen schon seit langer \%cit einen Aufgůs von Kaffeeblättern. Obgleich der Gehalt der gerösteten Blätter dem der bohnen ähnlich ist, schmeckt doch ein Aufgufs der ersteren. als wäre er aus einem Gemisch ron Thee- und Tabaksblättern bereitet. Die Araber bereiten ans dem Fruchtfleische, gleich wie aus Weintrauben, ein geistiges Getränk, das die anregenden Eigenschaften des Kaffees zu hesitzen scheint.

Kaffec liat nach dem Genuls eine mehr anregende als aufregende Wirkung und ist schnell hiilfreich gegen die Folgen grolser Ermattung und des Opiumgenusses, der Einatmung ron Kiohlendämpten, sowie der narkotischen Betäubung durch 'Tabak u. s. w. Kiaffee setzt die Zahl der Atemziige herab, beschleunigt aber den Pulsschlag, weshalb er, abends genossen, bei vielen Personen Schlaflosigkeit erzeugt; er vermindert die ITautthätigkeit und crhöht dic Körperwärme, vermehrt den Bhutdruck und erregt die Schleimhänte. Smith gicht an, dafs durch Einnahme ron Kaffee und Thee cine Vermehrung der ansgreatmetcn Kohlensïure eintritt. Dor Kaffee eignet sich für Schwache und Arme hesser als 'Thee. Auch zum Frühstuick ist er mehr zu empfehlen, da daun die Ilaut thätig und der IIerzschlag schwach ist. Trinkt man nach dem Mittag haffee, so sei es unmittelbar nach dem Mahle. Die Gesantstinmmung des Menschen wird durch den Kaffee eine andere, man fühlt sich wohl und aufgeheitert. Der Kaffec bewirkt, dafs wir unangenchme Zustïnde weniger bemerken oder uns darïber hinwegsetzen und dafs wir hefïhigter werden, Schwierigkeiten zu iiberwinden; er wird somit für den dem Wohlleben ergehenen zum Mittel, die Arbeit seiner Verdammgsorgane nach reichlich genossener. oft schwer verdaulicher Nahrung weniger fühlbar zu machen nud die Langeweile zu vertreilen, für den Gelehrten, ihn bei anhaltenden Studien wach und frisch zu erhalten, für den Arbeiter, die Mïhen des Tages mit leichterem Simn zu crtragen. „Der Kaffee", sagt Moleschott, .. wirkt anf dis Denkvermögen anregend, jeloch nicht, ohne \%ngleich Aer Tinbildungskraft eine viel grösere Lebhartigkeit zn erteilen. Ws entsteht ein Drang zam Schaffen, rin 'Treiben der Gedanken und Vor-

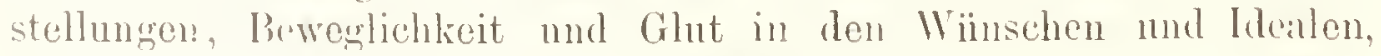
welchr mehr der Gestaltung durchdachter Iteen, als der ruhigen 
Prïfung neu entstandener Gedanken giinstig sind.:" Delisle schildert in seinem Lohgesang anf den Kaffec die Wirkung dieses Getrïnkes mit folgenden Versen:

\begin{abstract}
"Der Sim belebt sieh und geordnet kommen
Mir die Gedanken, Wogen gleich gellossen:

Sie, die so dürr, so hohl, so traurig waren,

Sie läclıcln mun und prangen recieh gekleidet."
\end{abstract}

Der beriilme italienische Arzt und l'rofessor Mantegazza sagt über die Wirknug des Kaffees: "Wenn man ein Cüsar oder Galilei oder Machiarell ist, kann man Gallien erobern, die Jupitertrahanten entdecken, ein "Buclı rom Fürsten" schreiben, ohne aulser dem imner gliihenden Vulkan des eigenen Geistes noch eines andern Feuers zu bediirfen; aber die Nasse der mittelmärsigen Geister bedarf der Anspornung und ler Stiitzen, bedarf eines Funkens, der das Eis der Trägheit bricht, und einer Spannfeder, die die Schaffenslust immer aufrecht erhïlt. Ein einsamer Hirt, dessen ganze geistige 'Thätigkeit sich zwischen der Weide und dem Schafstall ahspielt und der nicht aufgeweckter zu sein braucht als ein Kettenhund, kann von Brot und Milch leben; ebenso wie ein Gelehrter, dessen ganze geistige Anstrengung sich aufs Lesen und auf die Thätigkeit des Gedächtnisses beschränkt, sehr wolıl sich rühmen kann, weder der duftenden abessinischen Bohne noch des aromatischen Blattes aus dem fernen China zu bedürfen. Aber für den, der weder Genie, noch Hirt, noch Archivar ist. also für die meisten Menschen, sind die kaffeeartigen Getränke eine wertvolle Quelle moralischer Genüsse.“ Jean Paul sagt: „Der Kiaffee macht feurige Araber, der 'Thee ceremonielle Chinesen." "Durch den Genuls des Kaffees wird man befähigt, die gröfsten körperlichen Strapazen cine Zeitlang zu ertragen. Der deutsche Soldat erhält während der Märsche bedeutendere Kiaffeerationen. Als kaltes Getränk ist dünner Kaffee bei Feldarbeiten sehr angenehn. Anch hat der Genuls des Kíffees das Laster der Trunkenheit geschwächt. „Der Kaffee“, sagt Mantegazza, "wird schlecht ertragen auf hohen Bergen, in trockenen und windigen Klimaten, in Gegenden nit sogenannter feiner oder anregender Luft, aber der Kaffee ist ein sehr zuträgliches Getränk in warmen und fenchten Kilimaten, in miasmatischen Gegenden, in sogenannter dicker oder rerweichlichender Luft. Nervöse, nervenkranke, an Krämpfen leidende, reizlare, hysterische Personen sollten so wenig Kaffee wie möglich trinken oder sich des Kaffeegennsses aranz entschlagen; fottleibige, kraftlose, lymphatische Personen dagegen können oft ungestraft oder mit Vorteil viol kaffee trinken." „Nicht $z u$ viel immerhin! Line Tasse Kaffee täglich ist sehr zuträglich, zwei Tassen des Tages können zuträiglich sein. drei Tassen Liaflee tïglich sind eine Erlassungssinde; dariiber linaus beginnt die liegion der Todsiinden." Es ist völlig erwiesen, dals das Kaffë̈n in seinen Wirkungen auf den Organismus gefïlndich werden kann, wenn durch iiber- 
mïlsigen (iennlis von suh starkem Kaffee zuviel davon in das lint antgrnonmon wird. Bei nervösen Damen zeigrt sich dic schädliche Wirkung meistenteils in dem Iuftreten jenes quälcnden, halbscitigen Lopfschmerzes, den man Migräine nonnt. Dieses Leiden, wolches rienlich weit verhreitet ist, ist sehr oft aul übcrtrichenen liaffecgenuls zurickzufiihren. I bei Iäunern, zumal solchen von sitzcnder LebensWeise, crregt starker liaffee nicht sclten die Herzthätigkcit in so hohem Grade, dal's der davon Belallene vor lioüngstigung das Fenster öffnen und seine Beschaiftignng unterbrechen muls. Dafs dadurch nach und nach ernstere Ühelstinde hervorgerulen werden müssen, liegt anf der Hand, wird aber gewöhnlich nicht beriicksichtigt. Ganz besonders nachteilig wirkt Ühermafs im Kaffecgenufs in Verbindung mit starken liauchen, zumal im jüngeren Lehensilter. In newerer '/eit fülnte Dr. Guimarấs, ein Arzt in Rio de Janeiro, wissenschaftliche Versuche über die Wirkungen des Kaffees auf den tierischen Orumismus aus. Durch dicse Versuche wurde festgestellt, dal's der Kaffce hei Fleischnalrung die Verdaunng fördert, abcr bei einer Yahrung durch Mehl und Fett einen geringercn Verbrauch bewirkt. In liezug auf den Stoffwechscl ist liaffee ein Leiz-, aber kein Nahrungsmittel. Als Arzneimittel wendet man Kaffee geren Erbreclien, akuten Darmkatarrh, Kindercholera und bei Vergiftung durch narkotische Stofic (Bilsenkraut, Schierling, Opium u.s.w.) an. Oppler glaubte vor einigen Jahren die wichtige Entdeckung gemacht zu haben, dils dem grerösteten Kaffee, dank seinem Gelalt an Kaffeïn, Gerbsïure und aromatisch hrenzlichen Substanzen, sowie seiner Fïhigkeit, Wasser einzusaugen, eine sehr bedentende antiseptische Krraft imewohne. Doch ist dies sehr wenig wahrscheinlich. Derselbe erprobte anch die Figenschaften des Kaffees in der Wundbehandlung. Die iilocraschend schnelle Heilung bermhte indes in molmeren (allen?) Fällen nur dilrunf, dal's das Kiffeepulver cinerseits den Zutritt ron Fäulnisel'ogern zur Wunde allielt, und anderorseits mit den aus lctyterer alggesonderten Fliissigkciten einen festen Schorf bildete, welcher den Andrang äufserer Schïllichkeiten (Staub und Bakterion) vorhinderte. Auch in der 'Tierheilkunde hit das neuc Verfalron bei frischen Verletzungen, bei Druckschïilen, sowie sie in das Stadium der Geschwirhildung eingetreten wallen, und namentlich boi der Mauke sich anscheinend bewiihnt. - Alt ist die licobaclitung, dals enuc im Nunde rerkleinerte Kaffeebolnne sehr schnell iiblen Gernch ans ilenselben aufluebt, orler vichmeln ausgezeichnet verelcckt, woraus sich wohl zum 'l'oil crklärt, dals im Mürser feinzer'-

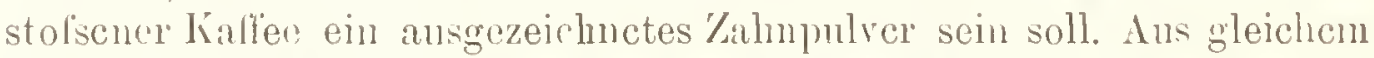
Grume gilt auch wohl sebrannter mol gemahlener Kitloe als cin knäftigre Stoff, mu tierische und pflanzliche Ausdiunstungen \%n \%'rstören und unschïllich zu machen. Jisschn̈inke nohmen \%. li. infolge

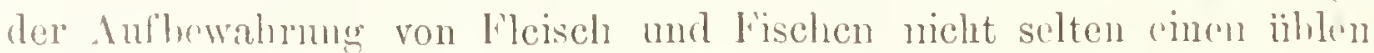
Grourh an. Dargegen soll es kein hesseres Mittel als gemahlencu liatiec 
geben. Wenn man Wildbret nut gemalilenem liaflee hestrent, soll os sich mehrere 'lagre frisch erhalten. Man will andlich heobachtet haben, dafs Cholerabicillen und illuliche Senchenkeinn in liafteeanligul's ihre Vermeluung einstellen.

In manchen Gegenden mïstet man mit Kaffeesatz ( ${ }_{3}$ liaffeesatz, $2 / 3$ lileie) die Gïnse und Kapannen nud will daduch ein sehr wohlschmeckendes Fleisch erziclen; anch diingt man lopfpflanzon damit. Er dient ferner zum Abfegen hram gestrichener Fulshöden. Anch stellt man dilans durch Auskochen mit Solalösung und Znsatz von Ilaun eine hraune Farlye her. Starker liaffeeaufguls dient zun Iirankoloricren.

Costarica fïht den Kaffeebaum als Wappenbild.

Warenkunde. Nach ihrem Viterlande unterscheilet man die Kitfleebohmen folgendermalsen:

1. Arabischer $\mathrm{K}$ affee. Die Anslese, Bahuri, kommt kaum zu uns. Beste, aber höchst selten zu uns kommende Sorte: Mokkakaffee, kleinste Bohnen, eirund, meist grau mit einem grüinen Hauche, etwas durchscheinend (eigentlicher Mokka), oder gelhlichgriin (levantischer oder alexandrinischer, aus Abessinien). llauptniederlagen des eigentlichen Mokkakaffees Aden (engl.), dann Hodeïla und Djidda. Er wird meist ron den reichen 'Türken und l'ersern verbraucht und nur in geringen Quantititen ausgefiihrt. Da man in Europa die grolsen, in Lordamerika die kleinen Bolnen kauft, wird in Aden demgemäls sortiert. Der levantische Kaffee, Sakki, Salabi, kommt ron Kairo aus als Mokka in den Handel. Trotz seiner Güte hat der arabische Kiaffee ein ungleichmälsiges, unvorteilhaftes Aussehen. Der Ii affee ron der Somâlikïste Zejla soll noch besser als der echte Mokka sein. Tielfich kommt kleinbuhniger Java-oder Ceylonkaffee als Moklia in den Handel.

2. Ostindischer Kaffee; mit den grölsten Bohnen.

a) Niederländisch-Indischer Kaffee. Beste Sorte ... Java" (Surabaja-, Batavia-Kaflee), längliche lohnen, wenig bestiuht, gold- oder hochgelb, braun, grelh, hlafsgrünlich. schön griin, fein blau oder blank. Die geringste Sorte. Samarang, grofs, golbbraun, braungriun, mit schwarzen Bohmen unternischt. Die Pohne wirl immer dunkler; je dunkler, desto hüler in Wert. Die kleinsten Bohnen auch dieser Art kommen unter dem Samen Mokkakaffec zu uns. Der Bezeichnung ".Javakaffee" ist noch diejenige der Landschalt beigefuigt, in welcher die Bohne gewachsen ist (liuntan, Krawang, Preanger, Tscheribon. Tanarang, Tagal u. a.); Menaldokaftee ron Celebes, grolsbohnig, blalsgelb, blafsgrim oder dunkelgelbbraun, sehr greschätzt. Die iibrigen Celehessorten sind wenigre huliebt. I) alagkilfoe ist auf gelichtetem Waldboden gewachsen. Snmatra, etwas gröber als die Javabohne; dunkelgelbe, braune, mit schwarzen vermischte lohnen; geht wie alle Iohnen des Indischen Archipels als Javahohne, wird aber vielfach als Mischware benntat; I’adang, Mandlieling, Ankola u. a. 
b) Englisch-Indischer Kaffee. Vou dem auf dem indischen Festlanile gehanten hilfee wirl als von hesonders feiner (?ualität der Gebirgskaffee von Mysore gerühnt und nit hohen Preisen bezahlt. Elrenbiirtig ist ilnu der Kaffee ron den Nilshirihïgeln. Wohlschneckend ist der Kaffee ron Ceylon, in Grölsen der Mokka-bis zur lavahohne: Plantagen-Kaffee mit greichmiifsig blaugrünen, schmalen und ziemlich kleinen bolmen, Nativa mit mehr gellogrünen oder dunkelı, länglichen Bohnen.

c) Spanisch-Indischer Kaffee. IInnila-kaffee, edle, blafsgrüuliche, grolse Sorte; der beste ron Cavita, weniger guter ron Batanges und Laguna. Der geringste von Mindanao, mit Silberhautstiicken untermischt.

3. Amerikanischer Kaffee. Der Kaffee Brasiliens ist sehr verschieden in Farbe und Gröfse. In Durchschnitt sind die Bohnen klein und hell- his dunkelgriin gef̈̈̈rbt, zuweilen besitzen sie einen gelhen IJauch und werden dann ..Golden Rio" genannt. Da diese Fïrbung in hohem Ansehen steht, olme Grund, wie Kenner behaupten, so wird sie grolsen Mengen kï̈nstlich beigebracht, zum Teil durch giftige Stoffe. An dem Anssehen und Geruch liifst sich der gewöhnliche brasilianische Kaffee leicht ron anderen Sorten unterscheiden. Da die besten Sorten den besseren ost- und westindischen Sorten gleichkommen, gehen sie vielfach unter deren Namen und so kommt es, dals nur die minderwertigen als Brasil rorkommen und dieser sich in Bezug auf Güte keines besonderen liufes crfreut, zumal dil die Waren der Gebicte, fiir welche Rio de Janeiro Verschiffungshafen ist, einen eigentiinlichen, etwas rinzigen Geschnack besitzen. In den Gebieten, welche iiber Santos und Iiahia ihre Ware ausfülnren, müssen Martinique und IBourbon den Namen herleihen. In Rio de Taneiro, wo drei Viertel der brasilianischen Ernte zur Verschiffung

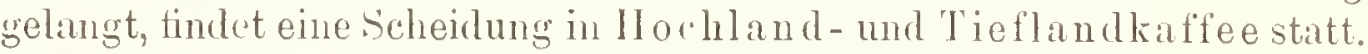
Geschiätat ist Campinals; Bahia wird seiner fahrlïssigen Behandlung wegen nicht unter die I'rimarqualitiiten gerechnet. - Der Kaffee von Surinam grehört zn den besten amcrikanischen Sorten (kleine, runde, volle, dunkelgrïne buhen. nit starken, eigentiimlichem Geruch); auch Franzüsisch- nnd liritisch-Guyana liefern gnte Sorten; lierbice, Demerari, sie sind klein. Hingriin oder gran-gelblich; für unseren Iandel ohme Berlentung.

Der Kiltee von Venezuela und Colombia konnut unter den

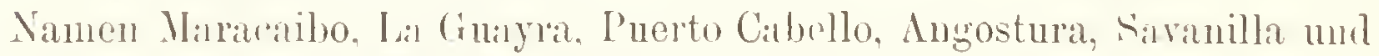
Bogota in llandel. Der Maracaibokilfee tüht die Unterscheidnngsnimen Cucuta (ans der Proviny Sintunder, gilt als der teinste, ist dem davakatfee sehr :ihnlich, aber grïnlich, wird, wenn er gellolich

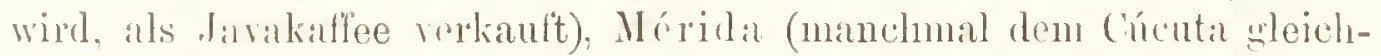
wertig), 'lovar, Bocona und 'l'rujillo (der letatere eine geringe, unreinlirhe Ware). I)er Lal (iuagrakaffee wird in den besseren 
(Malititen Gewaschener Caracas, Caracas La Guayla mul 'Prillados acuanut. Ein 'leil des letzteren wirl iibre l'uerto Cabello ausgefiilnt umel liihrt den Namen P'uerto-Cabello-'T'rillados; el ist gelingwertigrer als die Maracaibosonten und dem l'nerto-Rico ähnlich. dalier auch Kiisten-l'uerto-Rico. Der Angosturakaffee ist grofs,

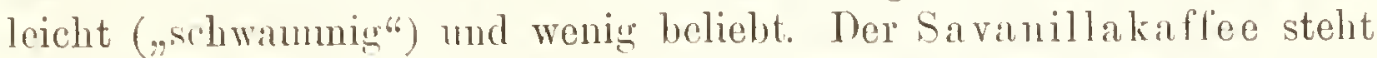
in der Güte dem ihm ähnlichen Cícutakaffee nach, während der Bogotakaffee dem Cúcutakaffee gleichwertig ist. Die besseren (Qualitäten aller genannten Sorten sind bläulich-griin und bekommen beim lïngeren Lagern einen Stich ins Gelbe. Die Bohnen sind ron gleicher Gröse und Form und haben ein eigentümliches, angenehmes Aroma.

Auch :n der Westküste südamerikas wird Kraffee in Ecuador. P'eru und Bolivia gebaut, aber mu der letatere Staat fülırt davon aus.

Del Kaffece von den westindischen Inseln ist meist bläulich oder griunlichgrau. Cuba (Havana, Santiago), in Gröfse und Farbe sehr verschiedenartig, ist seines starken Geruches halber beliebt; daher werden ihm manche Brasilsorten untergeschoben. Der wertvollste westindische ist wohl der Jamaikakaffee; er ist sehr gleichmailsig, lang und schmal, grün bis grünlichblau und sehr glatt. Santa lıcia und Trinidad sind mehr länglich-rund, graubläulich, mit Silberhautresten. Domingo hat meist schmale, gelb- blafsgriune, seltener bläulichgriune Bohnen; ist ebensw wie Puerto-Rico sehr ungleich. Ton letzterem sind die feineren Sorten blafs- bis blangrïn, die gewöhnlicheren griulichgelb bis gelb. Martinique liefert mittelgrolse, fast grane oder graublaue Bohnen, mit sehr feiner Silberhaut. Guadeloupe, Dominika und Granada graugriun, weniger grute, aber für unseren Handel nicht in Betracht kommende Sorten.

Centralamerika liefert vorzüglichen Kaffee. Der Rangordnung nach kommt zuerst Costarica, dann Guatemala, Nicalaggua und Honduras. Die Färbung des Costaricakaffees schwankt zwischen hell- und dunkelgraugrüun, in Form und Gröfse stimmt er nahezu mit dem Maracaibokaffee überein; in grerösteten Zustande besitzt er ein reiches, feines Aroma, das von manchem für unübertroffen gelalten wird; die Erbsenbohnen kïnnen als Mokka verkauft werden. Die Farbe des Guatemalakaftees schwankt zwischen bläulich und dunkelgriin, die Gröfse ist gleichmäsig, die besseren Sorten sind ron feinem Wohlgeschmack. Der Kaffee von San Salvador besitzt einen gelblichen Hauch und einen süfslichen Geruch. Der Kíffee von Nicaragua wird entweder als Costarica oder Guatemalakaffee, der von Ilonduras als Guatemalakaffee an den Mirkt gebracht.

Der mexikanische Ĺaflee wird in 'liefland- und Ilochlandkaffee geteilt. Der 'Tieflandkaflee ist gröiser, leichter und „schwammig", der Hochlandkaffee hat cin hartes, hornatiges Aussehen. Dic Ausfuhware trägt die Namen: 'I'abasco (Kiistenkaflee ron geringer 
Güt(s), Jalapa (klein, breit, kur\%, von unregehmälsiger Grölse und gelblicher l'arbe, schlecht gereinigt), Sierra (klein, grïnlich, schlecht gereningt), Cordoral (grölser und lä̈ger, von regehmälsiger Grölse und grinlicher Farbe, wird auch unter dem Namen liokaffee verkault; ans derselben Iandschaft kommt ein grofser, weifslichor Kaffee unter dem Namen ,mexikanischer Java“); Oaxaca (dunkelgrüner, horniger Gebirgskaffee) und 'l'ebic (beste Sorte. wird nicht ausgeführt, die Erbsenhohne wird vom Mexikaner iiber den Mokkakalfee gestellt). Die Inseln des Stillen Oceans (Sandwichinsehn, Filschinseh, Tahiti, Samoainsehn) liefern nur wenig Kaffee anf die Weltmärkte. Der Kaffee der deutschen Plantagen von Samoa ist von vorzïglicher Giite und erzielt auf dem IJamburger Markte einen guten Preis.

4. Afrikanischer Kaffee. Abessinien, das Ileimatland des Echten Kaffecbaumes, erzengt vorziigliche Ware, aber in ungeniigrender Menge; Ausfuhrhafen Obock. Nadagaskar, Mauritius, Reunion (daher der vorzïgliche liourbon, mit länglichen, blal'sgelben, grüunlichgelben, endlich goldgelben Bohnen), Mozambique und Xatal führen ebenfalls wenig aus. An der Westkïste wird der kleinbohnige, hellgelbe Cazengo, Golungo, sowie der Ambaka erzeugt, doch wie atich kamerun- und Liberiakaffee (letzterer von Confen librira), nur in geringen Mengen ausgefïhnt.

Eine gute (bulitiit, Usimbara, scheinen auch die deutsch-ostafrikanischen Plantigen zu erzielen.

Als leihenfolge der bei uns gangbarsten sorten ihrer Giite nach wird folgende angegeben: Brauner, gelber, grüner llanker Java, desgleichen Ceylon und Nilghiri; ferner P'uerto-lico, La Guayra, Domingo, Campinas.

Lis lïst sich nicht sagen, dafs ingend eine Kaffeesorte die beste sei, da lier lediglich der persönliche lreschmack mafsgebend ist. Der liat von sachkennern geht daher dahin, es solle sich jeder Kaffeetrinker zwei oder meh Sorten mischen, um seine Geschmacksrichtung treff’en zu künnen.

Aller Kaffee grewinnt durch das Lag'ern an Giite, während er an Gewicht verhert (im ersten buhre der Lagerung durchschnittlich s Proz. im zweiten 5 P'roz. und in dritten 2 l'roz.).

Geringe Sorten (unreif geerntete) müssen mehrere, \& bis 10 Jahre, feine lïichstens 3 Jahre lagern, ehe sie henut werden können. Jeim Transport mul's sehr vorsichtig verfahren werden, dafis nicht durch einen stark ricchenden Stoff" die ganze Ladnng verdorben wird.

Marinierte (hararierte) Ware sind glanzlose, likbrige, iibelriechende bohnen, die durch heewasser auf den Schiffen einen bitteren, salzigon liejgeschmack chalten hahen; Triageliaffee ist der mit zerstiickelten bolnen nutermischte liallee (teringes Aroma).

Verfälschung und Verunreinigung des Kaffees. In den Ermengunglïndern. znweilen auch in den liestimmungshäfen liilst 
man Bohncu geringerer Sorten "schwitzen", polieren nud firibon und verkiuft sic dann unter talselıen Nannen. Dunch Schwitzen wird \%. J). Savanilla und Santos in Java umzuwamlelı versuclit. Am verwerflichsten ist es jedentalls, aus Kaflecsat\% durch Anwondung von Kilebemitteln und starkem Druck neue liaffechohncn her\%ustellen; man kann es gewils nur gutheifsen, dals dicse labrikation und der Vertrieb diesbeziiglicher Maschincn in Deutschland verboten wurle. Verwerflich ist auch das Firben, das an allen grungen Sorten vorgenommen wird, dil oft giftige Stofic in Anwendung kommen. Die Grundlage aller derartigen Mittcl ist pulverisicrter Speckstein, welchem die Farbstoffe beigemischt werden. Das Färben der Bohnen erfolgrt in der Art und Weisc, dals dieselben in besonders konstruierten 'Trommeln mit Farbstoffen, wclchen die verschiedensten Nüancen gregeben werden kïnnen, geschüttelt wcrden. Der Speekstcin erteilt den Kaffecbolmen eine wachsartig glimzende Oberflächc. Als Farben benutzt man Eisenoxyd, chromsaures Blei, Orange, Arogclb, Eisenhylroxyd, Malachitgriin, Methylgriun, lierliner Blau, Ultramarin, gerlssaures Eisenoxyd, Graphit und pulvcrisierte Kiohle. Chromsaures lilei ist cin heftiges Gift; deshalb soll man die Bohnen auf der Haut reiben, un zu schen, ob sie abfärben, und alle Bohnen vor dem Rösten in lauwarmen Wasser waschen. Man soll niemals gemahlenen Kaffee kauten, weil es nachgewiesen ist, dal's $\mathrm{cl}^{\circ}$ oft mit Erbsen, Bohnen, Lupinen, Nïssen, Gerste, Reis, Weizen, Pastinak, Möhren, Rolskastanien, Eicheln, Roggen. Runkelriben, Tragantsamen (Astruyulus balticus), Weintraubenkernen, Spargelsamen, Kinollen der Kíaffeewurzel (Cypcrus esculcntus), Berberitzen, Togelbeeren, Bucheckern, Löwcnzahnwurzeln, Feigen, Dattelkernen. Johannisbrot, gebranntem Zucker und am häufigsten mit dem I'ulver der Cichorienwurzel, die man vorher röstcte, vermischt wird, und weil auch der reine Kaffee, wenn er in pulverisicrtem /austande länger aufbewahrt wird, vicl an scinem Gchalte verliert. Ist das Kaffeepulver mit Cichorienwurzel (Cichorim Intybus) vermischt, so läfst sich dicser Betrug leicht erkennen, indem man solchen Kaffee etwas anfeuchtet und ihn zwischen den Fingern rollt. Er wird sich alsdann kncten lassen und cin Kïgelchen bilden, wïlrend der reine, unverfälschte Kaffee ein Pulver bleibt. Gemalılener, gelsannter Liaffee in ein Weinglas voll Wasser gebracht, bleibt stundenlang oben und fïrbt die Flüssigkeit kaum, zicht nư ganz allmählich Wasser an, färbt dann die Fliissigkeit weingelb und sinkt endlich zu Boden. Cielnorie faillt dagegen rasch nieder und färbt dic Fliissigkeit rotbrilun. Der Kaffee linterlälst höchstens $3 \frac{1}{2}$ Proz., die Cichoric \%wischen 5 bis 7 Proz. Asclie. Mchr Asche deutet auf zurgesetzte Mineralstoftc. Die Cichorie wieder wird oft mit Torf vormischt, der in Wasser cinen Riickstand hinterlälst, unter dem Mikroskopl das pllamzlichc Gefige des Jordes zeigt und sich beim Verbremen durch den ihm cigenen widerlichen Geruch verrät. Auch Ocker mul Kicgelnchl wird den 
zenahlonen Liflee heigemengt. Als Verfilschung des gehramnten mul uromilnlenon Kallees kommen in nenerer \%oit auch die samen des

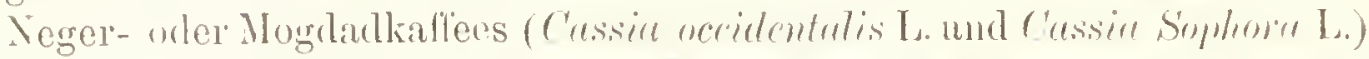
rur; don Aulgulls der gerösteten Samen (oft in Mischung mit Kilfee)

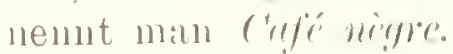

lieziiglich der mikroskopischen Erkenumg der Surrogate folgendes: Bei reinem, unverfïlschtem Kaffee sieht man, nach Ha ger, die gelbfirbigen Riuchstücke des (iewehes der Kaffeebohne, untermischt mit nur wenigen farblosen, durchsichtigen Teilen und auch einzelnen spindelformigen Steinzollen. Bei Gegenwart ron Surrogaten zeigen sich entweder Stiirkemellzellen orler' 'I'reppengeläfse, sowie abweichende Formen des Zellgewebes; die Irupine schlielst bandformige \%ellen ein. wie sie keines der anderen Surrogate anfweist, und der liüben- und Cichorienkaflee zeigt 'Treppengelälse und häutige Gebilde mit lockerem \%ellgewebe; Getreide-, Roggen-, Eichelkaffee und Beimengungen ron Samen der ITiilsenfriichte zeigen Mengen ron Stirkenehlzellen, welche wiederum leicht zu bestimmen sind.

Kaffee-Ersatzmittel giebt es sehr viele, sie teilen mit dem echten Kaffee nur den brenzlichen Gernch uncl Geschmack, kein's aber kann ihn ersetzen, da keines ron ihnen Kaffë̈n und Kaffeol enthält. Tiei ihrer Iienteilung ist zu berücksichtigen, dafs der eclite Kaffee ein Genufs-, nicht aber ein Nahrungsinittel ist. Unbegreiflich ist es, dals die Cichorie cine so grofse Einbürgermus bei reich und an erfalren hat, dils der deutschen Cichorienindustrie gegenwärtig nicht weniger als 11000 ha Isand tribntpflichtig sind, und iiber 120 Fabriken zur Verarbitung des el"zeugten regetahilischen Rohstolfs dienen, die fiir etwa 15 Millionen Mark Fabrikate liefern.

Ingenehmer schneckt der sogemannte Nordhiiuser Gesundheitskalfee; seine Ilerstellung crfolgt aus cinel Mischung ron grerïsteten hörnern verschiodener Getreidesorten. Der behringsche Kraftkaflec bestelit aus gelben I.upinen, die bis zu einem gewisson Grade entbittert und sorgfibitigr reröstet siml. Der Kaffecersatz der Firma Leusmanu und Zabel besteht aus reinen Lupinen, denen noch Stoltie zur Verbesserung des Geschmackes boigemengt simul. Nenerdings hat sich der Fuigenkaffre bingang rerschafft. Prber die Verwendung der gedöreten Kaffeeblitter sowie des Fuchtfleisches als

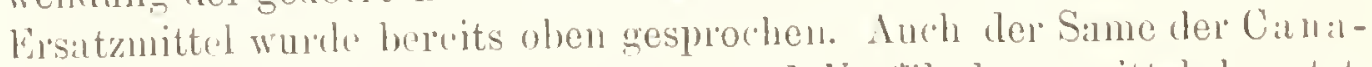
valia (lirasilien) wild als Surrogat und l'odiilschungsmittel henutzt. In Wentschland haben sich als hilligstes und gäinzhich muschäilliches Ersitzmittel gebrannte Gerstenkïrner. Kneiplinafee, eingefiilnt.

Angaben über Ernten, Handel und Verbrauch. Erzougung mul Verbranch dor Kafleebohnen sind im Strigen bengiflen;

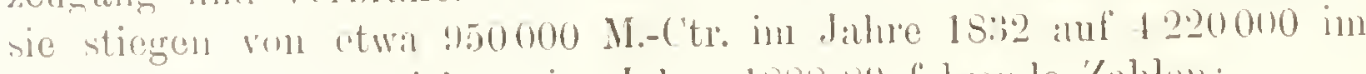

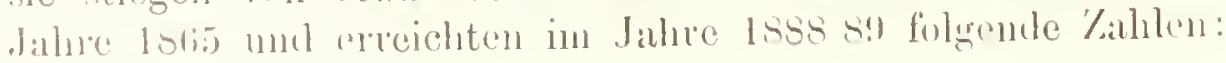


Brasilien . . . . Ansfuhr 1888 s: :840 600 Ml.-('tr.

Javil

Einte lis? 708710

('entralamerika. . Ansfuln 1S8s/8? 560:340

Vicnezuela

Hititi

Puerto-Rico

Brit. Ostindien

San Salvaldor

Columbien

Mexilio

Custarica

Philippinen

Ceylon

Jamaika etc.

Arabion

Afrikanische Westliiiste

Guadeloupe, Martinique

Liheria

Rímion . . . E Ernte 1887

Dominica . . . . Ausfulu 188!

Honduras

Erute 1887

$4507: 37$

270264

$1885 \quad 16227: 3$

$188990 \quad 121816$

$1884 \quad 103170$

$1889 \quad 100000$

1858, 99

$924: 31$

1SSS ST400

1889

61000

Neukaledonien

Erite

1886

Culia

Ausfuhr 1889

Andere Läuder.

45204

43110

42700

ca. 20000

6085

5000

4852

3408

ca. 2300

1789

1620

2615

Gesamt 6,737459 M.-Ctr.

Es führten aus:

Brasilien . . . . . . im .Talıe 1889 für 379,1 Mill. Mark

Niederlïndisch-Ostindien

Guatemala

Venezilela

Mexilio.

Costallica

Sill Silvador

Britisch-()stindien

Aden (Mokka) .

I)ic Einfuhr im Deutschen Reiche betrug im Jahre 1897 an rohem Kaftec $1: 36: 950$ M.-Ctr. im Werte ron 1604000000 Mark, womit der Kaffee die vierte Stelle (1. rohe Baumwolle, 2. Schafwolle, :W Weizen) in nuscrel Einfuln einnimmt. Ton dies'n /alslen ist die erstere seit 1890 alhmählich von 1181260 grestiegen, die letatere aber von 219700000 fast gleichnüisig gefallen.

Der Verbrauch des Kaffees ist aulserordentlich verschieden; in den Jahren 1855 bis 185 !) wurden im Dnrchschnitt verbrancht: 
In den Nirderlanden . auf den Kopf der Pevölkerung $4,55 \mathrm{~kg}$

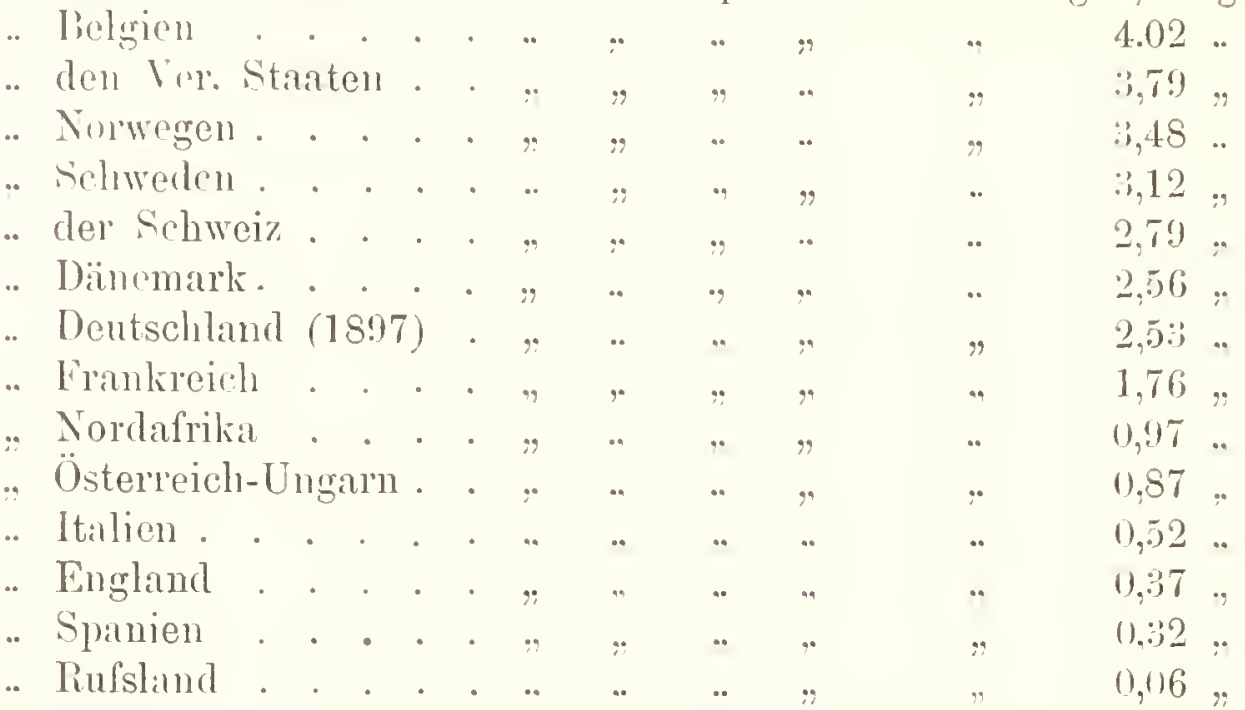

II uptmärkte und A uktionsplïtze fiir Kaffee sind IIamburg. Harre, Linterdam, London, Amsterdam, Iarseille; Hauptterminplätze Harre und Hamburg. in zweiter Linie London, Antwerpen, Amsterdam und Rotterdim.

Geschichte des Kaffees. Shehahcddin Ben'), Verfasser einer arabischen Handschrift aus dem 15. Jahrhundert, berichtet, dafs man den Kaffee seit undenklichen Zeiten in Abessinien gehraucht habe. Die líunde hiervon hatte sich aber nicht nach den benachbarten Ländern verhreitet, denn die Kreuzitihrer wufsten nichts davon, und der Arat Ehn Baitlar, welcher zu Anfang des 13. Jahrhunderts Nordafrika und syrien durchwandert hat. sagt liein Wort rom Kiaffee. In Persicn dagegen soll der Gebranch des Kaffees schr alt sein. Die Sage erzïhlt, der I'rior eines arabischen oder persischen Klosters habe durch seinen Ziegenhirten erfihren, dafs die Ziegen nach dem Genusse dieser Beeren die ganze Nacht hindurch unsiigliche Sprünge machten, und infolge dieser Nachricht soll er zuerst seinen llünchen oder Derwischen, um sie bui ihren nïchtlichen Andachtsiibungen munter zu erhalten, Kaffee gegehen hahen. Geschichtlich strht fest, lals der Nufti Gemaleddin in Aden den Gebrauch des Tiaffees hei den aritlischen Mänchen und Gelehrten in der Mitte des 15. Jalnrhunderts einfuilurte, da el auf einer lieise in Persien durch den Genuls des Kaffees IIeilung von einer Krankheit sefunden hatte. Nilch Mekka kam der katffe im Jahre 1507 .

In Jahre 1554\%), unter der llerrschaft Solimans des Girolsen, wurde der Kaffee in Konstmintinopel eingefiilnt. und zwei Laufleute, llekin ron Aleppo und Schems von Damaskus, eröffueten die crsten Kaflec-

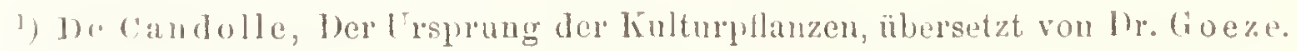
- ") Nach Milntegraza. 
hïnser, in denen dieses nene Getränk dem Publikum dargereicht wurde. Das (iewerbe der Kaffeewirte scheint danals sehr cinträglich gewesen zu sein, denu Schems kehrte nach drei Jahren als reicher Mam nach Damaskus zuriick. Der wohlthïtige Einflufs des ithiopischen Getrïnkes auf das Gchirn machte sich in jenen ersten Kattechïnern sogrleich bemerkbar, denn Dichter, Schriftsteller, Bürger, die geistreiche Unterhaltung licbten, und sogar Paschas strömten in grolser Menge herbei, weshalb dic Kaffeehïuser anch meliluli irfun, d. h. Bildungsstätten, genannt wurden. Dic mohammedanischen Priester fingen an sich zu beklagen, dals die Moscheen von Tag zu Tag weniger besucht würden, wïhrend die Menge immer mehr in die Kaffeehiinser ströme; sie erklärten, die Kaffeehäuser seien für das Heil der Seele verderblicher als die Wirtshüuser. Es wurde eine Eingabe an den Mufti gemacht und darin gezeigt, dals der Kaffee eine Art Kohle sei, und, da der Koran die Kohle und alles, was der Kohle gleicht, in den Bann thue, der Mufti ersucht, dafür zu sorgen, dafs einer solchen Verletzung der heiligen Gesetze endlich Eimhalt gethan werde, und er antwortete: „Es sei!“ Die Kaffeehïnser wurden geschlossen und allen Tiirken und Anhängern der mohammedanischen Religion der Genufs des aromatischen Getränks verboten. Aber man fuhr fort, es bei verschlossenen Thiiren zu trinken, bis ein neuer Mufti kam, der erkliirte, dals der Kaffee keine Kohle sei und auch von den glïubigsten und trenesten Anhängern Mohammeds getrunken werden könne. Infolgedessen mehrten sich die Kaffeehäuser so, dals der Grofsrezier es fiir angezeigt hielt, sie mit einer Steuer zu belegen. Jeder Kaffeewirt mufste num tïglich eine Zechine Steuer bezahlen und durfte trotzdem nicht mehr als 1 Asper (gleich 15 Pfennig) für eine 'Tasse Kaffee verlangen. Der Grofsvezier Köprili liefs die Kaffeehüuser während der Minderjührigkeit Mohammeds IV. von nenem sehliefsen, da er sich iiberzengt hatte, dals in ihnen zu stark politisiert wurde. Aber trotz dieser Mafsregel nahm der Kaffeeverbrauch in Konstantinopel nicht ab, denn man bot dieses Getränk auf den Plätzen und in den Strafsen feil. Anfserdem befolgten die Sölne eine andere Politik als die Väter, und als Köprilis Sohn ans Ruder kam, liefs er die Kaffeehäuser unbehelligt ${ }^{1}$ ).

In Jahre 1596 schickte Bellus an Clusins Samen, atus welchem die igypter das Getränk Core bereiteten²). Ungeführ zur selben \%eit erlangte I'rosper Alpinus in Agypten sollost Kenutuis divon. Fr bezeichnete den Strauch unter dem Nimen ... mror Bon, cum finctu sun Bunu". Der Name Bon findet sich bei den cristen Autoren auch unter der Form von Bunuu, Bumcho, Buncus) wieder. Die Xamen (uhne. Culuu, Chaube'), Care bezogen sich in Igypten

1) De Candolle, I. c. - 2) Dellus, lipist. ad Clus, p. 30\%. - B) Liawolf, Clusius. - ${ }^{4}$ ) Lauwolf; liauhin, IIist. I, 122. 
und Syrien anf das zubereitete Gotränk. Der Name Bumm orler ein diesem ähnlicher ist gewifs dher mrsprïngliche Name der l'flanze, da die Abossinier sie noch hentzutrge Jimn nemen's). lianwoll lernte den Kafiee in Aleppo kennen mul brachte die ersten Nachrichten diriiber 1582 nich Europa. Die r'ste botanische Beschreibums und eine Abbikhnug gab Prosper Alpinus im Jahre 15!)1. Dir Venetianer brarhten 1624 grölsere Mengen nach Kuropa, und 1645 soll das Geträink in Sürlitalien gebräuchlich gewesen sein. Dic rrsten Raffeehäuser: 1554 in Konstantinopel, 1615 in $\mathrm{V}$ 'nedig, $1652 \mathrm{in} \mathrm{London,}$ 1677 in l'aris, 168:3 in Wien, 1656 in Nürnberg und Regensh)ur. 1687 in Hamburg, 1694 in Loipzig. 1697 in Wïrzburg. 1712 in Stutteart. 1721 in Berlin. Kirchen und Regierungen verfolgten die Kaffeetrinker; später belegte man die Ware mit sehr hoher Stener. liesonders war Frietlich der Grofse dem Kaffee abhold. Er liefs Staatskilfeebrennereien errichten, wo man den liaffee sechsmal teurer bezahlen mulste als beim Kraufmann; er monopolisierte den Kiffeehandel, und nur die höheren St:inde. Adlel, Geistliche und löhere Reamte erhirlten ..Brennscheine" und durften den Kaffee selbst hrennen. Das Landvolk sollte sich nicht an den Kaffee gewöhnen, "denn das ist mit die Lbsicht", antwortete er aul eine Beschwerde. ..lafs nicht so viel Cield tür Kaffee aus lem Lande gehen soll. Übrigens sind Seine Köningl. Majestiit Hüchstselbst in der Jugend mit IBiersuppe erzogen worden, mithin künnen die Leute ebensogut mit Biersuppe erzogen werden. Das ist viel gesïnder wie der Kaffee." Landgraf Friedrich ron Hessen rerbot den Kaffee in seinem Lande bei 100 'Thlh. Strate.

Nikolas Witsen, Bürgermeister ${ }^{2}$ ) ron Amsterdam, Direktor der holländischen Handelskompanie, forderte den Gonverneur ron Batavia, Van Hoorn, dringend auf, Kaffeesamen von Arabien nach Batavia kommen zu lassen; dies geschah und ermöglichte es l'an Hoorn, lebende Pflïnzchen daron im Jahre 1690 an Witsen $z u$ schicken. Diese wrrlen in dem von Witsen gegründeten botanischen Garten in Ansterdam gepllegt und trugen dasellsst Frïchte. Im Jahne 1714 schickte die liehörde dieser Stadt eine krä̈ftige und nit Frïchten bedeckte l'tlanze daron an Lulwig XIY., weleher sie in seinem (iarten za Marly unterbrichte. Man zog den liaffeebaun anch in den Gewïchshïusern des künighichen Gartens in l'aris. Einer der Professoren dieses Instituts, Antoine de Jussieu, hatte bereits 1713 in den .Mŕmoires de licadimio des sciences" eime interessante lieschreibung der Pllanze veröfentlicht, und zara nach cincm lehenden Exemplar, wetrhes ihm ron P'ancrass, dem I)irektor des Ansterdamer Gintens, mengeschickt worden war. I) ersten in Anrerikir anceptlinkten Kafleebïmme wurden von den Hollïnler'n in Jahne $171 \mathrm{~s}$ in surinam

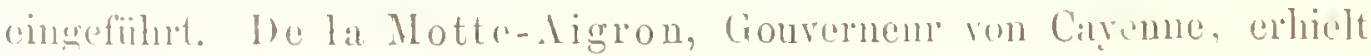


bui suinem Aufenthalt in Sminim unter der lland einige l'llanzen 1111 vermehrte sie. 1720 (nach einer anderen Angabe 1723) brachte der Schiffstoutuant de Clicu eine halleepllanze vou Paris nach Martinipue. anl' der langen Überfahrt seine kleine 'l'rinkwasserration trenlich mit ihr teilenr. Von diesem bïnmehen entstanmen die Káffeebïnme ant den westindischen Inschn. Auf den central- nnd siidamerikinnischen Festlande wurle die P'tanze zuerst in Vonezuela, dann in Brasilien angebant. Tom Jahne 1718 an hatte die fiamösische IIandolskompanie Mokka-Kaffeptlanzen nach der Insel liourbon geschickt. Seit 1762 bante man in Brasilien Kaffee, aber erst in diesem Jahrhundert winde dieses Land fïr den Welthandel ron liedrutung. Im Anfange dieses Jahrhunderts entstamden dann die Ptlanzungen anf dem ostindischen Festlande, in Britisch-Ostindien und in Cochinchina, aud' den Sundainsehn, den Mohnkken, Philippinen und Sïdseeinseln, in Mexikn u. s. w; in nenerer Keit in Liberia, am liahon, auf den Fidschiinseln, im nürdlichen Teile von Westanstralien und in den Vereinigten Staaten ron Nordamerika. Seit einigen Jahren werden auch in den deutschen Kolonieen des heifsen Afrika Anbauversnche gemacht, die Erfolg zu haben scheinen. 


\section{Tafel 4. \\ Theestrauch \\ ('Thea chimensis Linnó).}

Der Chinesische Theestrauch gehört zur Unterklasse der Freiblätterigen Dikotyledonen, zur lieihe der Wandfriichtigen (Purictules) und zun Familie der Theepflanzen (Theucene).

Die Familie der Theepflanzen (Thucene). Kelch, Plumenlirone und Staubblätter spiralig angeordnet. Staubfiden zahlreich, Fruchtknoten mehrficherig, Iilätter zerstreut gestellt, meist lederartig; Bäume oder Strïucher. 16 Gittungen mit 174 Arten.

Die Gattung Theestrauch (Theu Kaempfer). Immergriine Strïucher oder kleine Bäume mit glänzenden, lederartigen Blättern, achselständigen, einzeln oder in Bïscheln stehenden, weilsen oder rosenroten Bliiten und dreifïcherigen, dreisamigen Kitpseln. - 16, in Indien, China murl Japan wildwachsende Arten.

Chinesischer Theestrauch (Thea rhinesis Linné). Der 'Theestrauch hat viel Ähnlichkeit mit der anch bei uns gezogenen Kamelie. Sich selbst überlassen erreicht er eine $\mathrm{H}$ öhe von 7 his $10 \mathrm{~m}$ und eine'n Durchmesser von 3 din, er wird aber durch rechtzoitiges /urïickschneiden auf 90 bis 150 , höchstens $200 \mathrm{~cm}$ gehalten. Der Stamm trennt sich in geringer Höhe iilser der Erde in zilhlreiche Ïste und Wweise.

Ilie BIätter sind zugespity, nach der Spitze hin mregelmïisigg sïgeförmig yröilhnt, an Grunde ganzrandig, kum gestielt, abwechselnd, etwas glïnzend, immergriun, sehr diinn, steif, glatt. Wen jungen libittern haftet kurze '/eit nach dem Sprengen der Kónospen ein weifser l'linm :n den Spitzen an.

Die Blüten sind weifs, entspringen in den Blattwinkeln ant' kur\%en, dicken Sticlen und sind nickend mul schwach wohlriechent.

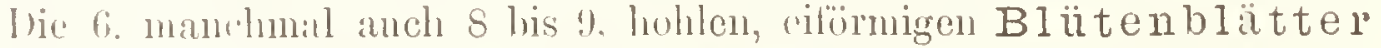
stehen zu je dreien in 2 Kreisen; dic äulseren sind etwias wrölser als die immen. sie wemlen sich später etwas answirts. Die zahlrowhen 
(gegen 100) in Blumenboden stehenden Staubfäden siur farlenförmig, etwas kiumer als die krone nud an ihrem Grumde miteinander verwachsen, dic Staubbeutel sind zwoificherig. 1)er Kelch ist bleibend, ku\%, flach und besteht aus 5 his 6 rundlichen, stumpten Biattchen; Fruchtznoten dreificherigr; Griffel drein1: rbbig.

Frucht kugelrund, dreifacherig. Same kirschkerngrofs, glïnzend lraum; mit Kicimgrube und dem Eindrncke verkimmerter Samenanlagen.

Hauptblütezeiten: September und Oktober bis Jamur und Februal.

Die verschiedenen 'Theesorten des Handels kommen ron einel' Pflanzenart, die aber infolge der tausendjährigen Kultur abianderte, so dals es kaum möglich ist, sichere Merkmale fiur die einzelnen Spielarten aufzustellen.

Man unterscheidet zwei Hauptabarten, die Grüue Theestaude (Ther vividis L.) nit ausgebreiteten Zweigen und blalsgrimeu, lanzettlichen, bis $12 \mathrm{~cm}$ langen und $4 \mathrm{~cm}$ broiten Iiättern und einzelstehenden Blizten, und die Boheastaude (Thea Bohea L.) mit aufstrebenden Zweigen, dnnkelgriinen, elliptischen, $6 \mathrm{~cm}$ langen, $3 \mathrm{~cm}$ breiten Blïttern und mit I3lïten, die zu zwei oder drei beisammen stehen.

Ob die in Assam einheimische Form Thea assamica Lindl. nur eine Spielart oder eine besondere Art ist, wurle noch nicht festgestellt. Der Assamische Theestrauch ist von ippigem Wuchs und treibt gröfsere, 13 bis $18 \mathrm{~cm}$ lange, schneller reifende Blätter. Er beansprucht wärmere Lagen und fruchtbareren Poden. Er steht zum Chinesischen 'Theestrauch in demselben Verhältnis wie etwa der Liberische Kaffeebaum zum Echten.

Der Ölg'ebende Theestrauch (Thea oleosa ${ }^{2}$ ) I.omr.) wächst in lev Näle von Kanton. Das Samenöl wird als Brenı- und Speiseöl benutzt.

Iie Heimat des Theestrauches ist nicht genau bekamnt, sie ist wahrschuinlich im oberen Assam, wo man (1823) ganze 'Theewälder' entdeckt hat. und in der Birmanischen Provinz Cachar.

Verbreitungsgebiet. Der Theestrach wird zu den sultropischen Gewiichsen gezïhlt. Der 'Thechau geschicht in China zwischen rem 15. und 40. Grarle nördlicher Breite, doch wird dic eigentliche Handelswar zwischen dem 24. und 30. Grude nördl. Breite und 113. und 122. Grade östl. Lïnge in den Provinzen Niganhwei, Kiangrsi und 'Tschekiang (Grïner Thee). Fukien (Landschaft Kionningfu) und Kinton (Schwar\%er 'Thee) er\%eugt. Aufserlem findet sich 'Theehau in Japan (wichtigstes Anbaugchict zwisehen den 30. und 36. Grarle nördl. lireite und lem 1:30. bis 145. Grade östl. länge), auf Korea, lava (in hoher Lage). in Cochinchina, Indien und Ceylon (bis $2000 \mathrm{~m}$ Meereshöhe). Der Indische Thee wird hauptsäehlich in Assam, anf den sibllichen 


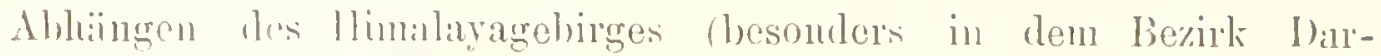

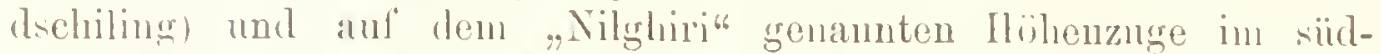
lichrn lndien kultiviert. Anlserden bant man 'llee in linasilien und eingen Gegenten von Vordanerika; anch aut Sicilien, in Portugal und ITestfrankreich gerleiht der 'Theestrauch ganz gout.

Dic 'l'heeptlanze bedarf, num ilne vollkonmenste Enswicklung zu erreichen, eines fonchtwannen Klimas (1s0 ( . Durehschnittswiome), und bei nicht zu niedriger Latge iiber nem Mceresspiegel eines fetten, tiefen, lockeren, gut entwisserten Borlens. Frost kann der 'Theestrauch nieht ertrason, nud ron Trockenheit hat er viel zu leiden. Vor Winden geschiitzte, sanft geneigte Ihïgelläinge eignen sich an hesten zur Anlage voll Theegrirten.

Die Kultur des 'Theestranches ist in den verschiedenen Erzengungsändern verschioden. Man setzt die mit Erdballen der Baumschule entuommenen Ptlïnzlinge gewöhnlich in $1^{1 / 2}$ in Entfernung voneinander in kräftigr gediungtes, lockeres Land, pflïgt und lockert den Foden fleifsig und sorgt fiur reichliche liew:isserung. Der Theestrauch wird aber, aulser in weiten, freien Foldern, aluch als Einhegung von Gärten und Feldern (zum Iinsbedarf) gebant. Die 'llieehlätter sind erst im dritten Jahre und wïlrend der Regenzoit zu sammeln. damit die Sträucher ziemlich grols werden. 'Treibt die Pflanze im zweiten Jalure lange Schölslinge, so müssen dieselben zuriickgeschnitten werden, damit sie Seitenzweige treibt, dick und buschig wird und reichlich Bliitter giebt. Die striucher könnten ein Menschenalter untzhar bleiben, wenn man ron Zeit zu Keit das alte Hol\% wegschncidet und neue Schöfslinge zieht, doch wrolen sie in 7. Tahre gerodet murl duroh noue I'flanzen ersetzt. Die Bläter werden, wenn sie sich eben antwickeln wollen, an liebsten an somnigen 'lagen, von jeder Ptlanzo viermal, in nassen Jahlen fïnfmal. in $/$ wischenrïmmen von $t$ bis 5 Wochen, gepHickt. Mrste Ernte Mitte April bis Ende Mai. Das Einsammeln der Kinospen, jungen Blitter und zarten stengeltriche guschieht in China durch Franen nut Kinder. Die Sorge $n 11$ die jungen Blatter der ersten Ernte geht in China so weit, dals den ron fugend auf für diese Beschäftigung geschulten Albeiterinnen verboten wird, Fiscle orler andere stark riechemle Speisen zu greniolsen, danit ihr Aten nicht das Irona der libatter verdeloc. Sic miissen anch täglich ein liad nehnen und dinfen die Blaitter nirht mit den nackten lländen

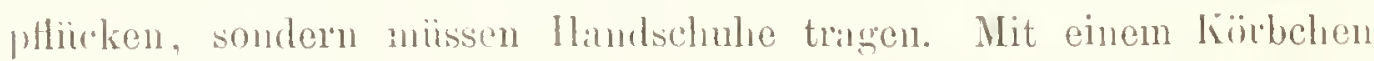

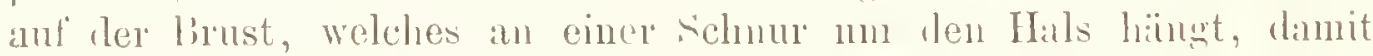
beide llinde froi bleihen, vollyiehen sio dis P'llicken in der Meise, hals sio nut der linken einen \%woig an sich zichen mul mit der rechten

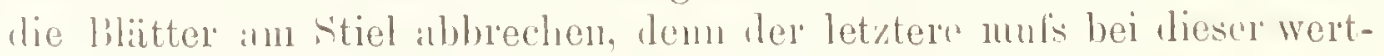

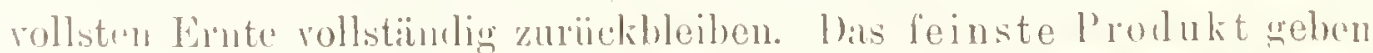
dic noch nicht roll entwickelten likithnospon un die zartesten Bliitter

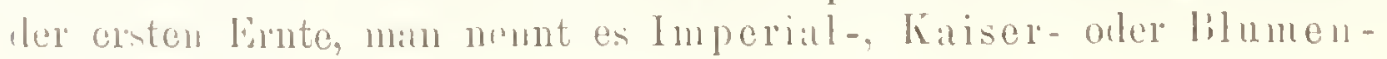


thee. Diese Sorte kommt wohl nicht in den llandel, sondern wirt nur rom kaiserhichen Ilof in China verhatucht. Die Blibter werden ron len brsten sträuchenn genomnen, und viele lieante muissen die Arheit ïberwachen. Die der antwickelten likttknosprn und jungen Blïtter heraubten Striucher wiirlen zu Grunde grehen. wenn nicht um diese \%eit reichliche liegenschaner fielen. Mit joder späteren Ernte

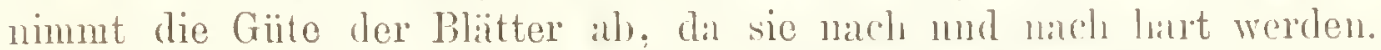
Zweite Ennte im Juli, dritte Angust bis Finde soptember. In Indien bleiben sich infolge des tenchteren, wälmeren Klinas die linten in linzing aul die Giite der IBitter mehr sleich.

Die Güte des Thees hängt ron der Jugend und dem Saltreichtum des Blattes ab, darum gehen larte Blätter geringe ( ualitiiten. Dadurch, dals die Blätter zu verschiedenen \%eiten und von rerschiedener Grölse gesammelt werden, entstehen verschiedene Sorten. Der Grime wie der Sohwarze 'lhee stammen von einer Art, erhalten ihre Farbe nur durch die Art des Trocknens, werden aber nie in ein und derselben Pflawzung zubereitet.

Gehalt, Bereitung und Wirkungen des Thees. Dals der 'Thee zum Lieblingsgetränk ganzel Nationen greworden ist, verdankt er seinem Gehalt an einem itherischen (ile und dem 'Theïn.

Durch das äth erische Öl chü̈lt ıer Thee sein liebliches Aroma. Es ist abscheillbar, citronengelb, erstar't leicht, schwimmt auf dem Wasser, regt, in reinem /ustande genossen, aufserordentlich stark auf und verursacht in grolsen Gaben selbst den Tod. Da es aber im Griinen 'llhee kisum zu l l'roz., im Schwarzen nur zu etwa ' Proz. enthalten ist und sein Auftreten aufserdem durch die Gerhsinn etwas unterdriickt wind, wirkt es beim mälsigen Genufs des ']hees wohtthuend und belebend, erzengt dagegen beim ühermilsigen Theegenusse Aufgeregtheit, Schlaflosigkeit, Eingenommenheit des Kopfes und schwindel, wirkt dann also narkotisch.

Das The in ist derselbe Stoff wie das Kaffeün. Erhityt man sehn starken 'Thee und stülpt dariiher eine Tüte, so setzt sich das Theïn als kleine, farblose Krystalle an das Innere des Papiersäckchens. Es ist von 0,8 bis 4,5 Proz. in den Thee enthaltrn, gilt aher nicht als Wertmesser für ihn, da bei den grinen Sorten die wohlfoileren as 'Thein reicher sind, als die in Handel höher geschätzten, wïheud beim Schwarzen Thee das Umgekehrte stattfudet. Es ist, wic hereits (\$.40) el'wähnt, in libermals genossen, höchst schällich, elzeugt aher. in thee getrunken, dieselhen angenehmen Folgen wie das iitherische (i).

Die Gerbsäure ('T'annin) ist im Thee zu 10 lis 25 l'rozent enthalten. lon dieser Sinure hat der 'Thee seinen herhen, zusammenziehenden Geschnack, scine verstopfende llirkung nud die Figenselaft. nit eisenlaltigen Wass'r eine tintenatige lösung zn geben. I)ie

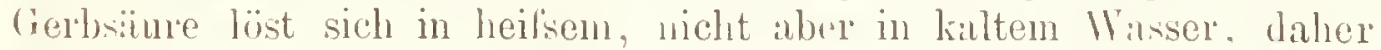
wird der $\Lambda$ ufguls bein Erkalten triihe, dit sie sich diun aussheidet. 
Je länger man den heilsen Anfguls stchen lïlst, desto vollstïndiger wird die Gorbsïure ausgezogen. Ilan soll deshalb dic 'Theeblätter

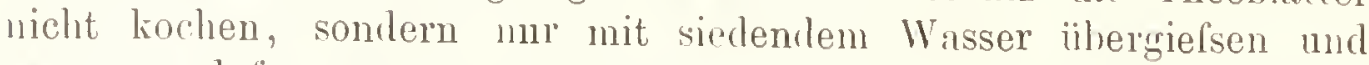
zwar so, dal's man erst nur ein wenig Wasser aufgielst und nach einigen Minuten das iibrige ebenfalls siedend linzuthut. Ältere blätter haben mehr Gerbstoff als junge. Ohgleich die Gerbsäurearten rou Natur farblos sind, lraben sie doch eine Neigung, an der Luft braun oder schwarz zu werden. Dies ist ein llanptgrund, weshalb dieselben lilätter, schuell getrocknet, einen grünen, und langsam getrocknet, einen schwarmen Thee geben. Unter den mineralischen Bestandteilen des Thees ist Kali, welches gröfstenteils in dem Auszug übergeht, vorherrschend, wiilnend Kalk, Ingnesia, Phosphorsämre in den ausgezogenen Blättern bleiben. In den Aufguls gehen etwa 29 bis 45 Proz. löslicher Stoffe üher, bedeutend mehr als beim Kaffee.

Köonig giebt die Zusammensetzungs des Thees im llittel run 16 Analysen in Prozenten wie folgt an:

\begin{tabular}{|c|c|c|c|c|c|c|}
\hline Wasser & $\begin{array}{l}\text { Stick- } \\
\text { stofi" }\end{array}$ & Thein $\ddot{A t h e r . ~}$ & $\begin{aligned} & \text { Fett } \\
+ & \text { Chloro- Gummi } \\
& \text { Ihyll + Dextrin } \\
+ & \text { Wachs }\end{aligned}$ & $\begin{array}{lc} & \text { Sonstige } \\
\text { Gerb- } & \text { stickstoff- } \\
\text { siiure } & \text { freie } \\
& \text { Stofie }\end{array}$ & $\begin{array}{l}\text { Holz- } \\
\text { faser }\end{array}$ & Asche \\
\hline 11,49 & 21,22 & 0,67 & 3,62 & 12,36 & 20,20 & 5.11 \\
\hline
\end{tabular}

Asche in

đer 'Trocken- Kali Natron Kalk Mag- Lisen-Phosphor-Schwefel- Kỉesel- Chlor sulistanz nesia: oxyd säure säure säure

\begin{tabular}{llll|llllll}
5,20 & 144,30 & 10,21 & 14,82 & 5,01 & 5,48 & 11.97 & $7,(15$ & 5,04 & $18 t$
\end{tabular}

Über die Bereitung des Theegetränkes sagt der chinesische Kaiser Kien-Long in einem Gedichte: ., Setze über ein mälsiges Feuer ein Gefäl's mit drei Füísen, dessen Farbe und Form darauf deuten, dal's es schon lange in Gebrauch ist; fülle es mit klarem Wasser ron geschmolzenem Schıce; lafs dieses Wasser bis zu dem Grade erwïrmt werden, bei welchem der lisch weifs und der lirebs rot wirl; grielse dieses Wasser in eine Tasse anf feine lBlitter einer ausgowïhlten 'Theesorte; lal's es etwas stehen, his die ersten Dömple, welche eino licke Wolko bilden, sich allmählich vermintern und mur leichte Yehel anf der Oberfliiche schwohen; trinke alsdamn langsan diesen köstlichen 'Trank, und du wirst krältig gegen dic fïnl Sorgen worden, welche gewöhnlich unser Geniit bennuhigen. Man kimn die siifse liuhe, welche man einem so znboreiteten Getränke revlankt, schmecken, liihlen, jedoch nicht beschreihen." In China trinkt min den 'Thee ohne allen '/usat\%, wir' mischen aber noeh Zncker und Milch, 
selbst limm oder liotwein. Zimt und Viunlle, dic las A loma rerdecken, linzu.

l)er Thee wirkt aul den menschlichen Oronismus gelinde zusamnenrielıcnd, ïbt auf die Schlaffhoit der Schleimhänte einen seln heilsamen Einfluls, erleichtert das $\Lambda$ tmon nud den Schweils, kiihlt dadurch den lï̈rper ab, bringt oin Gefïhl allgemeiner Behaglichkeit, Munterkeit und Heitcrkeit des Geistes lervor und unterdriickt die Berauschung und die Schläfrigkeit. Vor der Malılzeit 'Thee \%u trinken ist schïdlich. Aussprïche der Chineson lauten: "Der 'T'luee entfernt das lett und liilst den Menschen nicht schlaten; er spült Unreinlichkeiten fort, vertreibt Schläfrigkeit, leilt Kopfweh und verlüitet "s." .T ean Paul aber sagt: .Der 'Thee macht ceremonielle Chinesen." Del' 'Thce befordert die Umwandlung der Nahrungsmittel im Körper, aber' nicht deren Verdauung, und kann daher leicht Störung dre Vcrolaumng und Verstopfung herbeifuhren. Schwächlichen Personen ist der Gemuls Schwarzen 'Thees anzuraten, da er die aufregenden Wirkungen des Griinen 'Thees in geringercm Malse besityt.

Warenkunde. Das frisch gepflickite Blatt besitzt weder ein Aroma, noch gicbt es ein genielsbares Getriink ab; den Wohlgeschmack verdankt der 'Thee erst seiner Zubereitung für den Handel. In riesen gelangt er ans China in drei Iliuptsorten: als Schwarzer, Griuner und \%iegelthee.

Wenn Schwarzer Thee bereitet werden soll, laifst man die biatter einen ganzen Targ auf Bambushïrden trocknen und driickt und schliigt sie tuichtig. IJann werden sie, um eine Gïrung zu vermeiden, durch Luftzug abgekiuhlt, his sich cin schwacher Geruch entwickelt. $\mathrm{Lm}$ den Vorgang zu verstärken, werden sie zwischen den Händen gerieben und goschlagen. So vorbercitet werden die Blätter in Hachen, eisernen Mulden ïber IIolzhohlenfener geröstet, dabei in kreisförmigen Bewegungen mit den nackten Hiinden groult, auf Hiirden ausgebreitet und in einem kïhlen Raume gefïchelt. Wenn die ganze Tagesernte gerollt ist, erfolgt ein zweites und, unter Unständen, cin drittes oder gar viertes Rösten iiher schwächerem Feuer, was dann ausgefïlnt wird, wenn sich bcin Rollen zeigt, dals noch Saft aus den Blättern tritt. Zuletzt wird noch eine Abtrucknung der gerösteten Blätter in offenen sicben über hellem Tiohlenfener rorgenommen, wobei die Siebe öfters geschüttelt werden. - Nur den besseren sorten wird eine derartige sorglailige lieluandlung zn teil. Für den Vorbrinch in Inlaude werden die groringwertigen biater einfach an der Sonne getrorknet und mit gefurchten Steincm gerollt. Der so gewonnene Thee lat ein angenelnnes Aroma, eime rötliche Farbe und einen siilshichen Geschmack, häilt sich aber nicht lange.

Um Grünen Thee zu breiten, werden die Blaitter unnittelbar nach dem Einbringen .gerlämpft.* Aamit sie ihre Farbo hehalten, und 
damn nuter Inwendung gröfserer Ilitze gerïstet. Das .. I):impfen* geschicht in dre Weive, lafs man in eine mit einem durchlöcherten Boden rrisehene Kiste Ilïrden von liambusstiilsen lrinst, anf denen die 'Theoblitter ansgehreitet liegen. Diese Kiste wird auf einen Kónsel gesetzt, atus dem Wasserliimpfe anlisteicen. Infolge dieses I a mpfballes hewahren die 'Theblätter nicht nur ihre farhe, soudernath in grewissem Grade ihre chemische Zusammon-

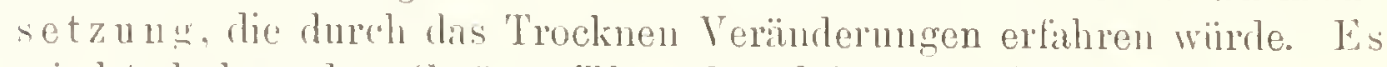
wirkt aher dor (iriine Thee krätiger a uf die Nerven als der Schwarze. Nach einer anderen Zubereitungsant werden dis Blätter in tiefen Pfumen bei starker Hitze in ihrem eigenen Safte ardämpft, mit Stöckchen rasch ungerührt, dann wie beim Schwarzen 'Thee gerollt und geröstet, nur in schnellerer Aufeinanderfolge. Schliefslich britzen sio eine olivengrüne Farbe, die beim dritten Rösten einen bläulichen Hauch erhält. Der I'rozefs des Firbens wird oft durch Zusatz ron lierliner Biau order Indigo unterstiitzt. Die ordinäre sorte wird mit wenig Sorghilt bereitet und meist sograr mit den Fülsen gerollt.

Backstein - oder Ziegeithee wird aus den jiingsten Zweigen, aus Abfällen von verdorbenen Blätern und Stielen zu lïnglichen Tafehn zusammengeprelst und dann in Öfen oder an iler luft getrocknet. Er wird in ('hina fast gar nicht verbraucht, steht dagegen bei den mongolischen und nomadischen Völkern Nordasiens in hohen Anschen. Die Tafoln gelten dort als Handelsminze. Der Kaiser ron China giebt diese 'Theeziegel seinen mongolischen Truppen als Sold. In der Mongulei und Tatarei pulverisicrt man diesen Thee, kocht iln mit Wasser, Salz und Fett, mischt den Absul noch nit Milch, Fett und gerïstetem Mehl und geniefst ilhn tïglich als (ietränk und als Speise.

Diese Hauptarten zerfallen in zahlieiche Sorten. Die chinesischen un indischen Theekuster wollen iiber 100 verschiodene Sorten unterscheiden, anch sugar bestimmen kïnnen, in welchrer Art ron Getailis das Cretrïnk bereitet wurde.

Der Grüne Thee Chinas') (Lo-tscha der Chinesen) wirt nach den Erzengungsgebieten in Moyne, Tienke, Fychow. Taiping und l'ingsney geschichlen. I lie Reihenlolge entspricht der Wertschiitzung. Sie werden wirder in folgonde Sorten getrenut: Gunpowler's, Imprials, Young IIysons, IIysons und Tonkays (T'wankilyse.

1. Gunpowder- (('hoo-tschia I'erthee), d. i. Schicfispluerthee: runde, zarte. grangrïne, zu sohr kleinen körnchen gerollte Bliittchen. Vanking Moyum (impowder, ans lablh gesprengten liattlinospen lw-

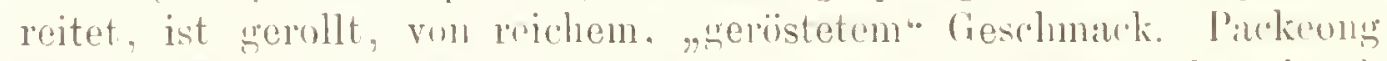

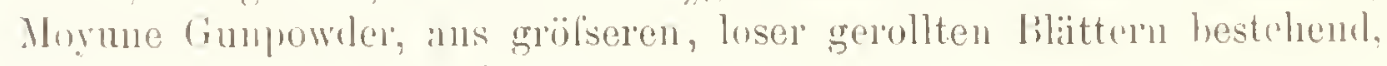
nichlit gintr so aromatisch.

1) Nitch Siomler, 'Tropiselie Agrikutur I. 
2. Imperial (Big (imporider = grofses Schiefspulvor), vom Linropäern und Norkamerikiner"n so gomannt, neil diese Sorte rom kaiserlichen Hofhalt. den Nandarinen und len reichen Chinesen rerlorancht wird. Der echte Kaiserthee wird anch ats "Hiitrnthre" bezeichnet;

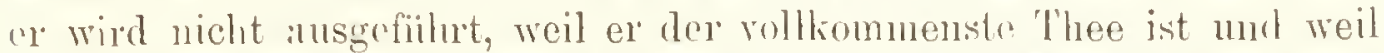
die Seereise mud das nordische Kinna seine feinen rigensehaften hald zerstïren wiirlen. Der Imperial ist etwas grölser als dir vorige Sorte, er wird aus grölseren und aus Knospenblättern bereitet. lie erste Ernte liefert einen Thee, der dem Gunpowder in nichts nachsteht. Der Aufguls ist helggelb, hesitzt viel Körper und ist schr aromatisch.

3. Fonlog Hyson nur in der Form ron 1. und 2. verschieden. aus entfalteten, kleiuen, schmalen, zarten, gekräuselten Blïtten bestehend.

4. Hyson (Haysan) hat grolse, lose gerollte, rauhe Blätter, die ältesten der jedesmaligen Einte.

5. Tonkar, auch Hyson Skin grenannt, ist "Ausschulsthee", der aus den Abfällen und Überbleilsseln der iibrigen Sorten bestelit.

Der Schwarze Thee Chinas wird in die beiden Gruppen Oolong und Bohea geschierlen. Das chinesische "Oolong" bedentet "Grüner Drache“; der Thee ist mit vielen gelblichgrinen Blättern durchsetzt.

I. Die Oolongs werden in vier Sorten geschieden, von denen jede, infolge des Einflusses von Boden und Klima, einen eigentuimlichen Gesclimack besitzt. Diese vier Sorten sind der Wertschützung nach: Foo-chow, Formosa, Amoy und Ankoi.

1. Foo-chow Oolong besteht aus langen, dunkeln, gut gekrïiselten, seidenartigen Blättern, die knisterig, aher nicht spröde sind. Aufguls ist ron reicher, goldgelher Farbe und starkem Aroma. Der Geschmack ist voll und milde.

2. Formosa Oolong, aus gelblichschwarzen, gleichmïifsig gekiäuselten, aber weniger gut gerollten, sehr aromatischen Blättern bestehend. Lr hat infolge seines stïrkeren Eisengchaltes einen eigentiimlichen Ges(hmack.

3. A moy Oolong kommt als Ningyong (dunkle, grolse, sorgsam grerollte Pliatter von reichem, vollem, mulsühnlichen Geschmack), Kokew (sehr dunkel, gut bearbeitet, ron (ieschmack geringer) und Hohea (leicht, von ausdruckslosem Geschmack) in Handel.

4. Ankoi Oolong kommt von den Bibittern eines wilden Strauches ans dom Gebirge Ankoi. Mit diesen Blïttern werden hesouders Anoy und Foo-chow verliblsr.ht.

II. Ine Boheas sind the rigentlichen schwaren Theesorten Chinas. Ihr Aulguls ist von dunkler Furbe, aber nicht so kriaftig wie der der Ootongss. Sie werken in folgende fünf Sorten geschieden: Capers, l'ekoes, Souchongs, l'ouchongs und Congons, die wieder in Untersorten zerfillen. 
1. Capris (He-Choo-tscha = schwarzer Perlenthec) besteht aus Bhätern, die rund und fest in Form von Perlen gerollt sind, wie die des Gmpowder. Seine Farhe ist rötlichschwar, glänzend. Der Aufwnls ist dunkelrötlich, aromatisch und vou einem eigentiimlichen, reichen Geschmack. Untersorten Foo-chow und Kinton.

2. Pekoes (eigentlich Pak-ho = weilse Daunen) besteht ans zarten IBlattern, die besonders gegen die Spitze hin mit weifsen, seidenartigem Filz bedeckt sind. Aufguls hell, roldgelb. Untersorten Fon-chow (aromatisch) und Kanton. Jan unterscheidet noch Orange l'ekne und Flowery Pekoe, die heide parfümiert sind.

3. Sonchongs reigentlich Saow-Cheong $=$ kleine oder seltene Sorte) wird von der Spielart Bohea, und zwar bei der zweiten Ernte, die nur kleine und wenig Blätter griebt, gepfliickt. Untersorten Lapsingु (nit langen, spitzen, gut gerollten Bliittern von rötlichschwarzer Farle; - der Aufrufs ist von reicher Weinfarbe und eigentïmlichem. teerartigem Geschmack) und I'adre (nit gröfseren, nur gefalteten Blättern; (ler Aufgufs ist klar, goldgelb. aromatisch).

4. l'ouchong (eigentlich I'aeow-chong = gefaltete Sorte). Die trockenen Bliitter sind spitz, rauh. platt, von dumpfem. eigentiumlichem Geruch, weil stark parfümiert.

5. Congous (Kamphu, Coong-foo $=$ miiherolle Sorte) zerfïllt in die beiden Gruppen Blackleaf (Schwarzhlatt) und Redleaf (Rotblatt).

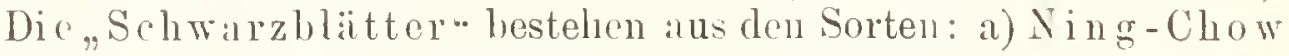
Congou, eine der feinsten jener llandelssorten, die als "Moningdistrict teas" bezeichnet werden, mit kleinen, fein gekräuselten, graulichschwarzen Iilïtern, an deren Spitzen sich oft der schon hei den Pekoes erwihhnte weifse Filz befindet; der Anfgufs ist dunkelrot, aromatisch; - b) Oanfa Congon mit spitzen, rauheren, nicht gnt gerollten IBlïttern, deren Aufgnifs teerig sclmeckt; - c) Oopack Congou mit Horschwarzen, gut gerollten Bliittern, die bak verderben und deren Aufgul's ein fliichtiges Aromia besitzt; - d) Kintuck Congou mit unregehmïsig gebrochenen und leiclit zerbröckelnden bliittern; e) Kiu-Kiang Congon mit tiefschwarzen, sehr reinen und gleichförmig gerollten Bilittern; der Aufgufs ron dunkler Weinfarbe nund schalem Gesehmiack.

Die "Rotblïtter" werden in folgende Sorten eingeteilt: a) Kaisow Congon mit kleinen, fein gekräuselten und rötlich angehauchten Bliittern, deren Aufonl's ..mild und teerig oder nach gutem Mokkakaffee schueckt; - b) Sur-Kut Congon ist etwas schwïcher und oft von "verlnanntem* Geschmack; - c) Sin-Chnn e Cungou, geringe, Sorte mit rauhen und stambigen likiftern; - d) Saryune Congon an riofliclsten von der liothlattgrnppe; bilitter lose gerollt; Aufguls dnnkehrot, sehr aromatisch, von prickindem, mildem, aluer verbuantem (ieschmack; - e) Ching-Wo Congu mit stark gerollten, schwammigen Biättern; der rote Aulguls ist von rundem. rollem 
Cieschmalk: - f) l'aklin Conģon von geringem Werte; - g) Pekne

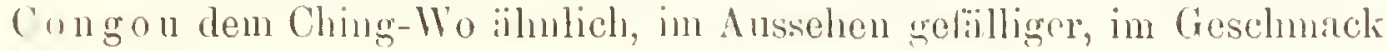
geringer.

Der Japanische Thee wird nur in grinen Sorten el\%engt. Jie foinsten Sorten Uji, Kioto und Ogura stammen ans der l'rovinz Yamaschiro. Die in den benachuarten Landschaften Oni nnd 'T'amba gnchinten 'Theesorten sind geringwertiger', lommen aber in groifseren Mengen auf den Markt. Der japanische Thee hat einen angenelumen, reichen und eigentümlichen Geschmack, einen hellarbigen, aromatischen Aufguls und wirkt kräftig auf das Nervensystem; er lïilt sich 11u cin Jahr in glcicher Güte und nimmt dann einen frischen und mehligen Geschmack an. Sorten: Pan-fired (in der Panne greröstet), liasket-fired (im Bambuskorbe geröstet), Sun-dried (in der Sonne getrockinet), Oolongs, Congons, - auch Pekoes, Gumpowders und Imperials.

Der Indische Thee crmangelt, vielleicht weil seine /ubereitung nur durch Maschinen erfolgt, noch der Milde nnd /artheit der besseren chinesischen Sorten. Er enthït mehr 'Theï nnd ätherische Öle als ler Chinesische Thee, ist so nervenerregend, dals er', selbst als schwarzer' 'Thee, nur in Vermischung mit dem milden Chinesischen oder. Japanischen 'Thee dem Goschmack der Europäer und Nordanerikaner zusagt; fïr diese wird nur Schwarzer The aus Indien gebracht, Grüner für die mittelasiatischen Länder. Man verpackt in Indien den Thee in schwere Kisten aus Teaklol\%. Er wird nach den Erzengungsgebicten in folgende Sorten eingeteilt: Assam, Darje elingr, Cachar, Kangra, Dehra-Doon und Chittagrongr. Untersorten: Flowery Pekoc, Oriunge Pekoe, Pekoe, Pekoe-Souchongr, Souchong, Congou und Broken-Leaf.

Der Ceylonische Thee steht dem Indischen sehr wahe.

Der Javanische Thee besteht an tiefschwrzen Biattern, deren Aufguls ron starkem, fast zu prickehndem Geschnack ist. Er dient vorzugsweise zu Vermischungren. Die Sorten zeigen wenig Unterschied, weil auf der Insel dic Erutearheiten fist ununterbrochen stattfinden. Aus den kicinsten libittern wird l'ekoe, ans d(su mittleren Souchong und aus den grösten Congon bereitet.

Dic Vermischung der Theesorten durch Sirchkenner soll eine Vervollkunmnung der einzelnen Sorten, cine Erginzung iluer Eigenschaften ermöglichen. Es kamn dadmeh jede persönliche Goschmackslieblaberei hefiedigt werden bei gleichzeitiger Verbilligmug infolge des \%usatzes leichter Surten.

Prüfung des Thees. Bei gutem 'Thee sollen die lilitter dicht gerollt sein, er darf nur wenig, besser gar lieme stiele enthalten, zerbrochene Blaitter können, wem sie von grnter (qualitit sind, olne Naclteil verwondet werden, mindern aber den Wert der' Ware. Der 'Thee soll sich in dor Hand glatt mul zilrt anfühlen, einem leichten Inruck 
nachgeben, aber nischt zerhrechen. Wenn die libïter sich bei leichtem hinurn anflösen, sind sie gut. Wurden sie sehr jung geptliiclit und sorgfiiltig behandelt, dann bilden sie in Mnnde rasch cinen zarten, feinen lirei, aus dem viel schmackhafter Saft tritt. Aus dem Munde genommen, zeigen sic cine teigige lieschaffenlıeit und cime natiirliche Farbe. Iracht man einen Aufgufs, so sinken die liätter der feinen Sorten sofort auf den Boden. Ein Aufgufs von starken Aroma, goldgelber Farbe. vielem „Körper" und prickelndem Geschmack deutet auf eine feine Quilitiit.

Fälschungen werden nach Flückigrer in erster Lini vorgenommen durch Fürben der griinen Theesorten mittels Bestïulens durch eine Vischung von Berliner Blau oder Indigo, Kurkima und Gips, wodurch die Farbe in dic gesuchte blïnlichgrüne oder graulichgrüns ïhergefiihtht wird. Fïlschungen durch Chromgelb und Graphit, welche man schon öfters bei Theesorten rersucht hat, die durch Seewasser gclitten haben, werden sofort erkannt und sind deshalb für las grofse Publikum von keiner Bedentung. Eine Hauptfïlschung besteht darin, dafs hereits gebrauchte 'Theeblätter' wieder getrocknet, gerollt und in die frühere Form zurïckgebracht werden. Ein solcher Thee hat durch den Verlust seiner wichtigsten Bestandteile, namentlich des aromatischen Öles und des Theïns, seine Haupteigenschaften verloren; eine Prïfung auf 'Theïngehalt wird diesc Fälschung nachweisen. Eine Fïrbung dieser schon gebrauchten Theebliitter, namentlich des schwarzen Thees, durch Katechu- und Kampecheholzextrakt giebt sich schon dnrch die eigentiimliche Farbe des Aufyusses zu erkennen. Katechu macht den Aufgufs beim Erkalten triibe; da jedoch einige gute Thecsorten ähnliches Verhalten zeigen, mus diese Fülschung auf chemischem Wege (durch Behandlung des Anforusses mit Bleizucker und Silbernitratlösung entsteht ein gelbbrauner, Hockiger Nicderschlag) aufged cokt werden. Kampecheholzextrakt macht den Aufoufs schwar\%braun; cinige Tropfen Schwefelsäure wandeln diese Fïrbung in hellgriü, chromsaures kiali tiefschwar\%.

Fine weitere Hauptfiilschumg bestelit in der Untermengung anderer gerbstoffhaltiger IBlitter: von Alorm, Eiche, Ehrenpreis, Erdbeere, Esche, Heidelbeere, Kirsche, Pappel, Platane, Rose. Schwarzdorn, Weide, Weifsdorn, Wridenröschen. Letztere Ibiitter dienen namentlich in Rufsland zu Fïlschungen. Die meisten dieser Blïter lassen sich, in lanw:mrnem Wisser anfgeweicht, schon durch ilne Form und Zcichnung erkennen, da das 'Theeblatt allein cinen in den Blattrand sich allmählich verschmïleruden Biattstiel, einen derben, nach unten etwas umgebogenen, gezälunten IBattrand und eine Nerratur besitzt, derart, hafs die rom Hanptuerv im spitzen Winkel sich alyweigenden Seitennerven in Findrittelentienumg rom liande sich einholen, in flachem bugen zusammenlatufen und eine mit dem Rande fist parallellanfende linie bildent.

lintlich werden noch \%u Fïlschmngen the mittels rines Binde- 
mittels theeartig geformten, in warmem Wisser jedoch zorfillemten Abfiille 1 . s. w. verwendet.

Die Znbereitung, wie malu sie fïir den Ausfuhrthee vornimmt, wird in der Regel von den Hïndlern, nicht von den Theepflanzern besorgt.

Die friihere liehauptung, dal's die für die Ausfuhr bestimmten Theesorten durch beriihrung mit wohlricehenden Blïten (Orangen,

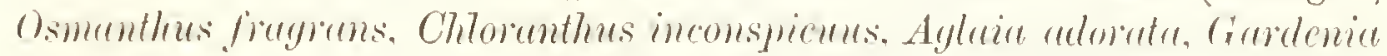
florida u. a.) rerbessert werden, wird in Abrede gestellt.

Ersatzmittel. Es giebt eine ungeheure Menge Pflanzenarten, die zur 'Theebereitung benutzt werden. Die besten Ersatzmittel für' 'Thee sind die Bliitter vom Kaffeebaume und der Paraguaythee (Ilex purngungensis). In Deutschland wird oft ein Thee aus den Blittern der Schlehe nnd der Erdbeere bereitet. Geringwertige Ersatzmittel sind der Faham- und der böhmische Thee. Die Blätter des Fahımthees stammen von einer besonders auf Mauritius einheimischen Orchidee (Anyruccum firumens Thomurs) und besitzen einen vanille:iilnlichen Geruch. Der böhmische Thee wird aus den breitlanzettlichen Blïttern des Arzneilichen Steinsamens (Lithospermum officinale L.) gewonnen und teils als chinesischer Thee, teils als VerfülschungsmitteI ins Ausland rerkauft.

Angaben über Ernten, Handel und Verbrauch. Die Theeausfulır aus China, das bis zu Beginn der 70er Jahre tïr den Weltmarkt fast allein in Betracht kam, nach Europa wird im Durchschnitt der Jahre 1884 bis 1888 auf 128 Mill. Kilogramm im Werte von 173 Mill. Mark geschätzt; im Jahre $18 s 8$ betrug sie 132 Mill. Kilogramm im Werte von nur 155,3 Mill. Mark. Aufserdem gehen noch 'Theeausfuhren iiber Tientsin und Kiachta nach Sibirien. dann von Hankau und dessen Umgebung den Han- und Tan-cheng-Flufs hinauf und weiter auf dem Landwege in die Nongolei. Das giebt eine Gesamtausfuht von 'Thee aus China von 138 bis 140 Mill. Kilogramm im Werte von 180 Mill. Mark. Mehr als die doppelte Nenge sollen die Chinesen selbst verbrauchen. Danach würde die Gesantgewinnung 370 bis 380 Mill. Kilogramm betragen. Obgleich die chinesische Theeausfuhr in liezug aul die Menge gestiegen ist, bringt sie doch dem Lande weniger ein, da die I'reise wesentlich billiger sind. So betrug die Theeausfuhr für 1891 nur 109 Mill. Kilogramm im Werte von 157,6 Mill. Mark.

Uher die Schwankungen in TheehandeI geben folgende Zahlen beredten Aufschlufs. Es fuilıten aus:

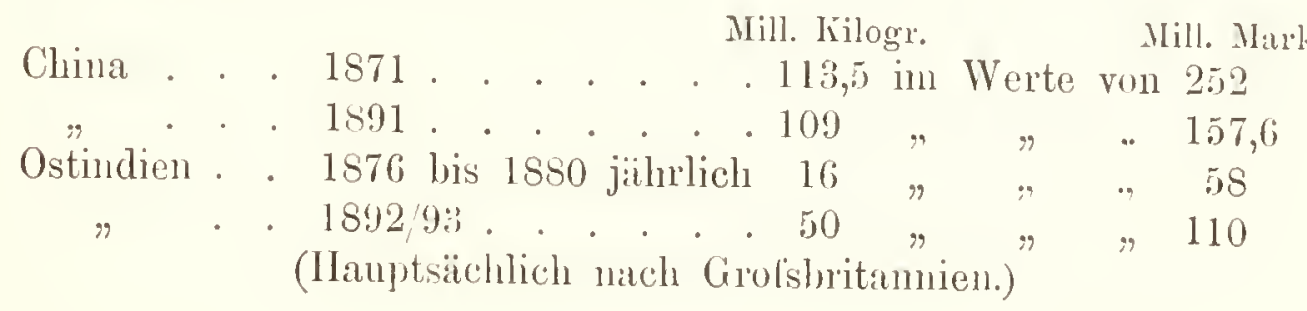


Mill. Kilogr.

Mill. Mark

Japill . . 1871 his 1875 jährlich 9,4 im Werte von -

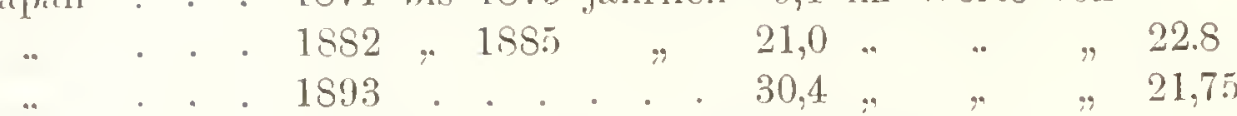

(Fast nur nach Nordamerika.)

Ceylon . . 1850 bis 1852 jülurlich 182500 Kilogr.

• . 189235.23 Mill. Kilogr.

Java u. Madura 18922 Mill. Kilogr.

Fidschiinseln . 189719480 Kilogr.

Deutschland führte $18972552000 \mathrm{~kg}$ im Werte von 4,1 Mill. Mark eiu, davon aus China $1645000 \mathrm{~kg}$, ans Niederländisch Indien $256000 \mathrm{~kg}$.

Der Verbrauch betrug im Durchschnitt der Jahre 1S5\% bis 1859:

In den austral. Kolonieen . . pro Kopf der Bevölkerung $3,35 \mathrm{~kg}$

.. Grof'shritannien und Irland . . . . . . . $\quad . \quad$. $\quad$. 2.24 ,

. Kinada . . . . . . . . . . . . . . . . . . .

. den Ver. Staten von Amerika . " $\quad$ " $\quad$ " . $\quad$. $\quad 0,63$..

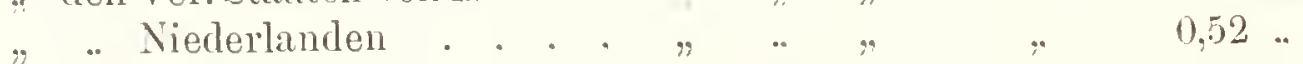

Im europäischen Rufsland . . . . . . . . .

In Dänemark . . . . . . . . . . . . . . . . . . . . . . .

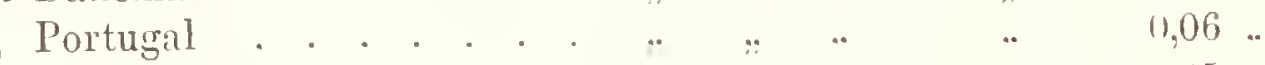

, der Schweiz . . . . . . . . . . . . .

$\begin{array}{llllllll}\text { Im Deutschen Rieiche (1897) . . . . . . } & . & & . & 0,05 & \text {.. }\end{array}$

In Nolwegen . . . . . . . . . . . . . . . .

.. Schweden . . . . . . . . . . .

. Österreich-Ungarn . . . . . .

"Frankreich . . . . . . . . . . . .

"Belgien . . . . . . . . . . . .

Geschichte des Thees. "Der Pent-sao"l) erwähnt den Theestrauch 2700 .Jahre v. Chr., die "liya" 500 bis 600) .Jahre r. Chr., und in 4. Jahrliundert unser'r Zeitrechnung hat der Ausleger des letzteren Werkes Einzelheiten iber die Pflanze und den Gebrauch ilner Blätter als Aulguls geguben. Thretrinken ist somit ein in China sehr alter Brauch. Schon im 4. Jahrhundert n. Chr. soll ein chinesischer Minister' 'Thee getrunken haben, aber erst in 6. Tihhoumlert, als ein loibarzt les liaisers seinem Ilerin den Kopfschmer\% mit 'Thee vertrieb, verschafle sich das Getränk allgemeinen Fingang und wurde Nationalgetrïnk. Jetzt trinkt mim in China den 'l'hee. um den Durst zu löschen, da das Wasser dort vielfach schlecht ist. Das Ansehen, dess'n sich der' 'Thee erfieut, geht daraus hervor, dals der

1) Dr. Hretscluneider, On the sturly atud value of Chinese botanical works, S. 1:3 und 45. 
chinesische liaiser Kien-Long anf einer onglpartie oinen lobgesang anf den 'Thee dichtete. Von diesen Gedichte wurde eine Prachitusgabe veranslaltet und anl zu kaiserlichen Geschenken verwendete lorzellantassen yeschrieben. In der historischen Skizze "Kiang-Moo" wird gesagt, der Kaiser Te-T'sing habe im 14. Jahre seincr liegicrung, d. i. 75: n. Chr., enien \%oll auf 'lhee golert. Ein arabischer Reiscnder, Ibuzeid-el-Ilazen, berichtet gegen Fude des 9. Ialuhunderts, dafs die Stener auf 'Thee eine der hauptsichlichsten Finnahmeruellen des Kaisers ron China sei. Eine japanische Isergende ${ }^{1}$ ) berichtet, ein im Tahre 519 muserer Zeitrechnung von Indien nach China sekommener Priester, welcher rom Schlafe überwiltigt wnrle, als er waclien und beten wollte, hätte sich, in einem Augenblick des Unwillens, beide Angenlider abgeschnitten mul anf den Borlen geworfen. Diese hätten sich in einen Strauch verwandelt, dessen Bläitter die besondere Eigenschaft hesitzen, den Schlaf zu verschenchen. Die Chinesen wissen von diescr Isegende nichts. In Enropa lernten die Russen und die Hollinder den Strauch zuerst kennen. Im .Tahre 1610 tanschte die holländisch-ostindische Handelsgesellschaft 'Thcepäckchen gegen Salbciblätter' (früher Arzneiptlanze); 1638 erhielt eine russische Gesandtschaft in der Mongolei als Gegengeschenk anf \%obelfelle einige Pfmnd Thee und fand damit Beifall in Moskan. Bald wurde der Thee von den europäischen $\ddot{A}$ zten als ein Mittel gegen allerlei Leiden angepriesen, aber anch als schädlich angegriffen. Etwa 1660 wurde Thee in Londoner 'Trinkhänsern ausgeschenkt, bald darauf auch in Paris. Bei dem bekanuten 'Theesturm (26. Februar 1773) warfen kiihne Bostoner Bürger eine Ladnng von 18000 I'find 'Thee ins Meer. In Enropa wurde die erste 'Theepthanze 1655 von Jonquet in Paris gepflanzt. 1812 begann die 'Theekultur in Brasilien, jedoch olme rechten Erfolg; 1825 in Jara, 1848 in Siidkarolina und 'Tenmessee. Es wird erzällylt, dals man inn Jahre 1526, als die den Burmesen abgenommene Provinz Assam dem britisch-indischen Gebiete einverleibt wurde, in den Urwïldern grigantische Theebänme rorgefunden habe. Dieser Umstand hat neben don geschichtlichen Forschmngen über eine angebliche trïhere, aber lïngst erloschene 'Theeknltur' in Indicn es der' indischen Regierungr nahegelegt, den Aubau des Thees fiir Indien ins Auge zu fassen. In den Jahren 1S:50 bis 1838 liels die Regiernng die ersten Versuche anstelien"), nnd schon $18: 39$ wnde die noch jetzt bestehende "Assam'Tea-Company", die gröfste aller den Theebau pflegenden Aktiengesellschatten, gegröndet. Aber die crsten Erfolge wurden erst im Jahre 1851 er\%ielt; ihnen folgte sulort ein wilkes Speknlationstieher. das 1865 seinen IIöhepunkt erreichte. Man kultivierte zuniichst lie cimheimische l'llanze, nud später, als sich dieses an den warmon šchut\% les I'rwaldes grewöhnte Gewächs als zu zart fiir offene Giirten erwies, aus

1) Kämpfer, Amoen. Japon.- ") 11 ugo \%̈̈ller, lieisebricle. 
chinesischem Simen gezogene l'flanzen. Schliefslich entsprang diesen heiden Arten ron 'T'hee eine Mischlings-orler Kreuzungspflanze, die jetzt fast ansschliefslich gebaut wird. Die ersten Pflanzungen wurden in Assam angelegt, das noch 188 s zwei Drittel des in Indien erzeugten 'Thees lieferte. Spaiter dehnte sich der Theebau auf die siidlichen Abhänge des Himalayagebirges, insbesondere auf den Bezirk Dardschiling, wo jetzt nächst Assam der meiste Thee wächst, dann auch auf den ..Nilghiris" geuanuten Höhenzug in suidlichen Indien, sowie schliefslich auch auf Ceylon aus, nachdem durch die Laubkrankheit die dortige Kaffeekultur sich dem Untergange nïherte. 


\title{
Tafel 5.
}

\author{
Kakaobaum \\ (Theobroma Cacar Linné).
}

Der Kakaobaum gehört zur Unterklasse der freiblätterigen Dikotylen, zur Ricihe der Malvenpflanzen (Mctlorles), zur Familie (ler sterkulien (sterminuene).

Die Familie der Sterkulien (Sterculincenc). l'äume, Sträucher oder Kräuter. Blätter albwechselnd, ganz und einfach, seltener hand- oder fiederförmig-gelappt und hand- oder fiedernervig. Nebenblïtter frei, abfallend. Bliiten regelmiilsig, zwitterig. Kelch unterstïndig, in der Koospenanlage klappig, verwachsenbliitterig, meist fünflappig. Blumenblïtter fünf, in der Kinospenanlage rechts oder links gedrelıt, zuweilen nur klein oder fehlend. Staubblätter in zwei Kreisen; die den Kelchblättern gegenüberstehenden unfruchtbar, als Staminodien entwickelt orler fchlend; die den Kronblättern gegeniiberstehenden of't rervielfacht; alle mehr oder weniger in eine Röhre verwachsen. Staul)beutel zweifächerig. Fruchtknoten oberstiindig, ans vier odcr fünf Fruchtblättern bestehend und ehenso viele Fïcher bildend, deren Scheidewände an eine Mittelsäule sich ansetzen. Diese trägt in jedem Fache zwei, oder zahlreiche in zwei Reihen stehende Samenanlagen. Griffel einfach, mit ebenso vielen Narbenstrahlen, wie der Fruchtknoten Fïcher hat. Frucht verschieden. Samen mit Heischigem Nïhrgewebe und geradem oder gebogenem Keimling.

Etwa 650 tropische Arten in 48 Gattungen.

Dic Unterfamilic der Büttneriacecu ist ausgezeichnet durch die Kïrze der Staubfadenröhre und kappenförmig ausgehölılte Blımenkironblïtter.

Die Gattung Kakaobaum (Tholmomm L.). Hiimme mit ungeteilten, grolsen Blättern. Frucht beerenartig, fleischig, mit in einem Mus nistenden, eilänglichen Samen.

Hierler 10 bis 12 Arten im tropischen Ameriki.

Echter Kakaobaum (Theolirmm ('ncu") L.s). Batum, der 4 his 8 , selten $12 \mathrm{~m}$ hoch und his $24 \mathrm{~cm}$ im Durchmesser dicki 
wird. Krone insgebreitet, Äste alstehend. Rinde lick und brïunlich, Holz leicht, weils. Immergriin.

Blätter abwechselnd, gestielt, ron ungleicher Grïlse und Form, gimzrandig oler leicht gebuchtet, (i bis $30 \mathrm{~cm}$ lang und 2,5 his $10 \mathrm{~cm}$ breit, linglich eiförnig, zugespitat, gegen den Iilattstiel stmmpf his oval-her\%fömigr, mit starken Nittel- und Scitemrippen, dünn lederartigr, beiderseits kahl. slïnzend, die jungen hlafsrot; Blattstiel rund mit kleinen, hinfïlligen Nebenblättern.

Blüten fast das ganze Jalır büschelweise an den IIauptzweigen, den İsten und am Stamm. Kelch fiinfteilig, rosenrot, mit alsstehenden, lïnglich lanzettlichen, behaarten Zipfeln. Blumenblätter fünf, unterstïndig; am Grunde aufrecht. eine kahnförmigr ausgehöhlte Kappe bildent, oben mit einem erst schmalen, dann spatelförmigen, abstehend gekrümmten, gezïhnelten und geaderten Fortsitz; citronengeell, und rötlich geadert. Staubblätter zeln, am Grunde in eine glockige liöhre verwachsen, rosenrot; fïnf davon aufrecht, linienpfriemförmig und unfruchtbar, die fruchtbaren anderen fünf bergen rüickwärts ihre Staubbeutel in die kahnförmig auscrehöllten Kappen der Blumenblätter; jeder Staubbentel besteht aus vier gesonderten, in sich wieder zweifïcherigen Teilen; infolge hiervon hiilt man jedes scheinbar einfache Stimbblatt als ein durch Verwachsung zweier Staubblätter entstandenes Gebilde. Fruchtknoten oval, fünflkintigfünffuicherig, in jedem Fache an jedem der beiden Ränder des Samentrïgers eine Reihe Samenanlagen. Griffel fadenförmin mit füntspaltiger Narbe.

Frucht gurkenförmig, 10 bis $16 \mathrm{~cm}$ lang. 50 bis $76 \mathrm{~mm}$ im Durchmesser, mit zehn stmmpfen, nuebenen Lïngsrippen, goll bis rötlich, getrocknet braun. Fruchtgehäuse fünffiicherig, fleischig, mit siifslichem, schleimigem, weifslichem Yus. Samen zahlreich. 30 bis 70 , in fünf Längsreihen, durch das Mus und dio bei dor Reife zersprengten Scheidewände des Fruchtgehïuses zu einer Sïnle vereinigt; "t his $13 \mathrm{~mm}$ langr, 4 bis $7 \mathrm{~mm}$ breit, mit zerknitterten Samenlippen. ohne Nährgewebe, mandelartig, weilslich, nach dem Trocknen braun.

Der Kakinobaum bliiht während des ganzen .Jahres, auch die liliitter erneuern sich stets. Man rechnet anf 3000 libiiten erst eine limelit.

Vaterland mol Verbreitung. Die Kiistenlänler und Inseln des Mexikanischen Merhusens, sowio das Stromgebiet des Cauca, dos Magdilenenstromes, les Orinckin und Amazonas diinften wohl als die Ileimat des kakaobaumes betrachtet worden. Als äulserste Nordgrenze seines Vorkommens erscheinen die heilsesten 'Thiilur des Mississippi und des Altamaha in Lonisiana mod Georgia. Die südlichston gröfseren líakapHlanzungen lusitzt unter dem 13. Gral siidl. lireite dic P'rovinz Bahia, weiterhin gegen den 20. Grat zeigt sich der Haum mu morh in (Bïrten. Als vorziigliclsste Kulturorte gelten die mexikanichen Stataten Colima mol Oaxaca, ganz Centralamerika. Wre 
Kiistenstrich vou Ecuador, Nonlperu mul liolivia. Gut gedeilut er auch aut' Java, Manila, bourbon und den lianarischen luselu.

Kultur. Der Kakiolaum gedeiht am hesten in reschiitrten, leicht zu bewässernden, feuchten 'Thälern und Flulisnedernngen, in lockerem, fruchtbarom, tiefgründigem Borlen miter schattenspendenden b:immen. Uber $350 \mathrm{~m}$ Höhe geht el un dann hinans, wenn er bei genügrender Luftfeuchtigkeit vor Winden geschützt ist. Die Kultur les bammes ist sehr schwierig, da el eine gleichmälsige 'l'enperatur ron 24 bis $2 S^{\circ}$ C. erfordert, sehr loicht hefigen Winden erliegr (auf Hayti, Jamaika und Martinique wroden wiederholt fast säntliche l'Hanzungen durch heftige Orkane zerstört) und fast keine Ernte griebt, wenn in die Haupthliitezeit Platzregen fallen. Der Anbau des Baumes stimmt in wesentlichen mit dem des Kaffeebammes ïberein. Man vermehrt ihn durch Samen und setzt zwischen die jungen Bäumchen, deren etwa 1200 auf ein Hektar gehen, reichlich Schatten gewährende Bananen, namentlich aber Korallenbäume (Erythrina corcllodendron), die deshalb den Namen Madre del Cacu (Kakaomutter) führen. Wenn die jungen Bäume etwa $90 \mathrm{~cm}$ hoch sind, spitzt man sie cin und lïl'st nur die ober'sten drei Triebe, welche die krone bilden sollen, stelien. Im guinstigen Falle mit dem 3., gewöhnlich mit dem 6. und 7 . bis zum 30. und 40. (am meisten im 12.) Jahre traigt der Baum Früichte. Das Unkiaut muls fleifsig entfernt werden. Ton den zahlreichen Schädlingen sind die Termiten die lästigsten. Man kann sie an besten rertreiben, wenn man die Pthanzung zeitweise mit Wasser iiberthuten lälst. Die Früchte entwickeln sich in fünf bis acht Monateu. Durchschnittlich liefert ein Baum jährlich 50 Friichte mit 1 bis 2 kg Samen. Die Abcrntung tindet numberbrochen statt, die Pflanzer bringen aber nur zweimal in Jahre ihre Ernten auf den Markt, im Januar und Juli. Wie solgfältig ahgeschnittenen Früchte werden durch einen heftigen Schlag mit einem schweren Prügel greöffnet, des Fruchtbreies und der Samen. die in Gefäl'sen gesammelt werden, beraubt. Andere Arbeiter scheiden die Samen ron dem Fruchtbrei auf einem Siebe oder durch Reiben mit den Händen, reinigen sie und trocknen sie anf Sand und werfen sie nachts anf einen Hanten, den sie mit bananenblaittern berlecken, wolurch eine die Keimkraft zerstörende Gairung bewirkt wird. In matnchen Gegenden rerrottet man sie; man gräbt sie vier bis sechs 'large in Erde, wo sie gären, und trocknet sie endlich :n der Sonne, wodnrch sie sich rotbran färben. Die Gärmng ist notwendig, denn durch sie wird der bittere Geschmack der Bohmen gemildert; gleichzeitig wird darurch das den Bohnen noch anhängende Mark entfernt, verdunstet Wasser, wird das 'l'rocknch der liohnen erleichtert, lösen sich die Schalen der Jiohnen leichter, weht die Farbe der Schalen in ein feines hothraun iilner, soll schlielshich die Keinkraft der Johnen rerstört werden; dihei geht aber anch die llälfte des Gewichtes verloren. Die geringeren liohnen werdrn grewölnnlich 
in die mutersten Schiffsriume wie das Getreide geladen und erst in emropaiischen IÏ̈fen in Sïcke verpackt; die besseren Sorten verschickt man von llans ans in Sïcken.

Gehalt der Bohnen. I) Bohnen enthalten 1. ein in Zusammensetzung und Wirkmug dem Kaffeïn und Theïn verwandtes Alkaloid, das Theobromin; 2. ein fettes (̈), die Kakaobutter; 3. Eiweil's und Stärkemelıl, welche die Nahrhaftigkeit erhöhen. Die ungerotteten Bohnen enthalten in 100 Teilen: Kakaobutter 45 bis 4!) Teile, Stïrke 14 bis 18, Stärkezucker 0,34, liohrzucker 0,26, Cellulose 5, 8 , Farbstoff 3,5 bis 5 , Proteinverbindungen $1: 3$ bis 18 , Theobromin 1,2 bis 1.5, Asche 3,5. Wasser 5,6 bis 6,3. Die Asche enthält 39.5 Proz. Phosphorsüure, 37,1 Proz. Kali, 16 l'roz. Magnesia, 2.9 Proz. Kalk, aufserdem Chlor, Schwefelsäure, Kieselsïure, Natron und Eisenoxyd. Dabei sind die Schalen der Bohnen reicher an phosphorsaurem Kali als die Samenlappen; sie wïrden mithin ein gutes Nïhrmittel bilden, wenn sie in irgend ciner Form zubereitet wiirden, lurch welche sie unter die Genufsmittel eingereiht werdon könnten.

Verarbeitung der Bohnen zu Schokolade. In den Schokoladefabriken röstet man die Bohnen, um sie von der Schale zu befreien, in geschlossenen, grofsen líaffeetrommeln rorgleichbaren Blechcylindern. Dabei ist die Temperatur, die etwa 100 (rrad betrïgt, genau zu überwachen. Damn zerkleinert man sie grob in eincr Nïhle und entfernt die Schalen durch eine Windfege. Erst durch das Rösten (wie beim liaffee) crhalten die Bohnen ihr liebliches Aroma und verlicren den zusammenziehenden, bitteren Geschmick. In geheizten Mahlwängen werden die zerkleinerten Bohnen in einen Brei zerdriickt, dem min Zucker, Vanille, oder andere Wiirze zusetzt. Man liilst diesen Frei in slatten Formen (Tafeln, Figuren, Ionbons, Plätzchen, Stäbchen) erkilten und hat die Schokolade gewonnen. Schokolade kommt anch in l'ulverform in den Handel. Frhält der Irrei keinen \%usat\% so bekommt man lie Kakaomasse des Handels. Setzt man der Masse nur Zucker zn, so erhält man die sogenannte Gesundheitsschokolade. In medizinische schokoladen hingt man Ar\%ncistoffe, un diese dem Kranken leichter zuzuführen (Islïndischmoos-, Salep-, Chini-, Santonin- n. a. Schokoladen und Pastillen). Die ..Magenschokolade" enthïlt doppeltkohlensanres Natron. Für schwache Nagen bereitet man entölte, d. h. durch starken Druck etwa der Hälfte der Kakaobntter hermbte Kakaomasse.

Die Wirkung des Kakangetränks anf den monschlichen()ronnismus ist cine angenchn erregende. zugleich sehr nührende. es heitert den Geist anf und ernïlnt zugleich.

Gebrauch. Die Kakaobohnen sind ein llamptuahrungsmittel vieler Amerikiner. Das l'leischige Mark der Fucht rermehren die Indiann wern roh, oder hereiten sich darins ein Getrïnk, das anschehm sïncrlich schmeckt nnd herauscht. Die südamerikanischen 
Indianer sammeh dic Frïchte zunïchst nur ilues fileisches halher. Die Schokolade wird in don mamigfaltigsten liormen als Arznei-, als Ciemns - mol Nahrungsmittel gebraucht. Die Kakaobntter verwendet man in der Schokoladen- und \%uckerwarenfabrikation, zn Salhen, feiner Seife u. a. Ihre geringe Neigmng zun Ranrigwerden ist dabei vou hesonderer Bedeutung. Die Schalen der gerösteten IBohnen dienen als leidliches Kaffee- und Theesurrogat. Der Farbstolf ler Kakaobohnen, das Kakaorot, hat weitergehende Verwendung noch nicht gefunden. Die Bastfasern des Kakaobanmes eignen sich als Gespinstfasern.

Warenkunde. Die Bohnen ron wild wachsenden Bäumen, oder Bohnen geringerer Sorten kommen als rote oder ungerottete in den Haudel. Die .gerotteten Bohnen" haben durch die starke Gäı'ung den unangenelmen Beigeschmack und einen T'eil der Gerbsiiure verloren und sind von höherem Werte. Das Innere der Samenlappen (Nibs) soll klar rotbraun, ihr Äufseres tief purpmrrot mit einem Stich ins Branne gefiirbt sein. Sie sollen sich leicht voneinander wie auch ron der Schale tremnen, ihr Bruch soll f'ein, gläinend, glasartig sein. Gekaut sollen sich die Samenlappen im Munde leicht auflösen, ihr Geschmack muls etwas zusammenziehend, erwärmend, stark schokoladeartig und frei von der leisesten Spur von Moder sein. Mit den Fingernägeln geritzt, mïssen die Bohnen (j) von sich geben und ein starkes Aroma entwickelı. Gerottete Bohnen tragen gewöhnlich einen erdigen Überzug.

Es giebt eine Menge ron Handelssorten; man unterscheidet:

\section{A. Gerotteter Kakao.}

1. Kaka ron Venezuela.

a) P'uerto Cabello. Sehr dicke, unregelmälsige, volle. eirundliche, weuig abgeflachte samen mit ockerwelbem Frdiiberzug; unter diesem braungelb mit schwarzen Flecken; Samenlappen rotbraun.

b) Caracas. Sannen stark gewölbt, mit blalsbrumner, erdig überzogener Schale; sonst der vorigen ähnlich. Gleich oder höher bewertet.

c) Maracaibo. Dem Kakao von Trinidad ähnlich und gleichwertig.

2. Kakao von Ecuador.

a) Guayaquil. Ihei uns viel benutat; mit schief-eiförmigen. flachen, auch rundlichen, unregehnälsigen samen mit schmutrig schwarzbranner Schale. Samentappen fast schwalr\%, imen schwalrhrann bis braunviolett; schwach bitter.

b) Arriba-Guayanil. Eine feinere Sorte; sehr grofse, 
Ilach dreieckige, scltener rundlich-eifürmige Sinnen; Schale schmutzigbram bis hell gelbbraun, mit starkem Erdüberzug. Samcinlappen fisst schwal\%, innen dunkelbraun, kaum bitter.

c) Esmaralıas. Ḱleine, seln dnnkle Samen, den mexikanischen ähnlich. Vor\%üglich.

3. Kakiı von liritisclı- mol Holländisch-Guayana.

a) Berbice. Kklein, aulsen gran, imen rotbran.

b) Essequibo. Grofse. feste, innen dunkel rötlichlıraune, etwas bittere Samen; Schale graubraun mit grauem İiberzug.

c) Surinam. Ier vorigen Sorte ähnlicl.

4. Kakao ron Siidmexiko.

Mexikanischer oder Soconusco-Kacao. Vorziigliche, bei uns indessen kiam in ten Handel gelangende Sorte. Santen klein, stark gewölbt. Schale hellgell, fast glïinzend. Geschmack rein, ölig, mild.

5. Kickao von Kolumbien.

Angostura und Petrazza. ähnlich dem von Ecuador.

\section{Ungerotteter Kakao.}

6. Brasilischer Kakao.

P’ará und Maranon, höher geschïtat als liio Negro und Pahia. Letzterer, bei uns sehr gebräuchlich, hat mandelähnliche, an den Rändern dick aufgewulstete, Hach dreieckige oder mit stark gewölbter Schmalseite versehene Samen. Schale dunkel rimtbraun oder schmutzig graubraun. Samenlappen aulsen selwarz, innen schwarzviolett oder schwarzhraun mit weilsgramen Streifen, schwach litter.

7. Kakato von Französisch-Ginyana.

Cayenne. Schale graulurann; Samenlappen blaurot.

S. Insel-, Antillen-oder Mittelamerikanischer liakao.

a) T'rinidat. Sohr grolise, lneite, glatte, innen schwar\%brame simmen.

h) Maldinique. Lünglich-schmale, slatte. innen lon:mnrütliche samen.

(c) st. Inomingro. Sehr llache, eifömige oder fast drocickige sianen, mit fiast mandellabiger Sichale.

d) Guatemalar. Dem Caracas ähnliche, vortreffliche Sorte.

Man hat lestgestellt, dafs im Durchschnitt je 100 Bohmen der folgenden forten dils in Gramm beigesetzte Gewicht hesit\%n: Trinidad, ordiniar 9s, - Trinidad, gnt 12:3,2 - Trinidald, hochfein 178.7. 
- Grenada, mittelgut 104,5, - Girnada, fein 131, - Caracas, gut 130,:3. - Dominica, gnt 110, - Surinam, fein 122, - Surinam, foin (klein) 71,5, - Bahia, gut 118, - Mexiko, gnt 136,5, - Afrika, gut 12s. Die schwersten Sorten sind im allgemeinen die besten. Un gute Schokoladen zu errielen, sind solelie Kakaosorten mitcinander zu mischen, welche sicl gegenseitig eriainzell.

Gute, unverfälschte Schokolade darf nicht raulı und zusammenziehend schmecken; sie bringt anf der Zunge ein Kiilterrefiihl hervor und zerfliel'st leicht im Munde; sie zeigt eine helle, rötlichbraune Farbe und im Bruche cine glatte, gleichartige, nicht raulse Flïche mit festem, glänzendem Korm. Billige Schokolade kam nicht rein sein; sie ist entweder künstlich erschwert (durch Mehl, betrïgerischerweise oft aber auch durch Kartoffeh, Eichehn, Kastanien, Cichorien, Erdnuls, gemahlene Kakaoschalen, Ziegelmehl, Ocker. Schwerspat, (rips u. a.). oder die Kakaobutter ist durch Tierfette (Rindertalg u. a.) ersetzt, oder es sind billige Gewiirzo (Peru- oder Tolubalsam anstatt der Vanill(e) zugefügt. Mikroskopische und chemische Untersuchung kann dies leicht feststellen. „Un \%. B. zu erfahren, welche Art von Mehl sich in der Scholiolade befindet, mufs man ein Pröbchen unter dem Nikroskope bei 100 - his 150 maliger Vergrölserung betrachten. Die Körner des Stärkemehls der Kartoffel sind am gröfsten (Durchmesser 0,06 bis $0,10 \mathrm{~mm}$ ), fast birnförmig, und ans zalhlreichen Schichten. welche sich in einem excentrischen Punlite (Nabel) rereinigen, zusammengesetzt; die des Weizenstärkemelıls viel kleiner (Durchmesser 0,035 bis 0,040 mm), kugelig oder länglich rund und in der Nitte mit einem Punkte versehen; die des Hiilsenfruchtstärkemehls, an Grörse zwischen jenen beiden stehend(Durchmesser 0,04 bis $0,07 \mathrm{~mm}$ ), länglich, in der Mitte einfach geschlitzt oder vom Schlitz aus noch Seitenrisse zeigend" (Wittstein). Beträgt die Asche der Kakaomasse meln als 4 l'rozent und die der gezuckerten Schokolade mehr als 2 Prozent, so ist dadurch die Verfïilschung mit mineralischen stoffen nachgewiesen.

Angaben über Erzeugung, Handel und Verbrauch. Die Caracisholnen kommen besonders nach Frankreich, Spanien nnd Italien, die von Quito und Popayan nach Deutschland, England und Rulsland. Die französischen Antillen fiihren nur unbedentend aus. Die Preise schwanken je nach der Gïte 1000 und mehr Prozent. Hu mboldt schätyte im Jahre 1806 den jïhrlichen Verbrauch an Kakao in Europa anf 200000 Ctr. und allein lïir Spanten anf 80000 bis 90000. Hente soll die Gesamtprodultion etwal 425000 Nitr.-Ctr. botragen. Hiervon erhïlt Frankreich jülrlich otwa 160000 Mtr.-Ctr., Fingland 107500 Nitr-Ctr.; Holland verhaucht jïlnlich 15000 , Bolgien S500, Österreich 4400 Mltr.-Ctr.; Deutschland, das 188955650 Mtr.-Ctr. rolıen kiakan für $7 \frac{1}{2}$ Millionen Mank berog, erhiclt deren 18:17 
154730 im Merte vou 18.5 Millionen Mark, fülnte aber, dank sciner hochentwickelten Industrie, zeitweise fiir das doppelte und melir an feinen schokoladewaren aus. Mit Riicksicht anf das bestïndige Steigen des lephranchs ist aueh der Aubau beständig in Steigen, und so hat man denu auch in unserem Kiamerungebiete his jetzt wolılgelungene Ansiedehungsversuehe gemacht.

Geschichte des Kakaos. Kakao ist ein mexikanischer Name: Cacuatl Kirkasame, Cacahoaquiliuitl der Kiakaobaum. Sichon vor der Entrlecknng Amerikas ist der Kiakao vou den Mexikaneru benutzt worden. Cortez traf bei seiner lioberung (1519) den Kakao in allgemeinen Gebrauche. Er, sowie Feruande\%, schildern in ihren Briefen an Kaiser Karl T. die Kultur und den Gebraueh des Kakaos, sowohl als Genuls - als auch als Zahlmittel. Kakao bilkete bei den Altmexikincrn die einzige Miinze, in welcher die Provinzen ilre Stener bezahlten, ein Gebraueh, der noch von Humboldt in Costarica beobaehtet wurde. Die Zubereitung des kiakíos als Genulsmittel. welcher in jener \%cit von allen Volksklassen benutzt wurde, war eine wesentlieh andere als jetzt. Die geröstcteı, von der Schale befreiten, gestolsenen Bolınen wurlen in Wasser gekocht, ron der ärmeren Kilasse mit Maismell gemischt, kräftig gewürzt (wozu man sich bereits ler Vanille bediente), kalt zu einem Schaum von Harzdicke verarbeitet und kalt genossen. Die Azteken bezeichneten den so zubereiteten Kiako als Schokolate. Die Wilden am Orinoko benutzten noch zu Humboldts Zeiten nur das Fruehtmus und warfen das ïbrige weg. Die Sehilderungen vou Cortez und anderen, welche namentlich auch den Kiakao als Ersatz andercr Silnungsmittel bei austrengenden Reisen aupriesen, versehafiten ihm bald einen ausgezeichneten Ruf, so dafs er 1520 und zwar in Form ron linclien nach Spanien gebracht wurde. Aber iber Spanien und dessen Kolonieen drang vorerst sein Rinlım nicht hinaus. Der Mailänder IIjeronymus benzoni, der 1544 bis 155\% Centralamerikal bereiste, bestitiort zwal die Aussagen seinel Vorgänger, kilm sich aher 1111 dort entsehlielsen, Kakao zu geniefsorl, wo der Wein fehlt, und schildert namentlich die Unsanberkeit der Eingeborenen bui Zubereitung des aus Callatl lergestellten Getrinkes. Felnandez (1560 bis 1571 in Mexilo) gielot eine ansfiilnliche Sehilderung nud leidliche Mbbildung der Pflanze und herichtet iiber das aus den Samen liergestellte Getrïnk. Merkwiudigerweise habon lie Brasilianer erst nach der Ein-

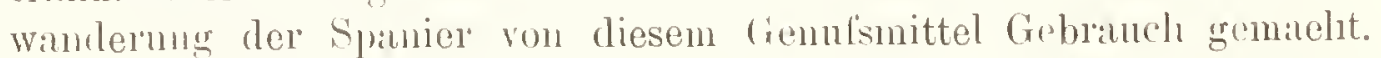
1) er italienisclue Weltumsegler Carletti (1597 bis 1606) brachte den Kakiu und die Kunst dor Sichokoladebereitung uach seiner Vaterstadt liloren\%, und von hier ans verbreitote sich das fieträhk nach dem

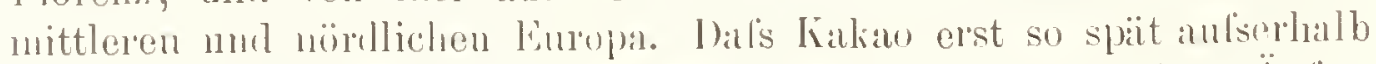
Spaniens in Furopa henutzt worde, mag in den muginstigen Iulselumsen des Renzoni mul des Spaniers Acosta begriumlet scin;

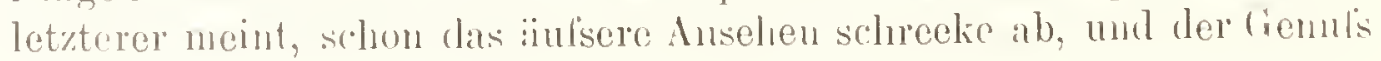


verursache Herzbeschwerden. Auch Clusius, der eine schlechte Ah- $_{\text {h }}$ bildung der kiakabohne lieferte, äulserte sich anf Grund von lienzon is Berichten, dal's Kakao eher fïr Schweine als fiir Menschen passe. Nach Frankreich soll die Schokolate $11 \mathrm{~m}$ 1615 durch die Gemahlin Ludwigs XII. gekommen sein. 1657 wurde in England das erste schokoladehans eröffnet; 1679 kam Kakao und Schokolade durch Bontekoc, den Leibarzt des Grofsen Kurlïrsten, nach Dentschland. Homburg, Chemiker in Paris, beschältigte sich 1675 mit der Gewiunung der Kakaobutter; letatere wurde 1719 von Qelus als Genufsmittel und zu Salben empfohlen. (Nach Pabst.) 


\section{Tafel 6.}

\section{Zuckerrohr (Sacchurm officinarum L.).}

Das Echte Zuckerrohr gehört zur Kilasse der Monokotylen, zur Reihe der Spelzenbliitigen (Chumitorue) und zur Familie der Gräser (Crrmincue).

Die Familie der Gräser (Grmmincae).

Krïuter, selten holzige Staudengewächse (z. B. Bambus). Der walzenförmige, grewöhnlich hohle Stengel (die Glieder des Zuckerrohrs und Mais sind voll) ist durch Gelenke oder knoten gegliedert und wird 11 alm genannt. Der untere Teil der Bliitter bildet eine Scheide, an die sich unmittelbar die Blattflïche setzt. Diese ist einfach, ungeteilt und ganzrandig, langgestreckt, von parallelen Nerven durchzogen. An der Grenze ron Scheide und Blattlläche sitzt ein lilatthäutchen. Die Bliiten sind meist Zwitterblïten, selten ein-

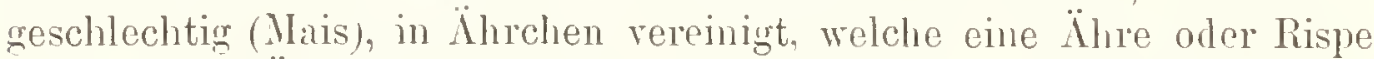
bilden. Das Ährchen besteht aus einer Spindel, an welcher zwischen zweizeilig geordneten Deckblättern, Spelzen, die eigentlichen Bliiten stehen (vergl. den nebenstehenden Holzschnitt). Jedes Ïhrchen wird umschlossen von zwai in ungleicher Iröhe entspringenden IIill-oder Deckspelzen, Balgspelzen oder lialgkliuppen; es kinn ein-oder mehrbliitig sein. und im letyteren Falle nehen vollstindig ansgebildeten, fruchtharen auch unfuchthare Biiten, die oft nur durch spelzen darsestellt werden, besitzen. Die libitchen sitzen einzeln in den Achseln zweier Spelzen, ler Deck- und der Vorspel\%. Von diesen ist die Deckspelze die äufsere, sic hat cincn deuthchen Nitteherv, welcher ann Ende orler anf dem Riicken hïufign als nackte, steife Sipitze (Granne) hervortritt. Die innere Vorspelze ist zarthäutig, hat keinen Mittelnerv, oft aher zwei seitliche Nerven mol endigt dam in spitzen. I) ie Stelle der liliitenhiille vertreten zwei, sultener (beim /nckerrohr) drei kleine, farblose Schiippchen, die Saltschuppen oder Schwellkörper. liese oft anch als weitere Vorbliatter betrachteten Körper schwollon zur \%oit der liefouchtumg ganz, oder doch wenigatens an ihrem Grunde. rasch an und hewirken diulurch dis Ausemandertreten 


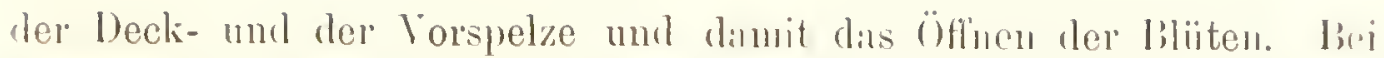
Grisern, wo sic wenig anschwellan, iffuen sich dio Spelzen wenig, wo sie dimmbäntig bleiben oder sanz lehlen, bleiben die Spelzon an den soiten rollkommen geschlossen mol lassen die liefinchtungsorgane mm

Iig. 1.
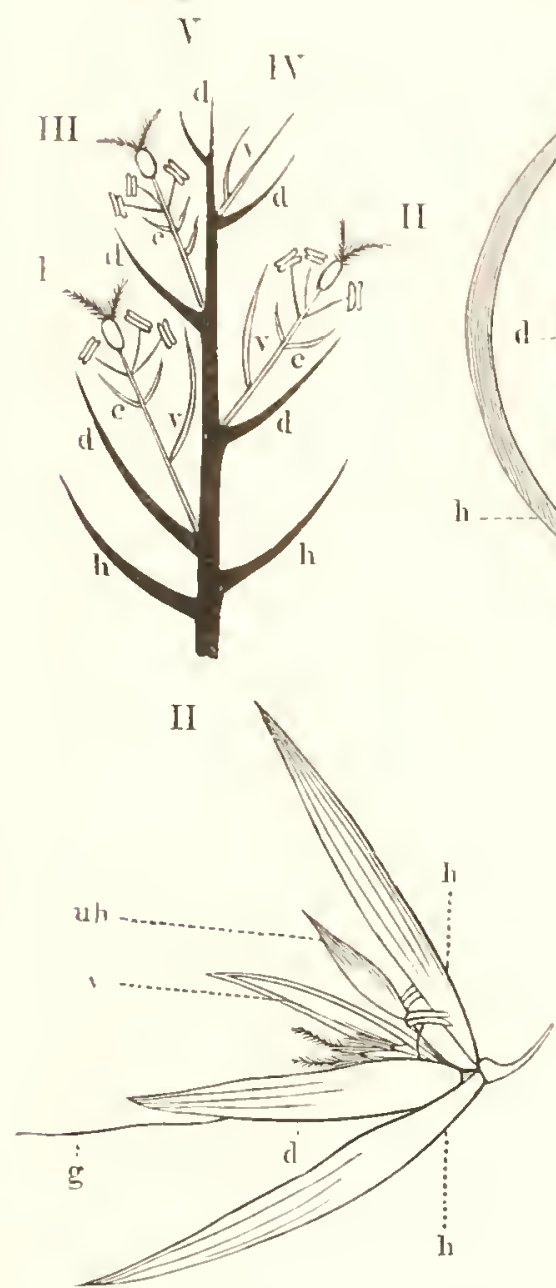

Iig. 2. I

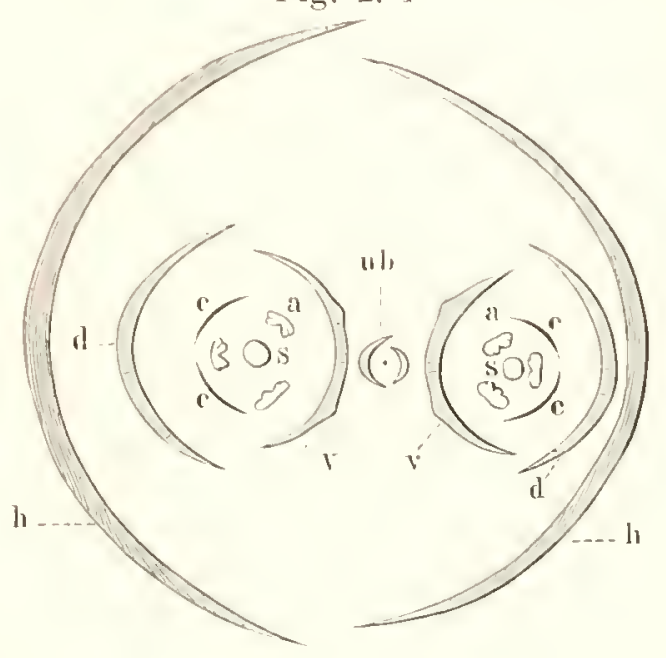

IV

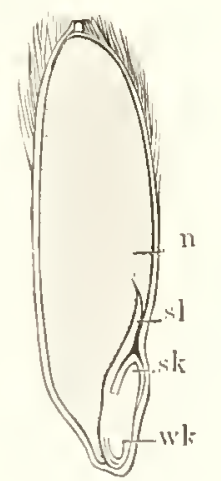

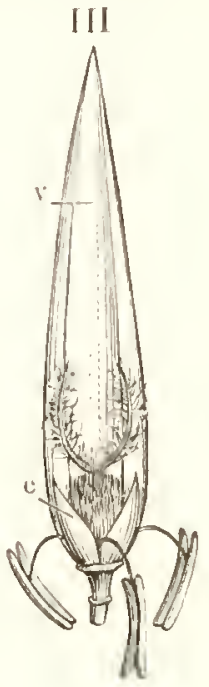

Iig. 3.

I II

III

Fig. 1. Schematiseher Aufrif's cines Grasührehens. I bis III drei vollständige Blüten; IV nur teilweise entwiekelte, unfruchtbare Blüte; V leere Deckspelze. " die beiden IIüllspelzen des $̈$ hrehens, I die Deckspelzo, "die Vorspelze jedler I3lüte, $c$ die Saftsehuppen. Die staubhü̈tter und der Stempel sim als solehe erkennbar. - Iig. 2. Hafer (Aemu salima). I Grundrifs eines Ährehens mit zwei fruelıtbaren und einer verküınmerten Blïte. ul das verkïmmerte Blütehen. l. IIüllspelzen, d Deckspelze, "Vorspelze, c Saftsehuppen, a Staubblätter, s Stempel. II auseinandergezogenes Z̈hrchen, h Hiillspulzen, \& Deckspel\%e mit der Granne g, c Vorspelze, nb unfruchtbares Blütehen. Ill Blüte ohne I)eekspelze; P Vorspel\%e, - Saftschupe. IV Durchschnitt durch die lineht. "Nälngewelse, sl Samenlappen, sli Stanmknospe, w\% Wurzelknospe des lieines. - I'ig. 3. I Kuanelgras (Dactylis glomeralu), Frueht mit enlständiger Granne. II und III Ruehglas (Authorumlum. orloralum), ïufsere spelzen der beiden unfuchtbareu Blütchen eines Älnchens; I mit gerader, II mit geknieter, rückenständiger Grimne.

an der Spitze austreten. Jecle Bliite enthiilt rrei, seltener aber seclis (Reis) Staublibitter, deren frei heraushïngende Stanbbentul iluen Stuub 
dem Winde \%ur Bestiiubung iibergeben. I)er kleine, oberständige, einfächerige Fruchtknoten trägt mindestens zwei, selten drei, ziemlich grofse und an der Spitze oder beiderseits am Grunde zwischen den Spelzen hervorragende Nirben, welche durch starke Haarentwickelung feder- oder pinselförmig ersclieinen. Im Grunde des Fruchtknotens ist eine einzige Samenknospe vorhanden. Die Frucht ist eine trockenhïutige, nicht aufspringende Schlielsfrucht, welche bei den meisten Gräisern von den beiden Bliitenspelzen bekleidet, beschalt, ist, wie bei Hafer und Gerste, seltener nicht mit den Spelzen bekleidet ist und nackt aus ihnen herausfaillt, wie hei Roggren und Weizen. Die Hauptmasse der Frucht nimmt das mehlige Nährgewebe ein, an dessen Vorderseite und Grunde der nur von der Fruchtwand bedeckte Keimling liegt. Letzterer ist meist klein und gerade; er hat ein schildförmiges Keimblatt, Schildchen, in dessen vorderer Aushöhlung oder Rinne das mit mehreren Blattanlagen versehene Knöspchen und das von einem Hüllgewebe umgehene Würzelchen liegt.

Etwa 313 Gattungen mit iber 3500 Arten.

Die meisten Grïser sind ausdauernd und laben einen verlingerten, kriechenden oder verkiirzten Wurzolstock; aus diesem entspringen "rasenbildend“, meistens büschelartig, blïtter - und lialmtreibende Sprossen. Es giebt aber auch ausdauernde Gräser (die rohrartigen), die nur Halme treiben und nicht rasenbildend sind. Der Mais und unser Sommergetreide sind cinjälnrig, unser. Wintergetreide zweijährig; sie treiben nur einen oder wenige Halme. Gräser finden sich ïberall; Wiesen, mit geschlossener Grasnarbe, bilden sie nur in der gemïl'sigten Zone.

Die Gattung Zuckerrohr (Suchurme L.). Hoch, schilfartig, mit langen, meist schmalen Bliittern und grofsen, dichten IBliitenrispen, in welchen die ein-oder zweiblitigen Ährchen von langen Seidenhaaren umgeben sind. Hierher zwölf, meist der 'Tropenzone der Alten Welt argehörende Arten.

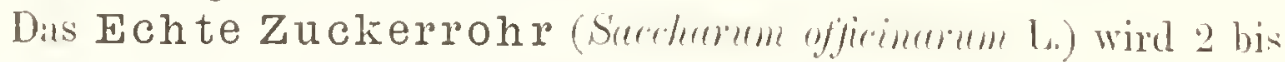
$4 \mathrm{~m} \mathrm{hoch}$.

Wurze1 ausilaternd, aufrecht, dick, kintig, knotig, faserig. bildet diclit verschlungenen Rasen.

Halme bis zohn und mehr Stïck, 2 bis 5 cm im Durchmesser dick, rund, knotig gegliedert, mit dichter, fester, glatter, glänzender Oberhant. Letatere, in der Iurond mit einem weilsen lieif versehen, der sich später nur in den Stengelknoten tindet und dort einen Über\%ug von stäl)chenförmigg abgesondertem Wachs bildet, durchläuft bei den verschiedenen Kulturspielarten alle Niancen durch P'urpur bis zu Gelb und Griiu, ist mitunter sogar verschiedenfarbirg gestreilt. I)ie linoten des Wurzelstockes nnd des Italmes hilden Reihen klener Warzon, welche bei ter Vermehrmer durch Stecklinge die Quelle nener liewn\%olung bikden. An IIalne sind die Alstände von Knoten 
\% linoten verschieden grols, bei einigen Spielarten betragen sie 5 bis † cm, bei anderen 20 bis $22 \mathrm{~cm}$. An jeden linoten hefindet sich eine hattachselständige hinospe, aus welcher sich eine nene l'flanze entwickeln kimn.

Der llalm ist solid und nur, wem er sich als Bhiitenschaft verläng̋ert, im oberen l'eile hohl. Sein innerer Bau ist durchaus monokotyledoner Art; die Gefilisbündel stehen über den ganzen Querschnitt zerstreut, liegen zwar nach der Rinde zu etwas gerrängrter, fehlen aber auch der Mitte nicht. Der Ramm zwischen ihnen ist von grolsen, diinnwandigen Parenchymzellen, die ein saftiges Grundgewebe, Mark, billen, erfiillt.

Blätter, mit ihrem Grunde den Halm scheidenartig umfassend, an der Mïndung der Scheide weifs behart, abwechselnd, oft bis $125 \mathrm{~cm}$ lang, 2 bis $4 \mathrm{~cm}$ breit, flach, glatt, sehr fein, aber scharf gezähnt, mit einer breiten, weifslichen, auf dem Rücken gewölbten Mittelrippe; Scheide bis $30 \mathrm{~cm}$ ling.

Blüten erscheinen selten, da min für die Kultur eine Abart wählt, welche durch die Jahrhunderte fortgesetzte Vermehrung durch Stecklinge das Vermögen zu blühen fast vollständig verloren hat. Sie finden sich in grolser, 40 bis 80 cm langer, ausgebreiteter, pyramidaler Rispe an der spitze des Halmes; ilne $̈$ ste sind vielgliederige 'Trauben. Öhrchen meistens nur am Rücken von langen, seidenglänzenden Haaren umgeben, paarweise und zwar so zusammengestellt, dal's dis eine sitzend, das andere gestielt ist. Jedes Thrchen hesteht aus zwei Blüten, einer unteren, unfruchtbaren, nur durch eine einzige Spelze (Fig. 2a) dargestellten Bluite und einer oberen Zwitterblute (mit den spelzen $b$ und c). Fruchtrnoten eitormig; Griffel nit zwei (seltener drei) gefiederten, purpurfarbigen Narben.

Frucht klein, oval, an beiden Enden zugespitzt, ron der Spelze liekleidet.

Feinde des Zuckerrohrs: Der Zuckerrohrkäfer (Ligyrus rugiceps) bohrt sich unterhalb der Erdoberflïche in das \%uckerrohr ein. Der Zuckerrohrbohrer (Diatraca sacrharalis); die Motte legt im beginnenden Frühjahr ihre Eier auf die Blätter des jungen /uckerrohrs, nahe am Halm; die Raupen bohren in dem IIılm einen aufwärts gerichteten 'Tunnel aus. In ähnlicher Weise bohrt dic Larve des I Leuchtenden Schnellkäfers (Elnter mortilners) den Halm an. I)je Kuckerameise (Formicre sarrharirore L.) tötet das Rolı dadurch, lals sie ihr Nest unter dessen Wureln anbringt. Die Afterameise (Formice amalis Latr.) wohnt im liohre selbst und zerstört es dadurch. Ferner der \%uckerrohrwickler (Tortrix suchariphuga); die \%uckerrohrschildlaus (Cocens succhri) und verschiedene Blat tläuse. Fndlich verursachen gewisse Fadenwiinner (Nematoden) wahrscheinlich die Serehkrankheit, bei welcher die Stengelglieder kurz hleiben, aher zahlreiche zuckerarme Seitentriebe, oft nur Blïtter erzengt werden. 
Heimat mubekannt. wahrscheinlich las tropische Ostasien.

Verbreitungsbezirk: Imerhall, der Wendekreise in allen vier Weltteilen (Asien, Afrika, Amerikia mul Australien). I)as /anckerrohr verlangt wames likma mul gerleiht dosto besser, je nähor dem ïpator es angehant wirl. Die mittlere Jahrestemperatur muls 2: bis 290(\% betragen. In China baut man es bis \%um 30. Grarle, in Nordamerika mnd Afrika bis zum 32. Grade (in einigen Gärten Siciliens und Andalusiens bis \%um 37. (Arade). In Kolmmbien und Mexiko wird es noch in einer Höhe bis $1 ! 00$ m ïber dem Mecre gebaut. In melreren Gegenden, besonders auf Inselı des Grolsen Oceans, verwihlert es leicht, bliilıt daun auch; wild findet es sich jetzt nirgends melır.

Kultur. Der Boden fïr Yuckerrohrkultur soll fett und feucht, aber nicht sumpfirg sein. Die Kinltur erfordert viel IIandarbeit. Legt man eine nene /nckerplantage an, so wählt man ein möglichst grofses Feld dazn, baut Wohnmugen fïr die Besitzer und die Arbeiter und Stallungren fïr dis Vieh an die Grenzen, Miihle und Siedehaus in die Nitte des Gelictes, legt mach allen Seiten zahlreiche Wrasser:bzngskanäle an, da das Zuckerrohr stagnierendes Wisser nicht ertragen kann, teilt dnrch Wege das Land in (purtiere ein und pfliget es, uachden man es gediungt hat, möglichst tief um. Damn werlen die Setzlinge reihenweise in Iöcher oder in Furchen $60 \mathrm{~cm}$ weit auseinander und $20 \mathrm{~cm}$ tief geptlanzt. Die Setzlinge werden aus dem oberen 'Teile der Rohre geschnitten, der zwischen jedem der zalılreichen, jugendlichen, dicht aufeinander folgenden libitter eine achselstïndige Kinospe trägt. Man setzt die Stecklinge schief ein, so dils nur der obere Teil ein wenig aus der Erde hervorsieht. Iald entwickehn die zahlreichen linospen nene Schïlte; auf diese Weise sind oft zelın und melı Rohre in der bide durch das Stammstiick dos Stecklings mitemander verbunden. In der remäsigten Zone erliegen die Wurzelstöcke des /nckerrohrs dem Winterfoste und müssen deshalb jedes Jahr erneuert werden; in den 'lropenlainder'n lälst man oft die alten Wurmelstöcke Jahre ling stehen, lockert einfach den Boden aul und ersetzt hier und da einen eingregangenen Stock. Anlangs wïchst das Rohr nur langrsam, und das sie umgebende, üppig wucherucle Unkrant wiirle die junge Kulturpllan\%e nicht anlkommen lassen, wenn man nicht sehe Heilisig jïtete. Dabei behäufort man das

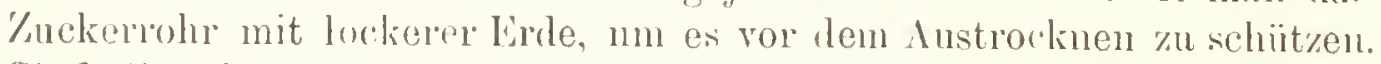
Sind die Blaitter der I'tlanze so grol's greworden, dals sie grenug Sclratten werfen. mu das Thkraut dadurch nntordrincken zu kïnnen. so ist das fäten nicht mehr nötion. Werden die l'flanzen groilser, so nimmt man ihnen ilme untersten Blitter; eimmal, dimnit die Somne his zum stirlisten Stengrelteil dringen und auf seine lieife wirken kann, dann aber, un die abgehochencm, grofsen liätter horimontal auf den boden unter dis l'flumen zu legron, danit, wenn diese sich neigren sollten, ilno Knoten nicht Wur\%el schlagen kömen. Vor der lieite gowihnt cin 
Zuckerrohrfeld cinen herrlichen Anblick. Ile Emte begimnt, wenn sich das liohr und die nuteren likitter gelb färben; in Ostimdien

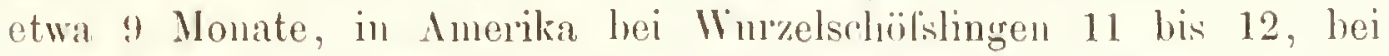
Stecklingen 15 Nonate nach der Pflanzing orler noch spiiter. In $\mathrm{Ab}$ teihnngen verteilt, streifen die Arbeiter erst die Blïtter von den Stengehn und hanen dann mit grolsen Messern das Rohr an der Wurzel ab, wïhrend andere die $\%$ Stecklingen bestimmten Spitzen abschneiden, und die in kleinere Stücke zerschnittenen Rohre nach der Presse besorgen. Da die Blattscheide an ihrer :infseren Seite mit sehr kurzen, einzelligen, rerkieselten Haaren besetzt ist, die sich beim Abstreifen der Blätter leicht ablösen und bei empfindlicher Haut bisweilen Entziindungen hervorrufen, entstand die zur Entschuldigung les Sklavenhandels öfter rorgebrachte Sage, dafs Europïer die Arbeiten auf' der '/nckerplantage nicht ausfïhreu könnten, wiihrend die Haut der Negersklaven gegen die Eiuwirkungen des Znckerrohrs nnempfindlich wïre.

Zuckergehalt der Pflanze. Zncker enthalten fast alle l'flanzen, wenigstens zur Zeit des Keimens, viele in den Bliiten und Frïchten. Die wichtigsten Zuckerpflanzen besitzen den meisten Zuckerstoff' im Stengel oder in den Wurzelknollen. In Zuckerrohr wird Zurker zu jeder Zeit und in einer grolsen Menge gefunden. Dis lockere, zellige Mark der Pftanzen ist der hauptsächliche Trïger des Zuckersaftes. Der Saft guten Zuckerrolues soll bis 18 Proz. Zucker, etwa 10 Proz. Salze und 72 Proz. Wasser enthalten. Von $100 \mathrm{~kg}$ '/uckerrohr bleiben ungefähr $6 \mathrm{~kg}$ Riiickstände übrig, die durch Trocknen anf $1 / 2 \mathrm{~kg}$ eiuschrmmpten.

Die Gewinnung des Zuckers aus dem Rohre stimmt in ihren wesentlichen P'unkten mit dem Verfahren bei der Rïibenzuckerfabrikation ïberein. Sie geschieht im Zuckerhause, das in der Regel ans Mïhle, Kessehraum, Filtrier- nnd Kïhh:aum besteht. In der Iiihle wird das Rohr vermittelst hydraulischer P'ressen ausgedruickt. Der Saft gelangt in mehrere etwas tieferliexende, von einem Feuer (die Prelsitickstande, Bagasse, Begasse, Merasse, dienen als Feuerungsmaterial) erhitzte Kessel; hier versetyt man ihu, weil er wegen scines Eiweifsgehaltes leicht in (iärmug iibergeht und damn sïuert, mit etwas Kalkmilch und erhitzt ihn bis zum Aufwallen. Hierbei geriunt das Eiweils des Saftes; die fremden Bestandteile (Säuren n. a.) werden abgeschieden, steigen als Schanm auf die Oberfliiche und werden mit grolsen. Hachen Kellen abgenommen. Das Verdanpfen wirk so weit fortgefiihrt, bis sich der Saft so verdichtet hat, dafs er beim Abtröjfeln Fïden zieht. IIat der Siedemeister diesen Verdichtungrsurad bemerkt. so wird der Saft, der nun Sirup geworden ist, so l'asch wie mönlich in den Kühltrog geschöpft, wo r zu dem braunen Roh- (M uscovado-) Zucker krystallisiert. In Filtrierranme stehen grolse Fïsser mit durchlöchertrn Boden anf einem Gerïst über einem liecken. 
In diese Fïisser wird num der Rolyucker gehracht, woranf die 111 krystallisierten nud unkrystallisierbiuren liestandteile abtrïnfehn und den Sirup (Melasse) bilden. Nenerdings hewirkt man durch Anwendung rom Dampliplparaten, Vacuumpfanen, dals sich eine geringere Menge Sirup bildet, nund erzielt durch Centrifugen eine vorziigliche Trennung ron '/urcker und sirup. Erfrorenes oder unreif yeerntetes Roln gieht riel Sirn\}. Aus dem Sirup und den unreifen Rohrstiickchen wird Rum gebrannt. Wird der Rolnzucker noch melrr durch Sieden und Läutern mit Blut und Knochenkohle gereinigt, so heilst er Kassonade, Farin oder Farinzucker, Mehl-oder Puderzucker. Der 'Jucker wird nun in den Raffinerieen nochmals gelaintert mol in weifsen Hutzucker verwandelt. Die erste lialfination ergiebt den Lumpenzucker und die zweite den Melis. Del feinste gereinigte Zucker hrifst Raffinade, Feinzucker, dessen beste Sorte der Kanarienzucker ist. Kandiszucker, krystallisicrter Zucker, wird erzeugt, indem die schon verdichtete, aber noch nicht bis zum Gestehen eingekochte /uckerfliissigkeit in mit Fïden durchzogenen Gefälsen längere \%eit stelıen bleibt, so diafs der Zucker sich in Kírystallform (klinorhombische Prismen) an den Fïilen ansetzen kanı. Der braune Kandis wird aus Farin, der weifsc aus Kanarienzucker gewonnen.

Die Arbeiten bei der Ernte und dem Sieden des Zuckers sind aufreibender Natur, werden aber gemildert durch den Genufs des Zuckerrohrs und des Saftes, da beides ungemein nïhrt. Nan braucht seh" viel Heizungsmaterial beim Sieden des /uckers.

Gebrauch des Zuckers. Das Zuckerrohr kann als Nahrungsmittel dienen. Der aus dem Rohre gewonnene Zucker wird als Versüfsungsmittel der Speisen und zu allerlei /uckerwaren verwendet, ist aber nebeuher ein gutes Nahrungsmittel. In der Medizin wird er oft liei stark schmeckenden Arzneien als Einlıiillungs- nnd Geschmacksverbesserungsmittel benutzt. Auf weitere Anwendungen von Zucker, 7. B. als Zusatz zu gïrenden Trauben, um den Alkolıolgehalt des Weines, dessen St:̈irke, zu vermehren, zur Likörfabrikation n.a. braucht hier nicht eingegangen zu werden, zumal da es sich dahei wohl nur in seltenen Fiillen um Rolnzucker handelı diirfte.

Warenkunde. Gut raffinierter Zucker schmeckt rein und sehr angenehn siifs und lenchtet, phosphoresciert, beim Yerreiben in Dunkehn, schmilzt bei $160^{\circ} \mathrm{C}$. olne Kersetzung und Gewichtsverlust zu einer Masse, die durch rasches Erkalten zu einer unförnlichen Masse ersturt und endlich undurehsichtig wird. Der Zucker löst sich schon in einen Drittel seines Gewichtes kaltem Wasser. in heifsem in jerlem Verhiiltnis auf. Reine Zuckerliisung hïlt sich zienlich lange unverïndert. Fiir den llansgebrauch soll man den bestrrystallisierten unl wenigst feuchten /ucker wïhlen. Sehr fruchten Rohrucker sowie raltinierten /ucker, der sich zientich leicht durchlurechen lälst 
und keine rein weilse farbe hat, soll man vermeiden. Reincr Zucker ist gan\% liei ron Geruch. Die Zuckermenge der verschiedenen sorten wechselt zwischen $100 \mathrm{P} \mathrm{l}^{\circ} \mathrm{o} \%$, in der feinsten Ral'funade und Zuckerkand, bis zu !4, 88, 80 und 67 1'roz. in der ersten, zweiten, dritten und vierten Sorte unraffinierten Zuckers. Geringe Siifsigkeit des Znckers ist cin Zeichen seiner Verfälschung oder Verunreinigung. Guter Rübenzucker steht dem Rohrzucker kaum noch nach. Nam verfiilscht und verunleinigt den Zucker mit Narmor, Gips, Schwerspat, Alam, Sand, Mehl, Stärke. Eisen, Kupfer, Blei, Zink u. a. Mattblan aussehender Zucker ist gewöhnlich mit Ultramarin gefïrbt. Alles, was beim Auflösen des Zuckers in der gleichen Menge Wasser ungelöst bleibt, ist Verunreinigung und Fälschung.

Angaben über Handel und Verbrauch. Um 1890 betrug nach Meyer die Produktion (I'), beziehungsweise die Ausfin hr (A) ron Rohrzucker:

\begin{tabular}{|c|c|c|c|c|}
\hline Cuba & & $\mathrm{I}^{\prime}$ & 530229 & 'Tolm \\
\hline Javil. . & & $\mathrm{P}$ & 336308 & $\because$ \\
\hline Philippinen . . & & $\mathrm{A}$ & $218 \$ 50$ & 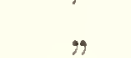 \\
\hline Britisch - Westindice & & $A$ & $1765 \mathrm{SS}$ & 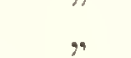 \\
\hline Vereinigte Staaten & & $\mathrm{P}$ & 156371 & 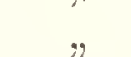 \\
\hline Brasilien . . . & & A & 151840 & , \\
\hline Mauritius . & & A & 136849 & \\
\hline Hawaiinseln & & A & 125450 & \\
\hline Britisch-Guyana. & & $\mathrm{A}$ & 117433 & \\
\hline Britisch-Ostindien & & A & 72796 & \\
\hline Peru . . . . & & $\mathrm{P}$ & 64007 & \\
\hline Puerto-Rico & & $A$ & 62400 & \\
\hline China . . & & A & $59 S 98$ & $"$ \\
\hline Queensland & & $\mathrm{P}$ & 50003 & .. \\
\hline Guadeloupe & & A & 45156 & \\
\hline Ï̈ypten. & & l' & 41730 & \\
\hline
\end{tabular}

Die Gesamtproduktion an Rohrzucker kann auf 4000 bis 5000 Millionen Kilogramm geschätzt werden. Ungefïh gleich grols ist die Riibenzuckerproduktion, in welcher Deutschland weitaus den ersten Rang einninmt. 1897 fïhrten wir 1141000 'Tonnen Zucker im Werte vou 229900000 Mark aus, dagegen nu 1636 Tonnen im Werte ron 500000 Nark ein. Mit obigem Werte nahm Zucker in unserer Ausfuhr den ersten Rang ein.

Der '/ackerverbranch betrug 1893 bis 1894 pro hopf der lierölkerung:

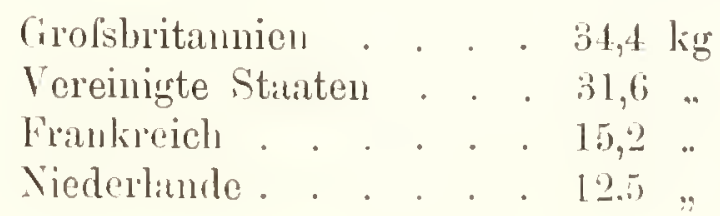




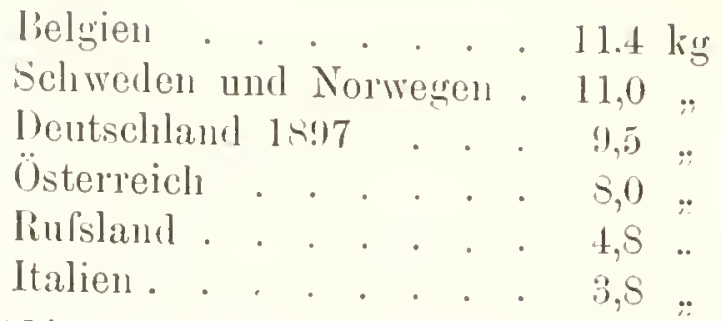

Geschichtliches. Wie jetzt noch in einigen Gegenden Asien. auf den Plhilippinen und den Siidseeinseln war das Zuckerrohr urspriinglich dine Naln'mugspflanze, die gekaut, ansgesogen. sogrn gegessen wurde. In Indien ist die Kultur dieses Grases uralt. Ius dem Sankritnamen surling entstand das arabische suliker, das persische scherlie und die emopäischen Namen Zucker, surve, smm etc, die in allen Sprachen den nämlichen Stamm erkennen lassen. Die Juden kannten den Zucker nicht und wïrzten, um eine Speise sïl's zn machen. mit Honig. Die alten Griechen (bei Dioskorides und Theopluast unsicher) und Römer haben ilın jedenfalls anch nicht gekannt, und erst Plinius sagt. dals Saccharum ein Honig sei, welcher sich in Indien im Marke eines Rohres von selbst durch Austrocknen des Pflanzensaftes zu Stiicken von der Grölse einer Iasehnuls verdichte und nur als Heilmittel gebraucht werde. Aus den Ileimatländern kinn das Zuckerroh" zuerst nach Südpersien und Arabien. Nach Europa kam der Zuckersaft zuerst als Sirup in den Handel und wurde nur in dov Apotheke verwendet. Bereits im 9. Jahrhundert sollen die Araber verstanden haben, den Zucker zu krystallisieren. Damals wurde dis. Zuckerrohr anch in Arabien, Xubien, Ägypten und $̈$ thiopien angebaut. Die Araher brachten die Pflanze nach liholns, Cypern, Kreta, Sicilien und Kalabrien, die Mauren nach Spanien. Ton hier wurde sie ant die Kanarischen und ron da auf die Westindischen Insehn, zuerst natel St. Domingo, späiter, zugleich mit den Negern. anf das anerikanisch. Festland rerpflanzt. Die Kreuzaiige nuchten siid- und Mitteleuropa mit dem Zuckerrohr hekimnt. Sein Gebriuch fïhrte sich am schnellst mit dem Kaffee zugleich ein. Wïhrend der Kontinentalisperre Napuleons I. kostete 1 l'fund '/ucker 4 Mark. Schon 1747 hatte Markgraf zu Berlin das Vorlandensein krystallisierharen Znckers in den Rüben entdeckt, aber erst A chard stellte ant seinem Gute Canulsdort bei Berlin Riibenzucker her und errichtete 17 !n and seinem Gute Kunern (Regierungsbezilk Ireslau) die erste Riibenznckertibrik. Infolge der Kontinentalsperre Napoleons I. hoh sich die lïiben\%nckerindustrie, verliel aber nach Napoleons Stur\% in Dentsohland wieder. falste urst in den Jahren 1830 his 183.5 hier wieder festen boden und ist seitdem von Jilne zn Jaln nüichtig gewachsen: in Deutschland dient ilı jet\%t etwa ein Pront der gesanten landwirtschaftlich benutzten Fliiche. 


\section{Tafel 7.}

\section{M a n d e 1 b a u m}

(Prunus: cmygdalus Stokes; Linygdalus communis L.).

Der Gemeine Mandelbaum gehört zur Unterklasse der Freihläterigen Dikotylen, zur Reihe der Rosenpflanzen (Rosules), zur Familie der Rosengewächse (Rosurece) und zur Unterfamilie der Rosenblumigen (Tiosoidere).

Familie der R osengewächse (liwstrene). Kräuter oder Hol\%gewächse, deren Bläitter wechselstïndig und mit kiautigen oder schuppigen Nebenblïttern versehen sind. Der Kelch der regehmälsigen Blüte ist gewöhnlich fünfteilig, wobei der unpaare Kelchzahn nach oben steht; er hat wie die Blumenkrone eine fïufschichtige Knospenlage; seine Blätter entspringen mit meist breitem Grunde dem freien Rande der IBlïtenachse. Die Blumenblätter sind frei, dicht innerhalb der Kelchblïtter eingefïgt, mit diesen abwechselnd und mit schmalem Grunde aufsitzend. Die Staubblïtter sind kelchstindig, gewöhnlich in vielfacher Zahl der Blumenblätter vorhanden und in der Kinospenlage sinwiirts gekriimmt. Der Fruchtknoten ist aus einem Fruchtbliatte gebildet und einfïicherig oder, wemn ans mehreren Fruchtbliittern gebildet, mit getrennten Griffeln rersehen. Die Frucht ist trocken (Fig. I) oder Heischig, eine Beere, Steinfrucht (Fig. II und III) oder Schliefsfrucht (Fig. IV) und enthïlt eiweilslose Samen.

Eine grolse Vielgestaltigkeit der IBhiten und Früchte konnt durch die Verbreiterung des Blütenbodens und durch dessen Verwachsung mit den Fruchtblättern zustande. Ersterer ist z. B. Hach bei manchen Fingerkrïutern, erhaben bei der lirdbeere (Fig II). becherartig gestaltet bei Kirsche und liose (lig. $V$ ).

Die familie zerfällt in sechs Unterfamilien:

A. Fruchtblïter 12 bis 1 , wirtelig gestellt, weder aul besonderem Fruchthlattrïger, noch in die bleibende Blïtenachse eingesenlit. mit je zwci oder meln Samenanlagen. Frucht meist anfspringend. Staubfirden aus breiterem Grunde rach oben verschmailert. Nebenblïtter hiinfig fehlend. 1. Unterfamilie: Sprrmen idere, spierst andenbliitige. 


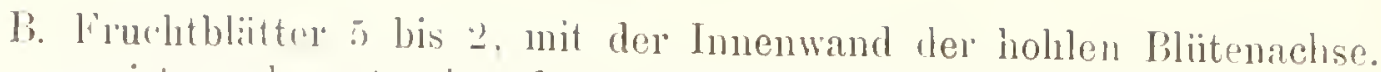
meist anch mutereinander verwachsen. Bliitenachse min unterer Teil der Kelchbliitter, an der Frucht, fleischig (Fig. VI und VIl). Nebenhlïtter dentlich. 2. Unterfamilie: Iomoïlene, Apfellnliitige.

(. linchthlïtter zallheich und auf einem gewölbten, kegeligen oder wal\%lichen Fruchtblattträger ein Köpfchen bildend; seltener nur eins I.

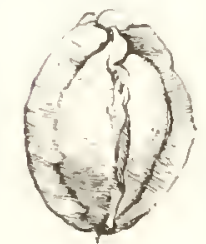

II. h

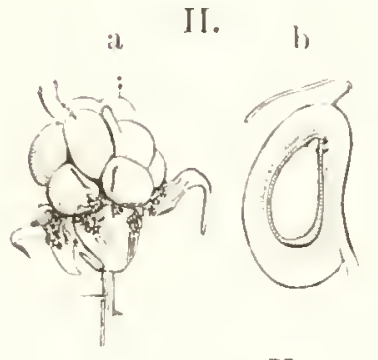

V.

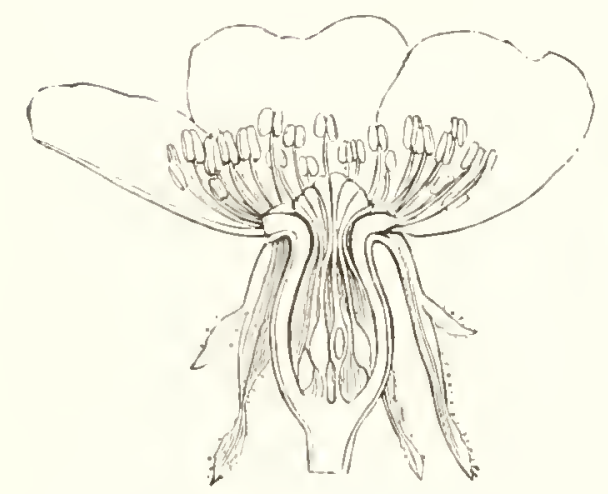

III.

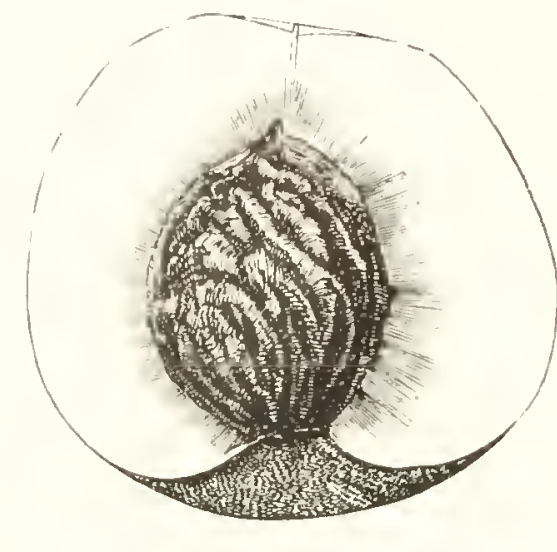

YI.

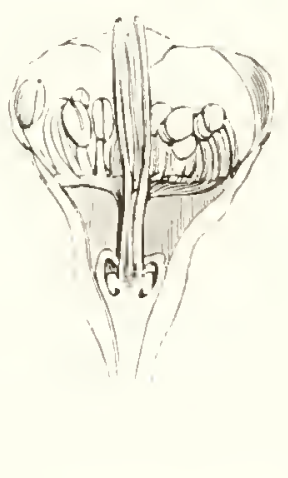

IV.

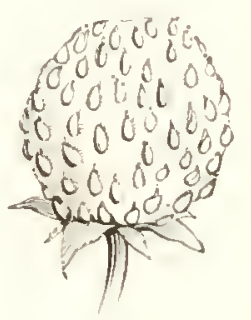

I. Trockene Frucht des Wiesenknopfos (rampuisorba officinalis), vergl.

II a. Sammelfricht der Bromieere (Kulhus).

II b. Einzelnes, steinfiuchtartiges Frühtchen im Längsselınitt, vergl.

III. Durehschnittene Steinfruchit der Pfursich (Peraica vulgaris).

IV. Scheinfrucht der Erdbeere (Faymin resa); jedes der kleinen, auf der Oberfläche sitzonden Steinchen ist eine Fucht, die saftige, wohlschmeckende Masse ein Heischig gewordenes stïiek des Blütenbodens.

V. Längssclmitt durch die liküte der liose.

VI. Lüngssehnitt dureh die Blïte der Birne (l'irus communis).

VII. Iängssehnitt dorch cinen Aptel (Jims. Mnlus). $K$ Vertrockneter Kelch,

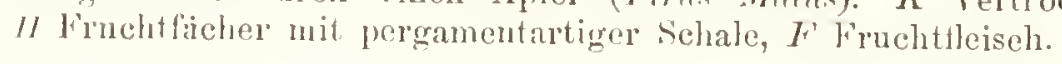

oder wenige nicht eingeschlossen, oder cins bis vicle in die krugförmig ausgehöhlte Bliitenachse eingeschlossen. Fruchtbliitter mit einer lis zwei Samenanlagen, zml lieifezeit stets einsanig nnd niemals anfspringend. :. Unterfimilie: liesoülene, Rosenhliitiga.

llierher u, a.: Bliitenachse krugfiirmign oder röhrig, zalulreiche 
Fruchtknoten umsehlicfscud. zur Fruchtzeit erwoichend. Gruppe: Roseac. liosonblumige.

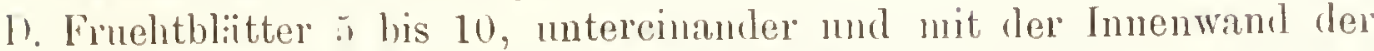
lohlon, boi der lieile troekenen Bliitenachse verwachsen. Kräuter. 4. Unterfamilie: Nemadö̈leue, Nenradabl ï tigre.

E. Fruchtblatter einzeln, selten zwei bis fünf, nicht mit der Plütenachse verwachsen. Steinfrucht. Bämme oder Sträucher mit einficlıen Blïttern. Nebenblätter deutlielı.

a) Grificl fast endständig. Samenanlagen zwei, häingend. 5. Unterfamilie: Prunoïlcac, Pfla u m enblit tige.

b) Griffel grundständig. Samenanlagen zwei, grundstïindig, anfrecht. 6. Untcrfamilie: Chrysobulanoüdeae, G old zwe t s cli e $11-$ bliitige.

Etwa 90 Gattungen mit 1325 guten Arten.

Gattung: Prumos, Pflaume. Diese zur Unterfamilie der l'flaumenbliitigen rehörende grofse Gattung ist ausgezeiehnet durch ein bis zwei Fuchtblätter, kronenartige Blumenblïtter, einen auch an der Fruclit endständigen Griffelansatz, hängenden Samen und eine steinharte, innere Fruchtschalenschicht. Sie zerfällt mit etwa 75 Arten in mehrere Untergattungen:

A. Blïtter in der Knospenlage gerollt. Griffel und Fruclitknoten mit

Lïngsfurehe. 1. Untergattung: Prunopleora, Pflaumenartige (PHaume, Aprikose).

1. Blïtter in der Knospenlage gefaltet.

a) Frucht meist saftarm, samtig behaart, Steinkern oft gefurcht und löcherig. 2. Untergattung: Amygdalus. Mande la r tige (Mandel und Pfirsich).

b) Frucht saftig, kahl oder zerstreut behaart. Steinkern glatt oder r'unzelig.

c) Nebenblätter ausgerandet. Griffel grefurcht. Blüten langgestielt, doldentraubig oder doldig. 4. Untergattung: Corasus. Kirschenartige (Kirsche, Weichsehrohr).

B) Nebenbläitter ganz. Griffel ungefurcht. Bliiten in rerlängerten 'I'rauben. 5. Untergattung: Padus. Alllkirschenar ige (Ahllirsche, Kirschlorber).

Der Gemeine Mandelbaum (Prumss rmygdulus Stokes. Amygdalus commmis L.) wird 6 bis $8 \mathrm{~m} \mathrm{hoch} \mathrm{und} 60 \mathrm{~cm}$ im Durchmesser dick, nit schöner Krone; alte Rinde dunkelaschrgrau, rissig. die der jungen '/weige glatt, rosthraun. Nur die mittleren Zweige treiben Blüten.

Blätter abwechselnd, kur\% gestielt, lauzettförmig, lang zugespitzt. stumpf gesägt, glatt, auf der oberen Seite glämend griun; Blattstiel oben gefurcht, mit einer oder mehreren Driisen.

Die Blüten kommen ror den Blättern, gewöhnlich zu zweien. auf sehr kim\%en, glatten Blütenstielen. Kelch glockenfömig, glatt, 
rötlich gefairbt. mit fünf eiförminen, stmmpfen, zart gewimperten $\mathrm{Ab}$ schnitten. Blumenblätter oval oler verkehrt-eiförmig, stumpf. etwas alusgerandet. Mafsrot. Staubblätter 20 bis 30. in zwei hreisen, glatt, weils oder rütlich, mit gelhem, zweifächerigem staubbeutel. Fruchtknoten ans einem Fruchthlatt bestehend, oberstiindig, mit weifsen, langen llatren. Griffel glatt, mit koptioverdickter Narbe, gelb.

Steinfrucht eiförmig. etwas zusammengedriickt, fleischig. fast saftlos, filzig, graugriin. Schale des Kernes hellbraun, holyig, mehr oder weniger dick, mit unregelmäl'sigen Vertiefungen, knochenhart und glïnzend oder leicht zerbrechlich und matt. Samen (Kern) einer. selten zwei (V'ielliehchen), eiförnigg, etwas tlach, nach einer seite zиrespitzt; nnter der Spitze dem K nospenträiger angewachsen; unter der brännlichgelben Samenhatut der weilse Kern. Keimling mit zwei Heischigen Samenlappen ohne Eiweifs; Wïrzelchen kurz, knösplehen eiförmig.

Man unterscheidet Bitter-, Siil's- nnd Krachunandeln.

Bei den Bittermandeln (Am!!mdulus ammo) ist der Kern selur bitter, an Amygdalin reich.

Bei der Süfsmandel (Am!!ylulus dulrise) ist der an Amrgilalin arme Ker'n siils.

Sei der Knack-oder Krachmandel (Am!yclulus frantilis) int die Steinschale krustig, tief gefurcht, korkig. leicht zerbrechlich.

Im Hinblick auf andere verwandte PHanzen möchte man geneigt sein, in der siifsen Mandel ein Lrzeugnis fortgesetzter Kinltur 7.11 erblicken, indes kommen, nach Flückigger. in urspriinglichen Standurten, z. B. in Südpersien, Mandelbïmme mit siifsen und hitteren Mandeln vor: Die Krachmandel ist zweilellos eine Kulturvarietiit.

Blüht in Sïleuropa schon im lammar.

Vaterland: Wiichst wild in I'nrkestan und Mittelasien (woselh-t es auch wilde Mandeln mit glatten Stein gieht). Verbreitungssbezirk: Orient und Nittehmeerliumler.

Kultur. Die Mandelbïume werden in srolsen, besonderen Anlagen oder zur Beschattung der Wege wie unsere Olisthïme geptlinzt. Will man eine hestimmte sorte erhalten, so muls man anf Mildlinget (auch auf Aprikosen- oder P’firsichwilllinge) okulieren. dit ans š̈̈nlingen bakl bittere, balk siifse Mandeh tragende Biinme hervorgehen. \%ur Saat benutzt man am besten die ganze Schalenfrucht. In manchen Cregenden zieht man sie in triihbeeten oder l'öpfen und ptlinzt site mit Erdballen ins Land. Sach drei lahren werden dio jungen biiumchen okuliert mud wioler nach zwei his dree lahen tragen sie früchte.

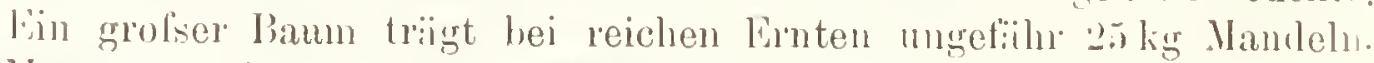
Man minterscheidet iiber : $\left.{ }^{\prime}\right)$ Mandelsorten.

Gehalt und Wirkung der Mandeln. Süfse Mandeln entlalten bis in l'ro\%. fettes Mandelïl, 24 'Teile cigentimliche linweili- 
-ubstanz, Emulsin und Isegumin, 6 Proz. Jucker. :; Proz. Gummi.

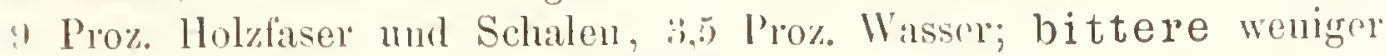
fettes (i), dagegen 30 l'roz. limulsin mul 2 his 3 l'o\%. des fiir sie charakteristischen Amygdalins. Das IVIandelöl ist lett, mild, ohne Blansäne und wird duch Auspressen sowohl der siifien als der litteren Manteh gुewonnen. Es ist geruchlos, schmeckt mild, siils, rein rilig. trocknet nicht an der Luft, erstarrt bei - 250 C. mud wirl leicht lanzig (spec. Gew. $=$ 10,917). Die l'relsriickstiondr (Mandelkleie) mur ler bitteren Mandeln sind wertwoll, da sie lon angenehmen Geruch dos Bittermandelöls behalten. Das Emulsin, ein eiweifsartiger. stickstollialtiger lörper, zersetzt nuter Gegenwart von Wasser das Amygdalin und zerfillt es in Wasser, ii the risches Bit termaudelijl (klal. gelblich, leicht beweglich, bricht die Lichtstrahlen, schwerer als Wasser), Blansiinre und \%ucker. Das Amygdalin lildet in reinem /ustande krystallinische Schiippchen, schmeckt hitter, ist geruchlos murl an und für sich nicht giftig. Die bitteren Mandeln sind infolıe ihrer Blansïureentwickelung giftig, sie sind kleineren Singetieren, sowie Vögeh tödlich und in Menge genossen auch den Menschen schäidlich. Da das Emulsin aber die Wirkung auf Amygdalin verliert, wenn seine Lösung bis zmm Siedepunkt erlitzt wird, so sind geschälte und gekochte oder geröstete bittere Mandeln nicht schädlich.

Gebrauch der Mandeln. Die Mandelı dienen als Speise, als Gewïrz, zm Herstellnngr ron Konditorwaren, solann anch, allein oder mit anderen Stoffen vermischt (Mandelmilch, Mandelïl, Mandelsirup, Bittermandelwasser), in der Medizin, endlich auch zu I'arfiimerieen (Mandelseife). In Griechenland, diese Unsitte luat sich leider atuch lei nns eingefuilnt, ilst man bittere Maudeln, um die Beranschung aufruhalten oler niederzindrücken und um noch meh lierauschendes trinken zu können.

Warenkunde. Gute Mandeln dïrfen nicht zerbrochen, nicht stark bestiubt, nicht zn alt, nicht eingeschrumplt, wnlmstichig, angenagt, inwendig nicht gell, oder ranzig sein; sie sollen voll ansgewachsen, lobhaft lellbraun. trocken, hart und spröde sein. Der eigentliche Kern sei rein weils. Vou den sül'se u Mandeln sind die spanischen ans Malaga (lang unc breit) sowie die ans Valencia und Alicante (grols und hreit) die hesten. Von lon französischen Mandeln sind die Provencer' (Aix) die besten; sio sind kleiner, diinner und schnailer als die spanischen und halten sich lange. Die iibrigen französischen Mandeh siud flach nud geringer. Vorziigliche italienische, Cavaliere, kommen nirht zu uns; nutel diescm Namen erlialt man die Kommune-Mandel, die aber geringer ist. Die florentinischen orler Ambrosiamandeln sind grofis, dick und schnacklaft. Den Provencern ähnlich sind die von (iirgenti und Termini (Vesur) als sicilianische Mandeln in den Iramlel ge- 
brachten. Die gewöhnliche Handelsware Italiens sind die P'urliaMandeln aus Apulien. Die greriugsten Sorten sind die berberischen Mandeln (Mirokko, Algier mud 'Tunis), klein, mit vielem Bruch, und die deutschen Mandelı (in Unterösterreich, lianken, an der Bergstrafse), klein und ohne Dauer. Dic bitteren Mandeln werden in geringerem Malse gebaut, sie kommen hauptsichlich von Nordafrika sicilien und Siidfrankreich in den Handel.

Das Mandelöl des Handels ist oft mit baumöl vermischt.

Angaben über den Handel. Italien versendet etwa 20 Mill. líilogramm Mandehn, Sp:mien 4 bis 5 Mill. Kilogramm. Die französische Ausfulı liifst sich nicht ïbersehen. da sie mit der von Niissen und Inselnüssen zusammen verzeichnet ist. Die marokkanische Ausfuhr beträgt jährlich etwa 1 Mill. Kilogramm. England empfängt jührlich für 4 his 6,6 Mill. Mark, wovon es fiir 3 Mill. Mark selbst verbraucht. Das Deutsche Reich fiihrte 18968433 Tomnen, 18977901 Tonnen ein. im Werte von 7,9 bezw. 8,5 Mill. Mark.

Geschichtliches. Der Mandelbanm wird schon seit uralten Zeiten kultiviert. Schon die Biicher Moses fiihren als Erzeugnisse Palästinas Mandeln auf. Homer kemnt iln nicht; doch waren die Mandeln im 6. Jahrhundert v. Chr. in Griechenland bekannt. In der römischen Kaiserzeit unterschied man sie, nuces fraceae, genau von Kastanien und Eicheln. Der Mindellaum nahm bei seiner Verbreitung den allgemeinen Kulturweg aus Asien (Kleinasien, Inseln des Ïgäischen Meeres, Griechenland); von Nordafrika kam or nach Sicilien und Spanien. Die Mandeln von Naxos und Cypern galten den Alten für die besten. Karl der Grofse empfiehlt in seinem Capitulare den Anbau; in Deutsclıland sollen die ersten Mandelbäume in der Gegend ron Speier gezogen worden sein.

In unseren Gärten ist die Zwergmandel (Amygdulus numb) ein heliehter Kierstranch. 


\section{Tafel 8.}

\section{Citrone (Citrus Limimun Risso).}

Die Citrone gehört zur Unterklasse der Freiblïtterigen Dikotylen, zur Reihe der Storchschnabelgewächse (Creraniules), zur Familie der Rauten (Rutuceue), zur Unterfamilie der Orangengewächse (Auruntioüleuc).

Die Familie der Rautengewächse zeichnet sich aus durch strallilige Zwitterbliiten, in welchen die Bliitenachse zwischen den Staubblätter'n und dem Fruchtknoten zu einem ring-, polster-oder becherförmigen, gekerbten oder gezähnten Diskus (Fig. 1 und $4 \mathrm{~d}$ ) erweitert ist, sowie durch Öldriisen, die durch Auflösung einzehner Zẻllen oder ganzer Zellennester entstanden sind und namentlich auf den vorzugsweise kahlen Bliittern gefunden werden. 111 Gattungen mit etwa 770 Arten.

Die Unterfamilie der Orangengewächse umfalst in 14 Gattungen etwa 75 dem tropischen und subtropischen Asien und Afrika angehörende Arten. Es sind iiberall mit öldrüsen versehene, immergrïne Ströucher und Bäume. Blätter abwechselnd oder zerstreut stehend, einfach, oft auf dem Gelenke mit einem gefliigelten Blattsticle befestigt, ohne Nebenblïtter. Bhiiten meist zweigeschlechtig, strahlig, drei- bis fünfgliederig. Kelch kurgglockig oder krugförmig, mit dreibis füntzälnnigem oder -spaltigem oder ganzem Samne. Bhunenblätter frei oder miteinander verwachsen, in der Knospe riegeldachförmig. Staubbliitter meist doppelt so viele als Blumenblïtter, mitunter vierbis zwölfmal so riel. Dic Stanbfïlen sind frei, oder teilweise oder sümtlich vercint; die Staubbeutel springen nach innen auf. Der zwischen den Staubblïttern und dem Fruchtknoten eingefuigte Diskus ist polsterförmig oder stellt einen Fruchtknotenträiger dar (Fig. 1). Fruchtkuoten frei, drei-, fü̈n- oder mehrfächerig; meist in Innenwinkel jerles Faches eine oder zwei, scltener zahhreiche Samenanlagen enthaltend; Griffel endständig, dick; Narbe kopfförmin. Frucht eine Beere, gebildet aus mehreren Fruchtblittern, dic $n$ m eine centrale Achse gestellt und untereinander verwachsen sind, aber leicht getrennt wrilen können. Sie besitzt eine Heischige. lederartige Schale, in der zahlleiche Öldrïsen 
liegen. Sie onthïlt hänfig ein saftiges fruchtfleisch, das aus kileinen strahlenförmig angrordneten, den Saft enthaltenden Bentelchen besteht, dic ihrerseits aus der Imenseite der Fruchtwand herrorwachisen. Die zwischen diesen finchtfleiscll eingehetteten Samen enthalten kein Nïlngewehe, abre nicht selten zwei oder mehr Keimlinge mit dicken, Heischigen Keimblättern und kurzen St:immchen.

Ungelïhr $70 \mathrm{Arten}$ in 14 Gattungen. Sie zeichnen sich aus durch schöne Belauhung, wohlriechende Bliiten und wohlschmeckende Früulte (Citronen, Pomcranzen, Apfelsinen etc.). sowie durch ihn itherisches (i)l.

l) ie Gattung Orangenbaum (Cims L.). In siidasien lei-

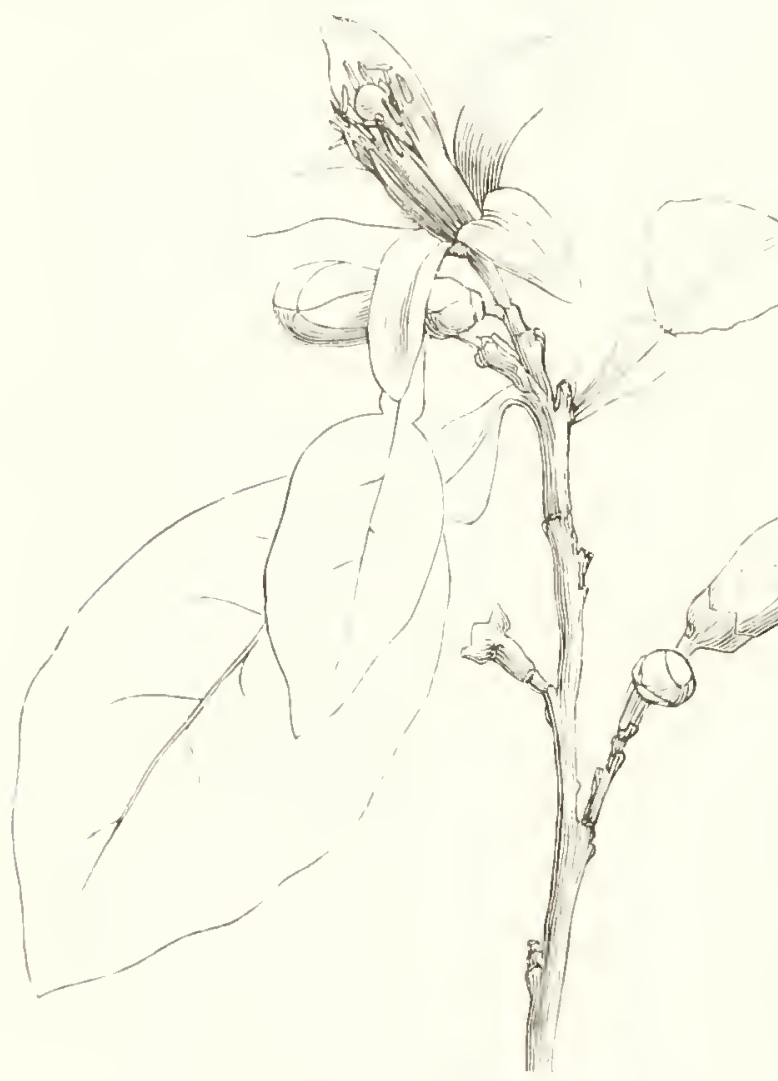

Zweig der Aptelsine. mische, meist dornige Sträncher viler liaiune. Blïtter in der Regel immergriin, lederis. dunkelgriin mit hallstielrundem, oder berandetem, mehr oder weniger getliigeltem Blattstiel und mit einem vom Blattstiel meist deutlich algegliederten, eiförmigen his lanzettlichen, ganzrandigen oder gekerbten oder gesägten Blättchen (siehe $\mathrm{Al}$ )lildungr des Apfelsinenzweiges). durchscheinend punktiert. Kelch napfförning, drei- bis fünfziilmig, Blumenlliitter linealliinglich, vier bis acht, fleischig. druisig, frei. Stanbblaitter 20 bis 60; Staulbfiden Hach, zu IBiindeln verwachsen. Diskus polster- oder ringtörmig. Fruchtknoten fünf- bis vielficherig. mit vier his zehu" in zwei Reiluen stehenden Samenanlagen, hängend. Brere Heischig. viellächerig; Fächer trennbar, von einer diimen Hant hekleidet mit einen von Salt strotzenden, zelligen Mus erfiillt. Samen wenige, nit lederantig(re, fust liäutiger Samenschale. lieimling mit zwei Hrischigen. häntig ungleichen Simenlappen; Wiirzelchen nach oben gerichtet.

Sauercitrone, deutsch gowöhnlich Gitrone, Kitrone, italienisch limone, frimzösisch limonier mol citronnior (Citms: Limomum Risso; C'itru. medire, vall. B. Linnoi).

laum :3 his 511 hoch; Dur chmesser 30 his to $\mathrm{cm}$. Stämme

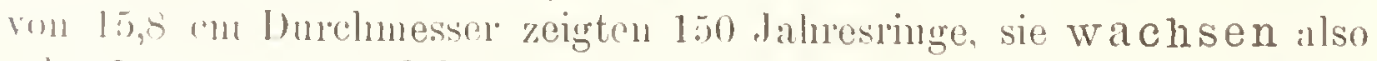
sehr langsam und kïnnen sehr alt werten. Rinde selı dïn. 
Wurzel istig, ausgelreitot.

Stamm lanumatig. Krone vielistig, Holz lest, loin porös.

Blätter \%erstrent stehend. Biattstiel herandet oder schwach

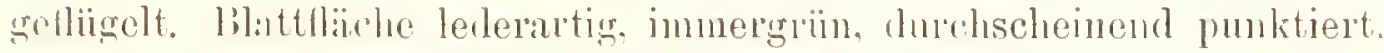
linglich, etwas zugespitzt, kenbig-nesäirt. laneben oft nocl den lilattachselsurossen angehörende, pliemenförmige Inornen.

Blïten einzelı in den Blittwinkelı oler an ser Spitze der Zweige gehïuft, gestielt. wohlpiechend, anfsen rot. Kelch bleibend.

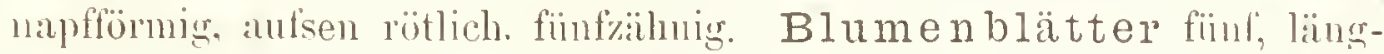

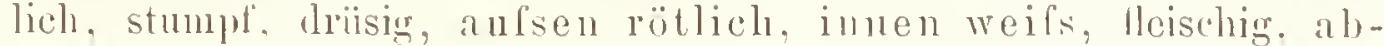
tallend. Staubblätter zahlreich. Staubfäden in mehrere flache. woifse liindel seitlich verwachsen, freie linden pfriemlich. Staub. beutel lïnulich, zweiläicherigr, an Grunde pfeilförmig, oben mit ciner kurzen, stumplen Spitze verschem, gelb, mit etwas nach imen gerichteten Läingspalten. Stempel einem scheibenförmigen Diskus anliresetzt. Fruchtknoten cilinglich, qeln bis zwölflicherig. Samenanlagen sogenlänfig, in zwei Reihen der Mittelsäule angeheftet, läingend. Griffel walzenrund, mit kopfförmiger Narbe.

Beere, die Citrone unserer Küclie, 5 bis 7 cm lang, länglich oder oval, oben mit einer grol'sen Warye, gelb, drüsio, zohn bis zwiilftiicherig. Fruchtschale diinn, mit vielen eingesenkten (j)helıilteru. aufsen gell, innen sclwammig, weifs; Fïcler um rie markige Mittelsäule gestellt, ron einer dïmnen Ilaut bekleidet, unter sich trennbar. ein- oder wenigsamig, mit einem saftstrotzenden, zelligen, selır sauren Fruchtbrei erfiillt. Same eilïnglich, mit einem Nabelstreifen, ohne Nïhrgevebe. Keimling gerade, Würehchen sehr kleiu, nach oben gokelint.

Die Citronenbäume tragen in Süden immer Blïten nud oft griine und reife rriichte.

Heimat: Südliches Asien. Verbreitungsbezirk: Aufser im indisch-nalaiischen Gebiete namentlich in den Mittelmeerlandern bis zum 43. Grinde nördlicher Breite angelout und verwildert; aufserlem angebaut ant den Azoren, einigen siidseeinseln, in Anstralien, Westiudien und Kalifornien; in unseren Treibhäuseru häufig gezogen (Orangeriegewiichs).

Kultur. Alle zur Familie der Orangen gehörigen biame werden in iller Ileinat wic hei uns lie Ohsthiime angepflanzt, gepfleg.t und vermehrt. In Nord- mol Mittelitalien ungieht man die Citronengiirten mit Mauern und setzt zwischen die Biiume I'feiler, mun sie in Winter mit Brettern ('ine M't Kalthïuser), die den'/utritt des Lichtes mul der Inft gestatten, eindachen zu kïnuen. Iiei grolser

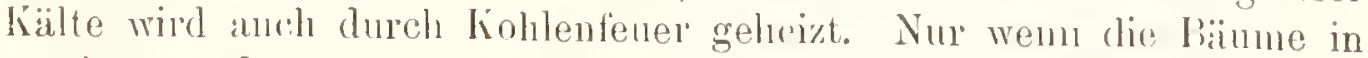
rescliitzter I age stehen, ertragen sie anch einige 'lagr sichnce. Frste Ernte Ende Juli bis Mitte September, wweite November, dritte Januar.

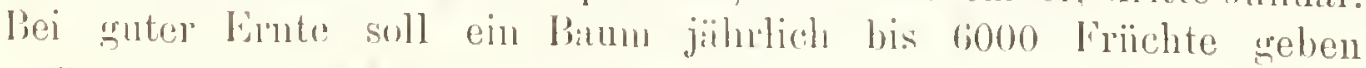




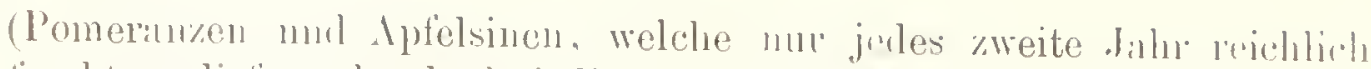

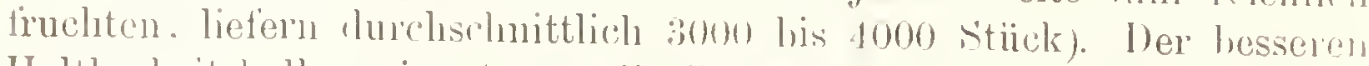
Halthalieit halber nimmt man die ('itronen vol der vollstindigen lieife al und velpackt sie \%n 100 his 700 sitick sorgfältig mit l'apios innd Werg in kisten.

Gehalt. Her au den Hëichten geprelste rische Saft enthailt lant s Proz. freie Citronensäure. Dir Schalen sind reich an ätherischem Öl, ('itronenöl. In den Samen finclet sich krystallisierbares, weilses, gernchloses, stark bitteres, nentrales Limonin. in der schwammigen selicht ler schale krystallisierluares, weilses. geruch- und geschmackloses Hesperidin.

Geblauch. Nie Anwendung der Citronen in der liohe nud Konditorei ist bekannt. Die sclualen werden in der likörfabrikition verwendet. Citronenäl wird seines Wohlgeruches halber an l'allfiimerieen, l'omalen 11. s. w. benut\%t. Scluale, Salt und (i) finden in der Medizin Verwondung. Das lielgriine. citroncuartïr ricehende llol\% wirl in der hinnsttischlerei benutzt. Das Citronenlıolz, das den Römern kostbare Tischplatten lieferte (nach Plinius soll Cicero tïr eine solche latte soviel wio etwa 100000 Mark bezahlt hahen). stimmt ron dem Morgenländischen Lebensbatme (Thuju miemlnlis).

Warenkunde. Je dümner die sichalen. desto höher der Wert. Die Friichte der ersten Erute sollen die besten sein. Vluckige. angefaulte, zusammengetrocknete Citronen soll man nicht kaufen.

Abarten der Citrone sind die Malta-limone (rm: rmlynris lisson unit meist cifömigen, anfangs blalsugelben, dann dunkler gelben Füucliten.

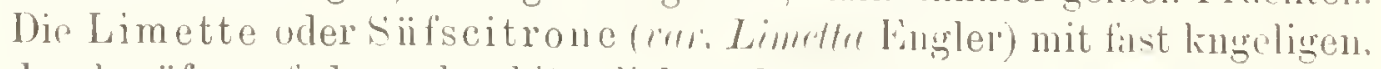
lurch siifsen, fadon oder bitterlichen Salt gekennzeichneten Frichton; letrtere liefert das limettenöl. Mls Spielaten der Limette sind bemerkenswert die Perette ( $($. I'rollu hisso), nit keilformigen, gezalunten, stachelspitzigen Baittern und blafsgelbrr. birnfömiger rucht.

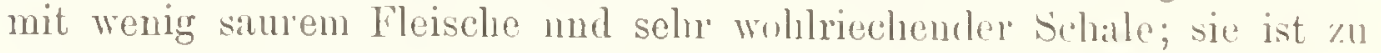
Konfituren belieht; ferner die (lhy somelie, Coldhesperide (c: me-

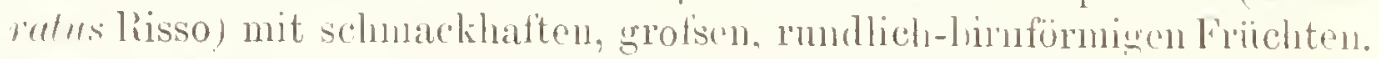
Weitere Abarten der Citrune sind die liosoline. Wa clislinone rar.

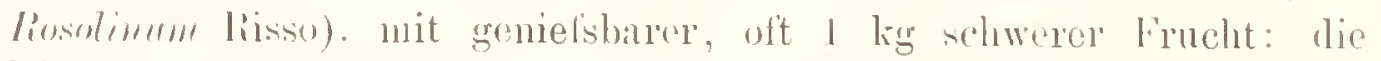

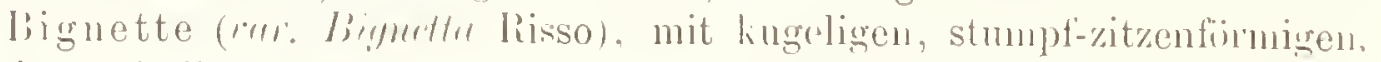

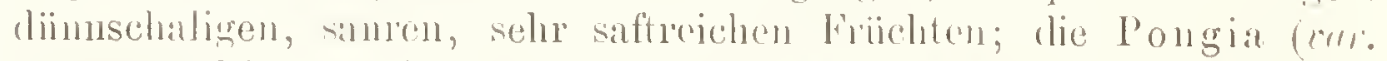

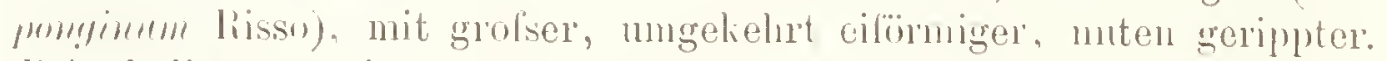

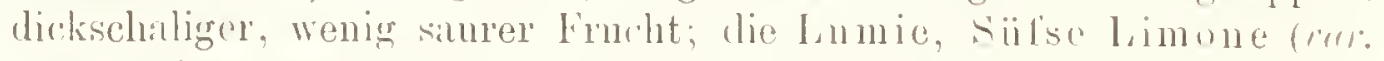
Inmin Risso), mit silfsen l'nehtlleisoh. Vorwandt ist anch die liontul'-

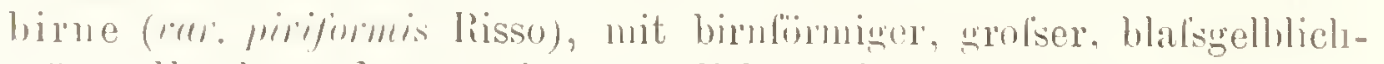

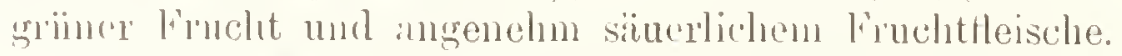

Allo Citrusarten ghleichen der besprochenen so selu, dals rint"

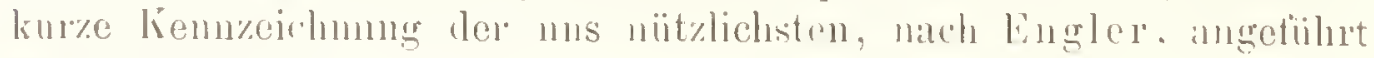
werilen moigre. 


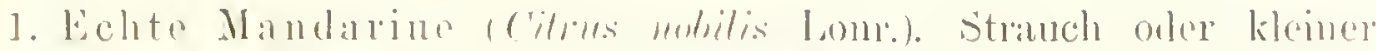
liamm, mit kur\%on, kaum gretlïgolten blattstielen und lanzettlidhen. schwach gekerlsten Blittchen, mit in biischeln stehenden. weilsen Iiliten, mit wenig vereinigten Stanblubittern und etwas nioder-

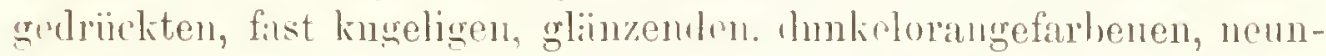

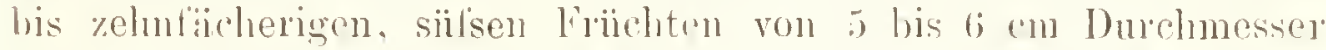

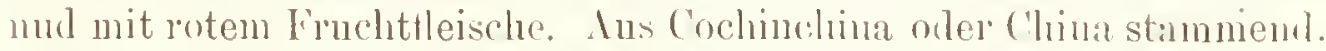
wird in Südenropa mul aut den simdanseln linltiviert.

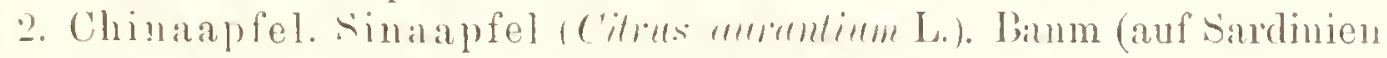
colche mit 10 his 50 cm Dur(hmesser), seltener Stranch; in der liegel mit hellgrünen Schölshingen, weilson, gewölnliclı \%witterigen Bliiten nul neist kugeligen oder etwas nielergedrickten, mituntro" auch mit eiformigem, zitzenförmigen Fortsatz endenden, in der. lieger orangelanbenen, acht- his zehnfächerigen friichten von sehr verschiedener Gröilse.

a) Unterart: Gemeine oder Bittere l'omeranze; ital. Aranciu wer Melangolo forte; franz. ligaradier; engl. the bitter

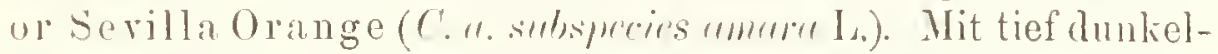
grüuen, stets schr aromatisch riechenden Blättern. mit reHiigeltem Blattstiel und eiformigen bis länglichen Bliittchen, mit weilsen, stark wohliechenden Blüten, kugeligen Friichten. l'omeranzenäpfelchen (Orm!ctes. Armzinclti), mit sehr' :momatischer, bitterer Rinde und sanrem Fruchtfleisch. Wahrscheinlich in südöstlichen Asien leimisch und von dis über die Sundainseln, Torderindien, Persien, Arabien, Syrien, Nordafrika nach Europi gclangt. I)ie Blätter und unreifen Froiichte

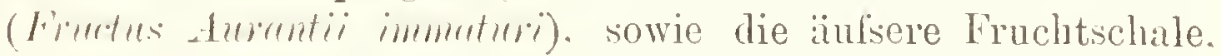
P'omeranzenschale, sind offizinell. Letztere rielst his $21 / 3$ l'roz. ligaradeöl von angenehmen Geruals und bitterem Geschmack. Aus den Blüten werlen namentlich in Siidfraukreich grofse Mengen Neroliij, Nafäil und Orangenbliitenwasser für die l'arfümerie gewonnen, Aulserdem werten die Friichte \%ur Bereitungr von Likören (Curarao) und anderen Geträinken (Bischof ı. a.), Konfituren u. s. w. benutzt. Aus reu Bläitteru. mmeifme 'J'riehen und mreifen Fröichten wird das l'etitgrainöl gewonnen.

besondere Kulturformen der l'omeranze sind die Kernlose Pomeranzo ( l'omelanze (cor: rism), dic Tizarre l'omeranze (ror.

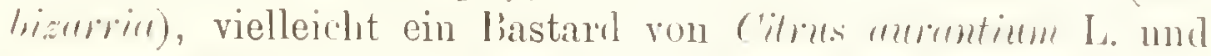
('ilves medirn I.. mit glatten, orongefarbenen (Oringe) und warigen, gelben (Citrone) 'Teilen; div Gelü̈nte Poneranze (ar. rornirulutu), mit hornartigen Auswüichsen an den liuichten.

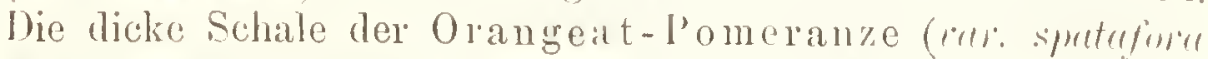
lisso) wird in Zucker eingemacht, Orangreat. 


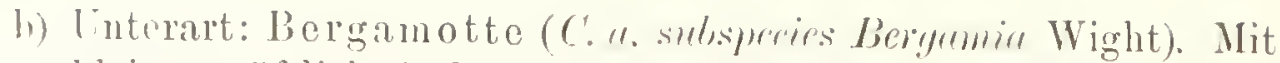
kleinen, siifslich riechenden libiten, kugeligen oder birnförmigen, shatschaligen, blafsgelhen Frïchten mit angenehn sïuerlichem Fruchtlleische. In Simleuropa nnd Westimalien kultiviert. Aus den Fruchtschalen wird dis wohlriechende lierganottöl gewonnen. Mbarten sind: die Kileinfruchtige Bergamotte (ear. lurea Risso et l'oiteun), mit kleiner, kngeliger lruclit; die Riploenfruchtige liergamotte (rur. lombsu Risso et l'oitean), mit biruförmiger, gerippter l'rucht; die liosenapfelbergamotto (Mellalosa, bur. Mrllorosu liisso et I'oiteau). mit r'mudlicher, niodergedrickter, an den Seiten werippter Frucht mit seln wohlriechendem (i), zn Konfituren belieht.

() Unterart: Apfelsine (('. a. sulsumics simesis Vallesio); ital. Arancio dolce, Portogallo; franz. Oranger; engl. the Malta or l'ortugal ()range. Iianm mit meist blalsgriunen sprossen, schwach aromatischen Iiaittern, mit gefligeltem lilattsticl, mit srolsen, weilsen Bliiten, meist kugeligen, selten eiförmigen orler hirnförmigen, orangefarlyenen, sehr selten gelben Frïchten, mit in reifen Zustande siifsem nud schwach sänerlichen Frnchtfleische und dicht anliegender Schale.

Abarten sind: die lilutapfelsine (ear. smmmima Engler), mit blutrot gestreiftem orler ganz hlutrotem Fruchtfleisclie. Die Pompelmuse. Paradiesapfel (ren. Itemmonu). Sprossen anfiuglich weich behant. zuletzt oft kahl. In selur zahlreichen Spielarten nit kugelig-eifömigen oder hirnförmigen, aulsen weilsen, fleischfarbenen oler roten, auch gelben oder rotwangigen, kleinen oder grofsen Frichten; mit oft sehr dicker, aber anch dimner Schile und herbem, simnen oder siifsem Eleische. Die Spielart Melonen-oder Kirbiscitrone, Ponpelon-I'ompelmuse trägt Früchte bis zn 40 (nu Durchmesser; sic besitzt cine seln dicke, als Delikatesse geltende Scluale. IVierher gehört auch der Adamsapfel, I'aradiesapfel, jüul. Esrog (C. I'omm Adumi lisso); die ei- his lirnförmige, goldgelbe, köstlich schmeckende, süls-säuerliche l'rucht wird wegen der bil'sïhnlichen Sirben und W'iilste ihrer Schale nach dem 'Talmnd als die Frucht rom bamme der kirkenntuis angeselıen, welclue Adam im l'araliese genols; Zweige des biumes kommen in den Mandel, weil sic von den Iuden an Ianbhïttenteste benut\%t werden.

3. Citrone im weitesten Simne: drs Wurtes ("itms medien L.). Stranch oller kleiner Banm, ncist mit rötlichen Sprossen, kilnlen Blïttron. mit mämlichen mml zwitterigen, moist rötlichon Bhiten, mit hugeligen,

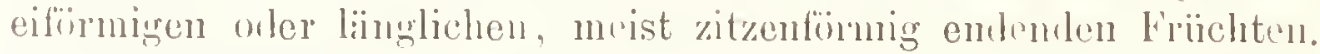
An linlise des Ilimalaya, in Cochinchinal oder in China hemisolı: iiber den Maliybischen Archipel nud Indien verbreitet, ron dar nach 
Medien und l'ersien eingefiihrt, woselbst sic etwa 300 v. ('hr. den ririechen hekimut wurde.

a) Ilierher zunïchst die oben genaner behandelte Unterart: Citrone, C: Limonmm hisso.

b) Unterart: Citronatbanm, Cedrate, ital. Cedro; franz. C'é dratier (an: Bujoum Bonavia). Bliitter meist an Grunde mehr eifömig. Frucht oft kopfinrols, mit sehr dicker oder runzoliger oder höckeriger, citronengelher, sehr ölreicher Fruchtschale. Die frisch eingemachten Schalen bilden das Citronat oder die Sukkade. Sie licfert den grölsten 'Teil der Citronenschale des Handels und sehr viel Citronenöl. Man unterscheidet Ponzine mit wachsfarbenen Höckern, dahin die Riesencedrate (rar. maximu), die bei Genua mit 15 (?) $\mathrm{kg}$ schweren Frïchten gezogen wird, Echte Cedrate mit siilsen Frïchten, Rivers Cedrate (Rirems Bijm Lemon. cur. Liccersii Hooker) von deu Azoren, mit kugeligen, 21/2 bis 4 cm dicken Friichten, u.a.

Handel. Nach Deutschland kommt besonders die Samercitrone rom Gardasee, ron Nizza, Genua, Nentone. Über Einfuhr und Verbrauch in Deutschland giebt es keinen zuverlässigen Nachweis, da die antlichen Angaben (itronen und Orangen der verschiedenen Spielarten, von 1896 an auch frische Feigen, Pistazien n. s. w. zusammenfassen. Von diesen Früchten wurden 1896 für 8,5, 1897 für 11,3 Mill. Mark eingeführt. Der Wert der in den Handel kommenden Friichte von Citrusarten ist gewaltig: allein von Apfelsinen soll England jährlich etwa 650 Mill. Stück einfülıren, wälırend Süditalien und Sicilien für 200 Mill. Franken, Portugal 170 Mill., Griechenland 50 Mill., Jamaika 40) Mill., Paraguay 35 Mill. Stiick ansfiihren. Allein Italien fuihrte 1897 315,2 Mill. Kilogramm Südfriichte (Orangen, Citronen, Kastanien. Feigen, Johannishrot, Korinthen, Mandehn, Datteln ı. s. w.) aus.

Geschichte der Citrusarten. Die goldenen Ïpfel der Hesperiden waren weder ('itronen, noch Pomeranzen oder Apfelsinen. Die Frïchte der (itrusarten wuden vielmehr erst nach den Kíriegsziigen des grofsen Macedoniers in das IJerz Asiens nach nud nach hekannt. Durch sio ertuhren die Griechen von einem Wunderbaum nit gohlenen Frïchten in Persien und Medien. Theoplrast beschrieh zuerst diesen ., Medischen $\Lambda_{p}$ fel". „Der $\Lambda_{p}$ fel", sagt er, "wird nicht gegessen, duftet aber schön, wie anch die Blïtter; nnter Kleider gelegt. schiitat er dirse segren Motten; wenı jemand Gift bekommen lat, gielst er ein wirksames Gegengift ab; wem man iln kocht und las Fleisch in den Mund ausdriickt und hiounterschluckt, verhessert er den $\Lambda$ ten" "n. s. w. Vergil nemt den Saft der Frucht stechend (ristis) und seinen Geschmack lange haftend (tordus). Da die lincht Ungeriefer abwehrte, erhielt sie den lateinischen Namen ritrus, mulmm cilirum n. s. w. und zwall war das Wort von dem griechischen kédros genommen, wounit man die Koniferenlı̈̈zer be\%eichnete, die dem Tngeziefor wider- 


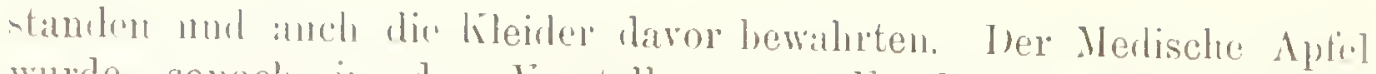
wude sonach in der Vorstellung zur Frurht den citrusbames. II:Hhend P'linius noch ron vergoblichen Versnchen, lebende oder doch

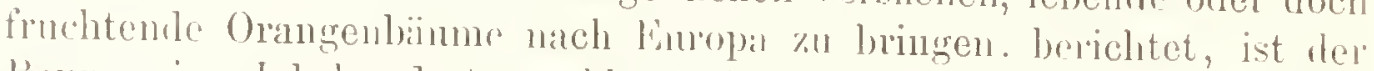
Hanm din Jahrhmolert nachher ein Schnmck der Gïrten. Wir. Palladius in J. Jahnhundert mitteilt, whchsen danals ('itronenbämme at Śardinion und hei Neapel Winter und Sommer unter freism Himmel. I)ie Limone heilst so nach dem arahischen limin; dies stammt ans dem I'ersischen; letzteren entlehute das Wort aus dem Indischen womit Herkunft. Wer und \%eit angedentet sint. Nach Europa whrle sie durch die Krenzfahrer, durch die Handelsleute der italienischen Seestädte mod durch die Araber bei ihren Kriegszïgen und Niederlassmngen auf den Insehn und Kü̈sten des Mittelliindischen Meeres zelnacht. Auch dic I'omeranze (persisch nitreng. arabisch nirang) lím durch die Araber nach Europa. Goethe namte sie "Goldorange". Die suilse Pomeran\%, dic Apfelsine, lam spaiter nach Europa; woher. sagt das Wort Apfelsine, d. h. chinesischer Aptel. also ans (hin:l, lurch wen. sagt die italienische Benemunn portosallo, durch die Portugiesen. Selhst die Kurden nemen sie portoghal. Der europäische Urhaum stand noch lange zn Lissabon im Ilause des Grafen von St. Laurent. Spielarten ron rerschiedenen Orangenbäumen künstlich zu erzielen, „war sonst der Stolz der Gärtner, als von den Tuilerien um später von V'ersailles aus neben ()per, Ballet, Vergoldung me T'orzellin auch der Besit\% weitlïutiger Orangerieen mit kugelig beschnittenen Bäumen in prachtvollen Kïbehn nnd Kasten, die im Sommer linge Alleen bildeten, zum kostbiren Erfordernis aller Hof haltungen. ja der Herrenhäiser des reichsumnittelhan ren Landadels geworden war.". Die Mandarinen sind erst in diesem . Tahnhundert in Emropa bekannt gr.worden, anch grielst 's in Asien noch manche sewilis anbaunngswïrdige Arten, die eine willkommene Bereichermg unserer Tafel darstellen wiirden, so die Gulgul (Citm. Klmettu Bonaria) ()stindiens, die Japanische Orange (Kin-Kan, (itms, jumnim Hooker). die ('hinesische 1) range (Butwal-Oringe, ritns chutun Engler). n. a. 


\section{Tafel 9.}

\section{Vanille (I'anille plunifulin Andrews).}

Die Flachl,iitterige Vanille gehört znr Klasse der Monokotylen.

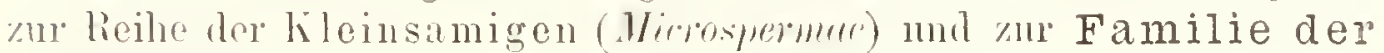
Knabenkräuter (Oindiduen').

Familie der Knabenkräuter (1)rhidurene). Ausdauernde. meist ein hohes Alter erreichende Pflanzen, die nach ihrer I ebensweise als Erdhewolner. Fänlnishewohner oder l̈berpflanzen unterschieden werden können. Die Fïnlnisbewohner, Saproplıten, sind blasse. laubblattlose Pffanzen, die sich ausschliefslich ron den organischen Stoffen ernïhren, welche im ILmusboden anfgenı̈̈uft sind. Die C̈berpflanzen. Epiphyten, Aërophyten (Vanille). hreiten ilıre Wurzeln auf der Rinde von Bänmen aus und sind für iln'e Eroührung auf die Atmosplïire, ihren Stauh und ihre Niederschläge, Regen und Tau, ancewisen. wälrend der L'anm dor Überpflanze nur einen geeigneten Standort und allenfalls einige \%ersetzungsprodulite seiner äufsersten Findenschichten darbietet. Wirkliche Schmarotzerphlinzen sind unter den Orchidern noch nicht hekinnt.

Allen orchileen fohlt cine Hauntwurzel; im iilsrigen künnen wir walzenförmige Erdwurzeln. Knollenwuzeln (I der unstehenden Figur) und Luftwurzeln (Vanille) unterscheiden.

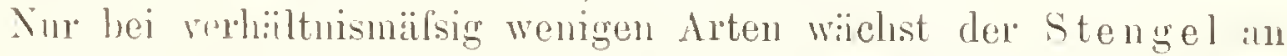
seiner Spitze nelırere Jahre. dinn aber oft Jahrzehnte, ohne Niederliatter zu hilden, weiter, wohei dir Bliitrnstände aus den Achseln der ailteren Bäitter hervorbrechen. Mcist hildet sich joles Jahr ein besombrer. an Girunde Niederblaitter bildender 'Trieb. der in der Regel 11 wrongen Monaten völig ausgebildet ist und nur ansnalumsweise in der nächsten legutationsperiode noch woiter wïchst. Bei diesen Arten - tellt entweder der 'Trieb sein Spit\%enwachstum völlig ein und entsendet bliitentragendr Seiten\%weige, oder aber the Stengelspitze sclbst wird \%um cudstiindigen Blïtentriehe (Fing. I). In letzteren lialle kommt es nun oft ror, dals die Soitentriebe die Bliitenstände leseite driicken,

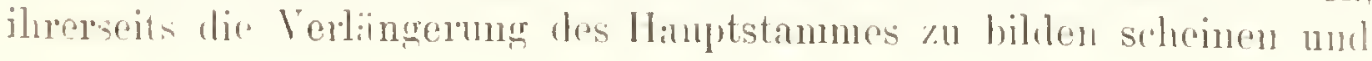


Vanille.
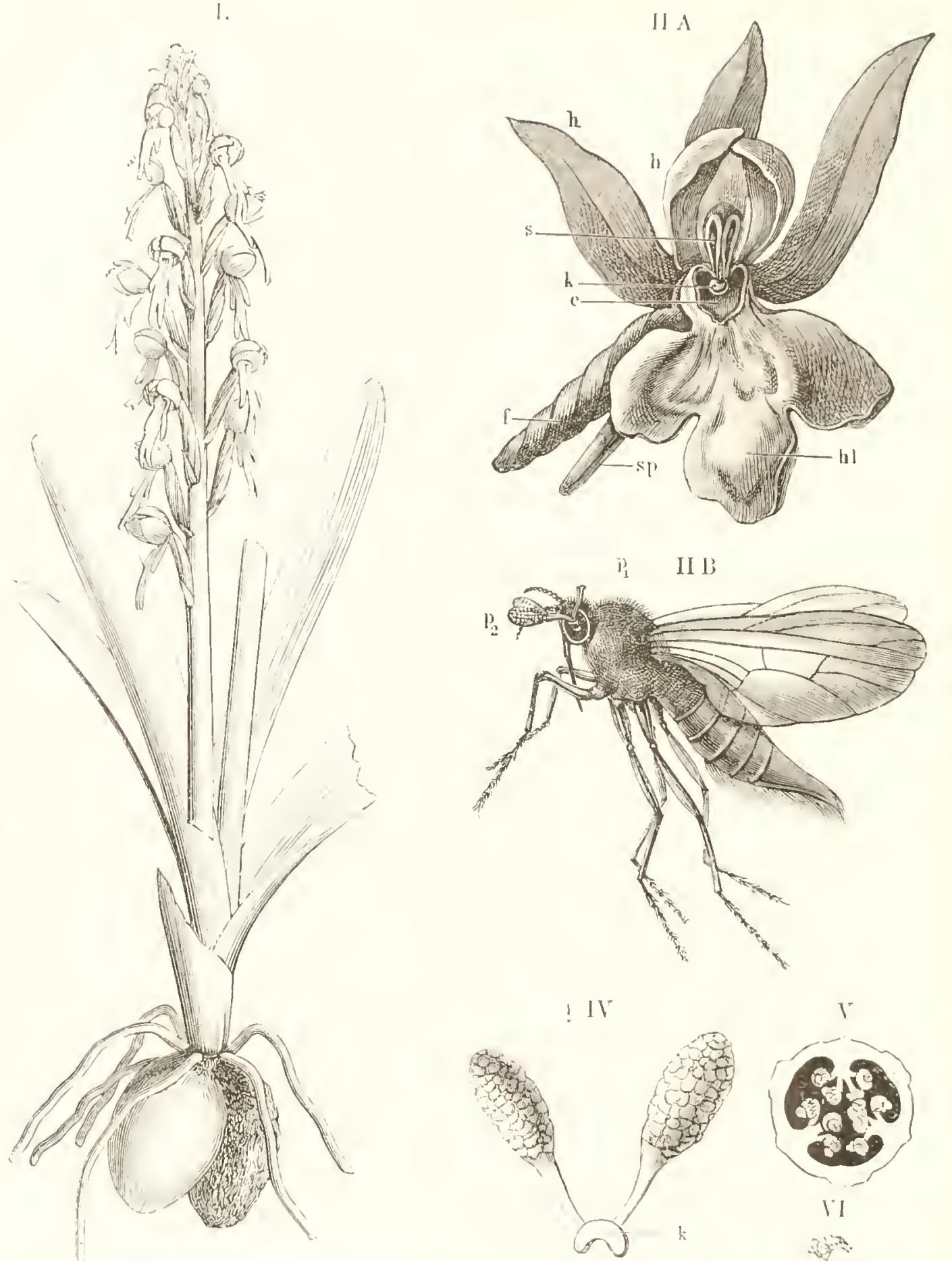

III A

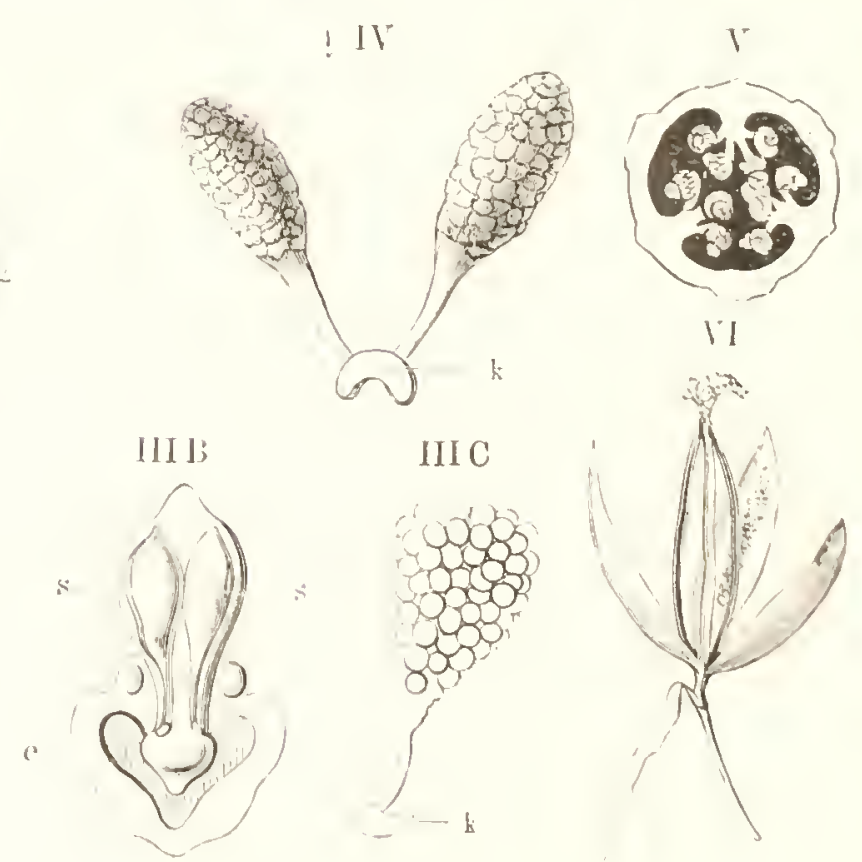


1. Ohnhorn (Arreces anthropophom).

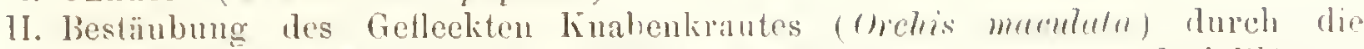

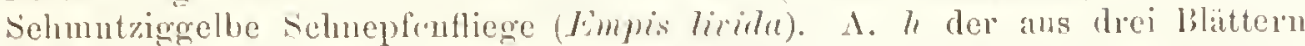

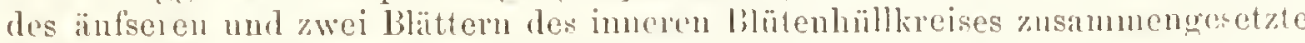

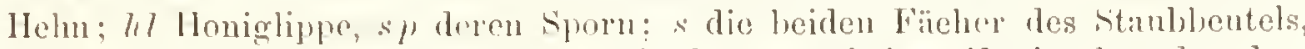
k lilebdrüse; darunter e der lüingang in den zwar keinen llonigr absondernden, in scinem saftreichen Gewele aber demoeh Nalumng dabiotenden sporn.

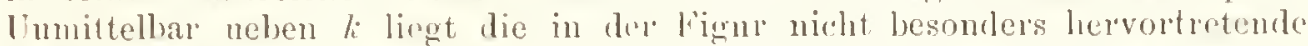
Narbe. Will die Fliege (B) aus dem Siporn Nahrung saumen, dam stölsst sie mit ihrem hople gegen die likebdrüse und lieftet sich so dio beiden blütenstaubiöper in der Lage $\mu_{1}$ an; naeh kurzer Zeit troekuen die Stielchen aus und die Staubkïlbehen nelimen die Lage $/ \%$ an. livi ernentem Blum.nbesnche worden dicse gegen die Narbe gestolson, an wolcher stets einige bihtenstaubkilhehen haften bleiben. Voror.

1I1. Braunes Kuahenkiant (Orchis firscu). A. Blïte im Längsechnitt. s Staubbeutel; $k$ Kebdrïse; $n$ Narbe; sp Sporn; fl Fruehtknoten. 13. ¿ Staubbeutel, lingang in den Sporn. C. Kolbenmasse mit Stielchen und likeldrüse li. Vergr.

IV. Die beiden l'ollenmassen des Hundswurz (inucumplis pyramidulis) sind dureh die Kilehdrise $k$ miteinander verbunden. Vergr.

V. Querschnitt durel den linclitknoten einer Orehis. Vergr.

YI. Anfoesprungene Orehiskapsel; zwischen drei stehenluleibenden lippen haben sich drei lilappen losgelöst.

so eime Scheinachse darstellen; gerade dies ist namentlich bei den Vanillearten, die sehr hoch kletternde Stämme bilden, der Fall: bei ihnen schlielst der Hauptstamm mit einem Bliitenstande al und Seitentriebe fuiluen die Pflanze weiter (Tafel). - Die grolse Mehrzahl der zu den Überptlanzen gehürenden Orchideen bildet kmollenförmige Verdickungen des Stammes, die als Reservebehälter für Wasser und organische Substanz dienen nnd die bei manchen Arten, die eine trockene Jahreszeit durchzumachen haben, in dieser, nach Abfall der Bläitter, allein vorhanden sind, so dals wir sommergriine und immergrüne Arten unterscheiden können.

Die Blüten stehen selten einzeln, meistens in ïhren, Tranben orler Rispen; sie sind meist zwitterigr, selten eingeschlechtig oder polygamisch. In den letzteren Fïllen innerhall, derselben Art, mitunter von derselben Pflanz, durchans verschieden gestaltet; so z. B. bei der in Mexiko vorkommenden C'atasetum tridentutum, deron zwitterige Form als Myanthus, deren weibliche als Monachanthus beschrieben wurde. Ile Blitenhiille ist seitlich symmetrisch und ans zwei-, in der legel dreizahligen, abwechselnden, gleichen orler ungleichen liveisen grebildet; in demselben Kreise simd je zwei Glieder eimander grleich, das dritte meistens anders geformt. Das obere blatt des immeren Kreises ist fast immer ganz besonder's ansgebildet und \%u einer oft gespornten lloniglippe gestaltet, wïnºnd die iihrigen lïnf Bliitter den sogenamuten llehn dilstellen (Vig. II $\Lambda$ ).

Die Stanbblitter stehen in zwri Kreisen, sind indessen nicmals alle vollzählig: entwerler ist mu das nupare Staubblatt des iulseren Kreises fruchtbar, oder aber ler Blitenstaul entsteht in don paarigen 


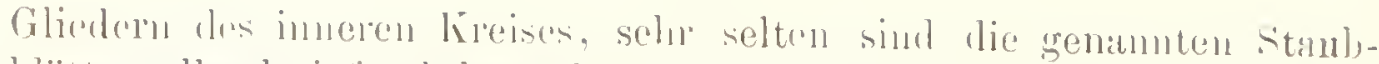
hbitter alle drei fruchthar (ligg. III A und li). Iliufig hilden die Staub)-

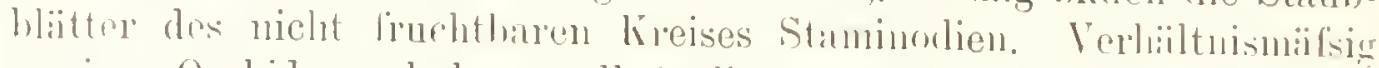
wenige Orehideen haben rollstiudigr getronnte Bhitenstaubkönor: moistrns sind diese zu rier. Tetralon, miteinander verbmden nud su zn liönigen Massen znsammengeballt. oder ein Schleim verbindet lie Körner einer jerln Scite des Staubbeutels zn einer sclappten. wachsartigen Masse (Fig. IIC). Diese luciden lolluenuassen, lollinien. rntwickeln oft nach ilrem Grunde zu Stielchen, und diese sind entweder an ihrem unteren Ende durch Kilebnassen, fiilschlich Klebdrisen genannt, miteinander verhunden, oder getrennt, Zuweilen sitzen die Klebdruisen anch noch in ciner lalte der Narbe. Fruchtlulitter sincl drei, mit dem imneren Staubblattkreise abwechselnde, vorlanden; sie sind zum grösten 'leile innerhalh der hohlen Pibitenachse cingeheftet (Fig. IIIA). Diese aber ist meist iiluer dio Ansatzstelle der liliitenhiille himans zur siule, Griffelsïule (Tafel. Figr. 1 und 3 ), rerlingert. anf melcher sich die Staubblätter und die Narbe befinden: letztere ist meist auf der Innenseite der Sïule gelegen. Fruchtknoten unterständig, meistens einfïicherig, mit drei gegabelten, wandstindigen Samenleisten (Fig. $V^{\prime}$ ); dadurch, daf's er siclı kurz ror dem Anfloliihen spiralig um 180 Grad drelit, hïngt die Honiglippe, ursprïnglich das obere Blatt des inneren Bliitenhiillkreises, nach unten (Fig. II A). Frucht trocken, kapselartig (Fig. VI), selten Heischig, nicht aufspringend. Sameu sehr zahlreich, äufserst klein, olne Niihrgewebe. Keimlingr sehr murollkommen, stets ohne Wurel, selten nit einem Kuimblatt, meist nur eine wenigzellige lingel darstellend.

Nur die wenigsten Orchileenbliten vermügen sich selbst zu bofinchten, die meisten sind anf Insektenbestiubung (Fig. II) angerviesen. woraus sich erklït. dafs in unseren Gewiichshïusern ohne kiinstliche liestïubnng fart nienuls ein Fuchtansaty stattfindet. Die Insektenbestiubung wird erleichtert durch dic ungemein lange Dauer der Blinte: bei den meisten bleilst dic einzelne liliite 30 bis 40 , ja in manchen Fiillen 70 bis 80 'Tage lang vollkommen frisch, wenn sie nicht bestäulst wird; anch werden die Insekten duceh die besonders schïn scefirbten, teils anch durch besonderen Gernch ausgezeichneten Bliten gewissernafien znn Besnehr der Bliiten eingeladen: endlich bieten diese, neben der in der Lipue gegelsenen bequemen Anflugstelle. in den versehiedenen Spornbildungen mud schwielen der Iippe (Fig. 2.5 )

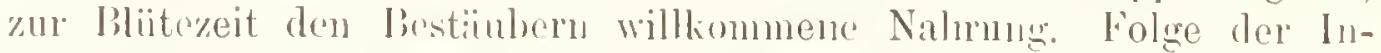
sektenlorstiubung sind die vielficlıen Bastarde. velclse oft, \%. B. bei Montoylosinn, die Artbegrenzung selu erselnweren. Die Orelideen hilden die zweitgrösto Funilie der bibitenptlanzen mit über 400 Gat-

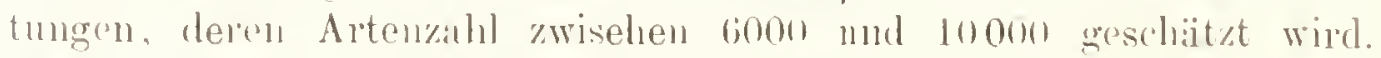

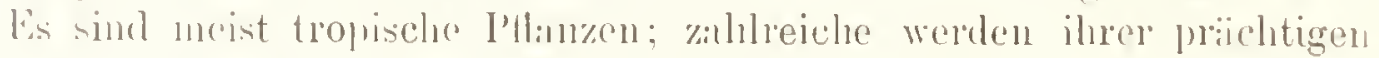

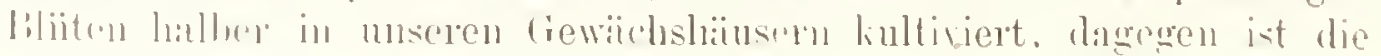




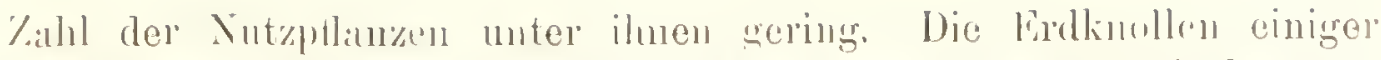
wrolen als salep ihres sichleimgehaltes wegra meliminisch benutat.

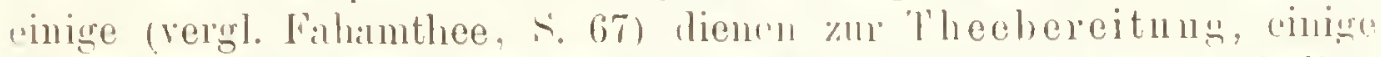

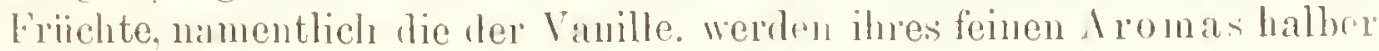
benutzt.

Gattung Vanille (I Imill" swarty). Lipun der (iriffolsiule ziemlich stark angewachsen. Pollen kïnnigr. Foncht kaun oder späit. mit zwei liluppen aufspringend. Samen nit krustiger schale. Ilierher etwa 20 Arteu.

Flachblätterig*e Vanille (Tunill, Mnmifolin Andrews). Ilochkletternde, krantige l'Hanze mit langen, fleischigen, fingerdicken, tiefigrimen stengelgliedern und teils mit Laubblättern, teils nur mit -chnppenbliittern versehenen kinoten, an denen je cine walzenförmige. bindf:Idendicke, weilse, bis 60 und mehr Centimeter lange Isuftwurzel entspringt. I aiuft der olt viele Meter lange Stengol von Pllanze zu Pflanze, so reichen diese Wir\%eln von dem in ler Iaft schwebenden Stengel oft bis zur Erde heril.

Blätter abwechsehnd. ku1\% gestielt, länglich-oval bis länglichlanzettförmig, zugespitzt, ganzrandig, niedergebugen, durch Liingsnerven schwach gestreilt. auf der oberen seite glänzend und lebhaft griin, allf der unter'm matter, 10 bis $17 \mathrm{~cm}$ lang und 4 bis ir cm breit.

Blüten zu bis 20 in blattachselstïndigen Tranben, ron denen eine den eine sicheinachse darstellenden Stengel abschliel'st, wihrend aus den oberen Blattachseln schon vorher solche entwickelt werden, so dal's der ganze obere Teil der Pfianze als eine mit lanbartigen 'Trablittern versehene, grofse Rispe erscheint. Die libiten sind geruchlos, welken nach einem 'lage und fallen später ab. Spindel les liluitenstandes 6 bis $10 \mathrm{~cm}$ lang und 3 bis $4 \mathrm{~mm}$ dick. Die einzelnen liliten entspringen in den Winkeln der $T$ bis $10 \mathrm{~mm}$ langen, eifömigr zurgespitzten, abstehenden Deckblätter; sie sind wegen des langen. walzenformigen Fruchtknotens scheinbar langrgestielt. Blütenhülle oberstindig, mit dem Fruchtinoten gegliedert, zweireihig, sechshlïterig, blal'sgriun, abfallend; Perigonblätter autrecht-ahstehend, länglich; die äulseren und zwei innere sind einander ziemlich glcich, doch sind die inneren anf dem liieken stark gekiclt. Die Honiglippe ist tutenfömig, mit den eingeschligenen Räindern Jer (iriffelsinle angewachsen; sie ist grellolichgriun, in der Mitte etwas aufreblasen, voln kraus, gezïhnt, weifslich, zurükgekriumnt, imnen mit einem acwoilhten, warigen Fleck mod dilmuter mit enen Polster dachziegrelförniger schiippchen versehen; Griffelsäule kür\%” als die Honiglippe; Staubbeutel leckelfömigr, gripfelstiindign, zwei l'ollenmassen, zweilappig; Fruchtknoten 5 his $S$ ('nl linus mit zwei Furclien, einfiicherig, mit drei doppelten, ansgelnchteten sanentrïgen mit zahloeichen Samenamlagen.

Frucht eine schotenförnige lialsel, 16 his : 00 con lang. 1 cm mul 
daruntor im Dnrelmesser dick (frisch), mit zwei furchen, an den Enden rerdiinnt. Hoischir, saftig, gelhtich mit schwaryen, weichem Brei. I)as A ufspringen der reifen Frucht erfolgt in zwei moleichen Klappen. Samen schwarzbraun, sandliorugrofs, ungefithr 25000 in riner kapsel. In den Winkeln der Frucht sitzen grofse, öltropfen enthaltende Zellen, welche den die Samen zu einem aromitischen Mus zusammenhallenden lialsam absondern.

Das Vaterland der Vanillearten ist Centralamerika; die I'lacltblätterige Vanille wïchst namentlich auf , t.t. Domingo und Jamaica wild, wird in den mexikanischen staaten Veracruz, Oajacil (die beste Kentilla), Tirhasco, lucatan, aul' der Iandenge vols 'Tehuantepec und in einigen Gegenden an der Westkiiste, wie im IIinterlande von Arapulco und Mazatlan angebant und kommt da auch wild vor. Verbreitungsbezirk: Aulser in den genannten Kulturländern auch in siidamerika und abweclisehd mit anderen sorten anf Mauritius. Bourbon, den Seyclellen, Ceylon, Java, T'ahiti, Jamaica und 'Trinidad.

Der Vanillestrauch bedarf einer betrichtlichen Feuchtigkeit. Von der höchsten Wichtigkeit ist ein ausgiebiger Windschut\%. Die Schntzbäume mïssen daher gedrïngt stehen und so hoch wachsen, dits sie den Wind wirksam abhalten. Gröfsere Pflanzungen müssen auch vou śchutzbïumen durchkreuzt sein. Die Pflanze beanspruclit einen humusreichen Boden.

Die Kultur der Vanille ist frïher fist ausschliefslich von den Indianern Mittelitmerikas, besonders Mexikos, betrieben worden. Sie wählten zum Aubau der P'tanze weniger dichte, aber feuchte stellen des Urwaldes, befreiten deu Boden ringsum vom Unkraut und pflanzten Cweige der Vanille an den Fufs ron Pfeffer- und Storaxbiämen. Die l'flege der Sträucher hestand nur darin, dals der Boden vom Unkraut freigehalten wurde. Diese Kulturmethode bringt nicht grolsen Erfolg. Wenn Europäer die Pflanze in der heifsen \%one anhalten, wählen sie mach den oben aufgeführten liedingungen einen geeigneten l'it». ptanzen Schutzhäume in entsprechenden Abstïnden [den Calabassebatum (Creserentin r'upete), die Binane, den Kakaobaum 11. a.J, diingen den Boden mit den biaittern der letateren P'flanze und ptlanzen daun bei regnerischem Wetter die Stecklinge von 1 m Lä̈nge in die Xähe der Sclutzbäume. Um die liodenfenclitigkeit znriickzuhalten, muls man beim Ende der Regenzeit die näichste Cingebung des Stanmfulses der Sträncher mit Steinen bedecken. Das Unkrant muls in Fintstehen minterdriickt werden. Sobald die Stecklinge /weige treilen, miissen liese lreit gezogen und wem möglich an spalieren helestigt werlen. Der Vanillestrauch beginnt im 3. Jahre traghar zu werden nod bleibt es his zam 20., aber hereits nach dem 7 . dahre liafst die 'lragbarkeit.

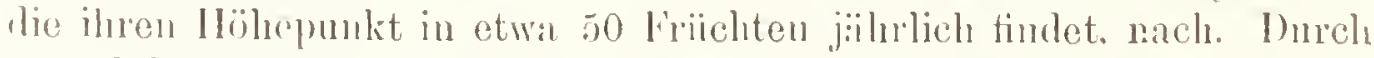

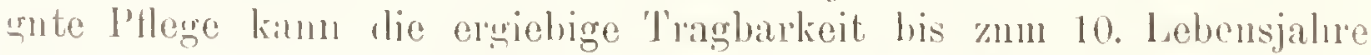
ansgedehnt werlen. In Mexiko hesorgt ein Insekt dir IBlitenbefruchtung. 
aher in unzurerlissiger Weise, weshalb dic noxiknnischen linten häiufig grofse Ausfälle \%eigten. Hiel greilt nun ler Mensch liclfend rin. Der P'llanzer fiihrt eincu \%ugespitzten limmbusstah orler cinen l'insel in das lnnere der Bhite, bringt dadurch den lilehrigen libiten-

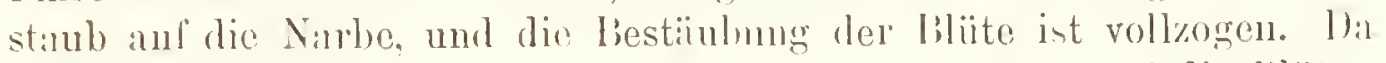
aber die Blüten nur einen Tag geöffnet sind, und dic liliiten am Morgen bestäubt werden miissen, so gelört grolise Aufuerksamkeit der Pllan\%er da\%u, wenn sie alle Bliiten hestiulen wollen. Ein flinkrr Arbciter kinn an cinem Morgen die liestiolumng von 1000 libiten bewirken. Nenige 'Tage danich kinn man hereits diejenigen liliten anslichten, die keine Fuehte ansetzen. Hinen Monat später haben dic Friichte bercits ihre volle Grölse erreicht, sie beriirfen aler noeh weitrer sechs his sieben Monite zur lieife. Die Ernte fiulct auf ler südlichen Fröhilfte ron .Juni bis August, auf der nördlichen vom Dezember his Feloruar statt. Die Friichte, welche ler Sonne vollstïndig ausreset\%t waren, werden die vorzingliehsten. Wenn lie Friichte grelb werlen, müssen sie, ehe sie an ihror supitze aufspringen, geerntet werden. Zu letrterem \%wecke sind die Arbeiter mit eincr langstieligen Selıere und einem mit Bibtern ausgelegton Kïblien versehen. Die geernteten sehoten werlen erst im Schatten, dimn in der Somne (dabri oft auch in wollene 'Tücher sewickelt), vielfich aueh auf Ilorden oder in (Ofien getroeknet, in Biindel zu 50 stück (mmsos) nach ler Grölse sortiert und in luftdichte Bleehkisten verpackt in den Ilandel gebracht; in Kolumbien bestreicht man sie rorher mit einem fetten (i)e, in anderen Kulturlindern taucht man sie in koehendes Wasser, trocknet sie und hestreicht sie zur Ablıaltung ron Insekten mit Kakaobutter. Dic Vanille wirl um so besser, je sehneller sie getroeknet wirl. Nic schrmmptt während des Trocknens auf etwa den dritten Teil ihrer Grölse ein und ihre gelbe Farbe verwandelt sieh in cine tieflorame. Die Affen kommen den Menschen in der Ernte oft zıror.

Gehalt. Die getroekneten Friichte ler Vanille sind selu oft mit weilsen, seidenglïnzenden, nadelförmigen Kirystallen bedeckt; diese müssen sehr klein und fein sein und in einer senkrechten Richtung zur Oberfläche der schote liegen; anderenlalls licrt eine Täinschung vor. Der wiehtigste bestandteil und zugleich der alleinige 'Trïger des lieblichen Geruches ist dieser weil'se, nadelfömige Körper. Vanillin

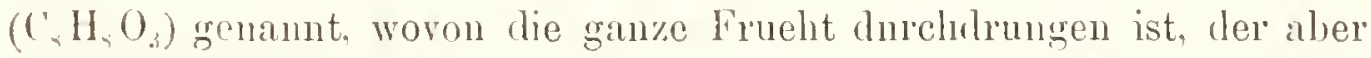
nicht anszukrystallisieren brancht und ler $1 \frac{1}{2}$ bis fast 3 Proz. betrïgt, nïmlich in mexikanischer Vanillo 1,69, bourbonvmille 2,48, Javilvilnille 2,75 l'roz. Anfserlem enthïlt die schote ein gelbes, mangenchm riechendes (i), las ahschwäichend ant das Mroma cinwirkt. Von diesen (ile enthält die Mexikovanille sehr wenigr; sie hat deslalb ein reineres Aroma und ist alsowertroller als dic iibrige.

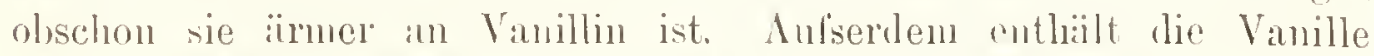

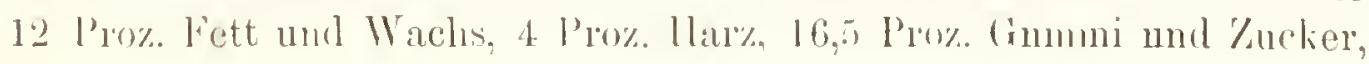


4.5) l'ro\% mincralische liestanlteile. Jetzt stellt man auch das Vanillin künstlich dar, lauptsächlich ans Eusconl, der im

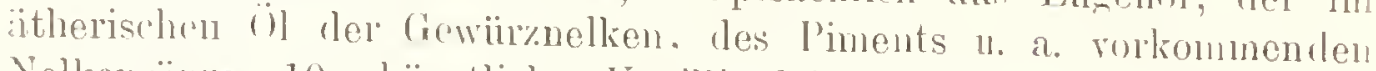
Velkensïme. 10 in kimstliches Vanillin leisten so viel wie oon @ foinste liombonvinille.

Gebrauch und Wirkung. Die Vinille ist eins der feinsten nnd licblichsten Gewiur\%e und wird in IInslialte (besonders in Ther. und Fichokolade), in der Medizin (um andere Mittel schnackliafter \%u machen) mut in der Konditorei und hesonders zur Schokoladebereitun lenutzt. l)ie Vanilletinktur verwendet man in der Medizin. P'arfinnerie und zun I ikinfahrikation. Reizhare, schwachnervige Menschen sollten dieses Gowiirz recht mälsig oder gar nicht anwenden, da es ihnen wegen de: .. sehr stirlien. Blut erregenden und erhitzenden Eigenschaften" selu schïllich werlen kann. In heilsen Amerikir meider man den Genul's der Vanille fast ganz.

Warenkunde. Die gotrockilete Vanilleschote ist 15 bi2.5 cm ling, 6 bis $S$ mul breit, rundlich, etwas zusammengedriekt, an len Enden verdïnnt, dunkellnaum. Gute Früchte sind lang (je lïnger, je lieher), platt, durch das 'Trocknen längsrunzelig, rötlich. rïnnschalig, fettigr, weich, biegsim und reich an Fleisch, nicht hart getrocknet. Das Fleisch der Schote riecht stark nnd angenehm und shmeckt "balsamisch gewiirzhatt, etwas fettig und säuerlich". Unreife, iberreife, ihrer Spitze beraubte, älige Friichte, auch scloten rou wilden bïumen gehen geringe Sorten. Es sullen viele bereits ihres liehaltes heraubte schoten wieder in den Handel kommen. \%mm Wiirzen schlechter cichokoladen bodient man sicll, anstatt der Vanille. anch des Perubalsans, der zwa wie geringe Vanille riecht, aber einen umangenehm siffsen lieigeruch und einen bitteren liesclnnack lat. Die schoten verlieren diuch Iagern.

Handelssorten:

1. La Corrienté besteht aus den Füuchten der kultivierten limillı Jlruifolin; sie zerfïllt in zwei crorten. Von diesen roscheint die bessero, die reich an Simen mud Mns ist mnd eine diinne lipuchtschale besityt, nicht im dentshen Handol. Jic etwis greringere. in Dentschland an höchsten urschätzte Sorte ist die Vanilla de ley (ley, von laci (ieset\%); sie ist lang, Heisohig, stark amomatisch. hramschwar\%, mit kiystallen berleckt und nicht aufgesprungron.

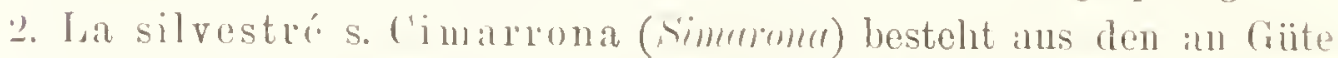

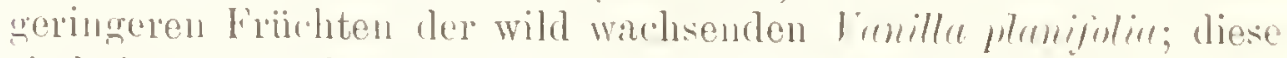

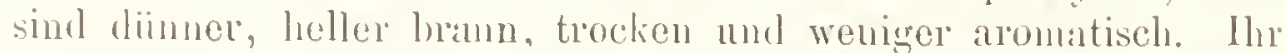
und den noch geringreven sorten wird häutig durch liestreichen mit Permbalsam mud Ïbergiehon mit Benzokrystallen ein bessereAusselıon gregelien; anch werden miturter aufgesprungene und "ntleort" linpseln nit wertlosen stoffon refiillt. 
3. I. II esti\%. Mehr cylindrische, beim Trocknen leicht anfsprinsende, mmeife, grime oder hraun gefleckte linichte.

t. la: Prn nora, sehr kleinc, dunkelgrine, hein 'rocknrm mnangenehn riechemle Friichte.

$\therefore$ Ia l'ompona (la Gmayra-Vanille. Vanillon) stammt von der in Ostmexikn mud den nordöstlichen Teile siidamerikas cinheimischen Vimill, l'ommonn schiede ab. Die thachen, bis 2 cm breiten, dunkiolbranen šchoten entwickeln ein mincler angenehmes Lroma, welches zudem bald schwindet. - Diese. sowic die Friichte noch anderer Vanillearten sind wenig gesucht, da sie denon der V'umillo. munifulia seho nachstehen. Hicrher wehören: Guayanische Vanille rou der in Guayana einheimischen Tomiln gminmmsis splittgerber horrührend, mit 15 his 20 cm langen, 2 bis $3 \mathrm{~cm}$ breiten, stumpf dreikantigen, sclıwarzbranen Friichten; P'alnenYanille rou der ebenfalls in Guayana rorkommenden Frmill. frlmurmm Lindley, mit $5 \mathrm{~cm}$ langen und $1 \frac{1}{2} \mathrm{~cm}$ loreiten, walzenfïrmigen orler schwach dreikintigen friichten.

6. Bourbon-Vanille, von der nach den Iaskarenen verpflanzten Vamill Mlunifolin abstammend, ist sehr wohlriechend.

7. Furopiische, in den Gemächshäusern Europas von Irmilla Jhmifolin grezogene Vanille, kommt in Form und Guite der besten mexikanischen V'anille glcich.

Gewinnung und Handel. Mexiko') rermag nach einer normalen Ernte etwa $: 5000 \mathrm{~kg}$ Vanille auszuführen und damit den amerikanischen Markt zu befrierigen. 1896 bis 1897 lieferte Bourbon $83000 \mathrm{~kg}$. die śeychcllen 19000 , Ostafrika 10000, Mauritius 4000. 'Tahiti $2000 \mathrm{~kg}$. Wherhaupt mag die gesamte Vanilleausfuhr in Durchschuitt jährlich 130000 lig betragen, deren Wert in Europa auf j bis 6 Mill. Mark zu schäitzen ist.

Geschichte der Vanille. Die Indianer kannten das Gewion chon vor der Entrleckung Amerikas, der Name desselben aber ist spanischen Ursprungs (bu!mm oder rm!mu = Schote, ‘n!nrllı = Schötchen). Die Mexikaner benutzten bereits die Vanille znm Wiirzen der schokolade, als die Spanier ihr Land eroberten; schon etwa un 1510 wnrde sie mach Emropa gुelnacht; doch kemnt Clusius 1602 weder Namen noch Vaterland der P'Hanze. Weil sie friiher selı hoch in Preise stand, 1821 kostete 1 Pfund etwa 120 Mark, siedelten die Hollinder 1819 mexiknische Pflanzen in Java an; allein sie trugen dort anfangs kaum Frichte, da die in der Heimat sie bestänenden Inseliten felılten. Erst als der Kulturdirektor 'Theysuanu die ïbertragung des Biitenstaubes anf die Narbe inittels eines ['insels kiinstlich vermittelte, wnrden Frichte arzielt; 1860 war in Holland ler l'ois bereits anf 22,2 Mark für das I'fund gefillen. 


\section{Tafel 10. \\ Ceylonischer Zimtbaum \\ (Cinnumomum Ceylanicun Breyn).}

Der ('eylonische Zimtlaum gehört zur Unterklasse der Freibläfterigen Dikotylen; zur Reihe der Vielfruichtigen (Rumates) und zur Familie der Lorbergewächse (Lumrocme).

Die Familie der Lorbergewächse (Lmmene). Bämme und Sträucher mit in der Regel abwechsehden, immergriuen, leclerartigen, einfachen, ganzen und ganzrandigen, fiedernervigen, nobenblattlosen Bliittern. Die Bliuten stehen meist in Trauben, Rispen oder Dolden und sind vollständig, odor durch Fehlsehlagen eingeschlechtig. strahlig gebaut. Bliitter der Bliitenliülle sind sechs oder acht rorhanden, welche in zwei Reihen stelıen. Die Staublulitter sind in drei bis vier Kreisen angrordnet; davon sind einzelne Kreise bisweilen als Staminodien entwickelt, d. l. verkiimmert und unfruchtbar (Fig. 2, s4), oder znweilen jederscits mit einer Driise versehen (Fig. 4). Die Staubbeutel sind zwei- bis rierficherig; sie äfnen sich mit Kilappen, wolche nach der Innenseite der IBlite gerichtet sind, oder die des dritten Kreises öfuen sich mach anfsen (Fig. 2, s:i). Der Fruchtknoten ist frei, später von der Achse orler dem fleischig werdenden Grunde der lBliitenhiillb)iitter mehr oder weniger numschlossen; er ist einfücherig, lat einen Griffel mit zwei- lis dreilappiger Narbe und eine einzige, lı̈̈ngende, umgrawendete Samenanlage. Fruclit eine

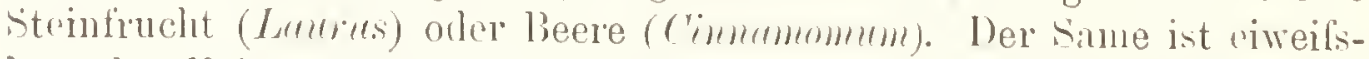
los, der Keim greralde, mit grofisen, fleischigen, Hachen Samenlappen. Inese Familic enthäit in ihren 40 Gattmugen mit etwa $\$ 80$ Arten viele Arzuci- und Ilandelspillanzen.

bir Gattung' Zimtbaum ("'imumemmem Burmeistor). B:ïune mit ausdanernden, gegenständigen odrer trilwoise abwedsselnden, drei-

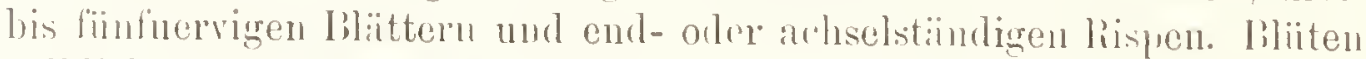
gehlichwoifs, zweigeschlerhtigr oder oin- nnd zweigesehlechtign und diln

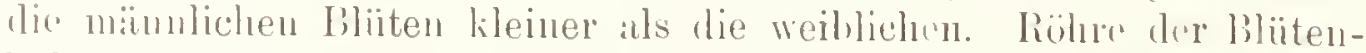

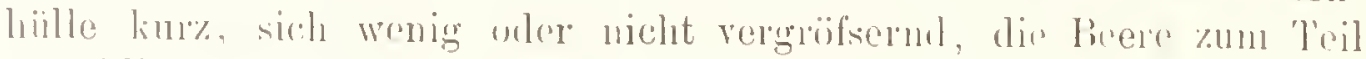
unmehlielsend. Hirpher etwal an Arten. 
Ceylonischer Zimtbaum (Cimmommm coylmirmm Breyn, L.mm!r cimmumommm L.). Der Kimtbanm erocicht in der Wilduis. und wo er nicht beschnitten wirrl, eine Höhe bis $10 \mathrm{~m}$ und einen Durchmesser von 45 his $50 \mathrm{~cm}$. Die knotigen iste breiten sich warerecht aus unl senken sich zuweilen erolwärts. In den Zinntugirten rieht man ilu als 3 bis 4 m hohen Strauch, weil die diunen /meige der Strïucher einen feineren \%imt gelen, als die starken İste der Biimuc. Rinde glatt und gelblichgrau.

Blätter gegenstindig oder teilweise abwechsehnd, horizontal orler allch abwirts gebogen, mit kurzen, rinnenförmigen, glatten Stielen. lederig, immergriin. glatt, gläinzend. ganzrandig, in der .Jugend schön rosenrot oder hellgriin und erst im Alter oben dunkelgriin und unten granlichgriun, eiförmig oder eirund-lïnglich, in eine stumpfe Spitze vorgrezogen; mit fuinf nach der Blattspitze hin verlaufenden Nerven und zahlreichen, netzartigen Queralern; 10 his $15 \mathrm{~cm}$ lang, $6 \mathrm{~cm}$ und mehr breit.

Rispen schlank, \& bis $13 \mathrm{~cm}$ lang, achsel-und fast enrlstäldigr. aufrecht-abstehend, mit vierseitiger, nach oben schwach seidenhariger Spindel, die sich erst über der Mitte verzweigt. Die drei, seltener vier Astpuare sind doppelt, das uuterste zuweilen dreifach gabelspaltig; das oberste sowie die Spitzen der ubrigen iste dreibliutig, sämtlich mit einel gesticlten, frïher cntwickelten Blüte in den Gabelteilungen. Blïtensticlchen abstehend, weifslich, schwach weichhaarig; Deckbliittehen schmal lanzettförmig, klein, abfallend.

Blüte aufsen weifslich, seidenharig, innen gelbgrün, 4 bis $6 \mathrm{~mm}$ lang, friil morgens offen, bald kreiselförmig zusammengezogen. Perigonblätter sechs, in zwei Reihen, aus dem äufsersten Rande des fleischigen, lireiselartigen Unterlielches entspringend, unter sich gleich, oral, gestumpft, etwas fleischig, durchscheinend punktiert, auf beiden Sciten seidenharig. Staubblätter zwölf, in vier Kreisen; die neun äufseren fruchtbar, unter sich gleich lang, kaum kiirzer als das Perigon, die drei innersten (Staminodien) unfruchtbar, verkiimmert. Staubfäden zicmlich dick, f'ein behart, die sechs ïufseren nackt, die drei inneren an dem Grunde breiter, daselbst zu beiden Seiten mit einer kurzgestielten, fast herzföruigen gelben Driise verseher. Staubbeutel etwas kiirzer als der Staubfaden, aber breiter, liinglich, fast vierseitig, oben ausgerandet, unten aufgerundet, laselbst dem Staubfaden angewachsen, gelb, vicrticherig; Fächer jederseits pararwe iibereinander gestellt, oval-lïnglich, die oberen kleiner, sïntlich in aufsteigenden Kklappen aufspringend; die ter scchs iulseren Staubliaitter nach innen, dic der drei inneren nach aufsen gewendet. Staninodien der vierten lieihe mit einen herzonnigen, zugespitzten liöpchen rersehen. Stempel lrei, oberstiindig, etwas kiirzer als die Staubbliitter, kalil; Fruchtknoten eiformig, hall, eingesenkt in die Ilöhlung des Unterkelches, cinficherig. Der Samenträger cine 
sehmale längsleistr, ist :n die innere Wand angewachsen, in der spitze des Faches mit einer häingenden Samenknospe versehen; Samenknospe umgerendet. Griffel kurz; Narbe nierenfömig, schwach dreilappig. Die Bliiten hiben cinen sehr zarten, aber unangenehmen. keineswegs zimtartigen Duft.

Frucht beerenartiog, $8 \mathrm{~mm}$ lang, vom auswachsenden Unterkelch bis gegen die Nitte eingreschlossen, eiförmig-lïnglich, sehr ku1z stachelspitzig.

Same von der Gestalt der Beere, eiweifslos; Würzelchen des Keimes nach oben gerichtet; Samenlappen flach, fleischig.

Der Zimtbaum blüht auf Ceylou im .Januar und Februar. Der beste Zimt wiichst auf der Siidwestküste C'eylons, wo er bis in die höchsten Bergwälder, bis $2000 \mathrm{~m}$. emporsteigt, auf einem 20 bis $50 \mathrm{~km}$ breiten, 160 km langen Küstenstriche, welcher sich von Negumbo, etwas nördlich von ('olombo, bis zur Siidspitze der Insel, sanft bis auf etwa $450 \mathrm{~m}$ ansteigend, hinzieht, auf schneeweifsem Boden, der fast ganz aus Kieselsand besteht und wo sich alle zn seinem Gedeihen notwendigen Bedingungen, tropische sonne, sandiger, trockener, von Niederschlägen häufig benetzter Boden, tinden.

Abarten sind:

a) Commune Nees (Lunrus cimumomum L., Cinnamomum cenlanicum vulgure Hayne). Bliitter ans abgerundetem oder sehr kurz zugespitztem Grunde eiförmig oder länglich-eiförmig, stumpf oder sehr kurz und stumpf zugespitzt, drei- bis fünfnervig. Rinde aromatisch.

$\beta$ ) Inodorum Nees. Von «) hauptsächlich durch die geruchlose oder wenig aromatische Rinde verschieden.

r) Subcordatum Nees (Cin. ceyl. cordifolinm Hayne). Blätter aus schwach herzförmigem Grunde eiförmig oder lïıglich-eiförmig. stumpf oder kur\% und stumpf zugespitzt, meist fünfnervig. Rinde aromatisch.

d) Mikrophyllum Nees. Blïtter klein, aus abgerundetem oder kurz zurespitztem Grunde lïnglich-eiförnig, oder lïnglich-lanzettlich, stumpf, drei-, selten fünfnervig.

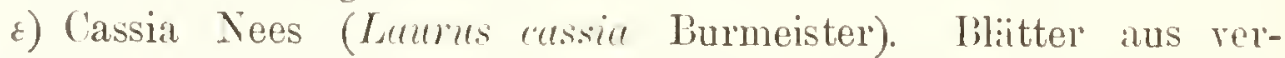
schmälertem oder spitzem Grunde, länglich-elliptisch oder länglichlanzettlich, gegen die spitze alhmählich verschmiilert, 5 bis $12 \mathrm{~cm}$ lang bei 2 his 3 , selten $4 \mathrm{~cm}$ Breite, drei- oder selten füutnervig. Rinde aronatisch, doch häntig schwïcher als bei c). Von ihr stamnt der Malabirzint (Holzkassie).

Vaterland: Insel Ceylou. Verbreitungsbezirls: sumatra, Iava, Kiiiste von Malabar, Cochinchina, Borneo, Philippinen und Nicobaren und in nenerer Zeit Brasilien, Cayenne, Antillen, China, Mauritius, lienion und selbst Ïrypten.

Kultur. Die Vermehrung der Zimtbïume geschicht meist durch Absenker. In den Zinnträirten pflanzt man die strïuche nngefiihr 
3 $n$ weit anseinander und zwar in Reihen, zwischen denen Gänge hinfiihren. Der Boden soll viel Kiesclsinre enthalten, iippiger Boden ist nachteilig. Den jungen Strïuchen ist eine leichte lieschattmng notwendir.

Gewinnung' der Rinde. Die ron der Aul'senrinde befreite lnneminde, oder vielmelı die mit geringen Resten der A ufsenrinde bedeckte Bastschicht bildet den Kimt(Zimnet). Im Mai und Juni (Haupternte) und im Oktober nnd Norember, wenn infolge des stärkeren Regens der Saftumlauf den höclısten Grad erreicht, geschieht auf Ceylon das Beschneiden der Sträinche, weil sich zu diesen Zeiten Rinde und Bast leichter vom Holze lösen lassen. Fingrerdicke, $1 \frac{1}{2}$ bis 2 . Tahre alte Schölslinge von 180 bis $190 \mathrm{~cm}$ Länge geben den feinsten Zimt. Jeder Arbeiter schneidet so viele Stiicke $a b$, als er in einem liiindel zu tragen rermag. Dann löst er durch Aufschlitzen mit der Spitze eines krummen Messers geschickt die ganze Rinde rom Holze. Man lälst die frisch abgeschïlten Rindenstiicke ineinander gesteckt einen Tag liegen; dadurch entsteht eine Gärung, und die geruch- und geschmacklose Aul'senrinde lälst sich jetzt leichter durch Abschaben von dem Bast entfernen. Man fügt nun acht bis zehn Rinden ineinander und trocknet sie auf Matten, erst im Schatten, dann in der Sonnenhitze, wobei sie vom Weils zum Gelb und endlich zum Hellbraun übergehen und fest zusammemrollen. In den Warenhäusern wird der Zimt von den Zimtkostern nach seiner Giite sortiert. ein die Nerven selır angreifendes Geschiift.

Die sortierten Zimtröhren werdeu in den Warenspeichern in Biindeln (Fardelen) von 1,14 m Lï̈nge und zu je 100 Stiick oder 45 kg verpackt, mit Schilf umwunden und in doppeltes 'Tuch genäht. Damit der Zimt sein Aroma besser behält, strent man in und zwischen die Iiöhren Pfeffer, was auch dem letzteren zu gute kommt. Kimt dirf nicht an einem warmen Orte gelagert werden.

Aus der Beere gewinut man ein schwach aromatisches, festes Fett. aus der Wurzel durch Destillation mit Wasser Kampfer, der nicht in unseren Handel kommt.

Aus den Abfïllen und den geringen sorten wird zn Colombo auf Ceylon das echte Zimtö1 dnrch Destillation mit Wasser gewonnen. $150 \mathrm{~kg}$ Zimtrinde geben etwa $2 \mathrm{~kg}$ (i). Dieses stimmt mit Ausuahme des feinen Geruches und Geschmackes bezüglich der '/usammenset»ung (namentlich Zimtahlehyd und Zimtsïme) mit dem (assiaöl iilerein, ist dickflüssig, goldgelb, nach längerem Aufbewahren rötlichgelb. Das anf ('eylon aus den Zimtblättern gervomene ätherische öl bestelit zum grolsen 'Teil aus Gewürzuelkenöl und wird als solches verkauft.

Bestandteile des Ceylonischen Zimts. Die Rinde enthïlt bis : ${ }^{2} / 3$, Proz. ätherisches Öl, welches ilı den Wohlgeruch rorleiht. Zellen mit diesem (̈) sind in nicht allzn @rol'ser Zahl in das 
Parenchym eingestrent. Sonstige Bestandteile sind Har\%e, Cierbsïme. Stritkemehl und sichleim.

Warenkunde. Der Ceylonische Zimt, ('eylonzint, Edler 'Zimt, Kancel, ist lcicht und nicht dicker als starkes Schreibpapier $(0,25$ bis $0,5 \mathrm{~mm})$, er lat lie bokannte gelbbraunc Zimtfirbe. die aufsen heller und stellenweise glänzend, innen brauner und matt ist; er besitzt ini hohem Grade einen fenrig-aromatischen, aber dabei siffslichen, etwas schleimigen Geschmack, der in dem oben erwähnten ätherischen 0 il seinen Grund hat. Zimt ist wenig biegsam, leicht zerbrechlich, im Querbruche eben, kurzfaserig, mit zahlreich hervorragenden weilsen liastbündeln; Pulver hellbraun. Er bildet etwa meterlange. etwas platte, centimeterdicke ('ylinder, welche aus acht bis zehn dicht ineinander geschobenen Rindenstücken so znsammengesetzt sind, dafs eine Doppelröln'e entsteht, ron welcher jedc Hälfte spiralig eingerollt ist. An der Aufsenfläche erkennt schon das freie Auge lichter gefiirbte, meist der Lühgsrichtung genan folgende Streifen, welche den Bastbündeln der Rinde entsprechen. Leider kommt es auch ror, dal's man das ätherische (i) aus der Rinde herausdestilliert und sie dann doch in den Handel bringt. Sie ist dann an ihrem schwachen Aroma zu erkennen. Am schlimmsten fährt man, wenn man gepulverten Zimt kauft, da dieser aus schlechten Sorten besteht und in der Regel mit gepulverten Mandelschalen u. a. verfülscht ist. Die Rinde ron den in der Wildnis wachsenden Zimtbiiumen ist dunkelbraun und hat einen etwas stechenden, bitteren Gieschmack. Der Ceylonische Zimt ist der feinste, der 'Tellicherryzimt von der Malabarküste Vorderindiens ist anch sehr gut; die jaranischen (zweiter Güte) und amerikanischen (Französisch-Guyana und lirasilion) linden (dritter Guite) bilden die geringeren Sorten. Jed g gre ringe Sorte ist an dem unangenehmen Nachgeschmack leicht zu erkennen. Nehr als Ceylonischer Zimt kommt der Cassienzimt, vielleicht von Cimmomm Cussiu Blume, in den Handel; er ist aber weit geringer als jener und vicl billiger. Diese Rinde ist stärker, meist nicht unter $1 \mathrm{~mm}$ dick, und jede einzelne Schale bildet eine Röhre für sich; sie hat eine etwis riuhe, matte. rötlichbraune, stcllenweise auch noch von gratuem Kork beleckte OherHäche und eine etwas dunklere Ininentlïche. Der liruch ist nicht kurzlaserig wic beim Ceylonzimt, sonder'n fitst ohen. Sie entbehrt des feinen Aromas, und ihn Groschmack ist herb. Die die mureilen Friichte einschliel'senden Bliitenhiillen dieser oder verwandter Arten bilden die Zimtbliiten des llandels, die znr Iarstellmug des Zimtwissers. sowie zur Gewinnung ron ätherischem (i) benutgt werden. Verwandt ist auch der in dapan und China, vorziiglich auf Formosa, heimische

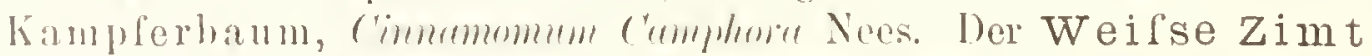

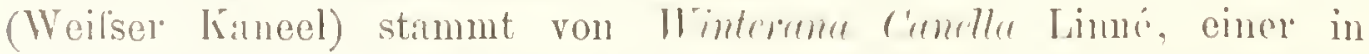

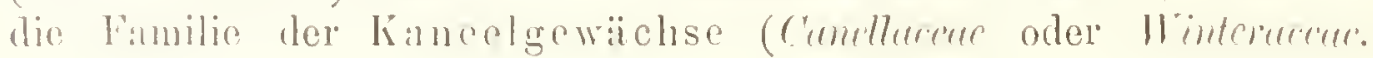


Reihe der Mandfriuhtigen) gohörenden, in Westindien einheinischen Pllanze.

Gebrauch. Her Gebrauch des \%imtes als Gew ürz ist bekinunt. Die Kintöle, auch offrinell (in Form von Tinkturen, Zimtwasser 11. S. w.), werden gegenwärtig besonders in ler Parfiimerie nnd I iliörfabrikation benntat.

Angaben über Ernte, Handel und Verbrauch. Die ceylonischen Kimtginten nehmen gegenwïrtig ungefïh 13500 ha cin. Es werden jählich über $1000000 \mathrm{~kg}$ Zimt geerntet. Von der Austinlı gehen s0 bis 90 Proz. nach England. Cochinchina gewinnt zwischen lem 15. und 16. Grade nördlicher Broite etwa $150000 \mathrm{~kg}$ \%imtrinde, welche meist die Chinesen an sich ziehen. Im yanzen diirfte die jäh'liche Ernte ecliten Zimtes $1500000 \mathrm{~kg}$ nicht wesentlich iiberstcigen. Die järrlichen Einfuhren in Europa schwanken zwischen 700000 und $900000 \mathrm{~kg}$. I)avou verblaucht England $150000 \mathrm{~kg}$ selbst, Deutschland gegen 200000 kig.

Geschichte. Der Gehrauch des Zimts ist ein uralter. II. Noses, 30, 23. - Sirach 24, 20, — Offenbarung Johannes 18, 13, auch Herodot, Hippokrates und Plinius erwähnen ihn. Der Zimtstrauch soll aus Hinterindien stammen. Plönicier und Hebrïer namnten ilın Kinnamom; in den Rezepten eines uralten 'Tempellaboratorinns vou Edtu wild er als Kainamaa aufgefiilurt; bei den Griechen licels er Kimnamónum. bei den Persern und Arabern Dar Chini (Holz von ('hina). Die Venetianer und Portugiesen nannten ilu Cannella oder ('anelle, bezeichneten indes jede aromatische Rinde mit diesem Namen. seit Alexander dem Grolsen bis ins 11. Jahrhundert nalim der Zintlandel seinen Weg ins Abendland durch den Persischen Golf und Mesopotamien. Das Produktionsland des Zimts in Altertume war daher wolıl zweifellos China. Die Zimtwälder um Colombo auf Ceylon werden erst 1340 von Ibu Batuta erwihnt. 1444 bereiste Nicolo ('onto die Zimtinsel ('eylon (,Saillana“). Niihere Nachrichten über" den liaum kamen erst zu uns, als Europäer die Insel in Fiesit\% genommen hatten. Anfänglich war der Zimblhaudel cin Monopol der anf Ceylon cinheimischen Könige gewesen. Fultivient wurle damals ther Zimthaum noch nicht, sondern man entuilnn die Rinde den wilden bïumen. Im . Tahre 1518 ergriffen die Portngiesen, 1656 die Iolländer und 1796 die Engländer von der Insel liesitz. Jeder der lrei Besitzer zwang die künige der Insel, jilurlich einen selı holıen 'ribut an Zintrinde abzuliefer'n. Veruntrente ein ('halia (Kintschäler) limrle, so wurde er. besonders zur Zeit der lolländischen Herrschaft, gransan bestraft. Kultiviert wnlde del Iatun aul ('eylon enst muter dem 1765 die Verwaltung iibernehuenden Gouvernenr I:alk. Der Ertoly wal ein glämzender. Hald konnten die Holländer jülulich 400000 l'fund '/imt ant den Markt bringen und den granzen enropiischen liedart decken, olne Beriigo aus dem damals morh bestehenten 
Kïningreich Kand! aul' C'eylon machen zu müssen. Aus Furcht, die hohen l'reise dieses (iewiirzes möchten sinken. wurden die Kulturbäume anf einc bestimmte Anzahl heschränkt, nnd in gesegneten Jahren wurde stets ein 'Teil der Erute in die see seworfen oder verbrannt. So wurde : m 10. Inni 1760 in Amsterian eine anf acht Millionen livres grschiitzte Menge Zimt verbrant und an folgenden lage eine gleich grolse Larlung. Als Ceylon in die Hände der Englïnder fiel, wurde der Zimthandel Monopol der englisch-ostindischen Kompanie und später (183:3) belegte die Regierung den Kimt mit einem lohen Ausfuhrzoll von der Ilälfte bis ein Inittel seines Wertes. Im Anfinge dieses Jahrhunderts machten die Chinesen, die Holländer u. s. w., die auch den Zimthaum und die ('assial zu kultivieren angefangen hatten. den Engländern selır gefährliche Konkurrenz, so dafs der Ceylonische Vimt rom Narkte fast ganz verschwand. Im .Jahre 1853 hob man den 'Zoll auf, und seit 1858, mit welchem Zeitpunkte die Insel in den Besit\% des britischen Staates überging, gab man endlich den Zimtbau und den Handel mit der Rinde auf Ceylon völlir frei, worauf sich die 'limigärten auf der Insel wieder vermelıten.

Als Kiaser Karl V., im Frülhlinge 1530 von Italien zurückkehrend. den in den Grafenstind erhobenen reichen Kaufherrn Fugger. der ihm gegen Schuldschein eine bedeutende summe geliehen hatte, besuchte, um sich zu entschuldigen. dal's er dem Kaufmann dis Cieh nocl nicht wieder zurückerstattet habe, fröstelte ihn, und er sprach iiber den Unterschied des deutschen und des italienischen Kimas. I i brachte der reiche Fugger einige Bündel der kostbaren 'Zimtrinde herbei, legte sie in den Kamin. des Kaisers Schuldverschreibung dilrauf und ziindete das an. 


\section{Tafel 11. \\ Schwarzer Pfeffer \\ (Piper nigrum L.).}

Der Schwarze Pfeffer gehört zur Unterklasse der Freiblätterigen Dikotylen, zur Reilıe der Pfefferpflanzen (Piperctes) und zur Familie der Pfeffergewächse (Pipcraccuc).

Die Familie der Pfefferpflanzen (Pipracenc). Kräuter und Sträucher, seltener Bäume, mit knotig gegliedertem Stengel und Blättern. die am Grunde einen kurzen, scheidenförmigen Stiel haben. bliiten meist in einfachen, endstïndigen Ähren, welche durch deu in der Ichsel des letzten Blattes entstehenden Fortsetzungssprols (wie auch bei der Vanille) beiseite gedrängt werden und iufolge davon an der Scheinachse einem Blatte gegeniiber stehen. Die Blïten sind zivei- oder eingeschlechtig; sie besitzen keine Blütenhïlle, enthalten 1 bis 10 Staubblïtter und einen einfächerigen Fruchthnoten mit einer grundständigen, geradläufigen Samenaulage. Die Beerenfrucht besitzt wenig Fleisch. Der Keimling ist sehr klein. kreisel-oder linsenförmig und hat zwei sehr kurze, dickliche Keimblïtter; er liegt in einem fleischigen Nälırgewebe, das seinerseits von einem umfangreichen, mehligen, aus dem Kern der Samenanlage hervorgegangenen, äul'seren Samenciweils umgeben ist.

Hierher 9 Gattungen nit ungefïln 900 Arten, die fast alle den Tropen angehören. Sowohl in der Oberhant wie in dem Grunlgewebe enthalten einzelne Zellen ein ätherisches (j), auf welchem der vielen Arten zuliommende scharfe Geschmack berulit.

I) Gattung Pfefferstrauch (Piper L.) ist ansgerechnet durch ihren kimzen, dem Rücken des dicken Staubfadens angehefteten Statublbutel und ilure zwei bis vicr, solten mehr, getrennten, meist griffellosen Narben. Die meisten der nahezn 600 Arten sind Strïncher, einzehe Pämme oder Kräinter, zalılreiche Kletterer. Die Traghlïtter der Bliiten sind schildförmig oder ansgehö̈llt und bedecken dicht die Arlise der ïlure. 
Der Schwarze Pfeffer (Piper nignm, L.) ist ein fingerdicker, 6 bis $7 \mathrm{~m} \mathrm{hoch}$ an Bïmmen hinanf kletternder Straucl, mit gabelförmigen, hin - und hergehogenen. knotigen, eckigen, gestreiften, kahlen Ästen von der Dicke eines Gänsekicls.

Blätter abwechsclnd, die untercn auf 4 bis 6 , die oberen auf 1 his $2 \mathrm{~cm}$ langen, rinnigen Blattstielen, mit fleischigen, abfallenden lïindern; am Grmde herzförmig, breit-eifümig, zugespit», netzförmig geadert, zin jeder Seite des Mittelnerven mit drei, in dessen unterem Drittel entspringenden Seitennerven; lederartig, unten hell-. oben dunkelgriun, mit starkem Zellgewebe.

Blütenspindel, scheinbar den liättern gegenüber entspringend. Die Bliiten sind zweihïusig oder vielehig, wobei die meist weiblichen Blïten:̈hren am Grunde Zwitterbliiten tragen; sie sind eingesenkt in entfernt roneinander stehenden Nischen der etwas Heischigen spindel, werden von deren freien Siiumen wic ron Gindinen iiberschattet und sind gestützt von einem der Spindel angewachsenen, rundlichen Traghlatte, dessen fieier Rand den Fruchtknoten wie ein halber Becher umfafst. Staubblätter zwei, dem Fruchtknoten zur Seite gestcllt. Fruchtknoten sitzend, kugelig. Narbe in drei bis vier weichbeharte, abstehende Lappen geteilt.

Fruchtkolben 7 bis $11 \mathrm{~cm}$ lang, mit 20 bis 30 ziemlich locker sitzenden, kugelrunden, erbsengrolsen, genabelten, crst grïnen, später ziegelroten, dann gelblichen Beeren.

Keimling sehr klein, herzförmig, mit zwei sehr knrzen, dicklichen Keimblättern, samt dem inneren Fiweif's in einer Lüicke des äufseren eingebettet.

Vaterland: Kïste Malibar ("Pfefferkïste"), wo er am besten gedeiht und wild rorkommt.

Verbreitungsbezirk: Tava, Sumatra, Borneo, Sian, die Philippinen, Ost- und Westindien. Das Klima mul's feucht und heil's sein und eine mittlere 'Temperatur von 26 his $29^{\circ} \mathrm{C}$. haben. Bodenbeschaffenheit ziemlich gleichgültig.

Kultur. Der 'Pfefterstrauch wird durch tichöfslinge oder . 1 bleger zugleich mit denen anderer schmell wachsender Holzgewächse (Jacca-, Dadap-, Mango-, lirotfruchtbaum, Gambirstrauch, Bananen und lrekapalme) gepllanzt, dir er nur im schatten anderer biiume und nur, wemn er an Stiitzpflanzen cmporklettern kimn, gedeiht. Dammit sich der Pfeffer gehörig ausbreiten kann, entfernt nim die unteren Zweige der Stuitzpflanze und stntzt auch deren hirone fiicherfürnig \%. Nach einem Jahre ist der Strauch mgefïh $4 \mathrm{~m}$ hoch geworden. Ian rechnet auf eine l'felferpllanze $0,6 \mathrm{ym}$. Anf singapore wird der P'eftè reilıenweise gebant, und man lïlst ihn lort. wie boi mos de'n Wem. an l'fihlen, die zwischen Bananen stehen. emporklettern. Mit den dritten, im nngiinstigen falle nit dem rierten Jahre träigt die Pfefícr-

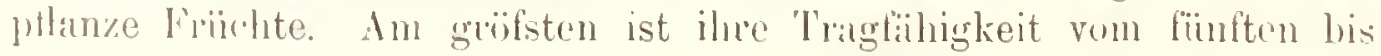




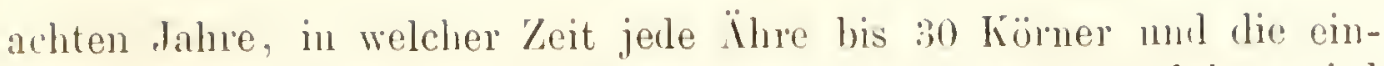
zelne Pflanze nicht selten $3,5 \mathrm{~kg}$ liefert. Xach dem 15. fahre wird der Strauch als weniger nutrbringen! entiernt. Wird der boden der Pflanzung oft gelockert und vom Inkrant befreit, so bringt der Strauch zwei reichliche Ernten (erste im Dezember bis Februar, zweite Mai mnt Iuli). Die Ernte nimmt ihren Inlang, wenn sich die Beeren zı röten beginnen, und wälırt melrere Monate, da nicht alle Beeren gleichzeitig sieh röten. Man sammelt die noch nicht völlig reifen rötlichen Beeren, die schnell anf Matten getrocknct, runzelig und schwarz werden. Sie geben den Schwarzen Pfeffer. Die Beeren zeigen bei der Ernte verschiedene lieifegrade; die reifere Frucht ist weniger rnnzelig.

Das Pfefferkorn ist fast kugelig, an der Oberfläche mehr oder weniger runzelig. Das dimme Frnchtgelïuse ist mit dem samen verwachsen, der, von einer zarten, braumoten Samenhaut umschlossen, fast ganz aus einem im Umfange hornartigen, grünlichgrauen, nach innen zu mehligen, weifsen Eiweifskörper besteht. Der Keim ist in der Regel nicht entwickelt, da die Samen meist mreif geerntet wurden.

Der Weifse Pfeffer kommt ron demselben Gewïchs, nur dafs man die Beeren etwas reifer werden lälst und sie nach der Ernte einige 'Tage in Kall-, Salz- oder Meerwasser (nach anderen auch heifses Wasser) legt und dann durch Sieben und Waschen die Schale leicht ablöst. Dieser Pfeffer sieht gelblichweifs und glatt aus, hat durch das Einweichen an Gehalt verloren und schmeckt daher milder als der Schwarze Pfeffer. Die feinste Sorte des Weifsen Pfeffers soll aus den vollstïndig reifen Beeren bestehen, die vor der Ernte von dem strauch ahgefillen und von der śonne geb) eicht sind.

Nachdem die Pfefferkörner durch Sieben und Schwingen gereinigt, und je nach ihrem Reifegrade sortiert worden sind, werden sie in Ballen verpackt.

Bestandteile. Der schwarze l'feffer enthiilt als eigentiimliche Bestandteile ein ätherisches öl (ein Terpen), ein eigentiimliches, krystallinisches Alkaloid, das Piperin unil ein scharfes, mediziniseh verwendetes Weichharz. Das Harz, das bis 16,6 Pro\% gefunden wurde, verleiht dem l'feffer seinen beifsenden Gesclmack; das bis 2,2 Proz. gewonnene iitherische $\ddot{O}$ ist der 'Trüger lles Geruches.

Warenkunde. Die beste Ware ist schwer, sinkt im Wasser unter, und wenig' g'erunzelt, weil reif geerntet. Die als unreif abgenommenen Körner sind leicht, gerunzelt, brechen leicht und verlieren dabei sehr an Geruch und Gesehmaek. Verfälscht wird der Pfeffer an einigen I'roduktionsorten mit-

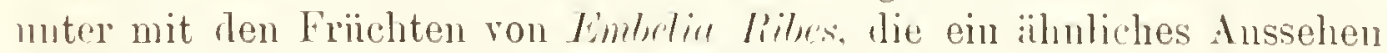
haben und rum so schwerer zu cutdecken siud, als sie cinen etwas 
wiirzigen Geschmack besitzen. Nie kaufe man grestofsenen Pfeffer, dil er entweller mit ganz geringen Sorten oder mit I'fefierstanb, pulverisierten Stengelresten (die beim sortieren abfallen), gestofsenem Senfsamen und Nelkenstielen, gerösteten Eichehn und Mehl ron Baumrinde u. s. w. vermischt ist. Man hat auch I'fefferkörner kiinstlich hergestellt (Lyon), die indes in der Regel ron Insekten selır zertiessen wurden, wïhrend an den echten, natiirlichen Pfeffer Insekten nicht gehen. Beste Sorte: Malabar-l'felfer, und zwar der nur in geringen IIengen rorkommende Tellicherry. Reichere Ernten guter Sorten liefern Pinang, Singapore und Cochinchina; der hollindische oder Batavia-Pfeffer ist der geringste.

Die Gattung Pfeffer (Piper) liefert noch zahlheiche andere Nutzstoffe. Die Fruchtïhren von P'iper 70 ngum L. und Piper offirinurm D. C. im Indisch-Malayischen Archipel, sind der Lange I'feffer; auch die Fruchtstïnde von Piper aduneum L. in Brasilien werden als solcher verkauft. Die Bhitter des Petelpfeffers (Pipr. Bctle L_.), im ganzen indisch-malayischen Gelset, werden ron den Eingeborenen Indiens, zusammen mit der Arekanufs und etwas Kalk, als Betel gekant; desgleichen die ron Pifer Siroboa L. und I'iper Melamiri L., die aber beide woht nur Formen des betelpfeffers sind. Wurzeln (Radix Jambarandy) ron Piper unguiculutum Ruiz et Pavon in Brasilien dienen als Nittel gegen den schlangenbils. Medizinische V'erwendung finden die Blätter von Piper Nabmrndi Velloz in Südbrasilien. Die Bhïter ron Liper geniculatum Swartz von Brasilien bis zu den Antillen und Mexiko werden dem Curare zugesetzt. Die Blitter von Piper angustifolium Ruiz et Pavon in Brasilien kommen als Matiko-Blätter in den Handel, die Beeren des im Indischen Archipel heimischen. in Westindien kultivierten Piper Cubeba L. fil. als Cubeben. Piper Iruineense Schumann in Westafrika liefert den Aschantipfeffer. Die Wurzel der Kavapflanze (Kiva, Ava, Piper methysticum Forster) auf Otahiti und den sandwichinseln liefert gekaut ein beranschendes Cretriink.

Wirkung und Gebrauch. Der I'feffer ist ein Weltbiirger unter den Gewïren und nimmt in Handel damit auch heute noch muledingt die erste Stelle ein. Er wirl besonders an schwer verdanliche, fette Speisen gethan. Die Körner, ebenso die Abkochungen davon, wirken, wie dis Piperin, besonders anf die Schleimhïute des Miıgens, indem sie zu grölserer Absonderung reizcin und das Getiilıl von Wiirme erzengen.

Angaben über den Handel. Der l'fefter ist das merkantilisch wichtigste (iewiim, Europiiische Hanptmïrkte sind London.

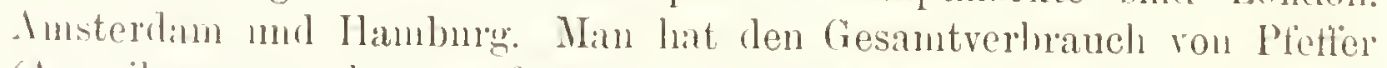
(Amerikit mingerechnot) auf $26000000 \mathrm{~kg}$ angegeben. Daron produzieren

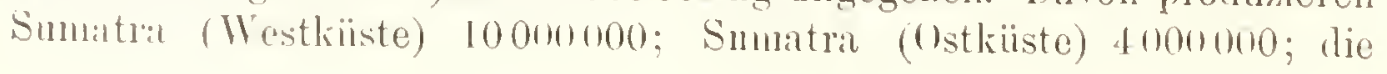


lnsehn in del Milakkastralso 1 $800000 ;$ die Malayische Halbinsel 1:000000; bormen 1500000; Sian 4000000; Malalbal 2500000 kog. Fiir Europa sind Malabar. l'enang. Lhio, Johole, Singapore und lie Westkiiste von Sumatra die wichtigsten limengungsgebiete. Singapore ist der wiclitigste l'feffermarlet der Frde, mol dort sind es die Chinesen, die dieson Markt beherrsuen. Vou da fiilurt Fugland etwa $13000000 \mathrm{~kg}$ ein, und hiervon grehen wach Dentseluland iiber $2500000 \mathrm{k} \underline{.}$.

Dic linltur les l'fefferstranches gewinut fortwiahent an Ausdehnung. 1814 war der l'feffer dremal höher im l'reise als jetzt.

Geschichte des Pfeffers. Der l'feffer ist eines der ältesten Gewiirze. I)er Sanskritname des Iangen I'feffer's (l'ipurli) gelit, auf den Schwarzen l'feffer ïbertragen, fast durch alle sprachen, nachden dic Perser das 1 mit einem $r$ vertauscht hatten.

Vor Alexinder dem Grolsen verstanden die Griechen unter l'feffere wahscheinlich die Frïchte von dem $/$ thiopischen Pfefferbaume (IIt)zeliu acthinpicu D. C., Selimsköruer). Erst nach dem Zuge des grofsen Macedoniers nach Indien wurde der Schwarze Pfeffer den alten Griechen und liönerı bekannt. Sie sclıätzten dieses Gewürz sehr hoch. und es stand fist in gleichem Werte mit den edlen Metallen. Als der Gotenkönig Alarich 408 liom belagerte, verstand er sich zur Aufhebung der lielagerung erst, nachilem ihm die Römer 5000 Pfd. Gold, 30000 Pfd. Silber, 4000 seidene Kleider, 3000 Pfd. Pfeffer u. s. w. entrichtet hatten. Im Mittelalter, vor der Auffindung des Seeweges nach Ostindien, lag der Handel mit Pfeffer in den Hïnden der Genuesen und Venetianer, und namentlich der Wunsch, die erselınten Gewürze Indiens auf direktem Wege billiger zu beziehen, trieb die spanier und Portugiesen, einen Wasserweg nach Ostindien zu suchen. Vasco da Gama brachte 1503 aus dem Hafen von Kalikut 5000 'Tonnen Gewiirze mit nach Hause. Ils die Portugiesen in Indien alle Gewalt an sich gerissen hatten, beschränkten sie die Produktion des Pfetiers, hestimmten allein dessen Preis und nahmen. Wie angegeben wird, 600 l'roz. Gewiun; nach Verdrängung der Portngiesen sollen die Hollinder don fowinn auf 1000 Proz. gesteigert hahen. 


\section{Tafel 12.}

Nelkenpfeffer (l'iment. Englisch Gewür\%, Gewiir\%. Nengewiirz, sipezcreipfeffer. Jamaicapfeffer, Allspice). (P'imenta uficinalis Berg, Myptus P'imenta L., Eugenia Pimentu D. (.)

Der Nelkenpfeffer gehört zur Unterklasse der Freiblätterigen Dikotylen, zur Reihe der Myrtenblumigen (M/ystifloruc) und zur Familie der Myrtengewächse (Myrfuccue).

Die Familie der Myrtengewächse (Mryturcur). Mälsig hohe orler kleine Bäume und Strïucher („Region der Myrten"), dithin aber auch die Baumriesen Anstraliens, die cine Höhe von iilser $150 \mathrm{~m}$ und am Boden einen Umfang von $30 \mathrm{~m}$ erreichen. Blitter immergriin, lederig, kurz gestielt, meist gegenübersteliend. immor nebenblattlis, drüsig punktiert, kahl, fast stets ganzrandig. Blïten einzeln in den Blittachselı oder in meist schirmrispigen, seltener traubigen Blitenstïnden; fast immer zwitterig, strallig gebant. Stanblilitter zahlreich; Fïdlen derselben meist in liündel verwachsen. Fruchtknoten ein- bis melnfficherig, unterstïndig oder halbunterständig. (iriffel einfaclı. Die Becren- oder Kapselfrucht trägt meist noch den Kielchsilum. Keimling ohne Niilırgewebe. Etwa 75 Gattungen mit 2750) Arten.

Die Gattung Nelkenpfeffer (L'imcintu Lindl.). In jedem der beiden Fruchtknotenfïcher eine bis sechs Samenanlagen, die an einer :m oberen Ende der Scheidewand befindlichen Samenleiste liängen. Die Frucht enthialt ein lis zwei fruchtbare samen, mit spiraligem Kieimling, dessen kurze Keimblätter zn imnerst stehen. Hierlıer fïnf Arten.

Nelkenpfeffer (I'imentu officinalis Berg, Iryptus pimentu L.).

Stamm: 10 lis $13 \mathrm{~m}$ hoch, 20 bis $25 \mathrm{~cm}$ Durchmesser. wlatt berindet. Krone buschig, becitïstig, immergrün.

Blätter gegenst:indig, kurgastielt, breit eiförmig bris länglinh lanzettförmign, bis $13 \mathrm{~cm}$ lang nnd $7 \mathrm{~cm}$ breit. gamzrandig, an der spitze stmmpl, glatt, schön grün, durchsichtig punktiert, aromatisch.

Blüten in zallhreichen anfredhten, zustummengesetzten. vicllhliitigen 'Trauben, die kiirmer sind als das Hilitt, in dessen Winkeln sie int-pringen. Der Keleh li:t vier kleine, eirmulliche, stmmpfe '/ïlne. 
Blumenblättchen rier, oval, algerundet, holıl, weifs, loppelt so lanw als dir lielchzïhne. Staubfäden zahlreich, so lang wic die Blumenkione. Staubbeutel rundlich, gall. Griffel fein behart, mit kopfförmiger Narbe. Der unterstïndige. vom lielch bekleilete Fruchtinoten ist eiformig. Gewöhnlich blühen die Biime zweimal in Jahre, aber nur die Bliiten, die im April und Mai erscheinen, sind fruchtbar.

Die Frucht eine graubraune, zweificherige und zweisamige, saftige, rom lielch bekleidete Beere, deren Oberhaut derbe Spaltöfnumgen und warzenförmige, gelbhraune (̈)behälter hesitzt. Samen rnndlich-nierenförmig, dunkelbraun, leicht herausfallend und von einer dümnen. brïunlichen Samenhaut umschlossen. Keim schneckenförmig eingerollt, olne Nïhrgewebe. Oft num in einem Fache ein bis zwei samen.

Alle Teile des Baumes, besonders die unreifen Früchte, hesitzen eineu starken, feurigen, aber angenehmen, aromatischen Geschmack.

Heimat und Verbreitungsbezirk: Westindien und Centralamerika, besonders auf Kalksteinlüigeln der Nordseite von Janaica, in der Nähe des Meeres.

Kultur. Der Pimentbaum hat ein geringes Anpassungsvermögen an reränderte Verhältnisse, so dafs es nicht einmal gelang, ihn auf den nördlichen westindischen Inseln anzupflanzen. Wer in den Besitz einer Pimentptlanzung kommen will, sucht eine Stelle, wo dev Baum häufig vorkommt. Hat man eine solche gefunden, so werden alle andecen Bäume gefällt. Die gefällten Bäume lälst man mit ihrem Holz und Laub liegen, sie bilden so zugleich eine gnte Diingnng und einen sicheren Schutz für die von den P'imentbïumen ausgestreuten Sämlinge. Nach ungefähr zwei Jaluren sind die jungen Pflanzen so weit gediehen, dafs man das Land völlig abräumen und lichten kiann. Nach sieben Jahren ist die erste Ernte. Da die reifen Früchte das Aroma verlieren. wird die Aberntung vorgenommen, sobald die Friichte die Grölse von I'fefferkörnern erreicht haben und noch griun sind. Dic grïnen Piceren trocknet man möglichst schnell in der Sonnenglut, auch in Darröfen, wodurch sie eine gelbbraune Firbe annehmen, verpackt sie in Säcke zu 50 bis $75 \mathrm{~kg}$ und bringt sie in den Handel. Ein Baum mittlerer Gröfse liefert in guten Frntejahren $75 \mathrm{~kg}$ griiner $(=50 \mathrm{~kg}$ getrockncter) Bceren.

Gehalt. Die Frichte enthalten bis 10 Proza ätherisches Ö1, das Pimentöl; es ist gelb lis gelbbraun, dickflïssig, hat ein specif. Gewicht von 1,03 und eine ïhnliche \%usammensetzung wie das Gewiir\%nelkenöl (Nelkensïure u. a.). Es wird in der Ar\%neikunde und, wie die Körner, in der Likörlabrikation und z.n Parfümerien rerwenlet.

W arenkunde. Die Schale hat keine Runzeln, sonclem feine, 
kleine Wïrzchen und spitze Inare, anch finden sich in der Handelsware oft noch trockene Stielchen, sowie I'berreste des kelches. In den getrockneten Beeren zieht man dic kleineren wegen ihres tïrkeren Aromas vor; anch müssen sie schwer, von den Kernen ganz erfiillt und rotbraun sein. Zu reif geerntete Beeren, Spanischer oder Tabasco-P'iment, nach anderen die Peeren vou P'imcuta Jubusrws: Schlechtendal, sind woich, dickschalig. dunkelgriinlich, grau und weniger aromatisch. Die beste Ware ist der Jamaica-Piment, der von Jamaica, Cuba, Barbados und Tabago kommt, er ist nicht gröfser als eine kleine Erhse. Der Gekrönte Piment (Bay-berries, ron Pimenta acris; Nartinique und Guadeloupe) hat längliche Körnes mit kleiner Krone (vertrockneter Kielch). Der gemahlene Piment unterliegt älıllichen Verfïlscliungen wie der I'feffer. Die geringeren Sorteu stammen meist von anderen Arten, so ron Pimenta Pimento Grisebach in Jamaica, und der Brasilianische Piment von Culyptranthes uromatica St. Hilaire. Der kleine Mexikanische oder CraveiroPiment, Krompiment, stammt von Amomisarten; er besitzt cinen fünfteiligen Kelch.

Gebrauch und Wirkung. Gewiirz an Speisen und Backwaren, weniger scharf und aromatischer als der Schwarze Pfeffer, sehr viel ätherisches Öl enthalterid. Dient in der Medizin (fructus Pimentu, fructus Amomi), wie die Gewiirznelken, als diätetisches Yittel bei Schwäche des Mlagens und Darmkanals und wird zu vielen Zusammensetzungen benutzt. Englische und amerikanische Schirmfabrikanten verwenden junge Stämmchen zu Schirmstangen und zwar in solcher Menge, dafs die Befïirchtung laut wird. die Erzengung des Gewiirzes könne versiegen.

Angaben über den Handel. Als Bezugsquelle, jährlich 6000000 bis $8000000 \mathrm{~kg}$, liommt nur Jamaica in Betraclit. Diron greht etwa die Fïllfte nach amerikanischen Ilïfen und die andere Hïlfte nach England, das von dieser Einfuhr die Mälfte an das ïhrige Europa wieder abgiebt. Hamburg erlält jährlich etwa $500000 \mathrm{kgg}$. In vorigen Jahrzehnt solleu jührlich etwa 5000 Bündel juuger Stiimmchen, das Biindel zu 500 bis 800 Stïcken, in den Handel gebracht worden sein.

Geschichte der Pflanze. Der Nelkenpfeffer gehört zu den nenen Gewiirzen (.. Nenes Gewiirz"), die wir erst nach der kntdeckung Anerikas kemnen gelernt hahen; er ist hieblingsgewürz der Engländer ("Englisch (iewiirz"). Leinschmecker wollen orkennen, dals der Velkenffeffer den Geruch und Geschmack von I'fefter, Gewiir\%nelken, Zimt - genmg, ron allen Gewiirzen in sich rereinige. Das laat Veranlassung zu dem englischen Namen Allspice (Allgewiir\%) gerreben. 


\section{Tafel 13.}

\section{Gewürznelkenbaum}

(.Jambosa Caryoplugllus Niedenzu, Camyoplugllus monaticus L., Eugenia caryophyllata Thunberg).

Der Gewïrznelkenbaum gehört wie der Nelkenpfeffer zur Familie der Myrtengewiichse (siehe S. 123).

Die Gattung Gewürznelkenbaum (.Tambosu D. C. C'aryopllıllus L.). Blütenachse beträchtlich ïber die Blütenansatzstelle hinaus verlïnger'; Fruchtknoten in dem oberen Teile dieses Gebildes. Kelchzipfel unter sich frei. Staubblätter einem ringförmigen Diskus eingefügt. Hierher ungeführ 220 Arten.

Der Gewürznelkenbaum erreicht eine $\mathrm{Höh}$ e von 10 bis $12 \mathrm{~m}$ und einen Durchmesser von 30 bis $55 \mathrm{~cm}$. Seine Äste entspringen schon in einer geringen Entfernung vom Boden und bilden eine kegel- oder pyramidenförmige, schöne $\mathrm{K}$ ron e. Rinde gelblichgrau, glatt. Holz schwer und dicht.

Blätter entgegengesetzt, kreuzstïndig, ziemlich ling gestielt, keilig in den Blattstiel iibergehend, absteliend, länglich-oval oder länglich-verkehrt-eiförmig, auch lanzettlich, etwas wellenförmig, nit zahlreichen kleinen Öldrüsen und viekn parallelen (Uuerrippen versehen. auf der unteren Seite blafs-, auf der oberen dunkelgriin, 6 bis $8 \mathrm{~cm}$ lang, : $3 \mathrm{~cm}$ breit. immergrün.

Trugdolden endständig, dreifach gabelig, Spindel vierkantig, gegliedert, an den Verzweigungen mit hinfialligen Deckbllittern besetzt. Blüten von zwei hinfälligen Deckblättchen gestiitzt, gestielt, wohlriechend. Bliitenstiele gliatt und gleichsam gegliedert, Blitenknospen rot. Kelch lang, trichterförmig mit dem linglichen Fruchtknoten verwachsen, denselben umschliefsend; die ganze Rinde von zallireichen Öldrüsen durchsetzt, erst griin, danm weifslich, endlich dunkelrot gefärbt, in vier längliche, abstehende 'tipfel auslitufend. Blumenblätter vier, konkar, abgerundet, milchweil's bis blalsrosenrot, vor dem Aufbliilien kopffürnigy zusammengeballt, bcim Aufblihen deckelartig abfallend. Staubblätter einem ringförmigen Diskus eingefiigt. zahlreich, lïnger als die lihumenblïtter. frei oder :Im 
Grunde in vier, mit den Kelchblättern wechselnde Bündel verwachsen. vor dem $A$ !nf bliihen eingebogen, nachher aufreclit, weifs. Staubbeutel oval, gelb. nach innen gewendet, zweificherig, Fäcler der lïnge nal aufspringend. Griffel kurz. Narbe einfacl. Samenanlagen zahlreich, an einer an der Hitte der Scheidewand betindlichen, nur wenig hervorragenden Samenleiste.

Frucht eine Beere, 2 bis $21 / 2 \mathrm{~cm}$ lang, oval. trocken, einsamig, ron den aufrechten oder nach innen gebogenen lielchblättern gekiönt, braunviolett, mit einem braunen, fettglänzenden liern.

Same länglich. Keimling ohne Nährgewebe; die zwei dicken, auf der Aufsenseite gewölbten Samenlappen sind ineinander gewunden, das gerade Wiirzelchen ist, nach Art des Stieles schildförmiger Blätter, in der Mitte der Samenlappen angeheftet und liegt zwischen diesen.

Die noch nicht entfalteten Blütenknospen sind die bekinnten Gewürznelken oder Gewürznägelein.

Blütezeit: September.

Vaterland: Molukken; nach Rumphius die kleine Insel Makian. Verbreitungsbezirk: Singapore. Polo-Pinang; Bourbon, Manritins, Sansibar; Antillen und Südamerika.

Kultur. Der Gewïrznelkenbaum rerlangt feuchte Luft. Die Gew ürnelken der kultivierten B̈̈iume besitzen grölseren ölreichtum als die der wilden. Die ersteren liefern vom 6. bis 12. Jahre die höchsten Erträge, sollen jedoch nicht über 20 Jahre alt werden, während den letzteren eine Lebensdaner bis zu 75 Jahren zugeschrieben wird. Nan vermehrt ihn durch Stecklinge. In den ersten Jahren muls ihm Beschattung gegeben werden. Die Pflanzungen teilt man auf Amboina in Gärten und Parks ein. Zur Zeit der Ernte (Oktober bis Dezember), sobald der Kelch sich zu röten beginnt, die Bliiten mithin noch nicht aufgebrochen sind. bricht man die Blïtenstïnde mit der Fland, oder schlïgt sie mit Bambusstïben ab und sammelt sie anf untergelegten 'Tüchern. Man räuchert sie etwas auf geflochtenen Matten über gelindem Feuer und trocknet sie dann vollends in der sonnenglut. worauf sie eine dunkelbraune Farbe annehmen. Darauf nimmt man den Knospen die Blïtenstiele. Lin Bam giebt 2 bis $4 \mathrm{~kg}$ Früchte. Auf Amboina kultivieren die Eingeborenen den Baum und mïssen für eine sehr greringe Entsclädigung die Ernte an die hollïndische Regierung abliefern. (iegen rine Prämie haben die lläiptlinge Ernte und Ablicferung zu überwachen. Die Versendung geschieht in Saicken aus kokospalmbliittern orler auch in Hiiuten.

Gehalt. Der Bamm enthält hesonders in den liliitenkelchen 16 his 25 I'roz, eines stark aronatischen, kräftimen, angenehm riechenden, auf der \%unge heftig brenn'nden ätherischen Öles, Nelken̈̈l; anferdem 1:; l'roz. Gerbstoff, feruer Gummi, Harz u. s. w. (i) wird auch durch Destillation aus unscheinbaren Nelken, Stielen und 
lilitteru des liammes gewomnen. Inrch eine zweite Destillation mit Wasser wird das erst dunkelgelbe orler brame (i) blalsgelblich oder auch firblos.

Gebrauch. Die Gewürnelken werden als sehr kräftiges, scharfes Gewïr\% bein Ëinmachen der Früchte, zur Likörfabrikation, an I'leischspeisen und in der Medizin verwendet; Nelkentinktur gegen $\mathrm{Ab}$ spannung, anch äufserlich zu reizenden Umsclilägen, als Mittel bei rheumatischen Zahnschmerz, zu Mundwässern. Das Nelkenöl hat dieselbe Verwendung in der Medizin, aulserdem verbraucht man es in grofsen Mengen in der Parfümerie. Die Früchte, Mutternclken (Anthomhllli), sind weniger aromatisch als die Gewürmnelken, auch nicht so scharf als diese. In den Heimatliindern werden sie in Zucker eingemacht. Anch die getrockneten Fruchtstengel sind aromatisch nnd kommen in beschränkten Mengen, als Nelkenstiele, in den Handel.

Warenkunde. Gute Ware mul's schwer, voll, biegsan, weich und öreich sein: Man drücke mit dem Fingernagel auf die Gewirznelken, um sich vou ihrem ïgehalte zu iiberzeugen. Die unaufgebliihte Bhmenkrone darf nicht fehlen, weil olne sie der (i) Igehalt des Kelches nicht gut erhalten ist und weil derartige Ware möglicherweise ihres Öles durch Destillation mit Wasser bereits beraubt sein könnte. Die ostindische Ware von der Gewiirzinsel Amboina und von Sumatra (Bezirk Benkulen) ist die beste (schön, lang, schwer, voll, wenig Bruch, von tief dunkler Farbe). Die Krone darf nicht trocken, mager und runzelig sein. Sorten: 1. Die sogenannten Englischen Nelken sind tiefbraun bis etwas grau, grofs, schwer und kurz, kräftig von Geruch und Geschmack, sehr gesclıätzt; 2. die Cayenne, lang, braun, riechen schwächer; 3. die Bourbon, lilein, kurz, heller, matt von Geruch, mit Bliitenstielen gemischt; 4. lie Holländischen, von Amboina, nicht sehr dunkel, von öligem Ansehen, starkem Geruch, aromatischem, scharfen Geschmack, sind die besten; 5. die ron Batavia, sehr trocken, grau; 6. die ron St. Lucia', weilsgelhlich, gering. Die Sansibarnelke, diinner und dunkler, ist die zweitbeste Sorte. Bereits ausdestillierte Nelken sind schwar\%, sehr rumelig, wenig ölig, riemlich platt und zusammengeschrumplt, schimmeh sehr leicht. Gemahlene Nelken stimmen in der Regel von geringen Sorten und sind gewöhnlich mit fremden Bestandteilen gennischt.

Angaben über den Handel. Für den Handel kommt nur die Wirre von den Straits Settlements (Pinang), ferner von den holländisch-indischen Insehn (Amboina) und von Sinsibir nebst l'enba in Betracht. Vom Verschiflungshafen Sansibar gelangen jührlich 2 bis :; Mill. Kilogramm Gewiirznelken zur Ausfuln. Auf Amboina werden 150000 bis $800000 \mathrm{~kg}$ Gewiirnelken rerschillt. l'inang nimmt den dritten laang ein, dann folgen Sumatra, Indieu und lieunion. Nach Lundon gelangen jührlich etwa $1600000 \mathrm{~kg}$. Hollands limfuln betrï̈gt 
ungefüh $150000 \mathrm{kgg}$, Frankreichs gegen $175000 \mathrm{~kg}$. Der wiclitigste deutsche Markt, Ilamburg, führt ungefiiln $: 310000 \mathrm{~kg}$ cin.

Geschichte der Pflanze. Der Geliauch der Gewürznelken bei den Völkern Asiens und Südeuropras ist uralt. In einem Zolltarif der römischen Kaiser werden Gewürznelken anfgeführt, anch von griechischen Ärzten des sechsten und siebenten Jahrhunderts werden sie erwiilnut. Sie wurden auch später von den arabischen Ïraten gebraucht. Marco Polo erwïhnt sie 1272. Doch scheint das westliche Europil dieses Gewïrz erst nach der Entdeckung der Molukken durch die Portugiesen (1524) kennen gelernt zu haben. Als sich die IIolläinder dieser Inseln bemäichtigt hatten (1599), verboten sie den Eingeborenen den Handel mit Gewürznelken, verbrannten den grössten Teil der Torräte und liefsen nur die Gewiirznelkenbïume auf Amboina und Saparna stehen, während die auf den übrigen molukkischen Inseln ausgerottet wurden. Nun konnten sie den Preis des Gewiurzes selbst in heliebiger Höhe bestimmen. Durch dieses Verfahren zogen sich die Holländer die Abneigung der Bewohner jener Inseln zu. 1670 gelang es l'oivre, dem französischen Statthalter von Isle de France und Bourbon, mit zwei kleinen Schiffen Muskatıufsbäume und Gewiirznelken auszufülnen, den Verfolgungen der holländischen Flottille zu entrehen und die Bäumchen nach den Seychellen und der Insel liourbon zu bringen. 1779 pflanzten die Franzosen den Baum auch in Cayenne an. Darauf kam er nach Martinique, St. Vincent, Domingo, Trinidad. Um 1800 erfolgte, angeblich von Mauritius her, die Einfïhrung in Sansibar, und seit $18: 30$ ist die Kuntur dieses liatumes dort sehr hedeutend geworden. Auf Amboina und Bourbon ist sie sehr gesunken. 


\section{Tafel 14.}

\section{Echter Ing w e r (Zingiber officinale Roscoe).}

Der Echte Ingwer gehört zur Kilasse der Monokotylen, zur Reihe der Gewïrzschilfe (Scituminew) und zur Familie der Ing'wergewächse (Zimpilseruccue).

Die Familie der Ing wergewächse (Zimpilerenrar'). Ausdanernde Krïuter, meist mit kriechendem oder knolligen Wurzelstock und häufig stark verdickten Wurzeln. Stengel ron den Seheiden der abrechselnd stehenden. ganzrandigen Blïtter unschlossen. Dis Perigon ist doppelt. Die Staubhlätter sind der Anlage nach in zwei Kíreisen angeordnet, von ihnen ist nur eins, welches dem inneren Kreise angehört. fruchtbar; das diesem gegenüberstehende Staubblatt des äufseren Kreises entwickelt sich zur lloniglippe, während die heiden seitlichen blumenblattartig werden und kileine Staminodien bilden. Der unterständige Fruchtknoten bildet sich aus drei Fruchtbliittern, ist dreifuicherig und trägt an einem achsenständigen Samenträger zahlıeiche Samenanlagen. Der fadenförmige Griffel läuft zwischen den beiden fruchtbaren Staubhlattfächern in die Tühe, ohne mit ihnen verwachsen zu scin, und endigt in eine kopfig verdickte, oft trichterfürmig oder sonstwic ausgehühlte, häufig gewimperte Narbe. Die Frucht, nicht bei allen bekimnt, ist eine dreificherige, meist in drei Kiknpen aufspringende Kinsel. Die Samen enthalten ein grofses, mehliges, äufscres Simenciweif, das ein kleineres, inneres muschliefst. 24 Gattungen, die meist dem indisch-malayischen Gebiet angchören (in Amerika sind nur zwei rertreteu), mit ungefähr 275 Arten.

Die Gattung Ingwer (Zimgilor Gaertn.) ist ausgezeichnet durch zwei kleine, zalmförmige Staminodion an Grunde der Lippe und durch einen verlängerten, nicrenförmigen, fast hornartigen lortsatz. (Fig. $1 \mathrm{~m}$ ) am Mittelbande des Staubbittes. Hicrher etwa 20 Arten.

Echter Ingwer (Zimgiber fifinale Roscre). W urzelstock ausdanerud, kriechend, knollig, gongliedert, verzweigt, zusammengodriickt, fleischig, blalshriun, von der Dicke cines Dammens, mit fadenförmigen, 
: his 4 mm dicken. schmutrigwcilsen Nebenw urzeln hesetzt. Ilic Ringel an den Knollen riilren von al)gestorbenen Stengeln her. Knollen wie Nobenwnzeln entlalten reichlich Ölzellen mul etwas stïrke.

Stengel melırere aus einem Wurzelstocke, einjährig, aufrecht. sclilank, 60 bis $100 \mathrm{~cm}$ hocll, 4 bis $9 \mathrm{~mm}$ dick, reich bebliittert. unten mit nackten scheiden lesetst.

Blätter zweireilig, mit einer scheide, die oben in ein zweiïhriges Blattlïutchen auslïult; Blattfläche sitzend, lineil-linzettlich. langgespitzt, 8 bis $30 \mathrm{~cm}$ lang, auf der Riickenfläche mit selır stark'r Mittelrippe, mit feinen Seitennerven und vielen durchscheinenden P'unkten versehen.

Blütenschäfte neben den blätterigen stengehn, unmittelbar aus der Wurzel, nackt, dick, rund, mit kurzen Scheiden, 15 his $30 \mathrm{~cm}$ lang; oberste Scheiden riolett punktiert mu in die breiten Deckblïter der Ähre iibergehend.

Blütenähre fust kopförmig, mit ziegeldachförmigen, mmgekehrt eirunden, nach oben kleiner, diinulüutig und gelb werdenden, einhiitigen, am Rande gelben, nach rorn brannviolett punktierten ïnfseren Deckbliittern.

Blïten eimzelı in den Achseln der Deckbliatter. von einem kleinen, scheidenartigen Deckblüttchen gestiitzt. rasch rergïnglich. Blütenliülle oberstïndig, doppelt; die ïufsere kürzer, häutig, rölnrig, tiefgespalten, am Samme dreizïhnig; die innere schmalröhrig, dreispaltig. Staubblätter eigentlich sechs, in zwei lieihen, die drei des ïufseren kíreises mnfruchtbar, von den drei inneren nur cius fruchtbar. I)ic beiden oberen Staubbliitter des änfseren Kreises stellen kleinn. zahnförmige Staminodin zu beiden Seiten, am Grunde der IIoniglippe dar (st, Fig. 2); das untere ist grols, blunenblattartin, in eine ungekelurt ciförmige, dreilappige, brammote bis violette, farblos oder selblich punktierte, geaderte Honiglippe umgewandelt. Staubbeutel des fruchtbaren Staubllattes sitzend, läuglich iibergebogen. sweifächerigg. gelb; oberer 'Teil des Mittelbandes in einen violetten, den Griffel scheidenförmign unfissenden sichnaluel verlïngert. Griffel fadenfömig, sich durch die Rinue des Mittelbandes des Staubbentel: srängend, ohen violett. Narbe trichterförmign, durch cinen Krans. langer Warzen grefranst.

Frucht wonig bekinnt. da reife lirichte noch nicht beolachtet wurden, cine dreilibcherige, fast beerenartig-fluischigr, dreiklinplige liapsel mit zahlieichen Samen.

Dic I'llanze blüht im Sieptember und zwar nur wenige stunden.

Vaterland: widision. Verbreitungsbezirk: dulserden Westindien, brasilien und Sierra Lene.

I ultur des Ingwers. Der Ingwer wird durch Wurchtork. trilung fortgepflanzt. Er lieht einen fenchten, nicht smupfigen 
lioden (helmboden) und Inltenchtigkeit. Man elntet nach !) oder 10 Nonaten, naehdem die Stengel ahgestorben sind, indem man dir "Wrurzelstöcke heransninmt. Es werden nu' die reitonknollen benutzt; lie Ilauptwuryelstöcke sterben ab. Die ersteren sind istig gegliedert, einzelı etwas flach und heinahe handförmig und werden deshath aneh woll In grwerklanen oder Ingwerzehen genamt.

Gehalt des Ingwers. Als der 'Trüger des in Wurzelstock enthaltenen liältigen Aromas ist ein sehr zartes, rerfilztes Zellgewebe anzusehen, das neben einem gewiirzhaften Weichharz iitherisehes öl enthält. Dieses blafsgelbe, auf dem Wasser schwimmende, beifsend scharf schmeekende Ingweröl giebt der Wurzel einen krïftigen Geluch und einen gewiirhaften, brennenden und beifsenden $\mathrm{Ge}$ schmack; es ist bis zu 2,2 Pro\% darin enthalten.

Wirkung und Gebrauch des Ingwers. Ingwer wirkt reizend und crwärmend auf die Verdauungsorgane und wird in der Medizin in dieser Eigensehaft und gegen Blïhungen angewendet. Er dient in der Küche als gewöhnliches, kräftiges Speisegewiir, aufserdem in der Konditorei, in der Bäckerei von Lebkuchen, sowie zur Likörfabrikation. Der eingemachte Ingwer ist ein besseres Magenmittel als die in den Konditoreien ïherzuckerten, trockenen Knollen.

Warenkunde:

A. Weifser Ingwer'; aufsen weils, grau oder blafs bräunlich; inneu blals gell,lieh oder weils. Die Wurzelstöcke wurden in Wasser gebriiht, durch Abschaben von der Rinde befreit, geschält, und rorsiehtig getrocknet. Hier unterseheidet man:

1. Chinesischen Ingwer; gröfsere, flache, anlsen runzelige, sehr harte, im Bruche glïnzende, geschïlte Stiicke. Beste Sorte. Hierher auch der mit Zucker eingemachte Ingwer.

2. Bengalischen Ingwer; auf den beiden platten r'eiten. nieht an den Rändern gesehält; kleinere stiicke von schmutzig-graubrauner Farbe; im Bruche dieht. Hierher auch der Ifrikanisehe Ingwer.

3. Jamaica-Ingwer; mehr gestreekte, gan\% geschïlte, aulsen streifige Stiieke, mit einer diinnen, durch Einweichen in Kalkmileh erzeugten Kalkrinde. Die dunkeln stiicke werden in. Englind oft in Chlorkalk gebleieht. wodureh sie eine mehligweilse Oberfläche erhalten.

B. Sehwarzer oder Barbalos-lngwer; ungeseläilt, aulsen graubrann, innen bleifarben; in Stiicke gyeschnitten, in Wasser aufgekueht (daher die Stïrkekïmer in seinen \%ellen aulgequollen und zusimmengeflossen) und selmell getroeknet.

Der weilse Ingwer hat zwar ein hiibscheres Anssehen, was wolıl der Grund ist, dafs man den Ianaica-, den Malabar-und liengalIntrwer für den wertrollsten liailt, or ist aher an ïtherischem öl und 
Weichhar\% geringwertiger als der berleckte Ingwor. da die durch dis Schiilen entfernten Gewebeteile die wirksanneren stofte in reidurem Milse besitzen als lie imneren (iewebe.

Weifser wie schwarzer Ingwer soll schwer, von starkem, anmenehmem Geruch sein mo einen feurigen, scharfen Grschmack besitzen. Wurmstichige, \%orbrechliche, stimk runzelige, weiche, sehr faserige, leichte Stiicke kitute man nicht.

In g werpulver ist in der liegel rerfïlscht.

Angaben über den Handel. Die Asiaten gehrauchen ron diesem Gew iirz selbst seln viel, so dals die Ansfuln dagegen unbedentend ist; doch ist die Ansfuln Indiens in stetem Zunelmen begriffen, sie ist in den letzten Jahren auf $1500000 \mathrm{~kg}$ gestiegen. Die Ausfuhren Cochinchinas und Brasiliens sind ron sleicher Höhe und werden jo mit 4001100 lis $500000 \mathrm{~kg}$ angegeben. An eingemachtem Ingwer fülırt ('hina etwa 500000 kig ans. Die Austuhren Iamaicas und Sierra Leones stehen im Durchschnitt auf gleicher Höhe, diejenigen Jamaicas sind aber grolsen schwankungen nnterworfen. Sie betragen für jedes der heiden Erzengungsgeliete etwa $100000 \mathrm{~kg}$. Für Europa ist London cler Hauptmarkt; es führt jührlich etwa 35010 Centner ein. Nach Hamburg sollen jährlich ungefïhr 7000 Centner rolier und 1 nou Centner eingemachter Ingwer (ron China, Jamaica und Barbidos) gehracht werden.

Geschichte. In Indien war der Ingwer seit den ältesten Zeiten bekannt (Sanskritname sringurrou). Aus den Sichriften des Dioskorides mid Plinius geht hervor, dafs der Ingwer. als dessen Vaterland Arabien angesehen wird (Montecorrino heschrieb, die PHanze um 1292), schon von den Griechen und liömern als Gewiirz benut\%t wurde. Im Nittelalter wendete mam ihn auch in Deutschland an, loch sah der Württemberyer. Dichter Bebel (1475 bis 1516) mit Besormis den Gebrauch dieses Gewuirmes. Er sagt über die Biirgermiilchen: "Wein und rewiir\%, Zimt, Pfeffer nud Ingwer hahen ilı Blut verdorben - . "

Der Ingwer wurde durch die Spanier (Mentoza) im 16. Jahn'lumndert nach dem tropischen Amerikit verpflanat; dort nnl's er sich sehr rasch verhnet hilben, dem 1547 fiihnten die spanier bereits .22000 C'entur' Ingwer' aus Westindien aus. 


\section{Tafel 15.}

\section{Echter Muskatnufsbaum}

(Mypristica fragrans Houttuyn; Mypristica moschatn 'Thunberg).

Der Wchte Muskatuufsbaum gehört zur Unterklasse der Freiblätterigen Dikotylen, zur Reihe der Vielfriichtigen (Íunales) nud zur Familie der Muskatnufsgewächse (Myristicucene).

Die Familie der Muskatnulsgewächse (Myristicacear). Tropische, meist Asien angehörende Bäume, seltener Sträucher. Blätter zweizeilig, lederartig, ganzrandig, olne Nebenblätter. Bliiten eingeschlechtig, zweilïiusig. Perigon einfach, röhrig, krug- oder glockenförmig, dick, lederartig, meist dreilappig. Staubblätter 3 bis 18, Staubfüden miteinander verwachsen. Die weiblichen Blüten enthalten einen einzigen, oberstïndigen, einfächerigen Fruchtknoten, mit einer fast grundständigen, umgewendeten Samenanlage. Die Frucht ist eine zweiklappige, aufspringende lieere. Same von einem flcischigen, vielspaltig zerschlitzten Sameumantel umgeben, mit grolsem, runzeligem, öligem, zerklïftetem Nährgewebe und geradem, kleinem Keimling. Diese Ptlanzen sind nur in den Tropen zu Hause. Im ganzen Parenchym finden sich Ölschläuche. dercn Wandung verschleimt; namentlich Samen und Samenmantel sind reich an fettem und itherischem Öl.

Einzige Gattung Muskatnufsbaum (Myristice I.); mit etwa 80 Arten.

Echter Muskatnursbaum (Myristice firmines Houttuyn). Dcr liaum wird 15 bis $20 \mathrm{~m} \mathrm{hoch} \mathrm{und} \mathrm{bis} 70 \mathrm{~cm}$ im Durchmesser dick.

Rinde grïnlich-aschgrau oder schmutzig-olivengriin, imen rot. K rone sehr grofs, nyranidenförmig. Äste in gleich weit entfernten (bnirlen, wagerccht.

Blätter immergriin, abwechsehd, fast zweizoilig, lederig, knrz gestielt, lïnglich-eiförnig, ganzrandig, glatt, ohere Seite dunkel-, untere halsgriin. dnurchscheinend punktiert, 4 bis $10 \mathrm{~cm}$ lang und $11_{2}$ bis 4. con breit, fiedcrnervig, Mittchippe und seitemnerven unterseits stark, anfangs schwach seidenhaarig, später kahl.

Blüten zweihäusig, mit kleincn, ovalen I)eckhlätlchen, etwas 
oberhalb des lilattwinkels entspringend, hängend. Staubblattblüten in fünf- bis sechslluitigen, einfachen oder zweiteiligen 'Trüul,chen oder 'Trugdolden. Griffelblüten fist immer einzeln. Blitenstielchen beider Bliiten mit einem breit-eiförmigen, hinfïlligen Nebenblatte. Perigon eiförmig glockig, dick. fleischig. gelblichweils, mit aufrechtem, dreizihnigem Saum, 6 bis 5 mm lang, aulsen mit sehr kurzen Seidenhaaren besetzt. Die z.n einer mittelstïndigen Säule verwachsenen 9 bis 18 staubblätter nur wenig kürzer als das Perigon. Staubbeutel linienförmig, etwas kiirzer als die siiule, zweificherig, nach aufsen aufspringend. Stempel oberstïndig, wenig kürzer als die Blïtenlı̈ille, mit einer Naht, verkehnt-eiförmig orler eiförmig-länglich, mit zwei Narben. Fruchtknoten Heischig, einfächerig; Samenknospe lilein, sitzend, aufrecht, gegenläufig.

Beere von der Gestalt einer Ptirsich, rundlich, Heisching und etwas wollig, auf der einen Seite mit einer Nalıt versehen. zwei-, selten vierklappig-aufspringend, 4 bis $5 \mathrm{~cm}$ lang, erst griin, dann ockerfarbig. Der Same ist mit einem fleischigen, karminroten (getrocknet orangegelben), am Grunde ganzen, nach oben vielfach zerschlitzten Samenmantel (Macis, "Muskatblume" oder . Muskatbliite") ledeckt. Samenschale sehr lart, glänzend dunkelbraun, feinwarzig, mit Eindrücken, die dem Samemmantel entsprechen. Der Samenkern, die "Muskatuufs" des Handels, löst sich beim Trocknen ron der Schale, er ist von der Crö̈se eines kleinen Taubeneies, oval, runzelig, bräunlich. Das Sameneiweifs ist grauweifs, in altem Zustande brïunlich, es ist wachsartig, zerkliiftet und erscheint durch die braune, unregelmälsig und strahlenförmig bis fast zur Mitte rordringende Samenschale dunkel marmoriert. Keimling in (irunde des Eiweifses rotbraun, mit kurzem, der Anheftungsstelle des Samens zugewendetem Wiirzelchen und zwei dünnen, becherförmig zusammenstehenden, mach oben zerschlitztränderigen Samenlappen.

Der Baum soll wälırend des ganzen Jalıres bliihen und Friichte trangen.

Heimat: Auf den Molukken, namentlich a uf den dazn gehörigen Bandainseln. Verbreitungsbezirk: Aulserdem Sumatra, Malakkia. Bengalen, Singapur, l'enang, Java, Mauritius, sowie, aber nur nit wenig Erfolg, Westindien und Brasilien.

KuItur des Baumes. Regehölisige P'Hanzungen rom Muskatunfsbaum giebt es anf den Bandainseln uicht; man untzt vielmeln. die alten Iiäume aus und ïberläl'st die Vermelurung der Natur. Auf Jara und Sumatra gedeilien die Bäume in ebenem, nassem und gegen Wind geschiitztem Loden, Man schiitzt sie dort vor dem Winde. inden nan schnellwachsende Bäume un die Plantagen pllanzt. Auf

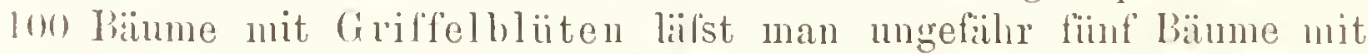
sitaublattbliiten stehen. Die Friichte branchen sieben Monate zu ihrer välligen licife. I)er batum soll rom 7. (am besten rom 1.5. lis '23.) 


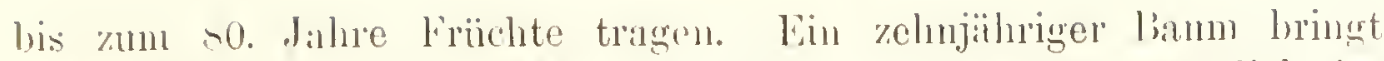

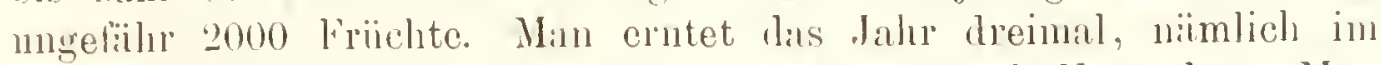
April (beste (Qualitiit), Juli (gröliste Mengre) uncl November. Man bricht die Friichte, wenn die ïufsere Schale lirst, nit langen Stangen, an dencn voln ein liörbchen nebst Ilitken angehnacht ist. Das in drir Juls entlualtene Fleisch ist sehr weich und wiirde bcim Aufbrechen der Schale sicher verletzt werden. Man trocknet dalier dio Nufs, machdem man den Samenumantel (Muris) solgfiiltig von rler Schale anommen, erst drei 'Tage an der Sonne und dann zwei Monate in hauchkimmern auf Horden bei cincr Wirme vou 750 C., his der Kern in der Schale kilappert. Man pocht dann die Schalen mit hölzernen llimmeln anf, woranf man die Niisse, 111 sie gegen Insektenstiche (Muskatwurm) zu schützen und das Ranzigrwerden zu verluiten, in ein Gemisclı von Kalk und Seewasser taucht und sie noch mit frisch gelösclitem Kalk bestiubt. Sic werden dann in fette, mittlere, magerc und angestochene sorticrt und allein oder nit Gewiirznelken rerpackt. Aus den geringsten wird in den Kulturorten Muskatnu fsöl geprelst. Das Verfahrcu beim Trocknen und „Einkalken" ist in den verschiedenen Kulturländern verschieden.

Gehalt der Nufs und des Samenmantels (ler Muskatblume des Handels). Der Baum ist in allen Teilen stark aromatisch. Nul's wie Macis enthalten ungefälı zu je 6 Proz. ein ätherisches Öl, das dem Gewürz den starken aromatischen Geruch und Gesclmack rerleiht, der bei den Macis stïrkcr und feiner sein soll als bei der Nuls. In Ostindien gewinnt man es durch Destillation mit Wasser. Es ist gelblich oder farblos und dickflüssig und besteht im wesentlichen aus zwei hohlenwasserstoffen. Nuf's und Macis enthalteu mngefihlu 25 I'roz. lett, das besouders aus weniger guten Niussen, aber auch aus Macis, zwischen erhitzten Platten ausgeprel'st und Muskatöl (Muskatwachs, Muskatbalsam, Bandaseife) genannt wird. Es ist eine talgartige Masse von heller oder dunkler orangegelber, weifslich oder rötlich marmorierter Farbe und Iluskatgeruch und -geschmack. Es kommt in riegelsteinfömmigen kinchen in den Handel.

Gebrauch. Muskatnul's, Macis und dic Muskatbutter gehören zu unseren beliebtesten Gew ürzen für Kïche mnd Konditoreien und werden einschliefslich des itherischen (j)es als Heilunittel (magcustialkend, wenig noch in Gebranch) und in der Parfümerie benutzt. In grolsen Gaben, eine gamze Nuls z. li., soll Muskat11 ul's giftign wirken.

Warenkunde. Dic besten Muskatnüsse und Macis konn11en vou den Bundainseln und Penang. Die auf Singrapore gebanten Niisse gehöron auch zu den besseren, die westindischen aber zu den geringsten Sorten. Gnte Xiisso sind grols (nicht lang) und chwer. Je grölser, je besser. Muskatuiisse, von welchen 70 ein Pfund wiesen. werlen doppelt so hoch bozahlt wie solche, dic in del Talıl 
ron 120 gleichwiegend sind. Als die Hächstgren\%e fiir eine gute

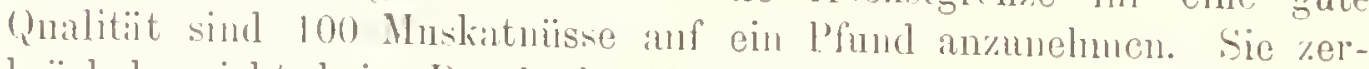
bröckeln nicht beim I)urchschneilen und schwitzen ein grelbliches (̈) ans, wenn man sic mit ciner heifsen Salcl durchsticht. Wird die Nanlel nicht erwïrnt, su reigt die turels den Stich hervorgerufene

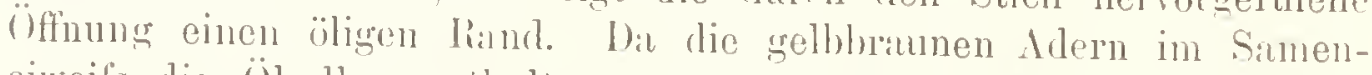
ciwcils die Ölzellen enthalten, so miissen gnte Xüsse cine schönc. krältige Alerung zeigen. Tuter dem Yanren Rompen verlandelt nan die zum ג'zneigebrauch undienlichen, znn Teil verdorbenen, vichleicht vor der lieife cingesimmolten, angefressenen, wurmstichigen. leicht zerhrechlichen, lrannschwïrlich marmorierten Nüssc ron schwachen Groncli und Ceschnack. Die milsgestalteten Niisse nemut man .. Diebs- oder Zwillingsüisse". Dic durch Destillation oller Aus\%iehen mit Weingeist des Gewürstoffes beraubten Mnskatniisse erkennt man teils an ihrer geringen Schwere, teils an dem auffallend schwachen Geruch mod Geschmack, teils an der gan\% grleichartigen. braunen larbe aufsen wie innen. Die Macis guter (lualitiit soll zähe und lornig scin und als das Zeichen der Frische cine lebhafte, gold- bis orangegelbe (im frischen Zustande scharlachrote) Färbung liaben und etwas durchscheinend sein. Nute Macis sind spröde, yerbrechlich und matt loräunlicligelb gefärbt. Beste Sorte dic Penang-Macis, Hockig und auseinander gebreitet; $\mathrm{zW}$ eite Qualität Bataria-Macis, Heischigc Beschaffenheit; geringe Sorte die Singapore-Macis.

Es kommen auch Nïsse ron anderen Muskatnulisarten in den Handel, die aber wenig wert sind; so von Myristica futum Houtt. inl Indischen Archipel, Nïsse lïnglich, von schwachem Aroma; Mryvistire Huluburirn Lam. liefert lïnglicle, einer Dattel ähnliche, wenig duftende Niisse; ferner Mulvistien Iryn in Ostindien und Myristirn surcedunen anf Tinor. Aus den Niissen ron Myristen subem Swart\% in Guiana wirl ein zin Ker\%en rerwendeter Talg gewomnen. Die Samen von Myristiru surinumensis lioland kommen als "African Nuts" in den llandel. Aus dem Simenmantel ron Myristicu Otulut Hnmb. et Bonpl. in den bergen Colmubiens wirl das Otabafett (amerikanische Nuskathutter) geprelist. Die Niisse ron M!nistirn offi-

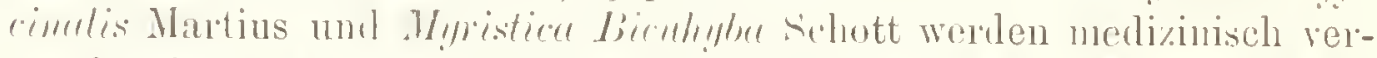
wondet, letztere liefert auch das Biknibafett. Von Mlyristicu Oculue IInmb. et Bompl. anu Amazonas gewinnt man das Okuballatehs. Mit

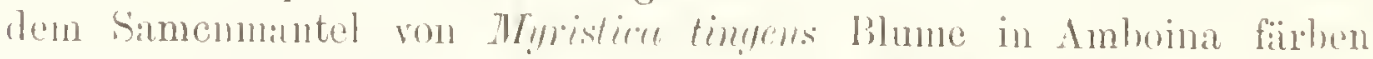

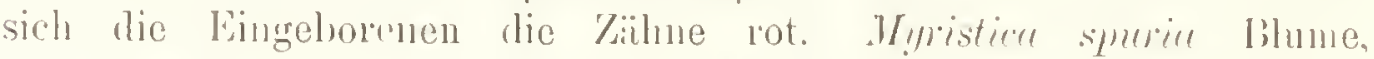
l) oogluan, licfort einen roten Sift, der ein Wisaty für Drachenblut ist.

Angaben über Ernten und Handel. Ilie Erträignisse ter versehiedenen lir\%engungsgebiete sind je nitch den Witternngsierlüiltnissen mud anderen Eintliissen weeliselnd. Auf' den Inseln Penany nud Singilpore, wo der Muskintunfsbanm erfolgreich angehant wurle. 


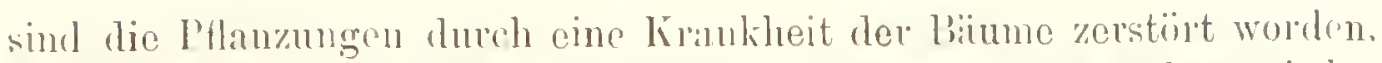
Aul l'euang haben Chineson den Versuch gremacht. den Anhau wierler

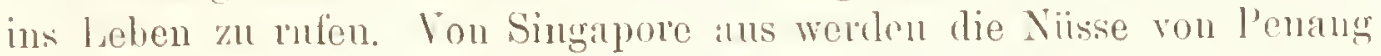
und den straits Settlements versehifft, os koumnen da\%u auch lieziige von Sumatrat und Borneo, in Simma durchschnittlich $250000 \mathrm{~kg}$ Muskatniisse mod Muskathlïten. Von lev Westkiisto Sumatras welden

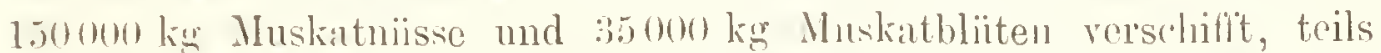
nach singapore, teils nach batavia, Penang, Indien und Furopar. Von den Bandainseln Lontor, Neira und $\mathrm{Mij}$ gehen etwa $300000 \mathrm{~kg}$. Muskatnüsse und $180000 \mathrm{~kg}$ Muskatblüten nach Java, $10 \mathrm{~m}$ mit $110 \mathrm{ch} 100000 \mathrm{~kg}$ Muskatnïssen durchsehnittlich vou hire aus in len Haudel gebraeht zu werken. Fugland führt etwa $400000 \mathrm{~kg}$ Mnskatnüsse und $40(1) \mathrm{kg}$ Muskatbliiten meist über singapore cin. Die Erträge in Westintien und lirasilien sind gering. Europa kault vorzugsweise Muskatniisse, Nordamerika Mnskatbliite.

Geschichte. Der Muskatunfsbam ist den Alten nicht und Linnc un unvollkommen bekannt gewesen. Malotius lat nach\%uweiscn gesucht. dals die Macis zur Zeit des Plautus (etwa 200 r. Chr.) und die Nufs schon Pliuius bekannt grewesen sei. In altaigyjotischen Mumiensälgen hat man dic Muskatmul's gefunden. Erst nach der Eroberung der Molukken durel die l'ortugiesen kam das Grewiir\% in Europa in Aufuahme. Als die Holländer sich dieser Inseln bemächtigt hatten, führten sie, $1 \mathrm{~m}$ die Proise der Gewürze in gewiunschter Hölıe zu halten, mit der Natur Krieg, liefsen den Muskatnulsbaum und den Gewiimelkenlaum num anf zwei Insehn (Banda und Amboina) stehen, rotteten die bïume auf den iibrigen Inselı aus und veranlalsten die eingebormen Fürsten, die Aupflanzung junger Bämme zu verhindern. Die hollïndische liegierung hat, um ihre Iandelspolitik durchzusetzen, mörderisehe Kriege gefïhrt. Iei reichen Enten suchte man die Fingrehorenen am Einsammeln der Frïchte zu hindern, oder man verbrannte einen Teil der Nïsse. 1760 wurden in Amsterdam fiir s Mill. Frankru Muskatniisse verbrannt, sitröme wohlriechenden Öles flossen auf den strafsen, aber niemand durfte bei schwerer strafe ciue ডufs oder einen 'Tropten Öl nehnen. Iennoch ist IV allace der Ansicht, dals die \%erstörung des Gewiirzhandels in den Molukken für deren Bewohner thatsïchlich aine Wohlthat gewesen sei, auch waren trotz allen Verbotes auf einigen lusehn von den Hollindlern unbeachtete,

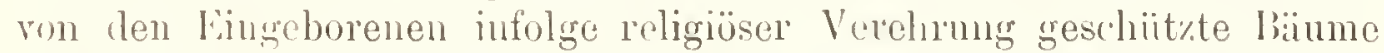

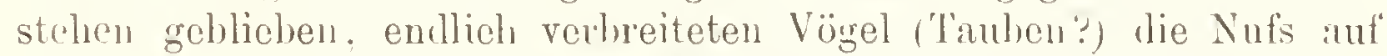
die benachbarten Insolu, so dafs Muskatuïsse und Gewiimnelken auch aul anderen Inselu gebaut wurden. 1769 golang es den firamosen, den Muskiatnufshaum nach st. Maturitius zu verpflauzen. T’m 1800 luachte Roxburgh den Muskatunfshaun uach Penang und Iienkinen auf Sunatra, spriter nach singapore. In letsterem ()rte wurden die PHanzungen Isfon durch linankheiten vernichtet. 


\section{Tafel 16. \\ Edler Lorber \\ (Lorbeer, Laums mulitis Limné).}

Der Edle Lorber (Lorbeer) gehört in die Familie der Lorbersewiichse, wie auch der Zimtlaum (s. S. 112).

Die Gattung Lorber (Lamms L.) umfafst bäume oder sträucher.

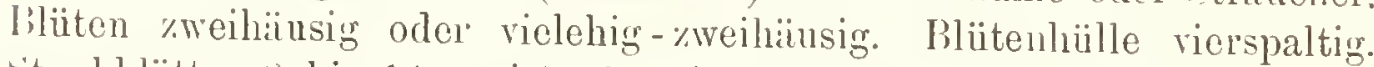
Staubblätter \& bis 14 , meist 12 , mit nach der Innenseite aufspringenden Staubbeutch. Alle Staubfiden sind mit Drïsen versehen. oder die \%wei oder vier änlseren sind drüsenlos, In der weiblichen Bliite finden sich meist vier Staminodien.

Hierher \%wci Arten.

Der Edle Lorber (Lumus molilis L.).

Stamm baumartig, 5 bis 10 moch, 50 bis $60 \mathrm{~cm}$ im Durchmesser stark, Äste biegsam, gerade, lraungriinlich und gegen den Stamm anliegend, mit kahler, griiner linde und weichem, blafsgelblichen IIole. Zaweige ron den Narben, wo frïher Blïter gesessen, knotig.

Blätter \%erstrent stehend, ku\% sestielt, länglich-lan\%ottlich. an leiden Enden \%ugespit», wellenrandig, lart, lederartig, immergrün, anf beiden Seiten glatt, oben dunkelgriin gliinzend. unten blasser, etwa $12 \mathrm{~cm}$ lang, 4 bis $6 \mathrm{~cm}$ breit.

Je nach der Bhattform unterscheidet man folgende . Wharten:

c) lireitblät teriger (valr. lutefolin); Blitter gröfser, länglich.

p) Gemeiner (rar. rommminis); Blitter klciner. lankettlich.

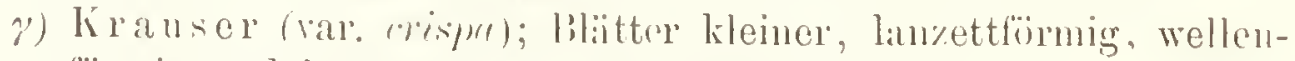
förmig und krams, an der spit\%e al,gestumplt.

d) Śchlnalblät teriger (var. (monstifolic); IBlitter schmal, lan\%ettförmig, nit keilförmigen Grmule, ansgeschweift.

Blüten meist durch Fehlschlagen жweihüusig, in ku\% gesticlten biischeln, die bis drei yusammenstehen, vier- bis sechsbliitig und \#n ihrem Grumle mit kleinen, hinfïlligen Blïttehon versehen sind. Perigon muterstinclig, glatt, mit vier oralen, rertieften, «nespit»ten, anfrechton \%ipleh. Männliche Blüte: Staubblätter $\$$ bis 14 , 
meist 12, in жwei líreisen, von der länge rles l'erigons. Staubfïden wenirg lïnger als dic Ntanbbeutel. Sta ubbeutel fast rechteckig, nach oben verschmïlert, ansgestutzt, zweilïcherig, nach inmen mit zwei aufsteigenden Klappen anfspringend; änsere in der Mitte mit \%wei rundlichen, kur\% gesticlt'n Drüsen beset/t. Stempel wal\%enförmig, verkiimmert. Weibliche Blüte: vier Staubblätter mit den P'erigonblättern wechschnd, unfruchtbar, mit je xwei linglichen, ungestielten Driisen. Stempel frei, Fruchtknoten fast eifömig. Samenträger der Liinge nach mit der inneren Wand verwachsen, mit einer hïngenden samenknospe. Griffel einfach, so lang als die Stanhfiiden, mit einer Furche und einer Hach ausgebreiteten, unregelmiifsig geschlit\%ten Narbe.

Frucht eine Stcinfrucht, eiförmig, länglichrund, kleiner als eine Kirsche, schwärzlichblan, ron dem Fruchtboden getragen; reift im Ilerbst.

Same einer, eiweilslos; Samenlappen dick, halbkugelig.

Blitter wie Friichte riechen und sclmecken stark gewürzhaft, ctwas kampferartig. Der Baum blüht im Mai.

Heimat und Verbreitungsbezirk: Die urspringliche Heimat des Edlen Lorbers, d. h. sein Vorkommen als wilde Pflanze in der hustorischon Zeit, ist vielleicht auf Kleinasien beschränkt gewesen. obgleich sich auch im siidlichen Europa Standorte finden können, an denen er die Eiszeit überdauert hat; denn soviel steht fest. dafs der Lorler sich vor der Eiszeit in Europa fand und dafs er jetzt das Kilima des Nittelmeergebietes vorzuiglich erträigt, ja noch hei Cherbourg gut überwintert. Dals der Lorberkult ans Kleinasien kam, kamn nicht beweisen, dafs der Lorber sich rorher in Europa nicht faut.

Kultur. Die Fortpflamzung des Bammes geschieht am besten durch Stecklinge. Die Ernte besteht in den Abpfliicken der Blïtter und Friichte.

Gehalt der Blätter und der Früchte. Cictrockinete Friichte enthalten 1), Pro\% ätherisches Öl, 1 Proz krystallisierbares, geruch- und geschmackloses, Hiichtiges, in Wasser unlüsliches La urin (Lorberkampfer, Lamrocerin), 13 Pro\% grinliches, fettes (j) 26 P'roz. rtälicmelıl u, s. w. Das durch Destillation mit Wasser gewonnene ätherische ()] ist blal'sgelb, durchscheinend, butterartig. schmeclit scharf und bitter. Um dis fotte (i), Lorber-oder Lohröl. zu erhalten, kocht man die frisch gustolsenen Früchte nit Wasser (Gardasee). l)as (̈) riccht stark nach den liüchten, ist bei gewöhnlicher Temperatur körnig, schmal\%antig mol enthïlt Laurinsiiure. Anch die lBaitter enthulten ein leichtes, iitherisches Ö).

Gebrauch. Ilic stank aromatischen lilitter werden als Gewiin

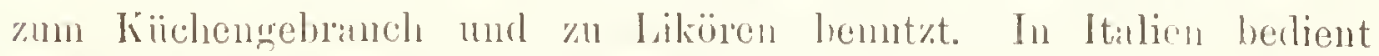

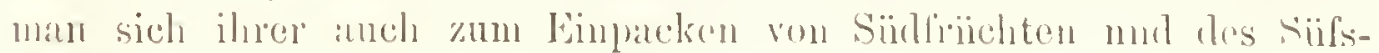


holzsaftes (Lalirit\%). Das lorberïl wird in der Medizin wenig, äuferlich zu stïrkenden Einreibungen verwondet; es ist ferner ein vortreffliches Mittel zur Mbhaltung von Fliegen, denen der Geruch unertrïglich ist; die Fleischer in den wïrmeren Lündern streichen deshall, obgleich es einen für die Menschen angenthmen Geruch lat, ihre Fleischhallen mit diesem Ö) an. Den Nordlïndern (Lappen und Samojeden) ist es ein Reiz- und Genulsmittel. Die Teeren werlen in der Vieharzneilunde gebraucht.

Warenkunde. Frische lorberbliitter von schöner, griner Firbe und kräftigem Geruch ziehe man alten von gelbhriuner Farbe vor. Die getrockneten, grünlichbraunen Früchte müssen glïnzend unr scliwer sein.

Angaben über Handel. Zuverliissige Nachrichteu uiber Gewinnung und Verbranch der Blïtter und Friichte des Lorherbaumes giebt es nicht. Die Ermengungsländer verbranchen sellst cinen buträichtlichen T'eil ilner Ernte. Wir erhalten die Blätter und das (i) meist iiber 'Triest.

Geschichte des Baumes. Hei len Alten war der Lorher dem Apollo leilig; je mehr sich Griechenland mit apollinischen Heiligtïmerı bedeckte, desto hüufiger wurden daselbst auch die Lorberlaine. Sein starker, gewiirzhalter (ieruch verscheuchte Moder und Verwesung. Er diente auch als Zeichen der siilnue für sittliche Befleckung. Fin Lorberkranz war die Belohnumg sowohl lıöherer geistiger als körperlicher Kräifte. I)ichter wurden damit geschmiickt, auch diejenigen, welche Orakel hefragten, ptlegten Lorberkrïnze anfzusetzen; durch kinen seiner Blïtter und anderer Teile glaubte nan in die Zukunft blicken zu können, weshalb die l'ythia, wenu sie zu dem mit Lorberzweigen geschmiickten Dreifulse ging, Lorberblätter kauten mulste, ja man wahrsigte sogar aus dem Verbrenuen von Lorherzweigen hei den (opfern der (aiitter: Knistern bellentete gliickliche, ruhiges Verlurennen schlimme Zeiten. Un prophetische Träume zu laben, trugen die Priester des Apollo Lorherkrïnze und legten zu (lem 'Jwecke anch Lorberbiatter unter ilne Kopflissen. Die Trimnphatoren und andere Sieger erhielten den Lorberkranz ans Zweigen von unfruchtharen Jïimnen aus Delphi gowunden. In ler neneren Zeit wurde jungen Doktoren der Iorber/weig sant den lirichten um

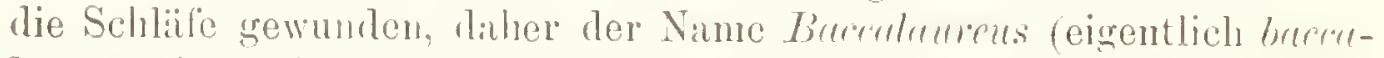

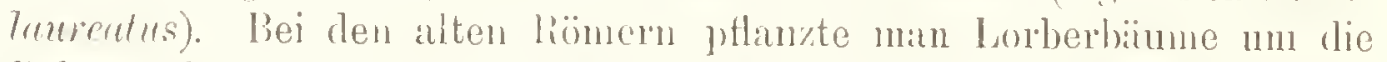
P'alïste der Kiaiser, mm 'T'empel nund die Wolmungen der P'riester; anch glaubte man, dals sie das länschligen des lilityes vorhiiteten; Kiniser 'Tiherius bodeckte deshall, be einem (iewitter semen kopf nit

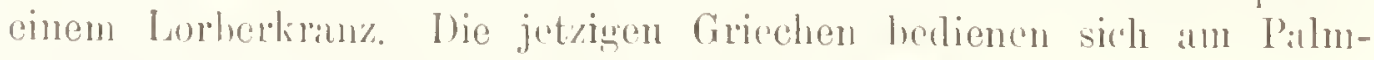
sonnting der lorber\%weige statt lor l'almenwedel. 


\title{
Tafel 17.
}

\section{Fie berrinde $n$ ba $u$ m,}

\author{
Calisaya-Chimabaum, Königs-Chinahamm \\ (Cinchuna Calisaya var. Josepliana Werldell).
}

Der Fieberrindenbaum hat diesclbe Stellung im System wie der Laffeelaum in der Familie der hirappptanzen (s. S. i3); er gehört aber zur Unterfamilie der Chinagewächse (Cinchonnideuc).

Die Unterfamilie der Chinagewächse ist durch ihre vielsamigen Fruchtknotenfücher gekcunzeichnet.

Die Gattung Fieberpindenbaum (Cinchonr). Immergrine Bäume, seltencr Sträucler. Kapsel wandspaltig; Samenleiste im Qnersclmitt hall)kreisförmig; Samen geflügclt.

Fieberrindenbaum (cinchone Culisuge var. Joscphiunu Weddell).

Stamm stranchartig, 2 bis $4 \mathrm{~m}$ hoch; İste aufrecht, die jiingeren viereckig, schwïrzlichgran berindet.

Blätter gegeniiberstehend, lang gestielt, länglich-oder eifömiglanzettlich nach beiden Enden verschmälert, ziemlich steif, fiedernervig, heiderseits kahl, bis $15 \mathrm{~cm}$ lang und $6 \mathrm{~cm}$ hreit, die lippen und lilattstiele der jungen Biame rosenrot. Blattstiele 10 bis $20 \mathrm{~mm}$ lang; Nebenblätter hinfällig, zwischen und iiber den Blattstielen sitzend, länglich, anf der Innenseite spärlich drüsig.

Blüten in gipfel- und in achselständigen (der drei obersten Blattpare), nicht sehr reiflblitigen, cilörmigen oder fast doldentraubigen Rispen; Spindel, İste und Blïtenstielehen dicht, weich und kư behart; Deckblïttchen hanzettrörmig. Kelch klein, mit den Fruchtknoten vorwachsen, urnenförmig, griü, lein behart, mit fïnf kul\%en, spitzon 'Vïlnen. Blumenkrone stieltellerförmig, blafsrot, mit fiinlspaltigem, zottig behatitem, weichem Sanm. Staubblätter fünf, mit kurzen. in der Mitte der Bhunenöhre angehefteten, pfriemenfümnigen Fäden; Staubbeutel linealisch, zweificherig. 
Griffel so lang wic die Iblitenröhre. Narbe zwcilappig, wenig aus dem Schlunde herrorragend. Fruchtinoten länglich, zweifïcherig. mit \%ahlreichen Samenanlagen. Samenträger mittelständig. Kapsel cilänglich, von dem bleibenden Kéchssun gekrönt, $13 \mathrm{~mm}$ lang, $8 \mathrm{~mm}$ breit, zweifïcherig, von unten nach oben scheidewandspaltig sich zweiklappig öfïnend. Die Klappen werden oben durch den Kelch zusammengehalten und springen unten auseinander; diese Sprengung setzt sich in dem Fruchtstiel fort. Samen riegeldachartig sich deckend, braun, plattgedrüickt, lïnglich, ringsum geflügelt, Keimling in der Mitte des Heischigen Nälnrgewebes klein, keulenförmig.

Bliilt von Mär\% bis September.

Vaterland: Siilamerika, in den liöheren Lagen auf den . Ibhä̈ngen der Anden (vorziighlich loolivia und siidperu).

Gegenwärtig unterscheidet man etwa 30 bis 40 Chinaarten, die cinander mehr oder weniger :ilmlich sind. Ïber deu Wert und den Umfang dieser Arten gehen die Ansichten weit auseinander; so teilt Weddell seine zallheichen Arten in fünf Stïmme, andere halten dagegen dic Hauptvertreter dieser stämme für fünf Arten, von denen alle iibrigen nur Abarten darstellen.

Der Verbreitungsbezirk der Chinabiiume ist das Anden-Gebiet siidamerikas; sie erreichen ihren nördlichsten Punkt in Vene\%uela unter dem 10. Grade nördlicher Breite und ziehen sich in cinem nach Usten offenen Bogen etwa 500 Meilen. bis zum 19. Grarle suidlicher lireite. in einer Meereshöhe von 1600 bis $2400 \mathrm{~m}$ hin; doch steigt Cimbone succimblia Pavon gelegentlich lis $800 \mathrm{~m}$ hinab, während C'inchomu officimulis Looker gelegentlich, aber rerkrippelt, bis $3000 \mathrm{~m}$ linaufgeht.

Von den verschiedenen Arten und Abarten werden zum Anban namentlich bevorzust: ( . Ledyericenu Noens (nit schmal-elliptischen. unterseits roten, fist lederartigen. durchius kihlen Blättern und kleinen. gelblichen, nickenden und wohlriechenden Bliten), die bis 121\% P'o\%. Alkaloüde, darunter 11,6 I'roz. Chinin ergab, mul C. surrirellue Pavon (Blitter sehr grols, bis $50 \mathrm{~cm}$ lang und $35 \mathrm{~cm}$ breit, breitelliptisch, diim, krantig; lielch purpurvot; Llumenkione rosenrot), die his 7.S P'roz. Alkalö̈de liefert, und die heide anf C'eylom und Jaral aufiserordentliche Mengen linden ergeben.

Anbau und Gewinnung der Rinde. In dem Mutterland. kultiviert man die ('hinabiume nicht; nur aus Bolivia wird berichtet.

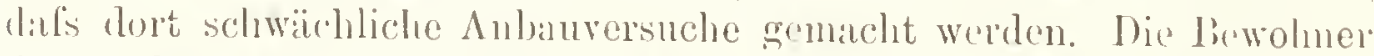
der Anden fïllen sie vielmeln planlos, so dills die Ansrottung dieses wichtigen biames in Sildamerika \%u besorgen ist. In dor kegend ron

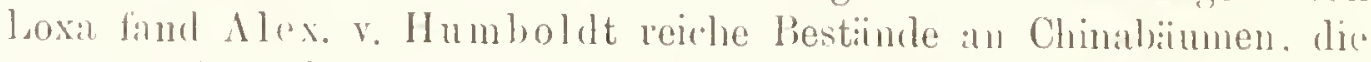
gegenwärtig vollstïndig ansurrottet sind. Unternehner ziehen in die

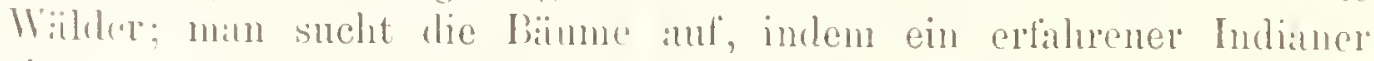
einen lohen liamm lestrigt und nach dem etwas bunten latube der 
Chinahïume ansspïlit. Die Sechwiorigkeit der Anftindnng wird diulureh rhöht dafs dio neisten biume his zu den Ïsten hinanf mit Mous ïherkleidet sind, welches mit buntfurhigen Flechten und zierlichen Farnen durchwohen ist. Dadurch geht die silherige Farbe der Rinde als Frkemmungseichen verlorm. Die aufgefundenen Biinne werden ron den (ascarillos orler Cascadores (Rindensammler) alm Borlen aligehauen und in 1 his $11,2 m$ lange Stiicke \%erlegt. Man schült nun die Riude ab nnd trocknet sie sorgfialtig, wenn nötig, mit kiinstlicher Wïrmo. da sie, hesonder's die dickere, loicht modert. Die Rinde diinnerer Ïste rollt siclı dabei zin Röhren rusammen (Rollchina), die dor St:inme bildet Platten, die oft noch dureh lieschweren gan\% flach werlen (l'attenchina). I)iese getrockneten Rinden werden ron den Ciscarillos, oft Wochen lang, durch den ilichtesten Urwald für wenige I'fennige getragen. In nenerer Zeit lïilt man ein vorsichtigeres Verfahren ein. In Ioxa, einer Provinz Ecuadors, verschont man bein Schälen kleinerer Bïnme, die nicht grefïllt werden, einen breiten Rindenstreifen, von welchem ans die ganze liinde sich wieder roneurert und eine vorziigliche Ware entsteht.

In Ceylon, Ostindien (in den Nilghiribergen und namentlich am Siidiblıange des Himalaya). Java und Sierra Leone baut man Chinarindenbäume an. Zum Anbau verlangen sie sine gebirgige Lage und ein wechselvolles, fenchtes Klima. Die läume gedeilien am besten auf anfgeklïrtem Walıboden. Die Vermehrung geschicht durch Samen, Stecklinge nud Absenker. Dort rersteht man die Kultivierung und Behandlung der Bäume besser, als in den Lindern des natiirlichen Chinabiumgebietes, obyleich der Anbau seh" schwierig ist, da die Stecklinge in Warmhäuseru zum Wurzeltreiben gehracht und dann erst ins Land gesetzt werden. Diese Ptlanzungen werden in forstwirtschaftlicher Woise in Jahresschlïge geteilt nuld die lindengewinnung anf zweierlei Weise betriehen: entweder durch Niederwallhetrieb, indem, nach Art der Iohegewinnung ron den Fichbïunen, in einem achtjührigen Umtriebe die Schölshinge abgeschnitten und entrindet werden, Schlagwaldsystem (coppicing der Englïnder); oder durch die Moosbehandlung (mossing). Bei letzterem Verfinhen löst man etwa $f \mathrm{~cm}$ breite, senkrechte findenstreifen in regelmilfsiger Weise ron jedem baume je nach seinem I'mfange ab und umwindot unmittelbal" nach dem Ablösen des lindenstreifens den Baunstamm mit einer dheken Schicht Moos. Unter dieser Schutzschicht cutwickelt sich eine neue Rinde, die stinker und alkaloidreicher ist als die urspringliche. Dic erste firnte wird in fünften bis suchsten dahre besorgt, alle drei dahre können die Bäume zweimal reschiält wriden.

Gehalt, Gebrauch und Wirkung der Chinarinde. Der Wert der Chinamble hesteht in $1 \mathrm{~mm}$ Gohalte einer Reilhe ron Alkildriden, nuter denen Chindin, ('inclunin und ('inchonidin, nament- 
lich aher ('hinin, die wichtigsten sind. Die linde enthialt anfserdem

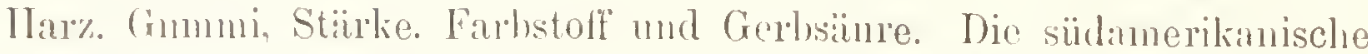
limde wird fiir reich sehalten, wenn sie $: 31 / 2$ l'roz. Chinin enthïlt, meist sind nur 21/2 l'ro\% vorhanden; die Rinde der knltivierten Büume enthiilt dargegen 7 his 9 , selhst $12 \frac{1}{2}$ l'roz. In liast sind die genannten Alkiloide in geringerer Menge enthalten als in ler Borke. Alle Arten der linden hesit\%on cinen bitteren Geschmack. alber in rerschichenem Grale. Chinin ist medizinisch von der alleroröfsten Wichtigkeit, namentlich dardurch, dals es bei Fielsermuständen die Körpertemperatur herilssetat und als heltiges Gift auf das l'rotoplasma vieler als Krankhritserreger (so \%. B. dem des Wechselfiehers) oder als Fermente auftretender niederer Organismen cinwirkt. Es rermindert aber anch die Zahl der weilsen Phutkörverehen, reizt die Nieren, erhöht in kleinen Dosen die Zahl der l'ulse, mindert sie in grofsen n. S. w. Der Verbranch an Chinin, dessen I birstellnng hauptsäichlich in Deutschland erfolgt, wurde für 1891 auf $200000 \mathrm{~kg}$ geschätzt; doch machen ihm jetzt Antiprrin mud ähnliche Nittel starke Konkurrenz. 18997 fülnte Dentschland 4.2 Mill. Kỉlogr. Rinden, für 2,9 Mill. Nark ein, und für 9,3 Mill. Mark Chinin und Chininsalze, im Gewicht von $250000 \mathrm{~kg}$, ans.

Warenkunde. Alle jetzt bekinnten Chinaarten enthalten in ihrer liinde mehr oder weniger Chinin. Sur durch genaue Ermittelung des Gehaltes an Chinin lïst sich der Wert der Ware erkennen; von wenig Bedentung ist daher die friihere Unterscheidmng der Rinden nach ihrem Aussehen, in gerollte und flache, bedeckte und unbedeckte, d. lı. von der Borke betreite Stamminden, oder nach der Farbe, innen braunrot, rot, orangugelb oder gelb.

Angaben über den Handel. Die trockene linde wird oberfliichlich sortiert umd in Ballen ron 50 bis 55 kg verpackt. In den Warenhä̈nsern dor Hafenstiidte findet noch eine Sortierung statt, auch werden hier nicht selten lailschungen rorgenommen. Anf Ceylon sind über 20000000 Cinchonabium angeptant, son denen nach erreichter Vollkraft eine Jahresernte von $7000(100) \mathrm{kg}$ erwartet wird. Es wiirde dann Crrlon alloin drei Viertel des Gesamthedarfes decken können. Die Ausfuhr Südamerikas in dieser linde sinkt ron Jahr zu Jahr. Der gegenwïrtige Gesamtverbrauch an Chinarinde wird anf $9000000 \mathrm{~kg}$ geschiit $\%$. Er steigt in den gemälisigten Kilimaten, liifst sich jedoch selbst :miniliernd nicht feststellen.

Geschichte der Pflanze. Die Indianer Sülanerikats mögen schon lange vor der Ankunft der Europier diese linde gegen dis

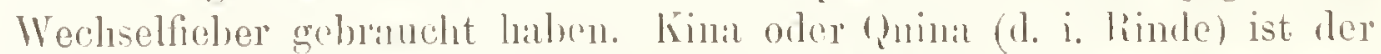

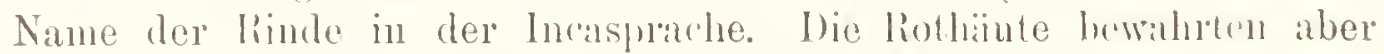

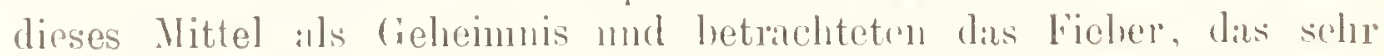
viele Kolonisten wegrafite, als ilnen stiirkstrn bundesgenossen gegen

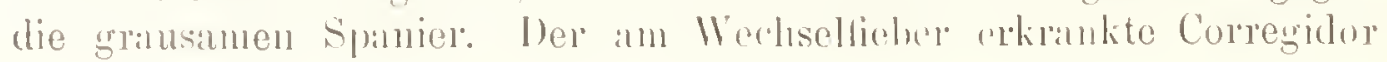


der l'roviuz loxa wurde anf den liat eines Fingebonenen durch die Chinarinde geheilt und emplalıl sie 1635 der (iemahlin des spanischen

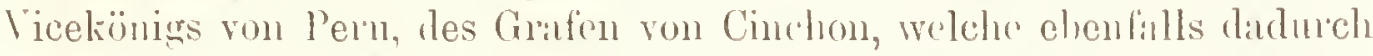
genas, woher der Name Grïlinpulver entstand, Nach der liiickliehr des Grafen wurle die China in kuropa bekannt. womu anch rom\%iiglieh die Jesniten beitrngen, welche sie nach Spanien brachten (1649, Tesuitenpulver); Kardinal de Lugo liefs die Rinde nach fiom kommen (Kardinalspulrer). 167! kanfte Isndwig XIV. das fiebervertreihende Areanum von dem Englïnder T'albor für 2000 Lonisstor und eine Leibrente. Nach anderen soll ein Indianer seiner am Fieber schwer erkrankten Tochter, die als Sklavin bei der an derselben Krankheit darnieder liegenden, leutseligen Gemıhlin des Vicekönigs von Peru, Cinchon, diente, Chinapulver in einer trockenen, ausgehöhlten Gurkenfrucht gebracht haben. Dic Sklavin rettete damit ihre Herrin und sich, und so soll der Gebrauch der Rinde den Weifsen bekaunt geworlen sein. - Von Naturfor'schern und Ar\%ten wurde in öflentlichen Blättern oft, aber vergeblich, anf die Verwüstung der Chinabiiume in Sïdamerika hingewiesen. Der Versuch der französischen Regierung, in Algerien Chinabäume zu ziehen (1S49), mifslang. Dagegen gelang es dem deutschen Botaniker Hafskarl (1S54), für die holländische Regierung unter grofsen Opfern und Miihen und trotz der Verfolgung der Behörden 500 junge Bïumehen des Könìgs-oder Calisaya-Chinabaumes über die Anden in den Hafen von Callao zu bringen, wo er mit seinen Schätzen von einer holländischen Fregatte aufgenommen und glücklich nach Java befördert wurde. Die Pflanzen gedeihen im neuen Kulturlande. Die Engländer, angefenert durch den Botaniker Sir William Hooker, Direktor der botanisehen Gartenanlagen zu Kew, haben in Ostindien ebenfalls den Chinabaum mit Gliick zu kultivieren begonnen, und zwar im Jahre 1860 in den Nilghiri- und Khosiabergen, später am Südabhange des Himalaya und in anderen geeigneten Gegenden, am grolsartigsten und erfolgreichsten jedoch auf Ceylon. Auch in Sierra Leone waren die Anbanversuche von Erfolg begleitet; ferner giebt es jetzt in Jamaica, Neuseeland, selbst in Australien Chinagiirten. 


\section{Tafel 18 (erste Hälfte). \\ Gemeine Hirse, Rispenhirse (I'ancam mitiarenm L.).}

Stellung im System, wie das /uckerrohr, in der Fimilie der Gräser (s. S. So).

Die Gattung Hirse (P'micum L.). P̈hrchen in Öhren, 'Trauben oder Lispen; ein- bis zweiblütig, mit drei Bliitenspelzen. von denen die oberen die Zwitterblïte umschlielsen, die dritte, untere Bliitenspelze aber eine verkïmmerte, geschlechtslose lilite darstellt. Deckspelze und Vorspelze der '/witterbliiten sind stets hïrter als die Hiillspelze und meist ganz unbegrannt, nur die Hiilspelze ist zuweilen mit einel Granne verschen. Die Körner sind durch die verhäirteten Kelchspelzen heschalt, glatt und glïnend. Gegen 300 Arten in allen wärmeren. weniger den gemälsigten Gegenden.

Gemeine Hirse, Rispenhirse (Punicum miliucom L.).

Wurzel einjährig, fascrig; Halme aus einem liorn melrere, 60 bis $90 \mathrm{~cm}$ hoch, schilfartig, knotig, etwas wollig behaart, mit abstehenden Scheiden.

Blätter lang, breit lanzettlich, am Rande und anf der Unterseite behaart. Rispe sehr alusgebreitet, schlafi. nach einer Seite iuberliängrend. Ährohen eilörmig, cinhlitig, mit drei lilitenspelzen. Erste Spelze halb so liang als die zweite. I) dritte Bliitenspelze ist der liest einer verkïmmerten Bliite, der die Griffel und oft aluch die Staubgefilse fehlen. Frucht (sprallhirse ren:nnt) klein, eiförmig, weifs, gell, bis schwallz, ghlänzend, dïnn- und lialrtschalig, gewölot, ron gethen. roten oder weilsen libiitenspelzen nmschlossen, aber nicht diamit

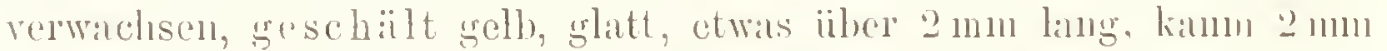

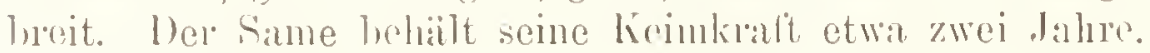

Blüht inl Juli mnl August. l)ie Vegetationszeit lauert 13 his 11 ; Wochen.

Vaterland unbekmut, vielleicht Ostindion: Verbreitungsbezirls: In simdgegenden innerhalh der Weingrenze; Siid- uncl 
Siidost-Europa, İgypten, Mrabien, Westkiiste Mrrikas, China, Iapan, nenerdings die Steppen mu das Raspische Mecr.

Kultur. I)ir Ilise gedeiht an besten in einem warmen, trockenen Klina, in lockerem, leichten, gnt rerarbeitotem, von Un-

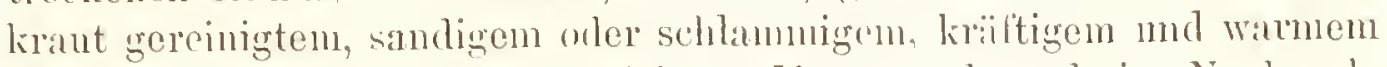
Borlen, in ansgetrockneten Teichen, Moor'grumd und in Nenbruch. Verträ̈rt viel Dïnger. Wïhrend des Wachstmms der L'flan\%e mufs der Boden zwemal gelockert werden. Wem die ersten Kïmer ausfallen, oder sobalı sich in der Spit\%e ler Lispe reile Kïiner zeigen, muls man die Ifirse ernten, Aann aber muter Dach nacheifen lassen. Die Rispe reift narls und nach nud zwar ron unten nach ohen. I'm bei der Frnte so wenig als möglich rimzubiifsen, schneidet man, wenn sie nicht im grolsen angebaut wird, die reifen Rispen einzeln al., Die ausgedroschenen Samen breitet man diim anf dem Borlen aus nud wendet sie fleifsig, bis sie trocken sind; unreife und feucht anfhewahrte Samen erhitzen sich mol bekommen einen hitteren Geschmack. Das noch sriine Stroh wird auf hölzernen Geriisten getrocknet. Die Köorner werden in Miilılen enthiilst. Die Ilirse giebt an Köruern so viel Evtrag wie der Wrizen, und an Strol so viel als der Roggen, sie ist aber selur emptindlich gegen Käilte und dem Brande und Vogelfrafs selư ausgesetr.t.

Gehalt. Die Inirse ist reich an Xïhrstoffen, aber etwas schwer rerdaulich; sie l) entlält:

\begin{tabular}{|c|c|c|c|c|c|c|c|}
\hline $11^{\circ}$ asser & $\begin{array}{l}\text { Stick- } \\
\text { stofil- } \\
\text { sub- }\end{array}$ & Fett & Zucker & $\begin{array}{c}\text { Dextriu } \\
+ \\
\text { Gummi }\end{array}$ & Stïrke & $\begin{array}{l}\text { Iloly- } \\
\text { faser }\end{array}$ & Asche \\
\hline Proz. & Proz. & l'ro\% & Pro\%. & l'roz. & P'1.0\% & l'roz. & l'roz. \\
\hline
\end{tabular}

\begin{tabular}{|c|c|c|c|c|c|c|c|c|}
\hline Ingeschält . & 11,66 & $\lfloor, 2 !$ & $\because, \because 10$ & $1,3: 3$ & 3,51 & (i1,09 & $7,2 !$ & 2.35 \\
\hline Geschiält . . . & 10,97 & 10,82 & 5,46 & 1.19 & 7.16 & $5 !),-10$ & 2,64 & $2,: 36$ \\
\hline
\end{tabular}

In der Stickstoffsulstunz finden sich otwa 0,j, l'ro\%. Albumin.

Gebrauch. Man rarbeitet sie zu Gritze und Gaupen, kocht sie sehr hïntig in Milch oder Wasser y lirei und ifst sie in suppen. In Italien, der Moldan und Wallachei backt minn alus Hirse- mul Weizenmehl Brot, dis firsch angenehm schmecken soll. Die Wallachen bereiten ilı liraha, ein alkoholisches Ceträ̈nk, darans. Die Kürner, in Wasser unı Milch gekocht, Werden den Vögeh als Mastfutter verfiittert. In der Medizin wnule lie Hirse friilıer als selıleimiges Mittel

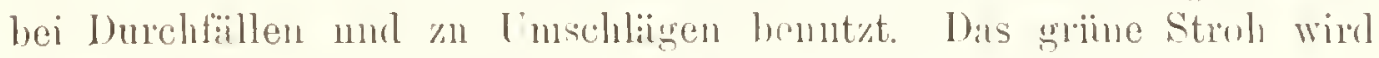
oft zur Füterung rerwendet; es ist hesser als Gerstenstroh.

Warenkunde. Enthiilstr Hirsekinmer verlieren dnrch langes Lagern nud werden beich, menthiilste kinn man molnere Jihre lang

1) Königg, l. c. 
olue Schalen aulhewahren. Gute enthiilste Hirse hat cine schïne. lellgelle Fïrhung. liilst sich nicht in der Hand zusannenpressen. sondern ontgleitet. I hl wiegt 65j his 75 . meist $68 \mathrm{~kg}$.

Mikloskopischer Befund. Obcrhatmellen luchtig wder wollenlörmig begrent. Stiirkenehl aus rinfachen kïrnchen orler lı̈̈chstens dimneben ans einzelnen Igrregaten ganz verschiedener Form bestehond. Stärkek̈̈rnchen durchans vieleckigg, ohne Kermhöhle. 0,0044 bis $0,0018 \mathrm{~mm}$ in Durchmesser.

Angaben über den Handel. Nenerdings wirl sehr viel Ilirse ans Ungarn und der T'iirkei lozogen. In Durchschnitt der . Ialure 1884 his 1888 betrug die Hirseente im Deutschen lieiche 295000 hl. Leider lïlst das rom Statistischen Ante herausgegebene „Statistische Jahrbuch fïr das Dentsche Reich" hier, wie auch rielfach anderwärts (vergl. Seite 101, Zeile 19 ron ohen), im Stich.

Geschichte. In Siddeurop: Ïgypten und Asirn ist die Kultur dieser Pflanze eine vorgeschichthiche. Die Griechen kannten sie als Kenchros, die Lateiner als Milinm. I)ie Ijewohner der Schweizer J'ahlbauten machten zur Steinzeit grolsen Gebruch von Jlirse. Man hat sie anch in den I'berresten der P'fahlbaten des V'aresersees in Italien gefunden. In Indien scheint die Ilirse seit uralten Zeiten kultivient zu werden. Doch wird sie dort nicht will wachsend angetroffen.

Zn erwähnen ist noch die Kolbentrise (I'enicum itulicum), die in den Pfitllbauten der Steinzeit in solcher Menge grefunden wurde, dals sie wohl Haupthrotfrucht jener Zeit gewesen sein muls, und die aluch in China und Ïgypten in den ältesten Zeiten gebaut wurde. Die Mohrenhirse (Durrha, Negerkorn, Sorglum mulgure), sowie die Negerhirse (Pemisctum typhoideum Rich.). heide in Mittelafrikil, sind keine echten Hirseirten. 


\title{
Tafel 18 (zweite Hälfte).
}

\author{
$\mathrm{R}$ eis (Orysa salica L.).
}

Stellung im System, wie anch lis '/uckerrohr, in der Familie der Gräser (s. S. so).

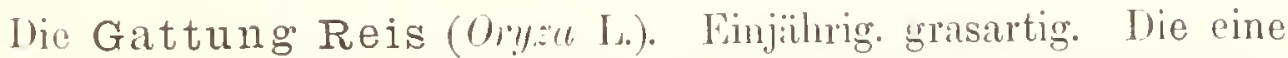
lispe bildenden Ïhrehen sind lïnglichoval, von der Seite zusammengedriickt, eimbliitig. Die IIiilspelzen sins zwei kleine Schïppchen oder Borstchen, darunter sitzen noch zwei winzige Hiillspelzenansïtze. Deckspelze zusammengefaltet, meist begrannt. Vorspelze schmal, einnervig. Sechs Staubblïtter. Frucht länglich, stumpf, wird rou den beiden IBlïtenspelzen eng umkleidet, mit arei seitlichen Furchen und kurzem, gekrümmtem lieimling.

Reis (Ory:a sutiru L.). W urzel einjührig, faserigg. Halme, mehrere aus einer Wurzel, 1 his $1^{1}{ }_{2} \mathrm{~m}$ hoch und wie eine Federspule dick. mit drei bis vier Knoten rersehen, einfach, manchmal auch etwas ïstig, mit langen, gestreiften, glatten Blattscheiden bedeckt; lilatthäutchen sehr lang, aufrecht, an der Spitze gespalten.

Blätter aufrecht, flach. lang \%ugespitzt, 30 bis $35 \mathrm{~cm}$ lang, auf der unteren Suite glatt, auf der oberen nit einzeln stehenden, kurzen Haaren besotzt und hier, wie ann kiande, sehr scharf und raul.

Blütenrispen wïhrend des bliihens aufrecht, späiter ahwärts geneigt, zusammengezogen. Ährchen kn\% gesticlt, einbliitig, elliptisch und stumpf. Kelchspelzen zwei, sehr klein, lanzettfirmig, spitz. Línspelz'n verhältnismälsig sehn grofs, kielförmig zusanmengefaltet, lederartig. mit kn1"zen Ilaaren bekleidet, fast immer gesehlossen, mit oder ohne Grammen. stanbhliatter suchs, mit dïnnen fïden und

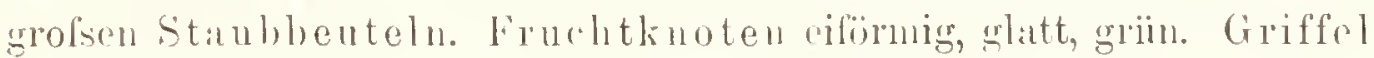
zwei, kur\%

Frucht oval, stmmpt, nit den lilitenspelzen verwalsen. Die enthülste Frucht hat \%wei seitliche Furchen, sie ist kahl num seitlich zus:mmengerlriickt; der kleine Keim liegt am Lude rer einen kinte. 
Sach Vhangel ouler Vorhandensein der Cirannen, sowie nach Farbe und ciölse der fincht werden etwas 40 Alanten unterschieden.

Vaterland: Wikl an feuchten Onten (Ostindiens, des tropischen Anstralien; eine Varietit auch in Alika. Verbreitungsbezirk: lieis wird als Gotreileptlanze in Asien mnd in linropa bis zmm 42. Grarle, in Nordamerika his zum : :6. Grarle nördlicher Breite, aul der Siithalbkugel bis zum 226. (irate angehant, und zwar besonders in China, Japan, Kolra, anf den l'hilippinen und Sundainseln, in Lordronnd Hinterindien, aul Ceylon und Marlagaskar.

Kultur. Am ergiebigsten ist der Sumpfreis. der deslall, auch am hiautigsten knltiviert wirl. Er erforlert eine Sommertenperatır von 290 und iel Fenchtigkeit. An liebsten verwendet min zun lieisban fenchte linfsuierlermugen, die leicht zu be- und entwaiseru sind. In Südcarolina werden vor der Aussaat die Felder tiuf gepHiigt. lann geeggt und nun in einem Abstande von etwa $40 \mathrm{~cm}$ Sautfurchen ron 5 cun 'Tiefe grezogen. In diese Furchen wirl der sane mit ein's Drillsiemaschine grestreut, die so eingerichtet ist, dals sie die Siat mit Grde bedeckt. Nun werden die Schleusen geöfnet mnd die Felder 30 lus 45 cm tief nnter Wasser gesetzt. Sobald die Keinspritzen el'scheinen, mul's das feld so lange trocken gelegt werilen, his die lieispthazen zwei lilitter getriehen lahen. Ist dies geschehen, so wird das Feld wieder bis zul vorigen IIühe überflutet. Je nach der IT:irmo des Wassers werden daun nach 7 bis 10 Tagen die Abzugssoblensen geöffnet, bis der IV asserspiegel so tief gesunken ist. dal's die Spitzen ler I'flanzen über ihm hin- nud herwogen. Sacl 60 tiagiger Überflutung wird das Feld langsam trocken gelegt. I)as Fold bleibt nun 15 bis 20 'Tage trocken liegen nud wirl wihnend dieser' Zeit dnuch leichtes Auflacken des liodens rom Unkraut helleit. Haranf finden wieder Überflutungen mit wöchontlichen Wasserwechsel statt. Wen die Könner hart, aber noch nicht sprörle geworden sind, ist die Ernte-

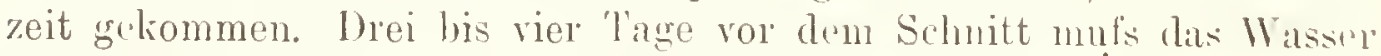
abgelassen werden. - In Ostindirn wild in Juni. in Ostasien in Juli, in den Vereingten Stanten Nordamerikas im Iugust nnd in den Mittulneerlïndern in September und Oktober seerntet. Sichehn und gekrimmte Messer, seltener Mähemaschinen dienen zun Ahschneilen der oberen Malnutuile, welche ant die hohen livisstoppeln ausgroleitet, ansucichend getrockinet, ramn solort ausgerloschen werden. V'ielfach zieht man anch anf Santbeeten junge Pllanzen, dio in kleinen Gruppen anl die huäisserten lielder gepullanzt werden mud sorot

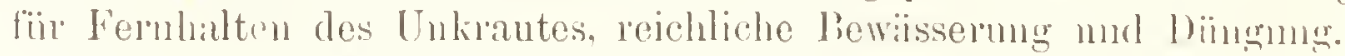

l) Kultur des Bergreises ist rinfacher, da er sich mit berieselung, wom rigene Maschinen nud Pampen crfmulen sind, he-

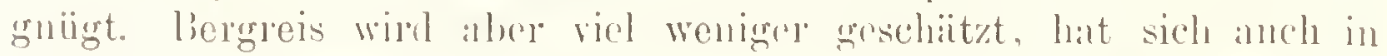
Furopar nicht bewänt nud komment somit fïn moseren IIandel kianm in lietrachit. 
Der Reishatu, nanentlich der des Sunpfreeses, ist selir ungesuml, das er durch dis stagnierende Wisser iibehrichende Ansdiinstmigen

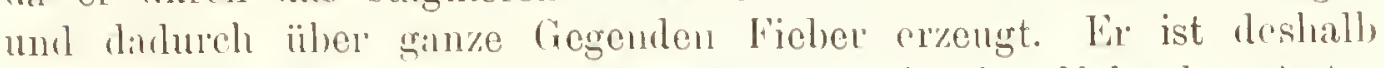
(Oberitalin, Frankreich und Grineliculand) in der Nïhe bewohnter Orte verboten.

Auf trockenem und nassem Boden geteilut Klebreis, eine iu China unl Japan angebaute Abart, ler'n Körner beim Kochen zusammenkleben und so eine feste Masse bilden.

Der aus der Dreschmaschine fallende Reis wird im englischen Ilandel P'addy, in Nordamerika rough rice (roher Reis) genannt. In den Reismïhlen wird dieser Reis (l'addy) geschält (Rrall's, Bray) nnd vielfach so nach Europa gebracht. Ilier wird er in den Hafenstiidten, wenn nötign, auf Miihlen geschält, oder aber, meist durch einen Bürstenapparat, poliert und dabei auch häutig durch Indigo sebläut. um ihm eine blendend weifse Farbe zu geben, wic er in Kloinlandel belieht ist. Aus den dabei zerquetschten Körnern wird Reisgrüitze hereitet.

Gehalt und Wirkung. Die Reiskörner sinl unter allen Getreidearten an reichsten an Stïriemehl, aber arm an Kleber. In 100 Teilen geschältem (Carolina-) Reis sind enthalten: Eiweils 3,60, Stïrkemehl 85,07, Zucker und Dextrin 1,00, Fett 0,13, Wasser 5,00. Die Samenschalen (Reiskleie, Futterreis) sind dagegen reich an Stickstoff (Eiweils 10,89, Fett 9,89, Rohfaser 11,09, stickstofffreie Extraktirstoffe 47.58 , mineralische Stoffe 10,61, Wasser 9,94).

Gebrauch. Der Ricis bildet für viele Menschen, besonders für dic Süd- und Ostasiaten und für zahlreiche Välker der lıeilsen Zone, ein wichtiges Nalurungsmittel; von ihm nïhren sich mehr Menschen als von irgend einen inderen Getreide. Das Reiskorn ist zur Nahrung in warmen Kilimaten ganz hesonders geeignet, weil es nicht erhitzt, im Nagen nicht säuert und die liuhr- mud andere Darmund Magenkrankheiten heilen hilft. So kam er im heifsen Klima die ansschliefsliche Nahrung der Menschen bilden, weil er, obgleich arm an Kleber, die erforderlichen Nïhrstoffe enthält und selbst bei Inngandanerndem Genusse keinen Überdrul's erregt. In der heifsen Zone spielt das Brot licine so wichtige Rolle wie hei uns. Die Kiirner werden nit Dimpt oder Wasser erweicht, fist ohne alle '/uthaten genossen uud bilden in ginzen Orient als J'ilur eineu IItuptteil aller Mahzeiten, ebenso und mit Fischen, Iü̈lnern u. s. w., nit Gewiirzen vermischt als Cury rin liehlingsgericht in ganz Ostasion. In l'annen backt man eine Art lirot. Aus dem lieismehl werden die verschierlensten Gerichte, ans heishlune, den feiusten Mehl, Delikatessen bereitet. Die Körner verwendet man mit lioh"zuckersirup orler l'alnsaft zur Destillation von Arroli oder lieisbranutwein. In Indien lereitet man aus licis das Hanptgetrïuk, den C'omge. in China

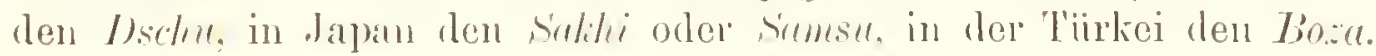




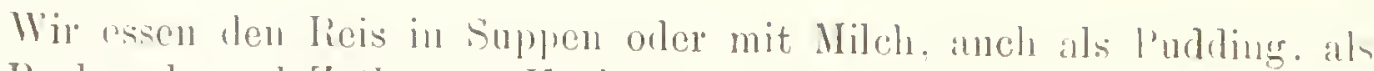

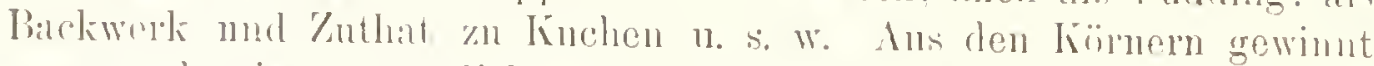
man anch eine vorzïgliche Stärlie. woraus man anch dic weilse

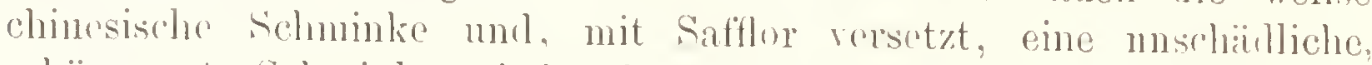
schönc, rote schminle erhäl. Die lieiskloio eisuct sich ihres stickstoff- und Fettgehalter wegen als vorzïglichws Vielıfutter. Dic lieis-

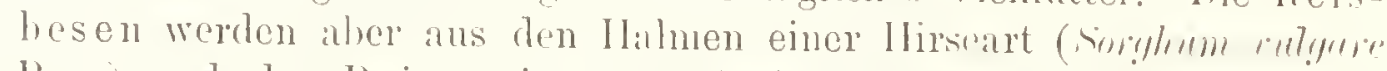

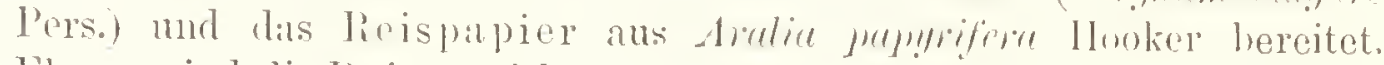
Ebenso sind die licisstrohlïite und lieisstrohgeflechte des Irandels nicht aus dem Stroh dor lieispthanze grefertigt. Wasser, in welchen lieis anfgoweicht worlen ist, ist schleinig und dient dann in Ostindien als Schlichte hei der Musselin- und soidenweberei und in Italien in Acr Gaze - oder Florweberoi. Reisschleim verwendot man in $1 \mathrm{cor}$ Medizin als einhiillendes und reizminderndes Mittel bei Entziindungskrankleiten. Gegenwirtig verwendet man don lieis auch sehr stark in dei licrblaucrei.

Warenkunde. Angaben über Ernten, Handel und Verbrauch. Jer beste linis ist ler Cilrolinaleis, d. h. der im siiden Jordanerikas „ebante lieis; er hat cin langer, eckignes. mattweifses oder durchscheinendes Korn ron reincm Geschmack. Ton ihn kommt verläiltnismäfsig wenig nach Deutschland; in Jahre 18!7 hïchstens 12000 'l'onnen, im ITerte von 21: Mill. Mark, Dahingrgen lieferte Britisch-0stindien 353000 T'onnen, in Nerte von 47,9 Mill. Mark, mud zwar wolıl zumeist Bengalreis, mit grolsem, riotlichem (tïr den Ilandel zu fïrbendem) Korn, danoben klein- und dïnnkönngen, selur weifsen Patnareis. mittelguten han wn reis und wolnteileren Arakanrois. Siamrois lezogen wir ïber 40000 Tonnen tüu 51, Mill. Mark. Javaleis ('Taf'elreis), mit sropften.

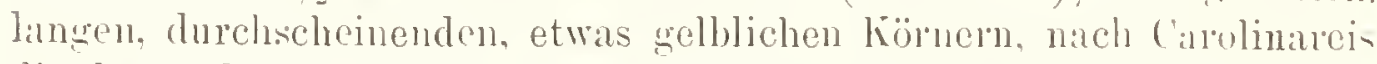
die beste Sorte. nahezu 20000 'Tomnen für 4 Mill. Malk. Italieniscller lieis, mit dicken, rundlichon. Weilsen Kürnern, sowie levin tischer oder tiirkischer mud ägytischer licis kommt kilum zu

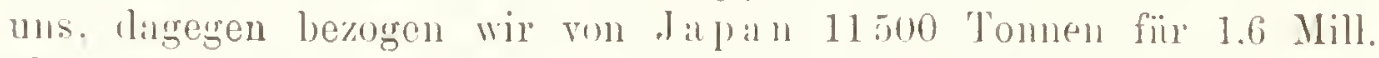

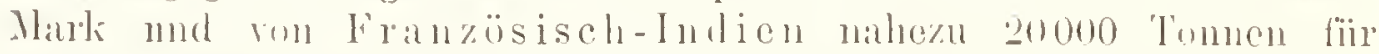
2,7 Mill. Mark. In ganzen luenötigten wir 1897 45!9000 'Tonnen Reis fiir (i4,4 Mill. Mark. - Europra verlurucht jetzt jänlich etwa

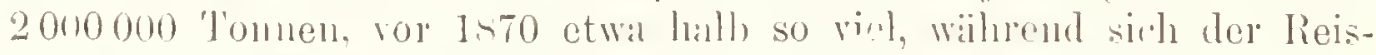
verloranch in ()stasien anf 100000000 'Tonnen helaten soll.

Geschichtliches. Her Samkritulume des lieises wal milli.

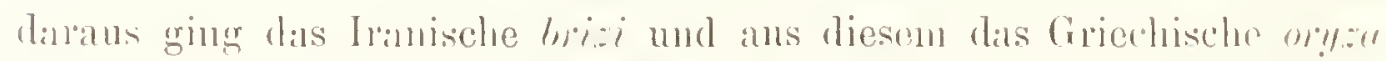

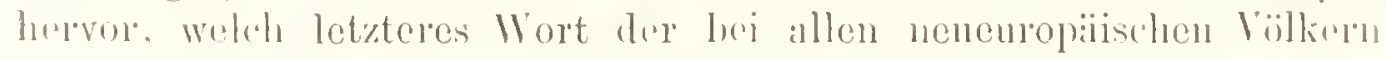

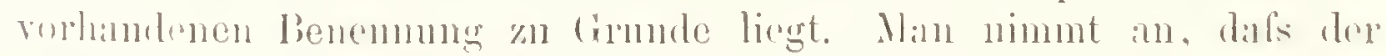

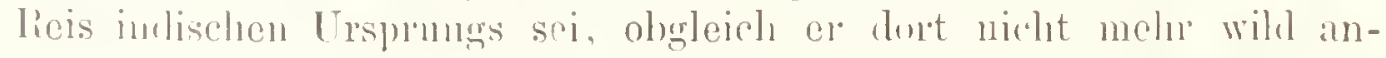

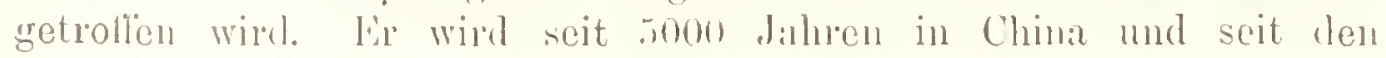


:iltesten Veiten anch in Ludien und dipan allgemein gebaut. In Abendlande wurde er wahrscheinlich erst durch die Ziige Alexanders des Grolsen bekinnt. Die Araber verpllanzten ihn nach J̈gypten, Sicilien und Spmicn. In ersten Drittel des 16. Jalnhunderts begam der licisban in Italien, und hald war wan\% Oberitalien mit lieissiimpfen bedeckt; die dadurch hervorgerufenen Fieber riefen Verordnungen nud Einschrïnkungen herror, die zum 'Teil noch heute in Kraft sind. Gegen Ende des 17. Jilurhumlerts kam er nach Amerika und zwar nach sïdcarolina. das jetzt den besten Reis haut. 


\section{Tafel 19.}

\section{Maniok-, Kassawa-, Jukastrauch \\ (Ifenilut urilissime Pohl).}

Der Maniok- oder Kassawastrauch gehört zur Interklasse der Freiblaitterigen Dikotylen, zur lieihe rer Storchschnabelgewächse (Cromiales) und mo Familie der Wolfsmilchpflanzen (Eimblotbincere).

Die Familie der Wolfsmilchgewächse (Lmhorlinene). Einjjïlrige oder perennierende Kränter, Sträucher, Bïume. einige auch kaktusartige Gewäichse mit Heischigem Stamm; alle enthalten einen wässerigen, oft scharfen, selten milden Milchsaft. Die Pliiten zeigen grolse Verschiedenheit. Sie stehen teils einzeln, teils in zusammengesetzten IBliitenständen von ïlniger orler tratubiger Form beisammen, sind eingeschlerhtig, ein- oder zweihäusig. Ein durchgreifendes Merkmal, das bei der sonstigen Verschiedenheit allen Wolfsmilchgewïchsen \%ukommt, ist der ban der Fruchtknotenfïicher. Der Fruchtkuoten ist der 'Lahl der Fruchthlätter gemäl's gefïchert. Samenanlagen finden sich in ,jedem Fache eine oder zwei, sie sind hä̈ngend und umgewendet; inre Anlieftungsstelle ist nach innen gewendet. Der Kieimmund ist meist ron einem fleischigen Gewebe, cincr Caruncula, deckeloder haubenartig iberdeckt, welche aus der Samenleiste entsteht, bei der Ireitung der Pollenschlänche eine wichtige Rolle spielt und damm anch noch an den Samen vorhanten ist. Die Simen haben gerade oder gekriimmte, in der Mittr eim's Heischigüligen Nährowehes liegende Keime. I ie Samenlappen sind meist breit, seltener schmal. latbwalzenfirmig. lie Würzelchen sind nach oben gerichtet.

Etwal 220 Gattungen mit ïber 3600 Artun.

Die Gattung Maniok (1/milhot Pohl) umfafst mittelurolse, wiederholt gahelistige Strïucher oder Ilalbstrincher. Die IBhitter sind einfich, gelappt oder verschieden seteilt, oft htangriin bereift. Nitmuter siud hinfillige Nobenbliitter vorlanden. Die Bhiten stelen in 'Trauben orler in Sehöpfen, sind inmer braun bis purpureutlich. 
anfsen bereift. Hiuten einhäusigr; die weiblichen bliten stehen an Grunde der Blitenstinde oder fiir sich allein. Das cinblätterige l'erigon ist nuterstiundign und blumenkromartig grefärbt. Dis l'e rigron (ler männlichen Blïte ist glockenförmign, anfrecht, an Ginnde llach, fuinfspaltig, mit breitlanzettlichen /ipfeln. Nuf den Bliitenhoden sitzt eine fleischige sclucibe (Jisers), die in der Mitte in 10 pulpul"rötliche Strahlen ibbergeht, seltener in unlinchtbaren Nanben endigt. \%wischen den Stralılen der Scheibe steigen 10 freic Stanbbliitter mit fadenförnigen, an der Spitze pfriemlichen Stuubfäden in zwei kreisen anf. Dic Staubbeutel sind länglich, zweifächerig und scitlich anfspringend. Das l'eligon der weiblichen Blüte ist hinfïlig, tief fïnfteilig, mit lanzettlichen Zipfeln. Die Scheibe, welche don Fruchtknoten am Grunde umgicbt, ist drüsig, dick, fünteilig, unregelmäisig geschlitzt, purpurrötlich. Der Fruchtknoten ist oberstïndig, ciförmig elliptisch, gefuncht. Die drei selur kurzen Griffel sind am Grunde zusammengowachsen und gehen oben in dic breiten, fleischigen, gokrïuselten, fast gewülbten, ticf vielspaltigen, überhängenrlen Narben über: Die Frucht ist ciförmig; sie zerfällt bei der Reife durch Läingsteilung in drei kinöpfe, von denen jeder zwei herabhängende Kilappen besitzt; sie ist aulsen runzelig, bräunlichgrau, berindet, selten am Rande gefliigelt; ilne Rinde ist dick, lederartig. Die drei Kn̈üpfe sind papierartig, mattwcils, elastisch, zweifäclierig. Die Mittelsiulle ist an der Spitze lieulenförmig, dreiseitig, bleibend. Die Samen sind cifömig, elliptisch, beiderseits gewölbt, weilsgrau marmoriert, mit schwammiger Caruncula. Diese Gattung umfalst etwa 80 Arten, die in Amerika wild wachsend gefunden werden.

Del Maniok- oder Kassawastrauch (Munihot utilissimu Pohl) lat Wurzelknollen, die, ähnlich denen der Georginemptlanze, in Biischeln beisammenstehen, aber 30 his $40 \mathrm{~cm}$ lang nnd gelblich sind und gleich dem Strauch cinen milchigen, äulscrst griftigen Saft enthalten. Der schwarzgelbe, bereifte und spröle sitengel wird 1,50 his 2,40 $\mathrm{m}$ hoch, ist holzig, aufrecht, etwas hin - und herwebogen, l'undlich, ästig, bebläittert, mit Nebenblïttern versehen und kalıl; er trägt wenige, brüchige, dicht bebliitterte $\ddot{A} s t e$. Die Blätter stehen zerstreut und dicht, sind ron verschicdencr Gröfse, bis über $20 \mathrm{~cm}$ grofs. lang gestielt: sie sind tief lingerteilig oler gleichzeitig mugreilt. Die Blattziplel sind ganz, zngespitzt, weich- oder stachelspitzigr, am

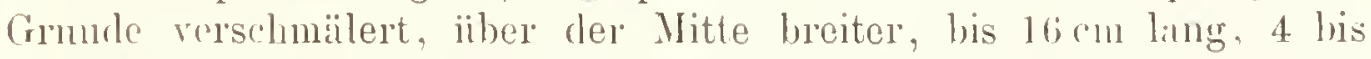
5 cul breit, die unteren kleiner, voncinander alsstelıend. I)ie IBlätter fallen al, sind kahl, auf der oberen Seite dunkel-, aul der unteren hellgrün mit gelben Neren. Jie Nobenblattchen stelien parrig, sind selı kur\%, lanzettlich und an (xumle verhroitert. I)ie libiten stehen in lockeren, kurzen, wenighliitigen, blattwinkelständigen I'rauben. Her gemeinschaftiche lib ütensticl ist aufrecht, stielrund, dis fadenförnigge Blütenstiehchen dor weibliehen lilüte ist lïnger 
als das der mämnlichen liliite. Am Gronde der Bibtenstielchen sitzen kleine, borstenartige, hinfillige l)eckbliattclen. Biiten schmutrigrotgelb, anl'sen bereift. Weibliche Blumenkrono his zum Grmmle gespalten, mit verschmälerten Zipfeln. Ine Beschreibung der iibrigen Teile ist hereits oben unter "Gittung Maniok" gegehen.

Del" Maniok-oder Kassawastrauch (Monilut utirsimu l'ohl) wirl auch Bittere Maniok genannt. Die Sü Sse Manioka

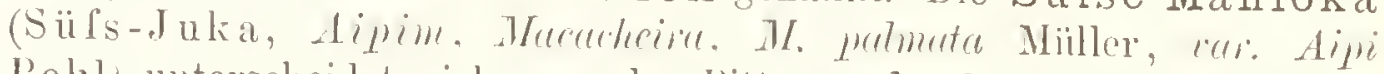
P'ohl) nnterscheidet sich ron dex Bitteren durch fünflappige libläter und durch eine kleinere, rötliche Wurzel, die nicht das mindeste Gift enthält, nicht so reiche Ertrïgnisse, wie die Bittere Manioka bringt,

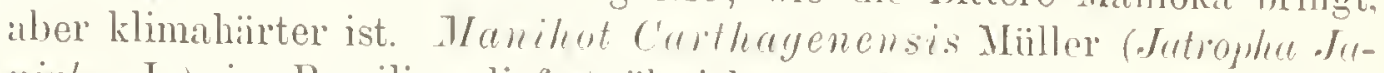
niphu, L.) in Brasilion licfert ölıciche, anch medizinisch verwendete Samen, aber fist faserige, daher auf Stiirkemehl schlecht zu rerarbeitende Kinollen. Mtomihot Glaziorii Müller liefert in seinem Milchsaft den nacl einer Provinz Brasiliens benannten Ceara Rubber, eine Art liautschuk.

Heimat: Brasilien. Verbreitungsbezirk: Aulserdem Westindien, Ostindien, Malaiischer Archipel, westliches Afrika.

Der Anbaul). Die Bittere Manioka stellt so lohe Ansprüche an Klina und Borlen, dafs ilır Anbaugebiet ein beschränktes hleiben muls. Die Temperatur darf keinen bedeutenden Schwankmngen unterworfen sein, sie muls zwischen 16 und $20^{\circ} \mathrm{C}$. liegen. Trockene und versengende Hitze wirken verderblich auf die Pflanze, Luftfeuchtigkeit ist Wachstumsbedingung, dabei muls der Borlen trocken sein. Der Kassawastrauch gedeiht in Küstengegenden und anf Inseln am besten. Hier liefern die Wurzelknollen die meiste Stiirke. Nach dem Binnenlande zu werden die Wurzeln fortschreitend holziger und stälie. ärmer. Die I'flanze wird durch Stecklinge vermelurt. Die PHanzweite von Rieilıe zu Reilhe liat etwa $90 \mathrm{~cm}$, der Abstand der Stecklinge roneinander in der Reilıe $30 \mathrm{~cm}$ zu betragen. I uf sehr fruchtbarem Boden mufs die Pflanzweite etwas grölser sein. Die Stecklinge wachsen so schmell, dafs sie schon nach Verlauf von 2\% Monaten das Unkiaut nicht mehr anfkommen lassen. Die Bliitenknospen werden ansgehrochen, damit sich die Blätter, welche die Stïrke erzengen, kräiftiger entwickeln. Die Stïrke wandert in die Wnzelstöcke. Haben die letzteren, welche ein Gewicht vou mehr als $10 \mathrm{~kg}$ emreichen, ihren höchsten Stïrkegehalt erlangt, was je mach den Klima etwat im 9. oder 10. Nonat nach der Anptlan\%nng zu geschehen pllegt, so beginnt die Lrnte. \%u diesen Zwecke werden die Sträncher mit einer sichel bedeutend gekii 'zt, diun tief nuten angefilst mol mit den Wurchn ausgezogen. Die im Boclen bleibenden Stiicke worken später ansgehackt oder answephliigt. Die noch in den Wurzeln haftenden Stengelteile werden abgehackt und

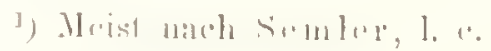


später als Stecklinge bemut\%t. Der Kassawastrauch iibertrifft an Ertragsfähigkeit alle ïhrigen Nnt»flanen der heilsen \%one, die Ernten muterliegen selten Schwankmgen; kein schählling wagt sich an diese Giftpflante heran, nur eine alles versengende Diire bringt ihr Verderlen.

Die Wm\%elknollon enthalten anfseromlentlich viel Stärke, und das ist der Grund. warmm man ïlerall in den Tropen diese Pflanze einzufiiluren bestrelst ist. Tehenbei besitzen die kinollen auch einen sehr giftigen, Iilausäurce enthaltenden Milchsaft.

Verwendung. Der frisch äufserst giftige Milchisaft, Manipucira der Indianer, verliert durch Erhit\%en den fliichtigen Giftstoff und kann d:mn genossen werden. So breitut man ans dem eingekochten Safte in Westindien unter IIinzmahme geeigneter (rewiirze eine fïulniswilrige Brühe. Carareep gemannt, die, besser als Essig, zur Autbewahrung des Fleisches rlient. In Sülamerika kocht man diesen Saft zu einem Teige ein, der, mit Pfeffer gewiirzt, unter dem Namen Alube als Beilage zu Fischgerichten dient. Auch wird daselbst der Saftrïickstand nach der Stïrkeauswaschmug ausgeprelist und zu einer dïnnen, T'ucupi genannten Brïhe eingekocht, die ebenfills gewiirzt genossen wird. Nit einem '/usatze von Melasse zur Girirung gebracht, liefert der Saft ein berauschendes Getränk, das in manchen südamerikanischen Gegenden Onycon, in anderen P'nvarie und 'Teruba genannt wird. Die Blätter werden als Gemiise genossen. Man schneidet auch die geschälten Wurzeln in dïme Scheiben, backt sie in Ische und verspeist sie, oder man zerreibt die geschïlten Wurzeln auf einem Reibeisen, prefst sie aus und backt auf heifser Ofenplatte kleine Kuclıen daraus, die man in Westindien Kassawabrot nennt. Der Handelsartikel Naniokamehl, Mandiokamehl,

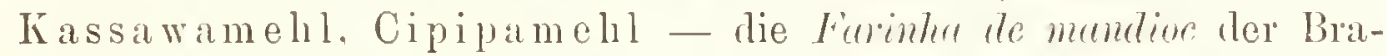
silianer - wird bereitet, indem die Wurzeln geschailt, gewaschen und grob zerrieben werden. Die Masse wird mittels einer l'resse ron lem Milchsafte befreit, geröstet und clamn in Mühlen gepulvert. Beim Rösten verschwindet der bis dahin den Wurzelteilen anlabtende iible Geruch. Dieses Mehl findet eine ausgedehnte Verwendung in Sïramerika, an häufigsten wird es mit Wasser zu Kuchen beiju. briochus, próo de 7o. comergue auf den Antillen u. a.) geharken, welche die tüghliche Nahrung der ärmeren Levölkerung bilden. Die Indianer bereiten aus diesen Mehl einen selı ber:uschend wirkenden Branntwein, den sie Canin nemuen. Der aus der zerstofsenen Wurzel alblaufende oder beim Srlnä̈mnen mit Wasser sich bildende Suft setzt ein gan\% feines Stärkemehl, 'Tapioka, 'T'ipiok, Brasilianisches Arrowot, Maniok-Arowrot, ab. Die beste Qualitiit rleser Stairke, Carima, ist in Kïgelchen goformt, die leicht zerbröckelı. Die 'Tapiokastïrke ist den Sago, Marksago, ̈̈hnlich. Nenerdings wird auch in kuropa aus den kiassawamehl Tapioka rlargestellt. 
Bemerkungen über den Handel. An der Spitze der Erzengungslinder steht Brasilien, das im unteren Imazonenthal allein 15. im sanzen Lande meln als 30 Spielatton des Maniokstrinches anhant. In den nördlichen P'rovinzen wird vorzunsweise Maniokumelıl dargestellt, welches als Farinha oder Farina in den Ilandel kommt, während der Ilauptsitz der 'Tapiokagewinnung in der Provinz Santal Catharina ist. Auf den Cap Verdischen Inselu wird verhïltnismä́sig viel Maniokamehl erzeugt, aber nicht viel daron ausgefiilnt. Dassellbe kann man von der ganzen tropischen Westküste Afrikas sagen. In Mozambique ist der Anban der Pflanze bedeutend. In Asien bilden die Straits Settlements das wichtigste Errengungsgebiet. Sie verschiffen von l'enang und Singinpore jährlich etwa $4000000 \mathrm{~kg}$. Alles in allem iibersteigt aber der Verbrauch des Mehles und der Stïrie an den meisten I'roduktionsorten die Ausfulı um ein ganz Beträchltliclıes.

Geschichte. Die Arten der Gattung Manihot wurden ron den Eingeborenen Brasiliens, Guayanas und der wärmeren Fegrenden Mexikos ror Ankunft der Europïer angebant. In 16. Jahnhundert war diese Kultur auf den Antillen verbreitet genug, un dort ebenfalls fiir sie ein ziemlich hohes Alter anzunehmen. Nach Afrika kam sie in 16. Jahrhundert durch die Portngiesen; anch ist sie dort weniger verbreitet, namentlich in den ron der Westküste entfernten Gegenden. Die Einfiihrung in Asien fand noch spöiter statt. Schliefslich ist auch die Kultur des Kassawastrauches in den Tropenlïndern der Alten Welt weniger verbreitet als in Amerikit. 


\section{Tafel 20.}

\section{Guttaperchabaum}

(Palaquium Gutta Burck; Dichopsis Gutta Bentham-Hooker;
Isonandra Gutta Hooker).

Der Guttaperchabaum gehört zur Unterklasse der Verwachsenblätterigen Dikotylen, zur Reihe der Primelblütigen und zur Familie der sapotaceae.

Die den Tropen angehörende Familie der Sapotaceen ist ausgezeichnet durch die grofse Regelmäfsigkeit der lireise, in denen ihre Bliitenteile angeordnet sind, sowie durch zahlreiche, in geraden Reihen angeordnete Vlilchsaftschläuche, welche in der Rinde und im Nark, auch in den Blättern gefunden werden. Sie umfafst 30 Gattungen mit etwa 400 Arten.

Die Gattung Guttaperchabaum (Isonandra Ilooker, Pultquirm Blanca, Dirhopsis Thwait). Grofse Waldbüume mit ganzen, lederartigen Blättern. Bliiten klein, unscheinbar, mit sechs in zwei Kreisen angeordneten Kelchblättern, sechs Abschnitten der BImmenkrone und 12, selten 18 Staubblïttern. Fruchtknoten sechsfïcherig, dicht behaart. Samen olne Nïhrgewebe; Keimling mit kn'zem Stïmmchen und dicken. Heischigen Keimblïttern. Hierher mehr als 50 Arten.

Echter Guttaperchabaum, Tubanbaum (Pulupuim. finttu liurck, Isoncmile Guttc Hooker, Dirhopsis Gutta BenthamIlooker). Der Baum wird 10 his $15 \mathrm{~m}$ hoch.

Blätter wechselstïnlig, lang grestielt, länghich-eiförmig, mnten schmäler werdend, mit einer kurzen Spitze. mit parallelen Adern, etwas lederartig, von sehr festem Bau, obere Seite griin, untere goldgliinzend.

Blüten bündelweise dicht am Stengel, etwas herahgeneigt, gestielt; Kelch glockenfürmig, tief sechsspaltig. mit zweireihigen, eirumden, fast goldglïnzenden Lappen. Blumenkrone sechszipfelig, wie eine fichale sich öfnend, mit kurger Röhre (liöhre nicht lïnger als der líelch), weils; Zipfel eirmd. Staubblätter 12, am Schlunde 
der Kirne angeheftet. lïnger als die Bhmenkrone. Staubbeutel lanzettlich. nach alulsen mit Längsspalten anfspringend. Fruch乞knoten sechsfächerig, mit sechs samenanlagen. dicht und weich hehaart. Griffel fadenfömig, in der Jïnge der Stanbblitter. Narbe stumpf. - Die Pflanze ist in hohem Grade erstweibin, proterogynisch, d. h. ilre Narbe ist ror dem Blïtenstaube reif. so dafs die Bestäubung der Narbe mit Blïtenstaub, der einer anderen Bliite entstammt, zur Fruchtbildung unbedingt notwendig ist.

Frucht eine Beere, ei-, fast kugelförmig, einsamig, vom bleibenden Kelch gestiitzt. Same steinhart, mit glänzender s'chale und breiter, länglicher Ansitzfläche.

Vaterland: Ehemals in den Urwäldern ron Singapore häutig; jetzt vollständig ausgerottet und woln nur noch im Kulturzustande lebend.

Guttaperchapflanzen. Der friher so wertvolle PalaquiumGutta-Baum ist durch rïcksichtslose Ausnutzung ausgerottet und daher fuir die Guttaperchagewinnung nummehr ohne Bedeutung. Ton den zahlreichen Palaquiumarten geben gutes Guttapercha nur noch I'alaquime oblongifolium. P. borneense und P'. Trembii.

Der Länglichblätterige oder Elliptischblätterige Guttaperchabaum ( $I$. oblongifolium Burck), ein hoher Baum. findet sich auf Malakka, Riauw, Sumatra und Borneo; seine Zweige sind in der Jugend rostfarben behaart; seine Blätter lederartig, lïnglich oder länglich-lanzettlich, lang zugespitzt, oben grïu, unterseits goldglänzend, mit jederseits 20 bis 30 kaum hervortretenden Nerven. Seine Blütenbüschel sind ein- bis sechsbliitig, die Kolchhlätter goldglïnzend, die Beeren eifürmig, kurz-braunfilzig. Er liefert die beste Sorte Guttapercha.

Treubs Guttaperchabaum (I'uluminm Tieubii Burck) hat langgestielte, umgekehrt-eiförmige, unterseits goldglänzende, jederseits mit 13 bis 16 schwachen Nerren versehene Blïtter; die Bliitenbiischel sind zwei- bis siebenbliitig, die Beeren eiförmig, dunkel purpurrot. Der Baum ist auf Banka heimisch, scheint aber anch in seiner Heimat schon ausgerottet zu sein. Er liefert eine sehr gute Guttapercha.

Der Borneo-Guttaperchabaum (I'nluquim boncense Burck) hat langgestielte. ungekehrt-eifömig-elliptische, oben algermndete oder kurz zugespitzte 1;litter. Wie Treubs Guttaperchabaum liefert er. vorziigliche IVare, scheint aber auch bereits in Borneo ausgerottet zu sein.

Ziemlich grte Guttapercha liefert noch Payena Leevii Teysmann auf Malakka, Sumatra, Borneo, Banka und Amboina. Sie gehört ebentalls in die Familie der Sapotaceen; doch hat bei der Gattung l'nyenu A. De Candolle die bihmenkrone mindestens doppelt so viele Abschnitte wie der lielch und ist der Same mit Nïhrgewehe aus- 
geriistet. I'. Levii besitzt linglich-eifönnigo, am Grunde spitze, am Ende plützlich km\% zugespitzte Blätter. Sehr grolse Mäiter hat dic,

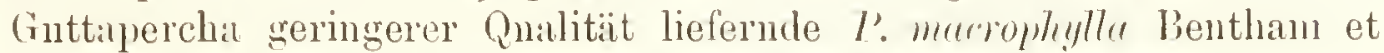
Hooker, welche die Reihe der Guttupcrchapflanzen heschliofst.

Gewinnung der Guttapercha. Da angezapfte Binme sehr wenig Guttapercha liefern, auch nur etwa alle vier Jalne angezapft werden können, fällt man die Iäume nud schwelt sie vom Grunde an. dann Hielst die Guttapercha aus vorher angebrachten Axtwunden heraus.

Die fortdauernde V'ernichtung der Bäiume und der immer steigende Bedarf an der namentlich für die Herstelhng unterseeischer hiabel unersetzlichen Guttapercha gaben Veranlassung, die Bäume zu kultivieren. Da sie aber vor dem 30. Jahre nicht nutzbringend ausgebeutet werden könmen, bringen solche Anlagen allzu späten Ertrag, um zu gröfserer Durchfïhrung zu reizen.

Bestandteile und Eigenschaften der Guttapercha. Die Guttapercha des Handels enthält 75 bis 82 Proz. reine Gutta und die Harze Alban und Fluavil. Die Gutta ist ein Kiohlehydrat, zusammengesetzt aus 87,80 Proz. Fiohlenstoff und 12,20 L'roz. Wasserstoff.

Nach Wiesner erstarrt frischer Guttaperchasaft' zu einer porösen, schwammigen Masse. Um diese in einen dichteren Zustand zu bringen, wird sie greknetet und geprefst und so in Blöcken oder Rollen von 10 bis $20 \mathrm{~g}$ in den Handel gebracht. In den Fabriken erweicht man diese Stücke durch heilses Wasser und durchknetet sie nochmals, um sie von den in ihr enthaltenen Rinden- und Holzstïckchen, erdigen und steinigen Teilen zu befreien. Guttapercha ist geschmacklos, riecht aber erwärmt angenehm und ist sehr leicht schneidbar. Hei $20^{\circ} \mathrm{C}$. ist sie lederartig, zälıe, biegsam, kaum elastisch, fest und dauerhaft. Durch lieiben wird sie elelitrisch. Sie ist ein schlcchter Lciter der Elektricität und Wäme. Bei $48^{\circ} \mathrm{C}$. wird sie biegsam und etwas clastisch, blcibt aber zälıe, bei $62^{\circ}$ erweicht sie so, dafs man sie mit andercu Guttaperchastücken zusammenkneten und überhaupt in jede beliebige Form bringen kann. Erkaltet, nimmt sie ihre frihere lestigkeit und Zähigkeit wieder an. Benzin und Schwefelkohlenstoff bringen Guttapercha schon bei gewöhnlicher 'Temperatur völlig in Lösung. Je nach ihren Verwendungen vermischt man sie mit Thon, Kreide, Schwerspat, Gips. Bleigelb, Mennige, Zimnober, Chomgelb, Zinkweils, Sand, Smirgel, Kienrufs u. s. w. Gegen Schwelel, bessel nocl gegren die Unterschwefligsäuresalze des Bleics oder Zinks, verläilt sich Guttapercha ganz wie Kautschuk, indem sie sich vulkanisieren und holnisieren läfst, in der Wärme aber nicht wieder erweicht, den oben angegcbenen Auflösungsmitteln wirlersteht und auch bei löhercn Hitze. graden ihre Festigkcit und Geschmeidigkeit nicht verliert. Oft wird sic anch mit Kautschuk vermischt. 
Der Gebrauch der Guttapercha, 'labangummi, Gettani: grmmi, Gumuiplasticum, P'ercha, ist ein selı ausgerlehnter. Inre besonderen Eigenschaften bestehen darin, dafs sie den elektrischen Stron isoliert, dals sie beim Erwärmen erweicht und bein Erkalten wierler fest wirl, sich mithin leicht in jede belicbige Form hringen lïst, endlich darin, dals sie vom Seewasser nicht leicht zerstört, vielmehr mit der Zeit eher dichter und undurchdringlicher wird. Man nmkleidet daher mit Guttapucha die unterseeischen Telegraplienleitungen, verarheitet sie zn Röhren zur Leitung und zu Gefïlsen zum Aufnehmen ätzender Flüssigkeiten in Laboratorien und bei Photorraphen, da sie den Einwirkungen ron alkalischen und sauren Stoffen mit Ausnahme rou starker Schwefel- und salpetersäure widersteht. Man fertigt aus Guttapercha Flaschen, Platten, Luftkissen, Bïlle, Saughütchen, Kiirsten, Kïmme, Überschuhe, Kopfbedeckungen, Mäintel, Hörrohre, Sprachrohre, Spazierstöcke, Billardbälle, Uhrketten, Brillensestelle, 'Treibriemen für Maschinen, sohlen fïr Schuhwerk, Röhren zu Wasserleitungen, Pumpen, spritzen, Geschirre; ferner dient sie zum Abformen plastischer Gegenstiunde n. s. w. In Bläittern, diinn wie Papier, dient sie als Guttaperchapapier und Guttaperchaleinwand zu gesundheitlichen Zwecken. Feine Guttaperchafiden werden zu schmiegsamem und festem Flechtwerk verwendet. Mit Aufliöung ron Guttapercha in Chloroform, Traumatirin, das aber leicht zerfïllt und wenig haftet, bestreicht man Wunden und Geschwire, wodnrch die atmosphärische Luft abgeschlossen und es doch, infolge der Durchsichtigkeit der Guttapercha, möglich ist, das Heilen der Wunde zu beobachten. Bei Ḱnochenbrïchen dient die Guttapercha als V'erbandmittel, das leicht anzuleren ist, sich jeder Form anbequemt und durch schnelle Verlärtung das eingerichtete Glied in fester Lage hält. Wichtig ist auch die Anwendung der Guttapercha zu den kïnstlichen Gebissen nnd zum Ausfüllen hohler 7ïhne. Guttaperchatirnis kann benutzt werlen zum Ïberzichen ron Dokumenten und derogleichen; das Papier wird darlurch nicht verindert, der Firnisüberzug ist durchsichtig und lïst die feinste Schrilt crkennen; solche Dokumente sind gegen Wasser, süuren, Alkalien unempfindlich, nur hat unan sie vor Wirme zu bewalren.

Warenkunde. In Handel der Erzengungslïnder sollen gewölnllich drei Sorten unterschieden werden: Ciullu lubur oder tubu,

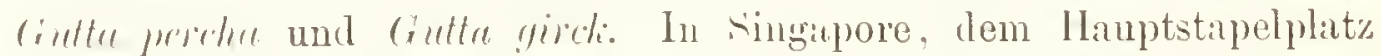

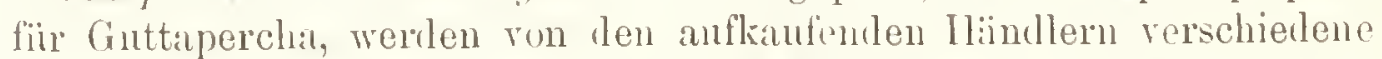
sorten genischt; das Erogehnis dieser Mischnngen scheinen die drei

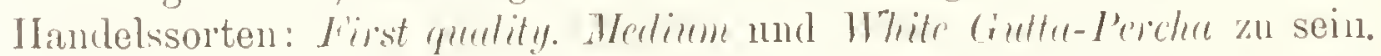
Die heste Sorte roher Guttaperchia ist fast weils und nur schwach rithich orler greblich und hat eine faserige, geschichtete Struktur. Ie dunklen dio Malsse aussieht, desto mehr ist sie mit anderen Stoflen vorulneinigt. 
Handelsstatistik. 1844 kamen die ersten 2 Ctr. Guttaperchil ron Singapore nach Fingland, 1S45 schon 224 Ctr., $1863: 36000$ Citr. 187125966 Ctr. Hamburg lïhnte 187:) 1961 Ctr. ein. Nach dem Statistischen Jahrbuch für das Dentsche Reich lïhrte Dentschland 1597 an Guttapercha und Kautschuk (die Einzelzahlen sind nicht getrennt) 9175 Tonnen im Werte von 4:,6 Mill. Mark ein und 2279 Tomnen Rohmaterial, sowie 3927 'lomen Waren im Werte von 33,1 Mill. Mark aus.

Geschichte. Montgomerry, Chirurg der Ostindischen Kompanie zu Singapore, fand, dal's die Eingeborenen getrocknete Pflanzenmilch zu Heften und Griffen fïr Messer und Waften und zu Axtsticlen verwendeten; er schickte 1842 verschiedene Proben dieser erhärteten Pflanzenmilch nach England. Der Gummisaft kam ron einer Pflanze, die der englische Botaniker Hooker nach ihm übersandten bliihenden Exemplaren als zur Gattung Isomendro gehörig erkannte und der er das malaiische Wort Crutte (d. i. Baumsaft) als Artnamen gab. 


\title{
T a fel 21.
}

\section{Kautschukbaum, Federharzbaum}

\author{
(llevea yuyanensis Aublet).
}

Stellung im Systen, wie dor Maniokstranch, in der Familie der Wolf'smilchgewächse (s. s. 156).

Die Gattung Kautschukbaum (Hever Aublet, Siphonia Schreber, Micandra Rob. Brown). Nilchsaftführende Bäume mit wechselständigen, am Ende der Zweige gehäuft stehenden, dreizähligen Blättern; Blïttchen gestielt, ganzrandig, fiedornerrig. Bliiten klein, in traubenartigen Rispen. Kelch glockenförmig, fünf́spaltig. Einhäusig. Männliche Blüte: Staubblätter zu einem Säulchen rerbunden. Weibliche Blüte: Fruchtknoten dreifichcrig; jedes Fach mit dicker, zweilappiger Narbe und mit einer Samenanlage. Kapsel grols. drei-, durch Verkiimmernng bis einknöpfig; in zwei klappige, einsamige Kinöpfe aufspringend. Etwa 10 Nrten.

Guy ana-Kautschukbaum (Herea!numensis Aublet, Siphmir elastica Persou).

Höhe des Baumes $20 \mathrm{~m}$ und melr. Dur chmesser $60 \mathrm{~cm}$. Fist von seinem Grunde an mit langeu, weit ausgebreiteten Ïsten beset.t.

Blätter zusammengesetzt, dreizählig, abwechsehd, mit stielrunden, kahlen, langen Blattstielen; die einzelnen Blättchen verkehrt-oiförmig, gegen die Basis verschmälert, in ein kurzes Blattstielchen herablaufoud und daher fast keilförmig, kurz zugespitzt, auf beiden Seiten glatt, ohen dunkelgriin, glänzend, unten grangrïn, 7 bis $15 \mathrm{cml}$ lang und 3,5 bis $5,0 \mathrm{~cm}$ hreit.

Blüten in langen, zusammengesetzten. sparrigen, end- mul achselständigen li ispen, gelblich, filzig, sehr kleu, nit oiner einfachen, glockenfömigen Blütenhülle. Am Grunde der Rispe sitzen sohr kleme Deckblättchen. Der grölste 'l'eil der liliten ist mämlich. nul die an den /weigspitzen sitzenden sind weiblich, daboi dick zesticlt und grö́lser. Blütenhülle (Kelch) weichharrigr, in ler Knospe kugelig mit enugefaltet-klappigon Abschnitten; hei den männ- 
lichen Bliiten his zur Hälfte, bei den weiblichen nur zu ein Drittel eingeschnitten, fünllappig, Staubblätter fïnf, zweifücherig, zu einer mittelständigen Nïule verwachsen; Staubheutel fast sitzend, zweifücherig, nach aufsen aufspringend; das sie ïbertagente Stempeliiberblcibsel hehaart. Fruchtknoten (Fig. 3, nach Ilooker und Pierg und schmidt) eiförmig. mit drei sitzenden, breiten, zweilappigen Narben, fein behaart, dreificherig.

Frucht eine dreifurchige, dreiknöpfige Kiapsel, von der Grölse einer Pflaume; durch Verkimmerung oft zwei- oder einknöpfig; steinfruchtartig, mit Heischiger Aufsenschicht und harter Innenschicht der Fruchtschale; in zweiklappige Kinöpfe aufspringend. Samen in jedem Fache einer, eiförmig, furchig, mit Caruncula, graugelb, ölig, efsbar (im Geschmack unseren Haselniissen ähnlich).

Vaterland: Guyana und wahrscheinlich auch am Unterlaufe des Amazonas.

Verwandt ist der Brasilianische Kautschukbaum (Heven brasitiensis J. Müller, Simhonia lrasitiensis Kunth). Bei ihm bilden, wie auch bei den noch übrigen Krautschukbäumen, die Staubbeutel, deren hier 10 vorhanden sind, zwei übereinander um die Säule stehende Kreisc. Die 5 bis $7 \mathrm{~cm}$ langen Blättchen sind elliptischlanzettlich, beiderseits verschmälert-zugespitzt. Die männlichen Blütenknospen sind eiförmig-kugelig, die Kelche bis zu zwei Drittel geteilt. Die mänulichen Blüten besitzen einen kleinen, krugförmigen, viellappigen, belaarten Diskus.

Der Saft einiger Arten vou Hevea wird in Brasilien unter dem Namen Seringua medizinisch verwendet.

Gehalt und Gewinnung des Kautschuks. Die genannten Kautschukbäume wachsen in solchen Mengen in Siidamerika. dafs man sie zur Zeit nicht kultiviert und ihre Fortpflanzung der Natur iiberlïlst. Um das Kautschuk zu gewinnen, zapft man die Bäume an, wodurch sie, wenn die Verwundungen nicht allzu bedentend sind, wenigg oder gar nicht leiden. Hat man den Bäumen ihren Milchsaft entzogen (Mai bis August), so läfst man sie drei Jahre lang ausruhen, kann aber alsdimm wieder Nilchsaft aus ihnen gewinnen ').

Wird der Kantschukbaum verwundet, so fliefst aus der Mittellage der Rinde, und zwar aus dïnnen Milchröhren, ein Saft heraus, der leicht erhïrtet, braun wird und das bekannte Kautschuk (Feder-

1) Viele, anch cinheimische Pflauzen (Wolfsmileh, Schöllkraut, Löwenzahn, salat u. s. w.) enthalten Milehsaft; besonders sint es die Glierler du. Wolfsmilehund der Hundswürgergewälchse, fler Nesselptlanzen und der Lobeliaceen, welche Milehsaft in lohem Grade besitzen. Diese Ptlanzemnilch ist ihrem Gehalte nach sehr ungleich. Die Nilch riniger Bäume kommt in ilnon Bestanteilen dre tierischen ualie unl wird als Nahrung für die Mensehen henutzt; die Milch anderer Pflanzen enthält starke Gifte, die dor Wilde gegen Menseh und 'T'ier als P'feilgifte anwendet, cine weitere Art Pflanzennileh giebt líntschuk und finttipereha. (Vergl. die nmsteliende ligur.) 
har\%, (illmmi elustirnm) darstellt. In den Urwäldern IBrasiliens wird der aus Einschnitten in den Stamm reichlich ausflielsende saft in irdenen oder mit Lelım bestrichenen Gefiilson gesammelt und einem eigentiimlichen Rïnclıerungsprozesse unterworfen. Dieser l,esteht darin, die ïber eine Form gegossene Milch dem Riauche von Nüssen einiger Palmen (Attulen fimifera oder Muritic inifer(u) auszusetzen, welcher

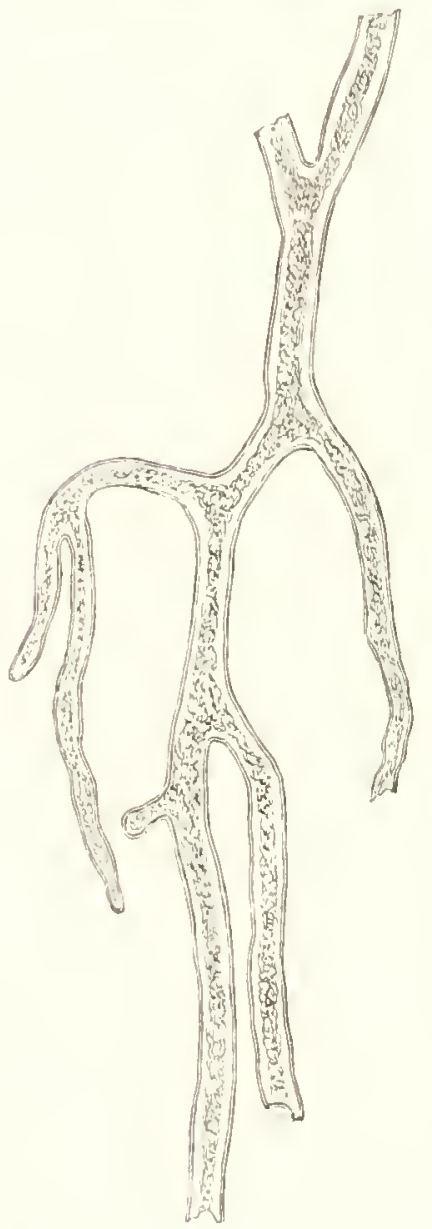

Ungegliederte Milehröhre aus dem Stengel der CypressenWollsmilch (kith)horbice cypervisisers scopoli). die Eigenschatt besitzt, sie augenblicklich gerinuen zu machen. Der Arbeiter, Seringueiro, giefst mit einer kleinen Kalabasse eine geringe Menge der weilsen, wie fett. Kuhmilch aussehenden Flüssigkeit über eine Art leichter, etwa meterlanger Holzschaufel, auf der er sic durch gesclicktes Drehen und Wenden so gleichmälsig wie müglich zu vertcilen sucht. Schnell fïihrt er damit in den weifsen Qualm der verbrennenden Nüsse, dreht einigemale hin und her, nnd alsbald sielit man die Wilch eine graugelbliche Farbe annehmen und fest werden. So wird Lage auf Lage gebracht, bis die Kitutschukschicht 2 bis $3 \mathrm{~cm}$ dick ist, sie wird dann von der Schaufel abgenommen und an die Sonne zum Trocknen aufgehïingt, dabei gelıt ihre Farbe, anfünglich ein helles Silbergrau, in das bekannte Braun der Handelsware iiber. Aus den am Fufse der Bäiume aufgeleseneu Tropfen nud den iu den Grefïlsen zusammengescharrteu Resten der Mileh formt man Kugeln, Negerköpfe, siermambys. - Durch Zusatz ron Ammoniak kann nan die Kautschukmilch in flïssigem Zustande erhalten und sie folglich in Fïssern verschicken.

Ein krïftiger Baum giebt in drei stunden etwa $1 / 2$ Liter Milch und wälnrend der ganzen Gewinnungszeit, von Mai bis August, etwa 50 bis $75 \mathrm{~kg}$ Kautschuk.

Das reine Kautschuk ist in diimen Schichten farblos, riemlich durchsichtig, in dickeren Stuicken gelblich und rötlich; es lat ein specifisches (kewicht von 0,92 lis 0,96 ; durch Trocknen an Fener mnd durch die eingemengten fremden Bestandteile ist es grewöhnlich in filaschen brämulich oder schwirzlich. Es riecht sehr wenig, ist geschmacklos, Inltbestïndig, zähe, hïngt sich an fremde lï̈rper etwas :m, hesonder's haftet es, an zwei frisch geschnittenen Stellen aneinnder gerlrïckt, -o fest, dill's es selbst luftdicht schlielist; es ist selur eliastisch 
(kann bis auf' dis Sieben- orler Achtfache gedehnt werden), in ter lïilte hart und steif, beim Erwärmen biegsam, erwoicht in warnem Wasser, schwillt etwas a uf, geht hein 'Trocknen wieder in den vorigen

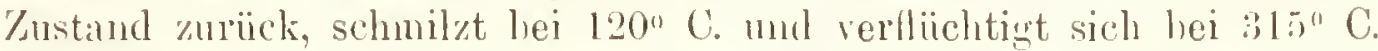
liei trockener Destillation giebt es eine wässerige lilüssigkeit und Kantschuköl, ein Gemenge flüssiger Kohlenwasserstoffe (Butylen, Faradayin, lsopyren, Heveen und Kautschicin oder Kautschin). biese Flüssigkeit besitzt ein specifisches Gewicht von 0,680 und eine starke Fïhigkeit, Kantschuk anfzulösen. Kantschuk verbrennt mit einer hellen, rufsenden Flamme; es ist unlöslich in Wasser, Alkohol, Alkalien und Sïuren, ansgenommen Salpeter- und Schwefelsäure in konzentrierter Form, - aher löslich in Ïther, Chloroform, Naphta, Petroleum, Benzol, dem flïchtigen $0 ̈$ l des Terpentins, Lavendel- uml ‘assafrasöl. Leinöl macht, wenn es mit Kautschuk vereint (180 g Kautschuk and S75 g Leinöl) erwärmt wird, das Kautschuk weich und kleberig; in dieser Form dient es dazu, Schuhe, Kleider u. s. w. wasserdicht zu machen. Kautschuk enthält keinen Sauerstoff, sondern 12,5 Wasserstoff und S7,5 Kohlenstoff, ist also ein Kohlehydrat. Ein Milchsaft aus Suidamerika enthielt 31,7 P'roz. Kautschuk, 7,13 Proz. Harz und Bitterstoff, 2,!) Proz. in Wasser lösliche, in Alkohol mulösliche Substanzen, 1,9 Proz. Eiweifs, 56,37 Proz. Wasser, Essigsïure Salze; in dünnen Schichten der Luft ausgesetzt, trocknete er ein und hinterliefs 45 Proz. umreines Kautschuk.

Anbau. Der Kautschukbaum wird leider in Brasilien nicht angebaut. „Übrigens geben nicht alle Bäume den Milchsaft in genïgender Menge, und nur diejenigen, welche von den jährlichen I"berschwemnungen durch die Fliisse (\% B. im Igapo, d. h. in den Wäldern an den Seiten des Amazonas, deren Baumstïmme monatelang bis. $10 \mathrm{~m}$ tief unter Wasser stehen) mindestens bis zur Höhe von $1^{1 / 2} \mathrm{~m}$ getroffen werden, lohnen die Ausbeute. Diese Frfihrung ist nicht genug in Riiicksicht gezogen worden, als man es unternalm, die Heveen in Ostindien, besonders in Assan, anzubanen. Es gelang, sie dort vollkommen einzubürgern; die schnell heranwachsenden I:äume blühten und fruchteten, als man sie aber anschlug, erlielt man von 40 Bäimen noch kein Pfund des Milchsaftes. Die Folge war, dafs die mit vielen Hoffinungeu auf reichen Gewimn unternommenen Kulturen indischer Pflanzer als völlig fehlgeschlagen erachtet werden mufsten, so dals sie die Büume fïllten und an ihrer stelle andere Nutzpflanzen zogen..”

Gebrauch und Verarbeitung des Kautschuks. Fist wendete man das Kiantschnk nur zun Auswischen der IBleistiftstriche (Crummi elusticum) an und verurbeitete es zu elastischen Kinderbïllen. Im Jahre 1790 fertigte man dehnbare Binden daraus. 1820 erfand Nadler, in die Kette von Schafwollen- und Batumwollengarnen Kautschukfüilen zu weben und erzougte daraus dehnbare liainder (Ihosenträiger, strumpfbïnder, Gürtel us. s. w.); kur\%e Keit daranf erfand 
Makintosh die wasserdichten Zenge, die nach ihm benannt werden. Durch Verbindung des Kautsehuks mit richwefel, vulkanisieren. verstand (ter Englinder Hankok (1815) zwei IIauptfelıler des Kautschuks, scine spröle Steifheit in der Kälte sowie scine Klebrigkeit und Weichheit bei höheren Wärmegraten, zn leseitigen. Die friiher ans Naturkautschuk gewehten dehnbaren Bänder verloren bei einem gewissen Hitzegrade ihre Elasticität, während die aus vulkanisiertem Kautschuk gearbeiteten stets die grleiche Dehubarkeit heibchalten. Um das gereinigte Kautschuk zu vulkanisieren. wird es mit 12 bis 14 l'roz. Schwefelblumen zusammengeknetet. Vulkanisiertes Kautschuk lïlst sich zu zalnheichen Gegenständen verarbeiten, zu luft- und wasserdichten Gummischläuchen, Spritzenschläuchen, Kappen, zu luftdichten, den Chemikern unentbehrlichen Verschlüssen von Flaschen, zu Milchsaugern, Trinkbechern, Cigarrenspitzen, chirurgischen Instrumenten, Werkzeugen und Geräten für die verschiedensten Gewerbe, gewebten und geklebten Schuheinsätzen, Gummibällen, elastischen Spiclzeugeu (Puppenköpfen, Tiertiguren u. s. w.), Gummischuhen, Radiergummi, clastischen Luftkissen, Reisetaschen, wasserdichten Kleideru, Eisenbalnupuffern, Buchdruckerwalzen u. s. w. Goodyer, ein nordamerikanischer Kautschukwarenfabrikant, erfand 1852 die Infertigung des hornisierten oder gehärteten Kautschuks, Ehonit, Gummilornmasse, indem er dem aufgelösten Kautschuk bis zu 50 Proz. Schwefel, Schellack und sehr fein gepulverte Marnesia zusetzte. Dieser neue Stoff ist hart wie Horn, elastisch wie Fischbein und nimmt eine sehr feine Politur an. Ans diesem Hartgummi werden verfertigt: Thïr- und Schirmgriffe, Messerhefte, Kinöpfe, Galanteriewaren aller Art, Uhrketten, Schirmippen, Korsettstaugen, Mübelfourniere, Weberkämme, Lineale kiinstliche Gebisse, vorziïgliche Kämme, Flintenschäfte mit kunstvollen Verzierungen, physikalische und technische Instrumente, Möbel, Gefäfse aller Art, Musikinstrumente, l'ulverlörner und Buchdruckerlettern. Auf der ersten Pariser Weltausstellung wurde ein grofses, dickes Buch ron den Besuchern angestaunt, das, in allen Teilen aus vulkanisiertem Kautschuk bestehend, mit Lettern aus hornisiertem Kautschuk gedruckt worden war und die Geschichte der Kautschukindustrie enthielt. Den Besuchern der Wicner Weltausstellung tiel in der Rotmule eine schwarze, glïnzente Sïule aus cinem Stiicke Ilartgummi ins Auge, welche $4 \mathrm{~m}$ hoch war und $1,15 \mathrm{~m}$ in Durchmesser hatte. Dic rechts und links angelorachten liasten ans Hartgummi zeigten Humboldt und Liebig meisterhaft ansgefiihrt. Die Reliefs Amerika. Asien, Afrika mel das IIamburger Stadtwappen waren aus Bronzehartgummi fomrniert und die iibrige livurnitur hestand aus Marmorhartgummi.

Mit in licnzin anfgelöstem kautschuk worden rerschiedenartige Stoffe zur Anfertigung wasser- und luftichter \%enge ïherstrichen (Beklojdmngstiicke, Unterlinen fïr Kinder und liranke: Hospitaltuch). Aus Kíntschnk, Guttapercha mul liorkibfiillen wurde 
las jetat rollstiundig ron den horkteppichen (Linolemm) verdräingte Kanptulikon gefertigt, das man zur Bedeckung von Fufsböden u. s.w. benutzte. Kiautscluk wird jedenfalls noch mannigfaltige weitere Verwendung finden.

Aulser den erwihnten II evearoten liefern noch kiautschuk:

Aus der Familie der Wolfsmilchpflanzen (Lumorlninceac) die bereits (S. 15S) erwähnte Manihot Glasiovii Müller, ferner Maben

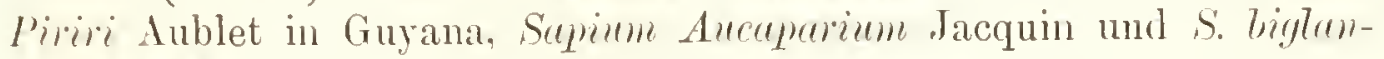
dutosum Miuller im tropischen Anerika.

Aus der Familie der Maulbeerpflauzen (Moracere) rerschiedene Ficusarten, namentlich Firas clastice Roxburgh in Ostindien, $i$. toxirovia Limé auf Sumatra, $I+$. mymphacifoliu Linné, $I$. jopnture IVilldenow, $I$. Ratulu Willdenow und $I *$ silvestris St. Hilaire in Südamerika, 1 . elliptica Humboldt und Bonpland in Brasilien und 1. minoides Knuth in Neu-Granada; von den zahlreichen Cecropiaarten werden namentlich Ceropiu peltuta L. auf Jamaica und C. pulmutu Willdenow in Nordbrasilien und Guyana ausgebeutet; Casti7lou chastir Cervantes in Mexiko (Arbor de Ule) liefert ausgezeichnete Ware in Nlenge.

Aus der Familie der Hundsgiftgewächse (Apocynacene) werden ausgebeutet in Westafrika insbesondere Landolphia comrorensis rar. Horidu Schumann und L. ourviensis Palisot Beauvais; in Ostatrika L. Kirki; Dyer und I. I'etersiana Dyer; auf Madagascar L. gummifera Schumann; in Malakka und Sumatra Uiceola clastica Roxburgh: sodann Trilloughlygu chutis Roxburgh und verwandte Arten, die ron Assam bis Borneo verbreitet sind; auch erhält man Kautschuk im tropischen Afrika von Lianen der Gattungen Tacu; :cu Decaisne und clitundra Bentham; ferner in Cochinchina von I'arameria Pierrei Baillow und in Brasilien von Hroncormia spceiosa Gomez. Besonders grolse Hoffnungen setzt man jetzt in Kamerun auf Kicliria africana Bentham, einen Bamm, der im tropischen Westafrika einheimisch ist und Kautschuls erster Giite liefert.

Gewils enthalten noch zahlreiche andere l'flanzen Kautschuk in einer Menge und Beschaffenheit, dals die Technik sich dessen bedienen kann; bei vielen anderen kautschukhaltigen Pflanzen ist letzteres nicht der Fall. so z. P. hei dem geringen Prozentsatz Kautschuk, der im Opium enthalten ist.

Warenkunde. 1. Parakautschuk von Heveariten ist lel beste mid biegsamste; sehr damerhaft, rein und in ausgedelntem Malse elastisch; in Form kugeliger, dickwandiger Flaschen von etwa $15 \mathrm{~cm}$ Durchmesser; aufsen dunkel, innen hell; auch in runden Scheiben, "Liskuits", die Aurch das Aulschneiten der Flaschen rntstelien; die geringeren Sorten, rundliche Hï̈ke, "Neggerköpfe" des Ilandcls, sind meist dunkler von. Farbe und mehr oder weniger unrein. Oft wird las Parakautschuk mit dem Safte des Massarandubahames (Mimmops 
Bulutu Gïrtn.) verfïlscht. 2. Das Cereakautschuk, fast ebenso-

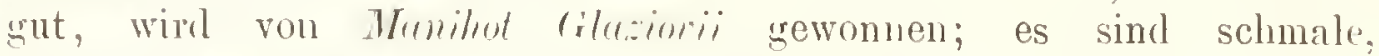
bandförmige, rötlichbraune, zu dicken Kinäueln gerollte Streifen, Ceara-Scraps. 3. Cartagenakautschuk, Ule-oder Castilloakantscluk, kommt ron Cartagena in Columbien. Guatemala, Venezuela und Neu-Granada in den Ilandel; es sind innen selır dunkle. aul'sen fast schwarze Blöcke, Kuchen oder auch etwa $10 \mathrm{~cm}$ dicke Platteu; es ist zuweileu etwas klebrig, aber recht geschätzt. Es enthält oft 35 Proz. Feuchtigkeit. Quelle unbekannt, vielleicht von Crrstillon mestiru. 4. Westindisches Kautschuk in aus diinnen Platten zusammengeprefsten Blöcken, sehr rein. 5. Guatemalaka utschuk, :̈hnlich geformt, klelırig, teerig, ron iilslem Geruch. geringste Sorte. 6. Guayaquilkautschuk, aus Ecuador. bald in weifslichen, grofsen Blöcken (bessere Sorte), loald in schwammigen, mit schwarzer. iibelriechender Fliissigkeit vollgesogenen Massen. 7. Ostindisches Kautschuk, meist ron Ficus und Lreolu, bildet dicke Platten, Klumpen oder Brocken, ist hellbraun oder weifsgrau, oft durch Znsammenkneten verschiedener Sorten marmoriert; es wird je nach seiner Herkunft als Assam-, Borneo-, Java-, Pinang-, Rangun- und singaporekautschuk mnterschieden, ist aber viel geringwertiger als Parakautschuk. 8. Afrikanisches Kautschuk kommt in wurm-, schnecken-oder zungenförmigen Stïcken, Niggers, von Loanda; in formlosen Ḱlumpen, Kuuckles, vom Kongo; als Negerköpfe, d. l. aus Schabseln gebildete Ballen, von Sierra Leone; als Zungen, thache. klebrige Stiicke, von Gabun; als Ballen ron Liberia; als kleine, riereckige Fingerhüte, oder mregehnäfsige Stiicke, N ïsse, aus den portugiesischen Gebieten in den Handel. Mozambiquekautschuk bildet Ballen von Orangegrörse oder wurstförmige Stücke; letztere werden hergestellt, indem mau dünne Füden um ein Holz, das später entfernt wird, windet; selten stellt es liuchen oder "Lebern", grofse. platte, muregelmälsig geformte Stiicke, dar. 9. Madagascarkautschuk hat eine rötliche (gute Sorte) oder schwarze (geringe Sorte) Farbe, es bildet unregelmäfsig geformte Stiicke.

Angaben über den Handel. England fülırte $18: 30$ erst 454 Ctr., 18507784 Ctr., 1889236275 Ctr. eir. In Brasilien wirl dis meiste und beste Kintschuk des Ilandels erzeugt. Fis fülırte 186.5 nur :3,5 Mill. Kilogr., 18!2 aber 19 Mill. Kílogr., d. i. mehr als die Hïlfte der gesamten IIandelsmenge, ans. Centralamerika fiihrt:) Mill. Kilogr.. ()stindien ebensoviel, Afrika etwa 7 Mill. lílogr, ans. Brasiliens Kantschukeinfuhr in das Deutsche Reich betrug in Jilne 1889 rund (10 s00 kg in Werte rom 636000 Mark. I'ber die Liufulu im Jahre 1897 vergleiches. 1 (6). Dentsch-Ostafiria, Kamerun und 'Tugo lieferten $18: 17$ fiir mehr als 22 5000000 Mark.

Geschichte. I)as Kautscluk wurde schou, ehe es nach Europa in den Inandel kirn, von den Indianerm benut\%t. Aus verwumleten 
I Bïuncn lïnft der Saft in Strïngen herab, oder ïhergielst ganze Zweige und trocknet bald. Die Indiamer nahmen das erhïrtete Kantschuk von den \%weigen. das him Röhren (Sinhmia. d. i. Röhnen) billete mnd henutzten es. Der französische Gelehrte La Condamine lurachte es 1736 mach Europa und gal) 1757 die erste Beschreibung des Kautschnks mo semer Gewimmmg. Doch kostete gegen linde des vorigen dahrhunderts ein wïrfelfömiges Stïck von $12 \mathrm{~mm}$ Kantenlïnge nach unseren Gelde etwa droi Mark. Zu IInmboldts Zeiten sebranchten die Indianer das Kautschuk fast nur z.n Fackeln. 


\title{
Tafel 22.
}

\section{M a hago $\mathrm{nibaum}$}

\author{
(Srietenia Mahagoni L.).
}

Der Mahagonibaum gehört zur Unterklasse der Freiblätterigen Dikotylen, zur Reihe der Storchschmabelgewächse (Geraniales) und zur Familie der Meliaceae.

Die Familie der Meliaceae. Bäume oder Sträucher, selten Kräuter, mit wechselstïndigen, meist gefiederten Blättern, ohne Nebenblätter. Blüten regelmälsig, in achselstïndigen liispen. Kelch vieroder fünfblätterig; Blumenblätter meist in gleicher Anzahl, mit den Kelchblättern abwechselnd, frei. Staubblätter doppelt so viel. Staubfäden selten frei, meist zu einer lï̈hre verschmolzen. Stempel oberstïndig, an seinem Grunde ron einer Scheibe (Diskus) umgeben, mit vier oder fünf Fächern mit je einer bis zalulreichen Samenanlagen; diese meist hïngend an der Achse befestigt. Frucht verschieden. kapsel-, beeren- oder steinfruchtartig.

Hierher 42 Gattungen mit 600, fast ausschliefslich tropischen Arten.

Die Gattung Mahagonibaum (Swieteniu L.). Meist hohe Bäune mit rotbraunem Holze, gefiederten Blitter'n und rispigen, in den Plattachsehn stehenden Blütenrispen. Staubfidenröhre cylindrisch, am Rande in 10 \%ïhne anslaufend. Staubbentel 10, zwischen den Zähnen an Rande der Staulfadenröhre eingefiugt. Frucht eine holzige Kapsel, die sich vom Grunde aus scheidewandspaltig öthnet. Mittelsänle fünfkantig, nit flügelartigen Leisten. Hierher drei einander nahesteliende Arten.

Amerikanischer Mahagonibaum (Swictenic Muhumoni L.). Stamm 25 bis $30 \mathrm{~m}$ hoch und $3,5 m$ in Durchmesser dick. Die auf fruchtharem Boden gewachsenen bämme werden noch eimmal so crols, als die auf felsigem Grunde gediehenen. Krone selur grols, reich an Ïsten und dicht helanht (.. Künig der liamme" bei den lïnineborenchl). 
Blätter drei- bis finlparigg grefiedert, abwechsehnd; Blättchen eirund-lanzettlich, zugespitzt, ganzrandig, lederig.

Blütenlispen aus den Blattwinkeh, ohne Deckblätter. Kelch klein, fünflappig, hinfïllig. Blumenlirone mit fünf eiförmigen, stumpf gespitzten, ausgebreiteten Blumenblittern, unterstindig, weifsgelblicl. Staubblätter 10, zu einer oben gezahnten liöre verwachsen. Staubbeutel zweifächerjg, sitzen an inneren Kande der Röhre gleich unter den Zälnnen und mit diesen abwechselnd. Der längliche Fruchtknoten geht allmählich in einen Griffel mit schildförmiger Narbe iiber, er ist fünfficherig und sitøt in der Mitte eines dicken, becherförmigen Diskus.

Frucht eine eiförmige, faustgrolse, holzige, fünfficlıerige, in fünf Klappen aufspringeude, braune Kapsel. Die fünf vom Grunde an sich ablösenden Klappen bestehen aus zwei sich später roneinander lösenden Schalen. Samen zahlreich, flach, an ihrem oberen Ende in einen langen, dünnen Fliigel verlängert und an diesem aufgehängt, in zwei Reihen an den Klappen dachziegelig derart angeordnet, dafs der untere Same von dem oberen bedeckt wird. Keimling mit kurzem Würzelchen und fleischigen Keimblättern, mit wenig Nährgewebe. Blüht Mai und Juni.

Vaterland: Westindien, Landenge von Panama, Mexilio und Siidamerika.

Gewinnung der Mahagoniblöcke. Der Malagonibaum wird nicht kultiviert, seine Vermehrung bleibt vielmehr der Natur überlassen. Wenn die Fruchtkapseln aufgeplatzt sind, trägt der Wind die dïmen, breiten und leichten Samen auf Berg und Thal. Diejenigen, die in eine Felsenspalte fallen, wurzeln sehr bald. Wenn die zarten Wurzelfasern Widerstand in der Härte des Felsens finden, so liriechen sie an der Oberfliiche entlang, bis sie in Ritzen eindringen und damn so anschwellen, dafs sie das stärkste Gestein zerbrechen. Diese auf unfruchtbarstem Boden langsam (300 Jahre) erwachsenen Bäume geben die beste Sorte Holz, während die in fruchtbaren 'Thälern in üppigster Vegetation gediehenen zwar noch einmal so grols als die ersteren werden, aber geringes, leichteres Hol\% ron bleicherer Farhe und mit gröfseren Poren liefern. Das Fällen der IB̈ume währt vom August bis zum Beginn der Regenzeit. Die Holzfäller teilen siclı in Abteilungen, und jede derselben zieht nun, einen erfahrenen Führer an der spitze, auf Entdeckungen ron Malagonibaumbeständen aus. Der Führer besteigt einen hochstehenden liaum, und sein kicnnerauge sucht das sich im August rötlichgelb färbende Laub der Mahagonib̈̈iume zu erspähen. Hat er eine Anzahl fïllbarer Bäiume benerkt, dann setzt sich der ganze Trupp unter seiner Anfiilnung in der angegebenen Richtung, was in dem Crwalde nicht leicht ist, in liewegung. Dio Arheiter legen in der Nïhe der Mahagonibäume zu liingerem Aufenthalt eine Art Kolonie an. '/wei Drittel der Arbeit kommen auf die 
Anlegung der Wege (lurch ixt mol Feuer), die sich in einem nach einem Fhusse führenden Ilauptwege vereinigen. Mann fahren sechs bis acht Paar Ochsen anf festem liidergestell die in Plöcke oder Pialken zerlegten Stämme nach dem Ufer. Am Fhufsufer versicht man das Mahagonihol\% mit dem Nimen des Eigentiimers und iibergiebt es dem Winser, das hei der im August einbrechenden licgenzeit die Blöcke hebt und mit sich fortträgt. Die lilöcke sind gewöhnlich in Flöfsen zusammengebunden. Die Albeiter fahren anf leichten Kïhnen nach und bringen das llolz in einen in der Näle des Neeres gelegenen Hatenort, wo es rerladen wird.

Eigenschaften des Mahagoniholzes. Das Holz des Mahagonibaumes ist ungemein fest, schwer (frisch, schwerer als Wasser) und fein gefïgt. Ls wird von den Würmern nicht zerstört nnd danert im Wasser. Das Mahagoniholz schwindet, reifst und rerwirft sich sehr wenig. Gewöhnlich ist das Holz schön hell und dunkel gemasert, geadert und gefleckt, was besunders nach ler Politur prächtig hervortritt.

Gebrauch und Verarbeitung des Mahagoniholzes. Infolge der angegebenen Eigenschaften rerwendet man das Hahagoniholz rorzugsweise zu Fournieren, dïnnen Ilolzplatten, womit man die Nöbel ïlserzieht und verziert. Die Mahagonimöbch machen neben einem schönen, ricrlichen Aussehen den Eindruck des Festen, Gediegenen und Massiven. Das Holz der Ïste und Zweige gehraucht man mehr zu Ormamenten. Da das Holz dem Wasser widersteht, eignet es sich ganz besonders zum Schiffbau. Die Rinde des Baumes, Amarantrincle, ist bitter, wirkt auf den menschlichen Körper anspannend und zusammenziehend und wird daher oft mit Fieberrinde vermischt. Man gebraucht sic im Vaterlande gegen Wechselfieber. Die Samen wirken giftig; aus denselben gewonnenes iil. Karapatöl, dient in Westindien medizinischen Zwecken.

Warenkunde. Man unterscheilet gewässertes. marmoriertes, gemasertes und völlig glattes Mahagoniholy (franz. Acajou). Das frische Holz ist gelbrot und wird spïter dunkler. Als die vorziiglichste Surte des amerikanischen Mahagoniholzes gilt das auf hohen. steinigen Standorten gewachsene Jamaica-llahagonihol\%, das sehr kleine Poren hat. Weniger gut, mit grofsen l'oren. ist das IlondurasMahagonihol\%; doch führt man dieses auch in grolsen Mlengen in Europa ein, da es weren seiner grofsen l'orositit viel leim aufnimmt und sich daher gut als Unterfintter (Blindhol\%, Unterfonmier) fiir Mahagonifonrnier eignet. Von Chile stamme das Arenas-Mahagoni. Dats geringste ist das Cuba-Mahagoni. lis kommt bei dem Mahagoniholz zumeist auf schöne Zeichnung und Miserung in abwechsulnden 'Tönen an.

Ebenfalls als Mahagoni kommt in den Hantel das 11ol\% von: 
kituly" semenulensis. Jussien im tropischen Westafrika, Centralafrika, Nyassaland, das Gambia-Mahagoni, Madeira-Mahagoni orler Calileodraluol\% des Handels:

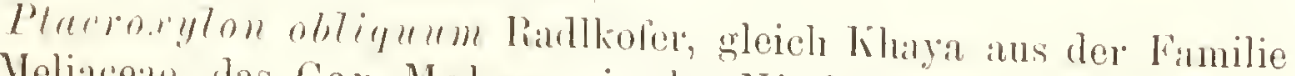
der Meliacear, das Cap-Mahagoni orler Niefshol\%.

Eunculyntus gignnten Hooker, zu den Myrtaceen gehörig, Nenholländisches, liastard-oder Kolonial-Mahagni, veilchenartig ricchent;

Anacurlinm oreidentule La, ans der Familie der Anacardiaceen. im tropischen Amrika, das Weifse Mahagoniholz, Acajou; aus den Stïmmen alter Bäume tritt das anch wohl statt des Arabischen Gummis hemutzte Acajougummi;

Phorbe indicn Pax. zu den Lauraceen, anf den Kanlren, in Spanien verwildert und kultiviert, Venacitoholz. Winatikohol\%, Madrira-oder Falsches Mahisgonihol\%.

Handel. Mahagonilol\% wird in grolsen Mengen cingelïlnt und rerarbeitet. Liir ausgezeichnete nul grofse Blöcle werden oft grolse Sunmen bezahlt; so kaufte die I'imofortefabrik Broadwood in London drei Blücke (5m lang und $1 \mathrm{~m}$ im Geviert), die aus einem stamm gewonnen waren. für den I'reis von 61200 Mark (:3000 Plid. Stcrl.).

Geschichte. Fin Schiffszimmermann des Sir Walter Raleigr entleckte las Mahagoniholz, als das Schiff 1595 in einem IIafen ron Trinidad lag. Die Spanier benutzten das Holz schon im 16. Jahrhundert zum Schiffsban. Kapitïn Franklin nahm anf seiner Expedition mach dem nördlichen Eismeere Boote aus Mahagoniholz mit, la diese, wenn aus dïnıen Brettern gefertigt, leicht und doch sehir fest sind. Die Wïlder von Jamaica wurden infolge der allzu starken Ausfulur hald gelichtet. Jetzt liommt meist Honduras-Mahagoni in den llandel.

\section{Berichtigung.}

Srite 7.s. Zeile 17 ron miten, fiige linzn: Reste surten. 


\section{REGISTER.}

\section{A.}

Acajou $17 t, 177$.

Acajongmmi 17.

Adamsaptel 100.

Airophyten 10:3.

Airican Nuts 1:38.

literameise 83.

Aslaia odorata 67 .

Aipim 158.

Mletia 11.

Allspice 1:4, 1:6.

Amarantrinde 176.

Amomis 126.

Anygdilin !3.

Amygdalus :1.

— amili: 9:.

- communis 8!9, 91.

- dulcis 92.

- fragilis 92.

Anacardium occidentale 177.

Ingraecum fragrans 67.

Anisocirpeate 6.

Anthophylli 1:9.

Antipyrin 146.

Apfel der llesperialen lo1.

-, Medischer 101.

Apfelsine 100.

Ipocynacea 171.

Aprikose 91.

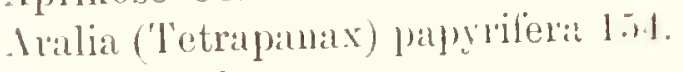

laneio dolce 100.

- lurte 99.

Alankinetti !!!.
Alrak 1.5\%.

Alrowrunt 159.

- Brasilianisches 15\%.

-, Maniok- 159.

Arube 159.

Attalea funifera 168.

Aurantiörleale 95.

Ava 122.

\section{B.}

Bantaseife 1:37.

Barclient 13.

Batumknister ㄴo.

Bitumwolle 7.

_, İpotische 1:2.

- Mabrima-12.

-, Amerikanische 12.

- Australische 12.

- Bahia- 12.

-, Batumartige 8, 9.

- Leharah-9.

- Bengal- !.

- bowerl- 10.

- Brasilianische 1.2.

- Broich-!

- bimmall-9.

- Ceara- 1.2.

-, Columbische 12.

- Comptal1- 9.

- Dhallwar- 9, 12.

- Dholerili- !.

- fitser 11.

- Feinhanures !. 
Bintmmolle. fieorgiat 1?.

- Cuayana- 1?.

- Hinghumghit- !, 12.

- Honolulu- 1.2.

- limmerer 1\%.

- Jumal- 12.

- Kiautige 7, 8, 10.

- Louisiana- 1.2.

- Malrass-!)

- Malio- 12.

- Mansuriall- !).

- Minas novas- 12.

- Mobile- 12.

- motte 11.

-, Nanking !.

- Oomrawutten- 9.

-. Ostindische 12.

- I'ernambuco- 12.

- Peruanisclie 1:.

- Raunun- !.

- Riauhliarrige 9.

- Russische 12.

- samenöl 14.

- -silnt $1: i$.

- scindu- !.

- Seir Island-9. 10, 12.

- Timerelly- \%.

- Upland- 9, 10.

- Verawal-9.

- Nestindische 5. 9. 12.

- Zagazig- y.

Bergamotte 100.

-, Kleinfruchtige 100.

- Rippenfruchtige 100.

- liosenajfel- 100.

lietel 12:.

lietelpfeffer 122.

Ligatradeöl 99.

Bigararliel !)!.

bignette 98.

Bikuibafett 138 .

Bischof 99.

Bittermandelïl $9: 3$.

Bittermandelwasser !y.

liattlinse 8:\%
Bilansiune 98.

Bilutaplelsine $100 \%$

lioza 1.):i.

brabal 14!\%

Brass, liny 153.

Buchenptlanzen 4.

Butylen 169.

C.

Citcao, s. Kaliao 75.

Calé nègre óo.

Cailcedraholz $17 \%$.

Calico 13.

Calyptranthes 1:6.

Canavalia 50 .

Cinellaceae 116.

Cange $15 \%$.

Carareep 159.

Carima 159.

Cilryophyllus aromaticus 127.

Cascador 145.

Cascarillo 145.

Cassia occidentalis 50.

- Sophora 50.

Castilloa elastica 171.

Cauin 159.

Ceara Rubber 158, 172.

Cecropia palmata 171 .

- peltatil 171.

Codiate 101.

- Rivers 101.

Cédratier 101.

Cedro 101.

Celluloid 14.

Celasus 91.

Chinaaptel 9!.

Clinabann 143.

- Calisaya- 14:5.

- Künigs- 143.

Chinagewaiclıse 14\%.

Chinarinde 146.

- , berleckte 146 .

-, brammote 1.16.

- Haclie 116. 
Chinarinde. wello 14 it.

- serollte 146.

, oliligeselbe 14 li.

Platten- 145.

Roll- 14i.

rote 146.

mubedeckte 146.

Chinidin 145.

Chimin 146.

Chloranthus inconspicuus (iT.

Chrysomelie 9x.

(ichoric 49.

Cichorium Intybus 49.

Cigare 23. 26.

Cigarlentabak 22.2.

Cinchona $14:$.

- Calisiya 14:5.

- Josephiana 14:\%.

l.edgerianat 144.

-_ officinalis 144.

- succirubla 144.

Cinclionidin 146.

Cinchonin 145.

Cinnanomum 11:.

Cinnmlion:a 116.

- Cassia 116.

- Ceylanicnn11 112. 11: 114. cordifidium 114.

Cipipanchl 1.5!.

Citronat 101.

('itronathaum 101.

('itroue !). !). 111.

Citroncullol\% !S.

Citroneniil !

('itronensïme 98.

- -scllillen !).

Gitromnier !).

(itlus ! 6.

- allal:a !!y.

- ayerma $9 !)$

- alllantium !)

atllatus !

- Diljolllar 100.

- Vielerindia 1011

- Miunlottal !s.
Citrus hizarria !)!.

- rorniculata \$9.

- crisplar !)!.

- decumana 100.

- jiponica 102.

- Khatta 10.2.

- limetta 98.

- Limonum 95. 96. 101.

- Lumie 98.

- maxima 100.

- medica !9. 100.

- Mellarosa 100.

- nobilis 9!\%.

- parva 100.

- Perettir 98.

- piriformis !s.

- Pomum Adami 110.

- pongrinum ؛s.

- Riversii 100.

- Rosolinum !os.

- sanguincir 1110.

- sinensis 100 . spatafor:a $9 ! \%$.

- suntarir 1112.

- tormlosa 1110 .

- vulgaris !s.

Clithandra 171.

Coceus 8:i.

collea 34.

Coffea arabieal $: 33$.

- var. lencocalpal :it.

- liberi(a 35.) 4 ๖.

Cofleoirleate : $: 3$.

Cottonöl 14.

Cubeben 12\%.

Cirairao !)!

Cinille 1丷.

Curvy $15: 2$.

Cyperus eseuleutus 40.

I).

1)anplikallion :3!.

1)attioln 101.

Hiatratea satrellallativ so. 
Hoowhin lis.

1):chu 1.i:;.

lomplar lion.

\section{E.}

Fibenales 6.

libenlolzptlanzen 6.

Ehonit $17 \%$.

lister 83.

limbelia ribes 121 .

limulsin 93.

Epiphyten 10:\%.

Èbsculiaffee

Erythina corallodendion 73.

lislogr 100 .

Eucalyptus gigantea $17 \%$.

Eugenia caryophyllata 127.

- Pinenta 124.

liugenol 110.

Euphorlia cyparissias $17(1$.

Enphorliaceate $156,171$.

\section{F.}

Ṕadenwïnner S:

Faradivin 169.

Fanlbannartige 5.

Federlar\% 167.

Federharzbaum 166.

Frigen 101.

Feigenkiaffee 50 .

Ficus elastica 171.

- elliptic:a 171.

- nymphaeifolia 171.

- populnea 171.

- prinoides 171.

liarlula 171.

- silvestris 171.

- toxicariar 171.

l"ieberindenbann 141. H: 145.

- coppioing 14\%.

-. Moosloblamdlumg 145.

- mossing $11 \%$.

-. Schlagwallabetrich 145.

Feilibittrige Dikotylen :
Fiuctus Smoni 126.

l'inlental 126.

G.

Gardenia Horida 67.

Fettaniagummi 164.

(icwiirz 124.

-. Englisch 124, 126 . -nägelchen 128.

- -nelkenbaum 1.27.

- -nelkenöl 115, 125.

- Neu- 124, 126.

(iewiurmelken 12؟. 12!.

- Amboina- 129.

- Batavia- 12!.

- Jourbon- 129.

- Cayenne- 129.

-, Englische 12!).

_- Holländische 1.9.

- St. 1sucia- 129.

- Sansibar- 129.

Giugau 13.

Glimmstengel 23.

Goldhesperide !S.

Gossypin 14.

Gossypium 7 . arborenm S. 9. 15. birbadense $8 . \%$. herbaceum 7. 8.

- lirsutinn !).

-_ religiosum !) 1.).

Glätinpulver 147.

Guarana :3!).

Gulgul 10\%).

Gummihorn 170.

Frummi elasticum 16s.

- plasticmm 164.

Gutta girck 164.

- tuban 16i.

tubill 16it.

Guttipercha 163. 16il.

- hornisiclen 16:\%.

- vulkanisieren 16:.

Guttipenolabirum lif. 
Guttaperchabanm. Borneo- Itie. Echter 161.

Elliptischbliittriger 16 . Länglichl, ïitriger 162. Treuls 162

\section{H.}

Ilabzelia athiopica 123.

llancornia speciosa 171.

Ilanfwurzel $2:$.

Ileliothis 11.

Hemileia :38.

Herba reginae : 1 .

Ilerbe du Grandprienr : il.

Ilesperidin 98 .

llevea hasiliensis 167 .

- guranensis 166.

Heveen 16 ?.

Hirse 148.

-, Echite 140.

-. Ciemeine 148.

Kolben- 1jo.

Nohren- 150.

Neger- 154.

Rispen- 148.

Sprall- 118.

Holzkassic 114.

Hospitaltuch 170.

Hundsriftgewïchse 171 .

\section{I.}

Ilex paranuyensis bit.

Ingwer $1: 31$.

Afrikanischer $18: 3$.

Bardialos- 133.

liengalischer 13:3.

Chinesischer 13:\%.

Echter 131.

Fingenarhter l:3::

Geschïltep 1:3:8.

I:manac:1- $13: 3$.

-klatmen lis.

Maluabill- 13::
Ingwerö 133.

- Ungeschiilter 183.

Weilser $33:$.

- zehen $13:$

Insektenf:inger $\therefore$

Isoprren 167.

\section{J.}

Jaconet 13.

Jamaicapfeffer 124.

Jambosa Caryophyllus 12T.

Jesuitenpulver 147 .

Johannisbrot 101.

Juka, süfse 158 .

Jukastrauch 156.

K.

Kitfee :i3. 4\%.

- Alessinischer 48.

- Afrikanischer 45. Ambakia 48.

-. Amerikanischer 46.

- Angosturia 47.

- Ankola 4.

- Mrabischer 45.

- baum 3:3.

- _. Echiter :33. 34.

-- Laubkrankleit 3-.

- L. Liberischer 35.

Weiffinchtiger :3\%.

- Bahia- 46.

- Bahmri- tij.

- Pantanl1- 45.

- Liatillages- 46 .

- Biltilvil- 4i.

- lierbice-4ti.

- bläter 67.

- Bocona- 4li.

- Bogota- 47.

- Bolivia- 17.

- bourbon- 46, 1-

- brisil- 4ti. 
liaflec. Bisilianischer 46.

- Campinas- 46.

Caracas- 47.

Carita- 46.

Cirzengo- 48.

(elebes-45)

Centralamerikanisclee 47.

Cerlon- 46.

\section{Nativa 46.}

I'lintagen 46.

Columbial -46.

- Cordovit-48.

- Costarica- 47.

- Cuba- 47.

- Cícuta- 46.

- Darlag- 45.

- Demerara- 46.

- Domingo- 47.

- Dominika- 47.

- Ecmador- 47.

-. Englisch-Indischer 46.

Erbsenbolnen-35. 47. 48.

Frsatz .5.

- Ersatzmittel 50.

- Firben 4!.

- Fidschi- 4r.

- Gesmmlleits- jo.

- Golden livin- 46.

- Ciolungo- 48 .

- Cirmuala-4.

- Cinadelonpe- 47.

- Guatemala- 47.

- Gllyana- 46.

- Halvalla- 47.

Inarierter 4h.

- Hochlaud- 46. 47.

Honduris- 47.

- Iliilsen- 35.

- Jalaja- 4h. Jamaikı- 47.

Javil- 45.

Jarit- mexikanischer fe.

linmerin- 4s.

kneipp- in.

Krafte in.
Laffere, Krawalle- 4.\%.

Kiisten- 47.

-wurzeln 4!!

Ia Gnayri- 46, 47.

Jaguna- 4.6.

- Levantischer 45.

liberial-4h.

Madagiskar-4S.

Mämuliche IBolnen 3..

Mandlieling- 45.

Manila- 46.

- Maracaibo- 46.

- Marinierter 48.

Martinique- 46. 47.

Mauritins- 48.

Menado.. 4..

Mórida- 46.

Mexilianischer 47.

Mindinna- 46.

Mogrdad- 50.

Molkka- 45. 47.

— - Abessinisclier 45.

—- Alexandrinischer 4.5.

— _, Eigentlicher 45.

- - Levantinischer 4.

Nozambirue- 4s.

- Mysore- 46.

- Natal- 48.

- Nicaragua- 47.

--. Niederländisch-Indinclıer 4.5.

- Oaxacil- 48.

-. Ostindischer 45.

- Padang- 45.

- Pergamput- 35. 3-.

Peru- 47.

- Polieren 49.

- Preanger- 45.

l'nerto Cabello- 4.

Puerto Rico- 17.

lieunion- 4n.

liio- 48 .

sikki- 41.

- Sakli- 45.

- Salabi- t5.

- Samarang- li. 
kallee. Samon- 15.

sindwich- 18.

Sim Salvalor- 17.

Santal lucia-47.

Sintiago- 17.

Sintos- 46.

Saranillat 47.

Schwitzen 4!)

Seidenluaut :35.

sicria- IS.

Somali- 4i.

Spanisch-Indischer 46.

Siidamerikanischer 47.

Sumatral - 4\%.

Sulahaja- 4 i.

Surinam- 46.

'labasco- 1.7.

'agal- 45.

'Tahiti- 4 .

Telic- tis.

Tiefland- 46. 47.

Toval- 46 .

Triage- is.

Trillados- 47.

Timidad- 17 .

Trujillo- 46.

'Tscheribon-45.

Usambar:a- 46.

Venezucla- 16.

Verfilschungen tS.

Vermuleingungen in.

Westindischen $\downarrow \bar{T}$.

\%ejla- 4i.

liaftein :3:.

lialleol :?!.

liakao, Angostur:a- T(i.

- Intillen- $7 i$.

- Arriba-finayaluil- 7.5.

- lialibi- 76.

- hamm T1.

berluce 76 .

_-. In:msilimischer $T$ ti.

-butter 71.

(allacas- T.

lajemlle- 76.
Kakiao, licuaulor- 75.

- Esmeraldis- To.

- Vissemilio- 76.

- Gerotteter 7.

- Cuatemala- 76.

- Cindyina- 76.

- Guayanil- 7.). Insel- 76 .

- Kolumbien- 76.

- Maracaibo- 75.

- Marauon- 76 .

- Martinique- 76.

- masse 71.

- Mexikanischel 76.

-, Mittelamerikanischer Ti.

- -mutter 73.

- Nilis 7 .

- Parí-76.

- Petlazzil- T6.

- Puerto Cabello- T.

- Rio Negro- 76.

- St. Domingo- 76 .

- Soconusco- 76.

—, Suidmexikanischer Tli.

- Surinam- 76.

- Trinidar- 76.

Tilgerotteter $7:$.

- Venczuela- 7.

Kampferlatum 116.

Kamptulikon 171.

Lammel 116.

Weifser 116.

Liapselianpe 17.

karapatiil 176.

Kardinal pulver 147 .

liassamalinot 15!!.

liassawamohl lis!?.

liassawatranch ling.

liassienrimt 11 i.

Kastanien 101.

Kattun 1:i.

Kalutschicin 1(i!).

lisutschin 16!?

litutschuk lit, 171 .

- Mrikinischer 17.?. 
liantschul. Assan1- 17'?.

- , Rallen 17:.

-haum, Brasilianischer 166. 167. Kïrbiscitrone 100.

- Guayana- 16 iti.

Biskuit- 171.

liorneo- 17\%.

- Carthagenia- 17.2.

- C'astilloa- 17.2.

- Cearil- 158, 172.

- Ceara-Scraps- 17.2.

- lingerhiite $17 \%$.

- Gehïrteter 170.

- Guatemala- 172.

- Guayaquil- 17\%.

- Iliirten 170.

-. Hornisieren 170.

- Iara- 172.

- Kinnckles 17.2.

-. Leberu 17.2.

- Madagakar- 17.2.

- Negerköpfe 16i, 171, 17\%.

- Niggers- 17\%.

-. Nüsse 17:.

- $-\ddot{1} 169$.

-, Ostimlisches 17..

-- Par:1- 171.

- P'ilinnor- 172.

- liangun- 172.

- Fingapore- 172.

[1]- 172.

Vulkanicieren 170.

Weatindisches 172.

-. Wurmoinmiges 17.2.

- Zungenformiges 172 .

hava 12.2.

latwa 1:2.?.

Khayal senegalensis 177.

Kickxia africana 171.

Kina 146.

kirschlorber 91.

Kishr. Kist 41.

Klebither 11.

Kohleule 2::

Kinllodiun II.

Konturbirn! 9s.
Korallenbatum $7:$.

Korinthen 101.

\section{I.}

Lativitz 14\%.

Landolphia comorensis 171.

- floridil 171.

- gummifera 171.

- Kirkii 171.

- owariensis 171.

- Petersiana 171.

Laurin 141.

laturocerin 141.

Lanrus 140.

- angustifolia 140.

- cissia 114.

- cimnamomum 11:;, 114.

- communis 140 .

- crispa 140.

- latifolia 140.

- nobilis 140.

Lebensbaum 9S.

Ligyrus rugiceps S:3.

Limette 98.

Limone 96.

-, suilse 95.

Limonier 98.

Limonin !s.

Linoleum 171.

Lithospermum officinale 6 T.

I.ohrül 141.

Lorbeer 140.

Lorber 110.

- -hïtter 142.

-, Breitblitteriger 140.

_, Edler 110. -friichte 1.l2.

-. Geneiner 140.

- -kimpfer 141.

一, Rimurer 140.

-iil $1 ! 1$.

Schmill,litteriger III.

lamie ! !s. 


\section{M.}

Makea Piriri 171.

Macacheira 158.

Macis $1: 36,1: 37,1: 3$.

- Jiatavia- 138.

- Pellang- 135.

- Singapore- 1:38.

Madre del Cacao $7:$.

Mahagonibaum 174.

- Amerikanischer 174.

Mahagonilolz 176.

- Arenas- 176.

- Bastard- 17\%.

Cuba- 176.

_., Falsches 177.

- Gam!ria- 177.

- Honduras- 176.

- Jamaica- 176.

-.. Kolonial- 177.

- Madeir:ı- 177.

--. Neuholländisches 177.

--. Weilses 177.

Malabarzint 114.

Malta-Limone 98.

Mamestra $2: 3$.

Nandarine !!!).

Mandel 91, 9\%. 101.

- Aix- 9:3.

- Algier- 94.

- Alicante- 9:3.

- Ambrosial 9:\%.

- -banm s!) !1.

-. Berberische !1.

- Berestralis- 94.

littere !2.

Cavaliere- !):3.

Dentsche !4.

Florentinisehe 9:3.

Fröinkinde 94.

Französische 9:\%

(iilnenti- 93.

Italieniscle $9: \%$.

-kicir !2.
Mandel, Knack- 92.

- Kommune 9:\%

- Krach- 92.

- Malaga- 9:3.

- Maroklio- 94.

- milch 93.

— -öl 93. 94.

Provencer- 9:3.

- Puglia- 94.

- seife 9:3.

- -sirup 91.

-. Spranische 9:3.

- Siifse 92.

- Termini- 9:3.

- Tunis- 47.

-. Interösterreichicche !f.

- Talencia- 9::

Mandiok, Farina de 159.

- Farinlı- 159.

Mandiokamelil 1.jo.

Maniliot 156.

- Carthagenensis 1.in.

- Gliziovii 15s, 171.

- utilissima 156.

Maniok 156.

-. Sittere 158.

- melil 15!?

- -strauch 156.

- - Siilse 15ir.

- Minchester- 1:i.

Manipucira 15s?.

Marksog:t 159.

Massaratudubibaum 171.

Naté 3!)

Minuritial viniferal 16 s.

Melangolo 9!.

Meliaceac $17 \%$.

Melonencitrone 100.

Micindla 166.

Mimmsops lialita 17i.

Mufflanaster 26.

Mulegann 1:3.

Mnle-twist $1:$.

Muskatbalsam 1:T.

-biite 136. 
Muskatblune 1:iti.

- - lutter lisin.

- -n11s 196. 1:i6.

— Diebs- 1:8.

Rompe- 1:38.

Zwillings- 1:is.

- -nufsbaum 135.

- E. Echter $13 \pi$.

— - iil 1:5.

- waelis 1:it.

- - wurm 137.

Musselin 13.

Mutternelken 1:2!.

Myristiea 1:5.

- Biculiybar 136.

- fatua 138.

- fragrans 135.

- Irya 138.

- Malabarica 138.

- Oeuba 138.

- offieinalis 138.

- Otaba 13 r.

- sebifera 138.

- spuriir 138.

- suceedaner 138.

- surinamensis 1:5.

- tingens 138.

Myristicaceae 135.

Myrtaceac 124.

Myrtenblumige $\therefore$

Myrtengewiichse 124.

Myrtus P'imprita 121.

Nafaiol !!!.

Nanking 13.

Negerhirse 150.

Negerkiaffee 50.

Negrerliorn 1.50.

Nelkenöl 11々. 12!!

- -pfeffer 124. -sinure 110. 125.

- stiele 129.

- -tinctur 12!.
Nematoden 8 .

Neroliiil !9.

Neusewiirz 124.

Nieotiana 18.

- Ligelovii 21.

- elunensis 20.

- frutieosa 20.

- gigantea 20 .

- lancifolia 20.

- maerophylla ¿0.

- pandurata 20.

- persica 21.

- quadrivalyis 21.

- repanda 21.

- rusticar 20, 31 .

- tabaeum 1s.

Niessholz 177.

Nikotian 24.

Nikotianin '24.

Nikotin 23

Nitroeellulose 14.

0.

Okinbawachs 138.

Onycon 15!\%

Orangen 67, 99. 101.

-. Chinesische 102.

-.. Japanische 102.

Orangenbliitenwasser !!!.

Oranger 100.

Orangette 9!).

Oryza 151.

- sativa 151.

Osmanthus fragrans Gi .

Otalafett 136.

\section{P.}

P'atldy 1.5:;.

P'ancoum italicum 150. miliacem 1 ts.

Par:adiesilpfel 100.

l'arameria l'ierrei 171.

l'alapalla 38. 
l'alyena leerii 162. macrophiyla 163.

l'ennisetum typhoidenm liv).

l'erchal 164.

l'erette 9S.

l'ergamentkaffee :ss.

l'erkal 13.

l'erkalin 13.

l'erlkatfee: 35.

Petitgrainiol 99.

l'feffer 11!.

- Aschanti- 122.

- Batavia- 122.

- Betel- 1.2.

- Cochinchina 122.

—. Holländischer 122.

- Jamaica- 124.

- -kiiste 120.

- Lalnger 1:2.2.

- Velken- 124.

- -ptlinten 119.

- Pinang- 12.2.

--, Schwarzer 119, 1:1. Singapore- 1:21.

- Spezerei- 124.

- -strauch 119.

- Tellicherry- 12.2. Weilser 1²1.

Phoebe indica $17 \pi$.

l'ilav 153.

l'iment $12 t$.

--, Brisilianischer 126.

- Cratreiro- 126.

-, Gekrönter 126.

Janaica- 126.

Kron- 126.

Mexikinischer 1 126.

-ïl 125 .

Spanischer 126.

'T'ibisko- 126.

Pisnentil 124.

acris $1 \geq 6$.

officintilis 124.

l'imento lyli.

P'ipel" 11 !). liper atuncum 12.2.

- angustifolium 1:2.

- lietle 122.

- Cubebir 122.

- geniculatum 122.

- Guincense 122.

- Tahorandi 122.

- longum 122.

- Melamiri 122.

- methysticum 122.

- nigrum 120.

- ofticinarum 122.

- Siroboa 122.

- unguiculatum 122.

Piperaceae $11 \%$

Piperin 121.

l'iqué $1 \%$.

Plusia 23.

Pomeranze 99.

—. Bittere !!!.

—. Bizarre 9!.

- Gehörnte 9!.

—, Gemeine 9!.

-, liernlose 9!.

-. Kraushliitterige 9!. Orangeat- 99.

Pomeranzenäptelchen y!.

- schale 49.

Pompelmuse 100.

Pompelon 100.

Pongia $9 S$.

Ponzine 101.

Portogallo 100.

Prumus anygdalus S!, !l.

P'taeroxylon obliquum 17.

Purarrie 159.

Pyroxylin 1.l.

Q.

(1)111a 146.

li.

liadis lambanand! ly.2.

Reis 1 inl.

- draliall- 15.1. 
lieis, liengal- 154.

lierw- 152.

-besen 154.

- -blume $15 \%$.

-bramntwein 153.

C:arolina- 154.

Französisch-Indischer 1.4.

Futter- $15 \%$;.

Jipanischer 154.

Javi- 154.

-. Italienischer 154 .

- Kleb- 153.

-kleie 153. 1.4.

-. levantischer 1.54.

-palpier 154.

l'atna- 154.

liangun- 154 .

lieismehl 153.

- Siam- 154.

- -strohgetlechte 1:it.

- Sumpf- 152.

- T'afel- 154.

-.. Tiirkischer 154.

liiesencedrate 101.

Rompen 1:is.

livsoline 135.

Rolskastaniengewächse i.

liostpilze 11.

lium -6.

\section{S.}

siccharum officinarum so.

Saklil 15:\%.

Simlsu 153.

Santaliles 4.

Sapium Ancuparium 17 .

-_ biglandulosum 171.

schiefsbaumwolle 14.

Schmellkifer 8:3.

schumuft:ibak 22. 23.

Schokolade 74 .

- medicinische 71.

- Verliilschungen ifi.

solimskiirner 123.
Serehklmuklieit 8\%.

Seringual 167.

Sernamby 168.

Sinatplel :9!.

Siphonia brasiliensic 167. elastica 166 fi.

Sorghum vulgare 150, 15.4.

Spaniol 26.

Spezereipfeftier 124.

Steinsame 67.

Siidliüchte 101. 141.

Siilscitione !8.

Sukkade 101

Sultanskaffee 41.

Swietenia 174.

\section{'T.}

Tabatk 18.

-. Afrikanischer "2-

- Ambalema- 26.

-. Amersfoorter 20, 27.

-, Asiaticcher 20. 27.

-. Australischer 27.

- Banern- 20. :31.

- Belgischer 27.

- Irasilianischer 20, 26.

- Cabanos- 26.

- Carmen- 26.

- Chinesischer 20.

- Columbia- 26.

Cuba- 26.

-... Cumana- 26 .

- Debrecriner- 27.

-. Delroer 27.

- Demirli- 27.

-. Dentscher 28 .

- Diche 22.

- Domingo- 26 .

- Druma- 27.

Fingliseher 20 .

Enopuiischer 2 \%

Fermentilion 2:3.

Floriclar- 27.

-. (ivizen 22. 
'Tahak, Gemoiner 1s. '-20. Ginbeck-2S

Giron-Pahmyrat- 26.

Gundi- 20.

Hatrana- 26.

II111- 20, :il.

Javit- 27 .

Kamaster 26.

- Kirotten- 22.

- Kirrotteugut- ⒉2.

- Kentucky- 27.

Kleinasiatischer 27 .

-köpfe 22.

Land- 20 .

hangl) iitteriger 20.

I atakiil- 20, 27.

Manila- 27.

Maryland- 20, 27.

Mexikanischer 26.

Nijkerker 2.7.

Nijnegener 27 .

Nordamerikanischer 27.

Ohio- 26.

Orinokokanaster 26 .

Paraguay- 26.

Partidos- 26.

Persischel ㄴ1, 27. :31.

l'fiilzer 28.

Portorico- 27.

P'rarista- 27.

Remedios- 26 .

liiesen- ㄴ. 0.

Samane- 26 .

Sarishaban- 28.

Schiras- 27.

schmergel 24.

schmurgel 24

Schneidegut 2:.

Seerlleat-27.

Serone 26 .

spinngut 22.2.

siilimerikanisclıer 26.

Sumatra- 27.

sylischer 27.

Tortilg: - 201;
T'abak, Türkischer 이. 2 T.

-. Ungarischer 20, 27.

- Varinas- 26.

- Veilchen- 20.

—, Verfälschungen 28.

- Virginia-, Virginischer 15.20.27.

- Vueltar Abajo 26.

-. Westindischer 26.

- laril- 26.

'libangummi 16 t.

'Tacazzer 171.

Tapioka 159.

T'eruba 159.

Thea assamica 57.

- Boheal 57.

- chinensis 56.

- oleosia 57.

- viridis 57.

Theacene .56 .

Thee, Amoy- :3: 6:\%.

- Inkoi- 6:3

- Assam- 65.

- Ausschulis- 6:3.

- Backstein- 62.

- Basket fired 6.5.

- Big-Gumpowder- 6:\%.

- Blackleat- 64.

- Bliiten- 6:\%.

—, Bïhmischer 67 .

- Boheil- 6i:

- Broken-Leat- 6.

- Carchir- 65.

- Capers- 6:3.

- Ceylonischer 6.

- Ching-Wo-Congon- 64.

Chittagung- 65.

Choo-tscha- 62.

Congree-, Congon- 6:3, 6.t, 65.

Darjeeling- 65.

- Dehra-Doon- 65.

- , riblschumgen 66.

- Flowery Pekoe- (i.4, 6.5.

- Foo-chow- 6:3.

- liorulosa- 63.

- Fehow- 62. 
Thee, Grimer 61, 62. 16.5.

- Cimpowiler- 62, 6.5.

- Haysan- 6\%.

- 11r-choo-tscha- 64.

- IIy

- Hyson skin- 63.

_-., Jalpanischer 65.

- Jalranischer 6i.

- Imperial- 6\%, 65.

-. Indisther 65.

Kitiser- 63.

Kilisow- 6t.

kamp-hu- 64.

Kimgtit- 65.

Kintuck- 64 .

- Kin-Kiang- 64.

- Lapsing- 64.

- Lo-trchia- 62.

- Majune-62.

- Mouing- b4.

- Ning-Chow-Congou- bt.

- Oanfa Congon- 64.

- Oolong- 6:\%. 65.

- Ouparck-6.t.

- Orange Pekoe- 64, 6.5.

- Padre- 64.

- P'aleow-chong 6t.

- Pakilin- 65.

- Pan-firerl- 65.

- L'aragraty- 67.

- Pekoe- 63. 65.

- Pekue-tionchong- 6.5.

- Perl- 62, 64.

- Pingsue- 62.

- Ponchong- 6i;, 64.

- Redleatf- 64.

- Saow-Cheong- ijt.

- Saryune- 64.

- Schiefspulver- 1;2.

—, Schwall\%er (j1, (6.).

— - Sin-Chune- 64.

- Sourhong- $63 i 3,64,135$.

- Sur-Kut- ri4.

— sun-clried- 05.

- Taiping- ti2.
Thee. 'Tienke- $1 ; 2$.

- Tonkay- 6 is.

- Twinkay- 63.

- Yomme-1lyson- 63.

- Yiegel- 62.

Theestratuch 56.

- Assamischer it.

- lioher - it.

-. Chinesischer áti.

- Viriner 57.

—. Ölgebender 57.

Theïn $39,59$.

Theolroma Cacas 71.

'Theobromin 74 .

Thuja ys.

'Tipiok 159.

'Tortrix sacchariphlatga 83.

Trammation 164.

T'ubanbaum 161.

T'ueupi 159.

Tüll 13.

Twist 1:3.

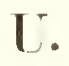

Urreola elastici 171.

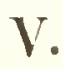

Vamilla guianensis 111.

- palmarum 111.

- Manifolia 103. 107.

Vinille 10\%, 107. 110.

- I'ourbon- 111.

- Cimarona- 110.

- Corrientí- 110.

—, Europüische 111.

—, Guayanische 111.

- La Guayra- 111.

- Lai Mestiza- 111.

- lar l'ompona- 111.

- Lai l'unoria- 111.

- La silvestrí- 110.

- P'almen- 111.

- Cimarona- 110.

Vanillin 109. 
Vanillon 111.

Velvet 13.

Veñateitohol\% 1ד.

\section{W.}

Wachslimone !S.

Wassergarn $1 \%$.

Watertwist 1:\%.

Watte 1:.

Willoughbya edulio 171.

Winatikohol\% 177.

Winterana Canella 116.

I.

Yusilonenle 2:\%

\section{Z.}

Kimmet 115.

rimt 11 is.

- aldehyd 115.

-. Amerikanischer 116. -barm. Ceylonischer 112. 113. -bliiten 116.

-. Ceylonischer 116.

-, Eller 116.

-. Fardele 115.

- Jaranischer 1116.

- Kassien- 116.

- Malatur- 111.
Cimiöl 115. 117. -siiure $11 \%$.

- Tellicherry- 111 .

- -wasser 116. 117. Weilser 116.

Kingiber $1: 31$.

- officinile 131.

Zingiberareae 191.

Zitrone !). 101.

'lucker S5.

-ameice S:i.

- Farin- S6.

- Fein- s6.

- Hut- S6.

- Kanariell- sti.

- Randis- sti.

- Lassonade- 86.

- Limmen- 86.

- Mehl- s6.

- Melasse- S6.

- Melis- S6.

- Muscovado- 85.

- Puder-s6.

- Kaffinade sci.

- Roh- 85.

- rohe sol.

_ - -bohrer 83.

_ - - kiiffer 83.

_ _ - schildlaus s:

-_ - - wickler 8:.

- Riil)en- ST.

- Sirup sti.

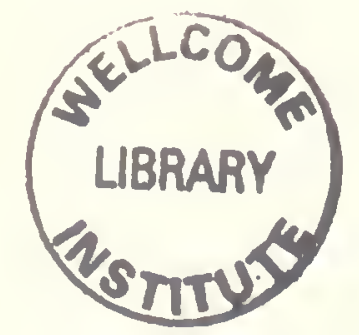







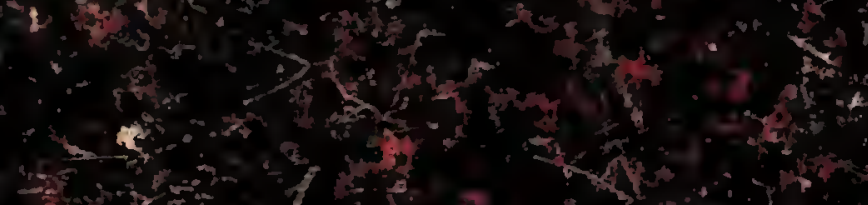

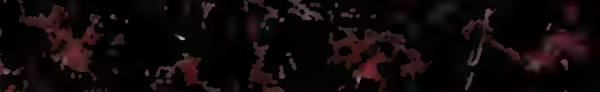

-

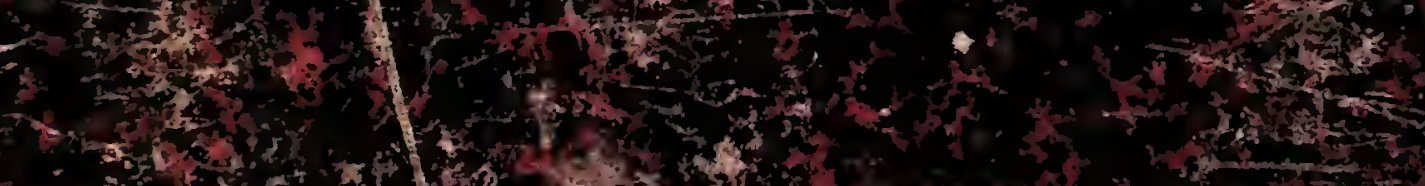

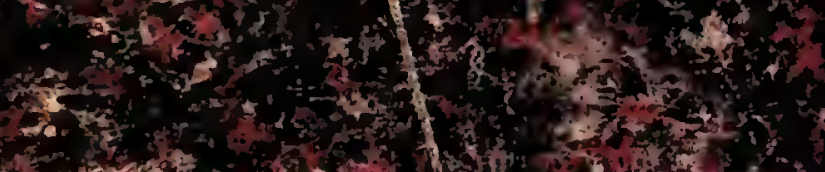

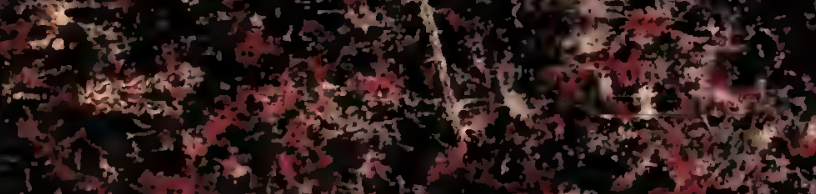

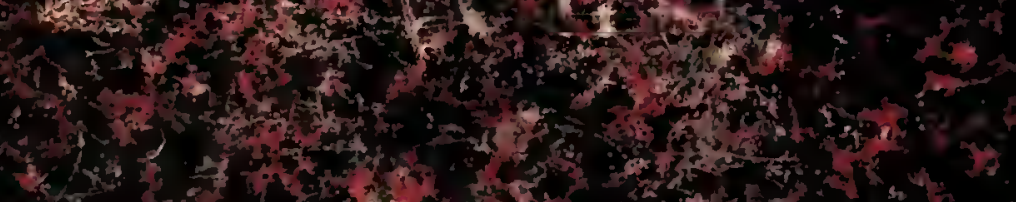

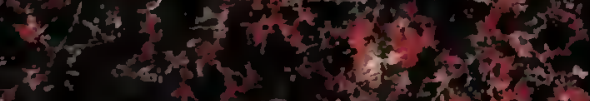

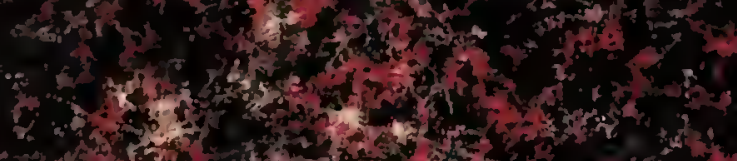

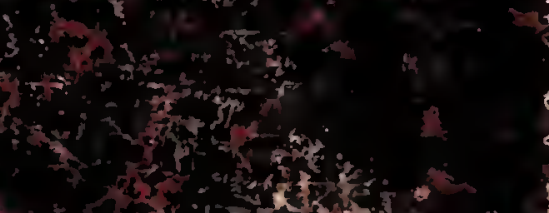

4

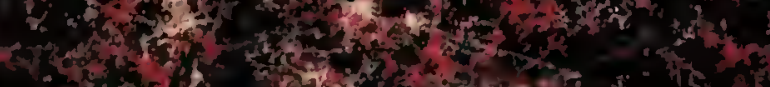

(a)

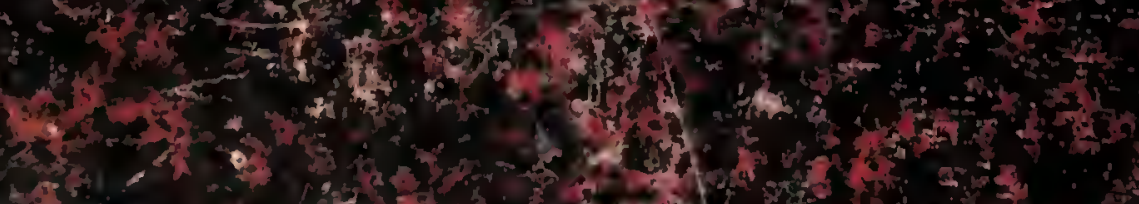
o.

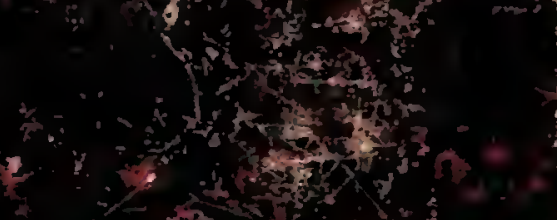

